ORNL/TM-2014/233

\title{
A Pilot Study to Explore Origin- Destination Passenger Travel Flow Patterns at Sub-County Level
}

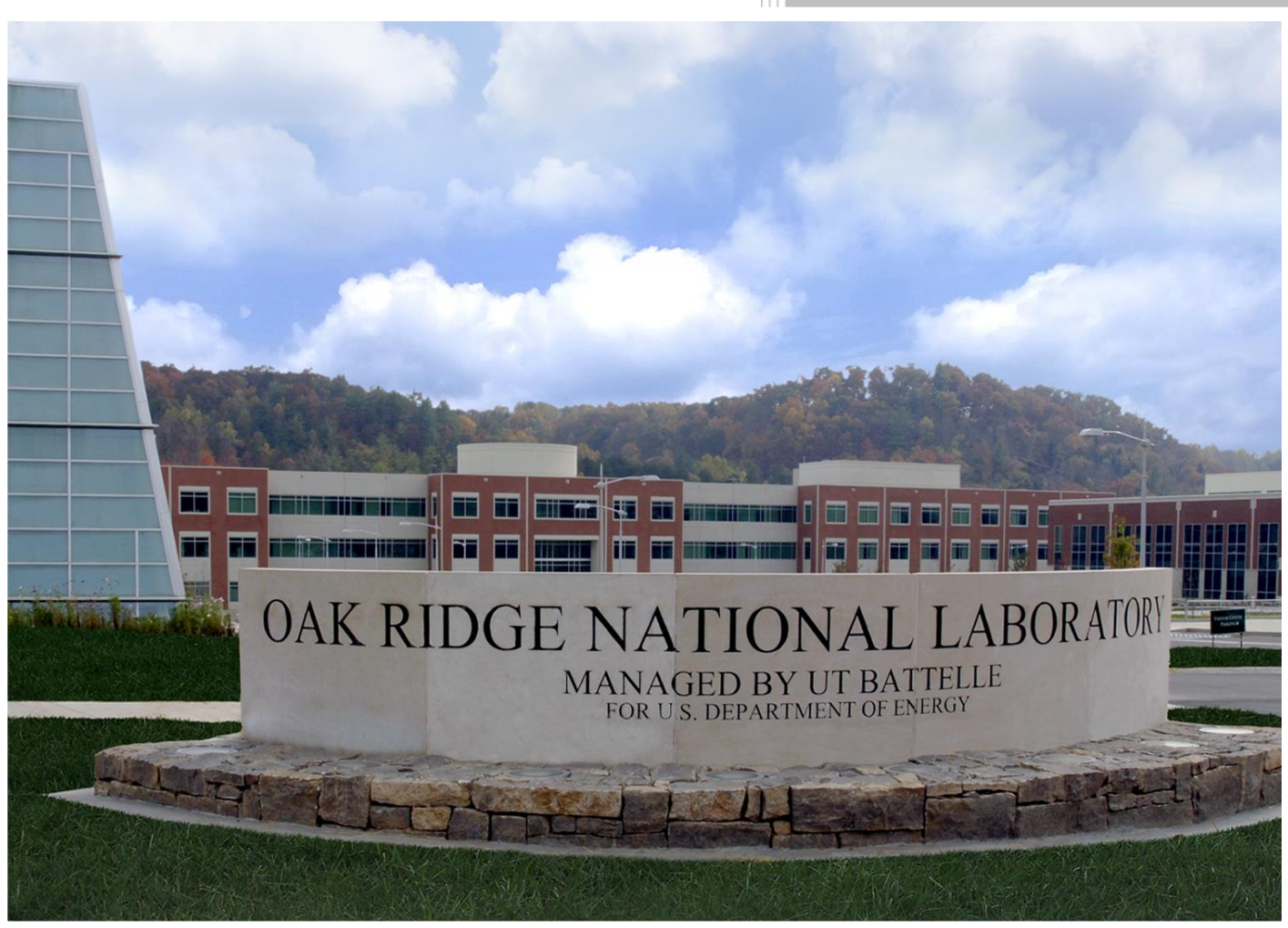

Approved for public release; distribution is unlimited.
Ho-Ling Hwang, Ph.D.

Daniel Wilson

Tim Reuscher

Shih-Miao Chin, Ph.D.

Rob Taylor

June 2014 


\section{DOCUMENT AVAILABILITY}

Reports produced after January 1, 1996, are generally available free via US Department of Energy (DOE) SciTech Connect.

Website http://www.osti.gov/scitech/

Reports produced before January 1,1996 , may be purchased by members of the public from the following source:

National Technical Information Service

5285 Port Royal Road

Springfield, VA 22161

Telephone 703-605-6000 (1-800-553-6847)

TDD 703-487-4639

Fax 703-605-6900

E-mail info@ntis.gov

Website http://www.ntis.gov/help/ordermethods.aspx

Reports are available to DOE employees, DOE contractors, Energy Technology Data Exchange representatives, and International Nuclear Information System representatives from the following source:

Office of Scientific and Technical Information

PO Box 62

Oak Ridge, TN 37831

Telephone 865-576-8401

Fax 865-576-5728

E-mail reports@osti.gov

Website http://www.osti.gov/contact.html

This report was prepared as an account of work sponsored by an agency of the United States Government. Neither the United States Government nor any agency thereof, nor any of their employees, makes any warranty, express or implied, or assumes any legal liability or responsibility for the accuracy, completeness, or usefulness of any information, apparatus, product, or process disclosed, or represents that its use would not infringe privately owned rights. Reference herein to any specific commercial product, process, or service by trade name, trademark, manufacturer, or otherwise, does not necessarily constitute or imply its endorsement, recommendation, or favoring by the United States Government or any agency thereof. The views and opinions of authors expressed herein do not necessarily state or reflect those of the United States Government or any agency thereof. 
Energy and Transportation Science Division

\title{
A Pilot Study to Explore Origin-Destination Passenger Travel Flow Patterns at Sub-county Level
}

\author{
Ho-Ling Hwang, Ph.D. \\ Daniel Wilson \\ Tim Reuscher \\ Shih-Miao Chin, Ph.D. \\ Rob Taylor \\ Center for Transportation Analysis \\ Oak Ridge National Laboratory
}

Date Published: June 2014

\author{
Prepared for \\ NEW YORK STATE DEPARTMENT OF TRANSPORTATION \\ Office of Transportation Policy and Strategy \\ Data Analysis and Forecasting Bureau \\ 50 Wolf Road, 6th Floor \\ Albany, New York 12232 \\ Prepared by \\ OAK RIDGE NATIONAL LABORATORY \\ Oak Ridge, Tennessee 37831-6283 \\ managed by \\ UT-BATTELLE, LLC \\ for the \\ US DEPARTMENT OF ENERGY \\ under contract DE-AC05-00OR22725
}





\section{CONTENTS}

Page

LIST OF FIGURES $\mathrm{v}$

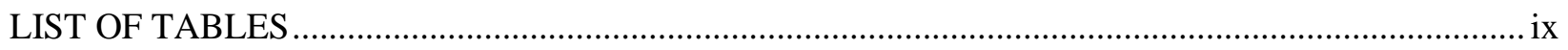

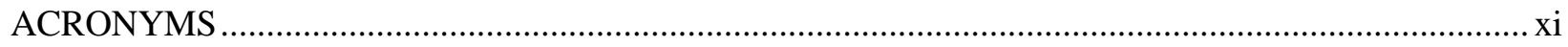

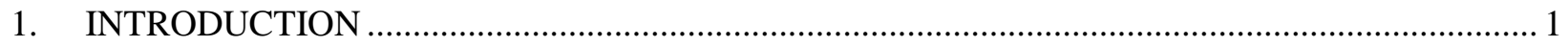

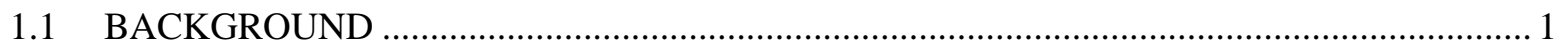

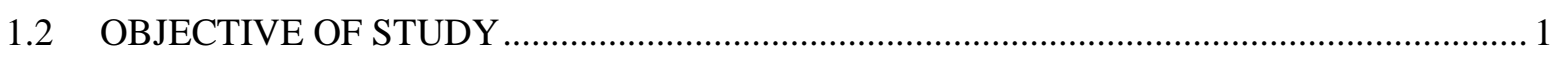

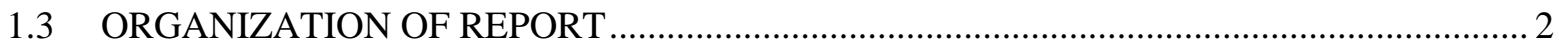

2. SCOPE OF GEOGRAPHIC REGIONS ................................................................................. 3

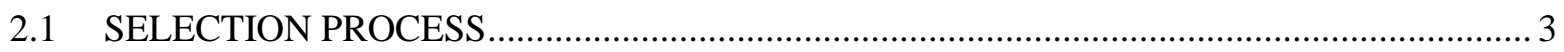

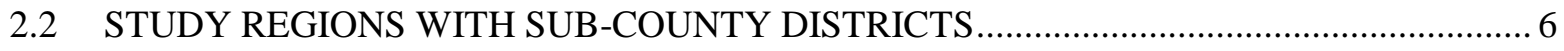

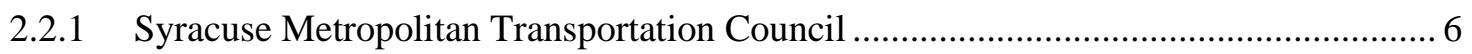

2.2.2 Binghamton Metropolitan Transportation Study ….............................................. 7

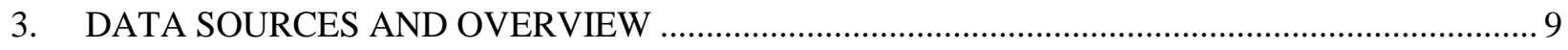

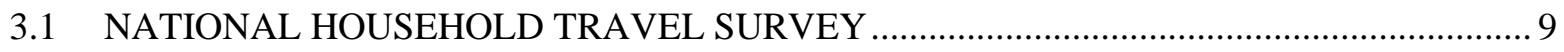

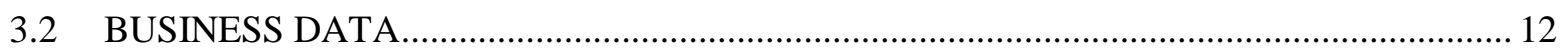

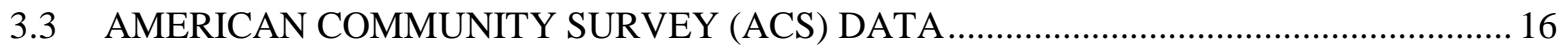

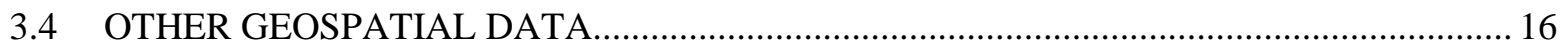

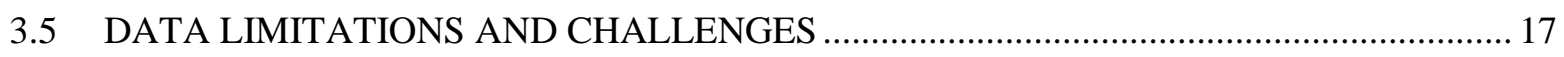

4. DEMOGRAPHIC CHARACTERISTICS AND TRAVEL PROFILES IN SMTC REGION ........... 19

4.1 REGIONAL DEMOGRAPHIC CHARACTERISTICS ........................................................ 19

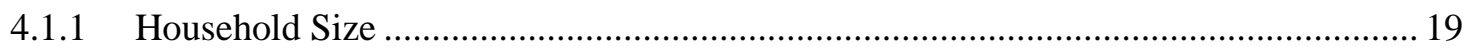

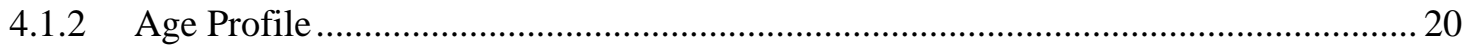

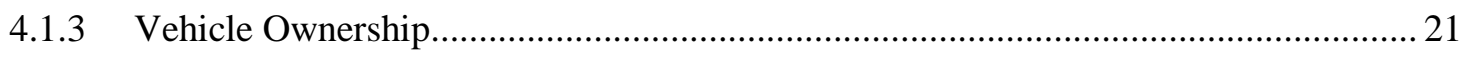

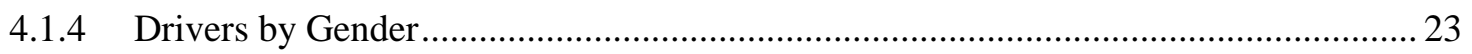

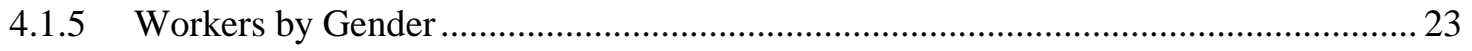

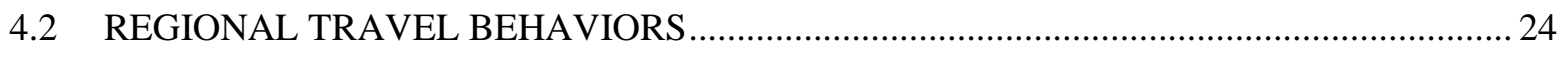

4.2.1 How Much Travel Activity Is in SMTC? .............................................................. 24

4.2.2 How Frequently Do SMTC Households Travel? - Measure of per Household

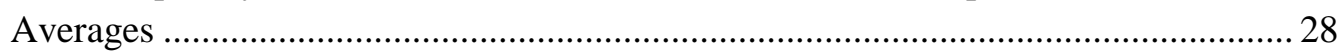

4.2.3 Why Do SMTC Residents Travel? - A Look at Trip Purposes ................................... 31

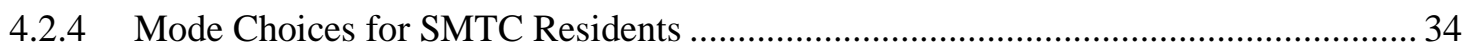

4.2.5 Travel Start Times by SMTC Residents ................................................................ 36

4.2.6 Average Trip Distance and Average Occupancy Rate in the SMTC Region .............. 46

5. DEMOGRAPHIC CHARACTERISTICS AND TRAVEL PATTERNS IN BMTS REGION .........51

5.1 REGIONAL DEMOGRAPHIC CHARACTERISTICS IN BMTS DISTRICTS .................. 51

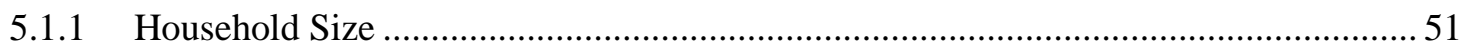

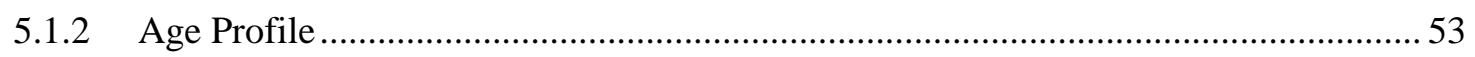

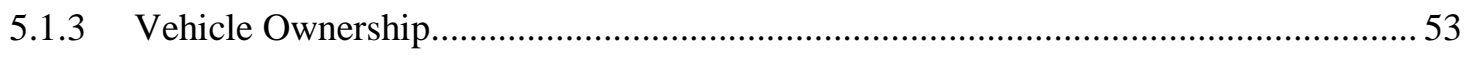

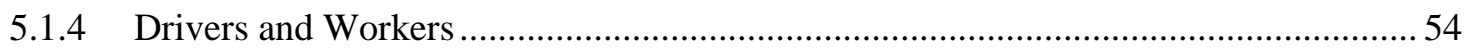

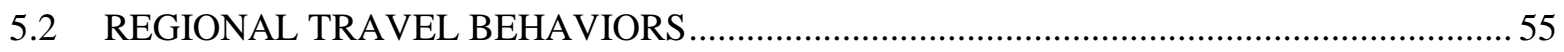


5.2.1 How Much Travel Activity Is in The BMTS? ....................................................... 55

5.2.2 How Frequently Do BMTS Households Travel? - Measure of per Household

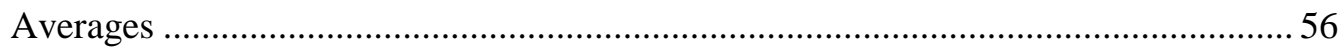

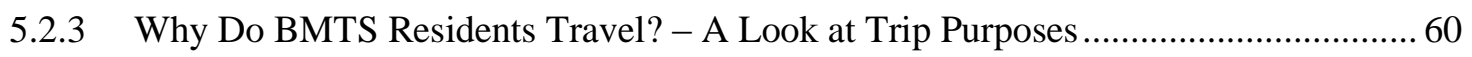

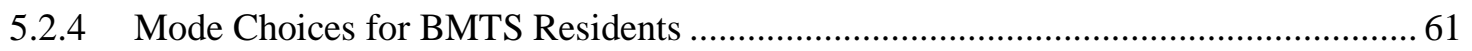

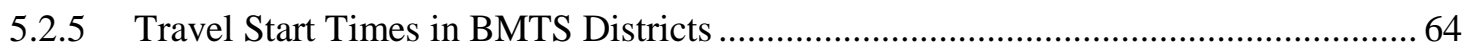

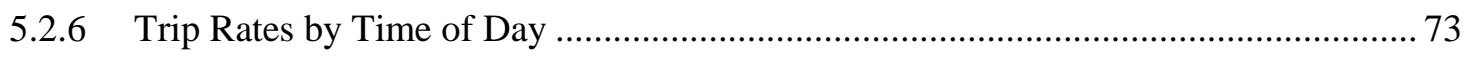

5.2.7 Average Trip Distance and Average Occupancy Rate in BMTS Regions................... 75

6. LAND-USE PATTERNS IN SMTC AND BMTS REGIONS ..................................................... 79

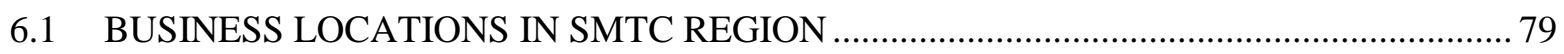

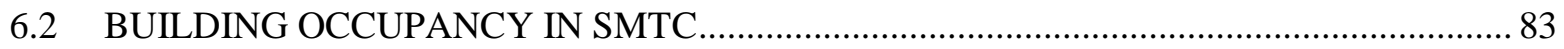

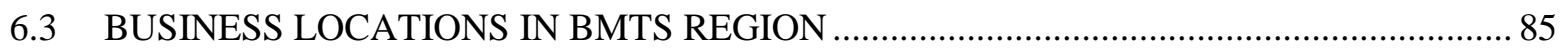

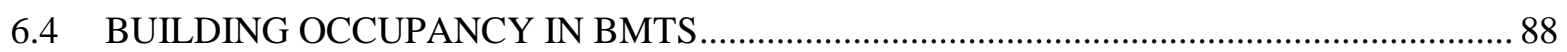

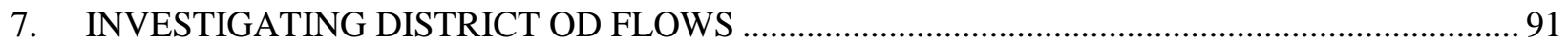

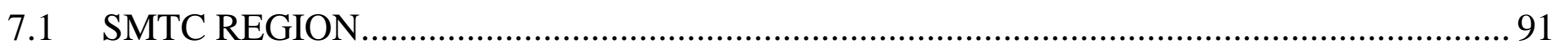

7.1.1 Volume of Travel Activities among SMTC Districts .............................................. 91

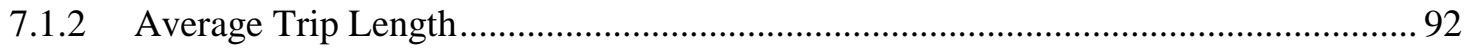

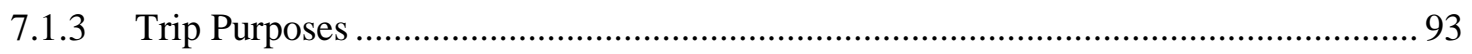

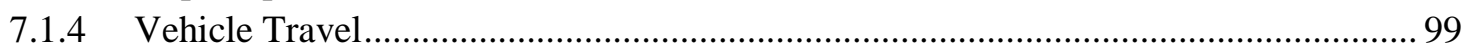

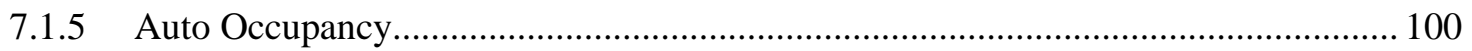

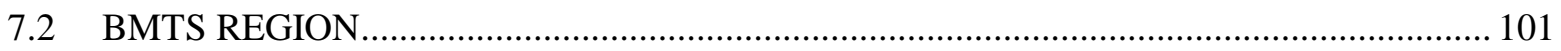

7.2.1 Volume of Travel Activities among BMTS Districts ............................................. 101

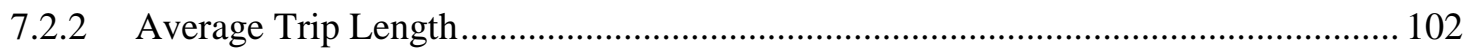

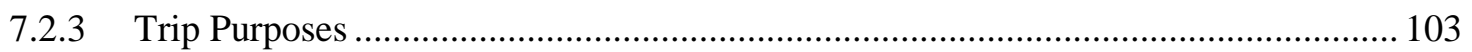

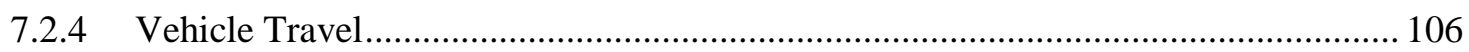

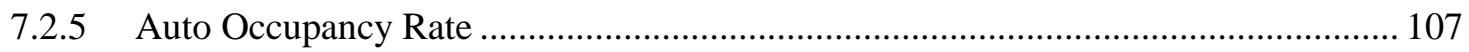

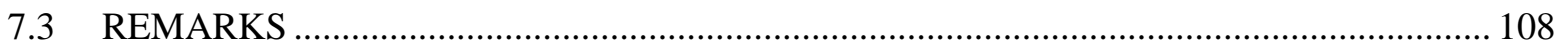

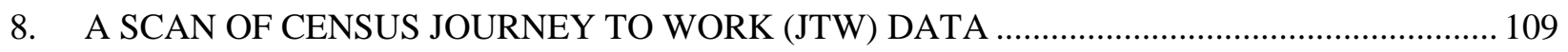

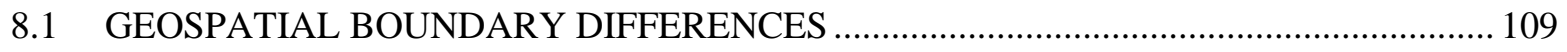

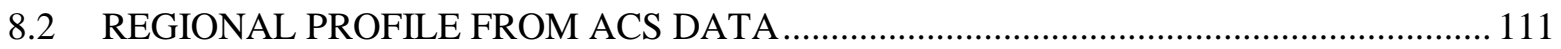

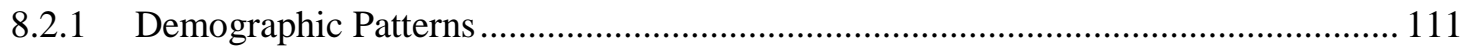

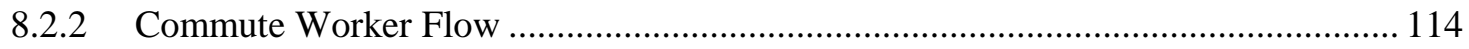

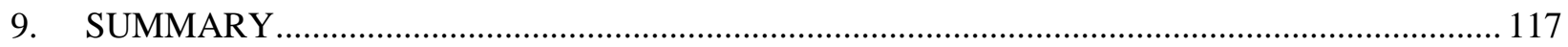

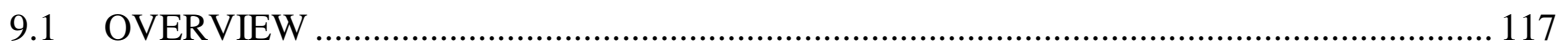

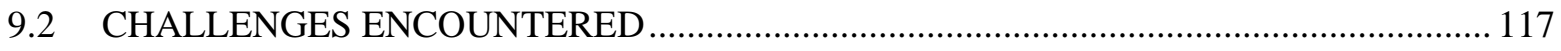

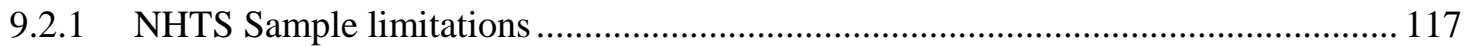

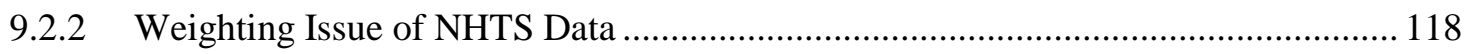

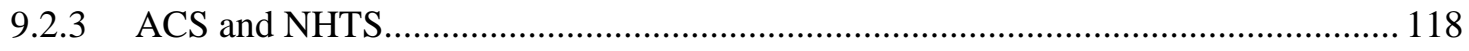

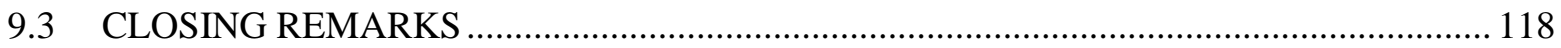

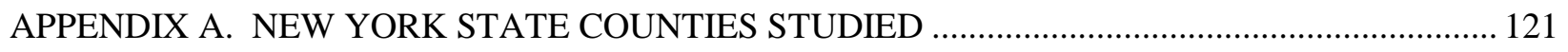

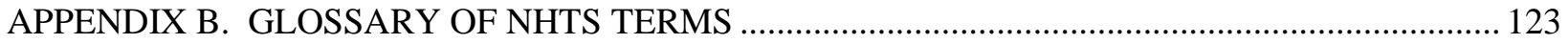




\section{LIST OF FIGURES}

Figure

2-1. Travel geographic region share by trip origin counties (2009 NHTS). ...................................... 4

2-2. Zoom-in view for New York City region. ......................................................................... 4

2-3. Travel geographic region share by trip destination counties (2009NHTS). ................................ 5

2-4. Zoom-in view for New York City destinations. ................................................................... 5

2-5. Sub-county zones defined for the SMTC region in this study................................................ 7

2-6. Sub-county zones defined for the BMTS region in this study................................................. 8

3-1. Distribution of household sizes in Syracuse and Binghamton MPOs........................................ 10

4-1. Distribution of households in SMTC Districts by household size (2009 NHTS data)................. 19

4-2. Share of households by household size in SMTC districts...................................................... 20

4-3. Age profile in SMTC districts (2009 NHTS data, age 5 years old and older only)..................... 21

4-4. Distribution of households by vehicle ownership, SMTC Districts. ........................................... 22

4-5. Distribution of household by vehicle ownership, SMTC districts............................................. 22

4-6. Percent of drivers by gender in SMTC districts................................................................... 23

4-7. Percent of workers by gender for SMTC districts. ............................................................. 24

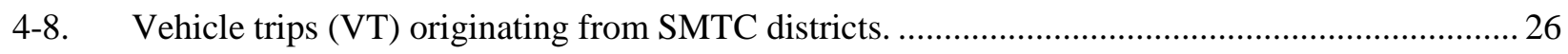

4-9. Vehicle trips (VT) terminating in SMTC districts............................................................... 26

4-10. Vehicle-miles traveled (VMT) originating in SMTC districts................................................. 27

4-11. Vehicle-miles traveled (VMT) terminating in SMTC Districts............................................... 27

4-12. Average person-trip and vehicle-trip per household in SMTC districts. .....................................28

4-13. Average PMT and VMT per household in SMTC districts................................................. 28

4-14. Average person-trips per household by household size by household district in SMTC. ............ 29

4-15. Average vehicle-trips per household by household size by household district in SMTC.............. 30

4-16. Average person-trips (PT)per household by vehicle ownership by household district in

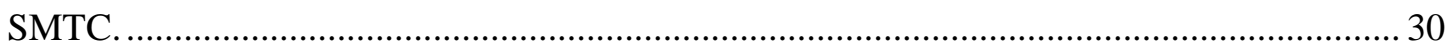

4-17. Average vehicle-trips (VT) per household by vehicle ownership for SMTC districts. ................. 31

4-18. Total number of person-trips originated from SMTC districts by trip purposes. ......................... 32

4-19. Average number of POV person-trips per household by trip purpose for SMTC districts............ 33

4-20. Average number of vehicle-trips per household by trip purpose for SMTC districts................... 34

4-21. Mode shares of person-trips by SMTC district..................................................................... 35

4-22. Mode share of person trips for intra-district travels in SMTC districts. ...................................... 36

4-23. Person trips made by SMTC households during AM peak hours by trip purpose (Top:

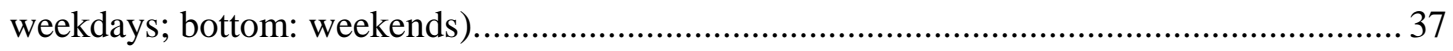

4-24. Travel patterns during weekday morning peak hours (6:00-9:00 am) in SMTC districts. ............ 38

4-25. Travel purpose for trips made during weekday AM peak hours (6:00-9:00) in SMTC (Top: intra-district trips; bottom: inter-district trips).

4-26. Travel during midday peak hours (11:00 a.m. to 2:00 p.m.) in SMTC districts (Top: weekday travel; bottom: weekend travel)

4-27. Travel patterns during midday peak hours (11:00 am to 2:00 pm) on weekdays for the SMTC districts, in person-trips. 
4-28. Travel made during weekday midday-peak hours (11 a.m. to 2 p.m.) in SMTC districts

(Top chart for intra-district trips; bottom chart for inter-district trips).

4-29. Travel during PM peak hours (4:00 to 7:00 p.m.) in SMTC districts (Top: weekday travel;

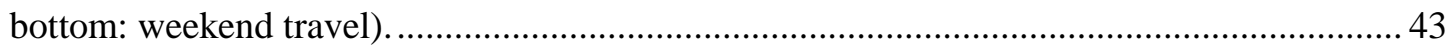

4-30. Travel patterns during weekday PM peak hours (4:00 to 7:00 pm) in SMTC districts................ 44

4-31. Trips made during weekday PM-peak hours (4 to 7 p.m.) in SMTC districts (Top chart for intra-district trips; bottom chart for inter-district trips)...................................................... 45

4-32. Travel patterns of person trips during weekend (all hours) in SMTC districts............................ 46

4-33. Average distance of a person-trip in SMTC district by trip-origin and trip-destination............... 47

4-34. Average distance of a vehicle-trip in SMTC district by trip-origin and trip-destination.............. 47

4-35. Average distance of a person-trip by originated SMTC district by trip type............................... 48

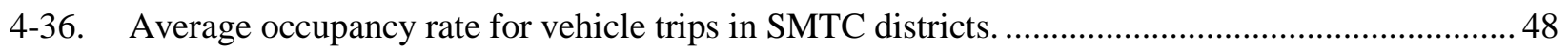

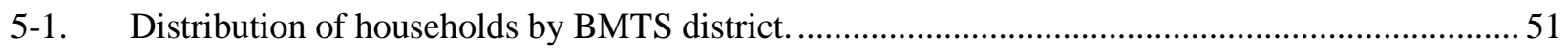

5-2. Distribution of household size by district in BMTS region...................................................... 52

5-3. Profile of household sizes by district in BMTS region.............................................................. 52

5-4. Distribution of households by age for the BMTS districts. .................................................... 53

5-5. Distribution of household vehicle ownership by BMTS districts.............................................. 54

5-6. Total number of person-trips and vehicle-trips by household location......................................... 56

5-7. Average person-trip (PT) and vehicle-trip (VT) per household by BMTS household-district...... 56

5-8. Average PMT and VMT per household by BMTS household-district........................................5 57

5-9. Average per-household PT by household size by BMTS household-districts............................. 58

5-10. Average per-household VT by household size for BMTS household-districts. .......................... 58

5-11. Average number of person-trips per BMTS household by vehicle ownership........................... 59

5-12. Average number of vehicle-trips per BMTS household by vehicle ownership.......................... 59

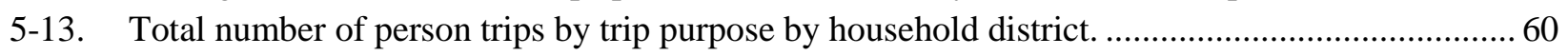

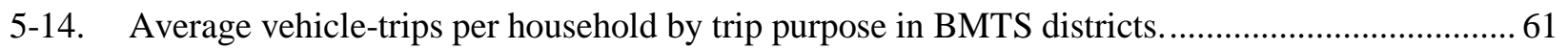

5-15. Mode share by trip-origin district in BMTS (based on person-trips)......................................... 62

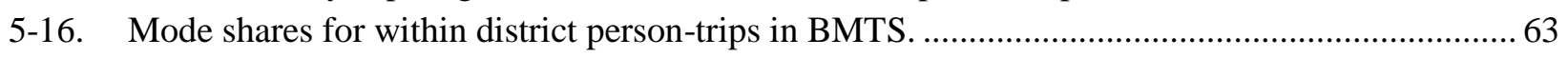

5-17. Person trips made by BMTS households during AM peak hours by trip purpose (Top:

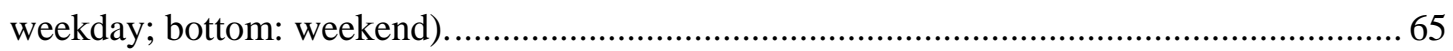

5-18. Travel patterns during weekday AM peak hours (6:00-9:00 am) in BMTS districts. .................. 66

5-19. Travel purpose for trips made during weekday AM peak hours (6:00-9:00) in BMTS (top chart for intra-district trips; bottom chart for inter-district trips).

5-20. Travel purpose for trips made during weekend AM peak hours (6:00-9:00) in BMTS (top chart for intra-district trips; bottom chart for inter-district trips).

5-21. Travel during midday peak hours (11:00 a.m. to 2:00 p.m.) in BMTS districts (Top: weekday travel; bottom: weekend travel)

5-22. Travel patterns during midday peak hours (11:00 am to 2:00 pm) on weekdays for the BMTS districts, in person-trips

5-23. Travel purpose for trips made during weekday midday-peak hours (11 a.m. to 2 p.m.) in BMTS districts (Top chart for intra-district trips; bottom chart for inter-district trips).......... 70

5-24. Travel during PM peak hours (4:00 to 7:00 p.m.) in BMTS districts (Top: weekday travel;

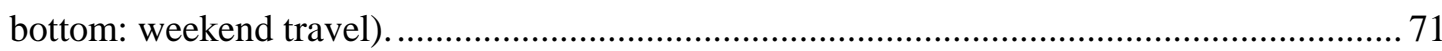

5-25. Travel patterns during weekday PM peak hours (4:00 to 7:00 pm) in BMTS districts................ 72 
5-26. Travel purpose for trips made during weekday PM-peak hours (4 to 7 p.m.) in BMTS districts (Top chart for intra-district trips; bottom chart for inter-district trips)..................... 72

5-27. Travel patterns of person trips during weekend (all hours) in BMTS districts............................ 73

5-28. Weekday average number of person-trips per household by time period and BMTS household district.

5-29. Weekday average number of vehicle-trips per household by time period and BMTS household district. .74

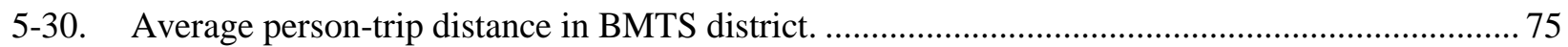

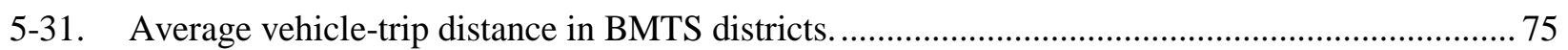

5-32. Average person-trip distance by trip purpose type by trip-origin district in BMTS districts. ....... 76

5-33 Average occupancy rate by trip-origin and trip-destination in the BMTS districts...................... 77

6-1. Number of businesses (10 or more employees) by industry type in SMTC districts.................... 81

6-2. Employee Counts of businesses (10 or more employees) by industry type in SMTC

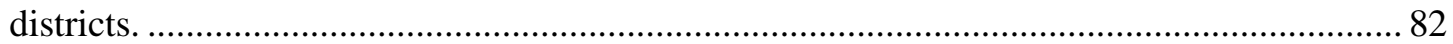

6-3. Sales share of businesses (10 or more employees) by industry type in SMTC districts............... 83

6-4. Share of sectors using FEMA's building square-footage occupancy data.................................. 84

6-5. Share of non-residential sectors using FEMA's building square-footage occupancy data............ 84

6-6. Counts of businesses (10 or more employees) by industry type in BMTS districts. ..................... 86

6-7. Share of businesses (10 or more employees) by employee counts in BMTS districts................... 87

6-8. Shares of businesses (with 10 or more employees) by annual sales for BMTS districts.............. 88

6-9. Share of sectors using FEMA's building square-footage occupancy data in BMTS districts. ...... 89

6-10. Share of non-residential sectors by building square-footage occupancy in BMTS districts. ........ 89

7-1. Commute flow to District 1 from all SMTC districts in person trips. ....................................... 95

7-2. Family/personal business trips made from all SMTC districts to District 2 in person trips. ......... 96

7-3. Home to work flows of person-trips from District 7 to all SMTC districts.................................. 98

7-4. Home to Other flows of person-trips from District 7 to all SMTC districts............................... 99

7-5. Earn a Living (commuting) person-trips from all BMTS districts to District 2. ....................... 104

7-6. Family/Personal Business person-trips from all BMTS districts to District 2.......................... 105

8-1. Portion of certain TADs not included as a part of the SMTC MPA.......................................... 110

8-2. Portion of certain TADs not included as a part of the BMTS MPA....................................... 110

8-3. Household size distribution in SMTC region based on ACS 2006-2010 data........................... 112

8-4. Households shares by vehicle ownership in SMTC districts using ACS 2006-2010 data........... 112

8-5. Household distributions by size for BMTS districts based on ACS data. ................................ 113

8-6. Household distribution by vehicle ownership in BMTS using ACS data.................................. 114 


\section{LIST OF TABLES}

Table

Page

2-1. $\quad$ New York State County-to-County Trip Counts (by all modes and all purposes) ........................ 3

3-1. Count of business with 10 or more employees in SMTC region, by NAICS. ............................. 13

3-2. Businesses with 10 or More Employees in BMTS Region, by NAICS.................................... 14

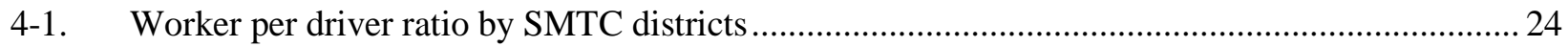

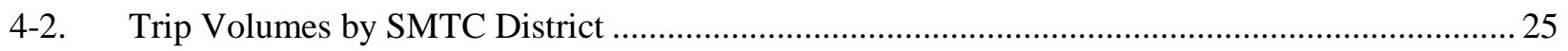

4-3. Average Number of Person-trips per Household by Trip Purpose for SMTC Districts ................ 33

4-4. $\quad$ Person Trips by Mode Based on Origin District of Trips Made by SMTC Residents................... 34

4-5. Person Trips by Mode on Destination District of Trips Made by SMTC Residents. .................... 36

4-6. Occupancy Rates Based on PT/VT of POV Trips by SMTC Household District. ....................... 49

4-7. Occupancy rates based on PMT/VMT of POV trips by SMTC household districts...................... 49

5-1. $\quad$ BMTS Driver and Worker Populations by Gender by District................................................... 54

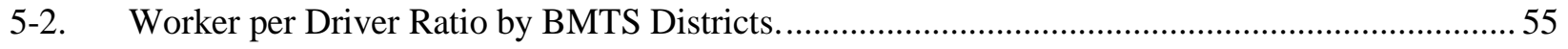

5-3. $\quad$ Trip Volumes by BMTS District (in number of person-trips) …................................................ 55

5-4. Average Person-Trips per Household by Trip Purpose by Household-District............................ 61

5-5. Person trips by mode based on origin district of trips made by BMTS residents ......................... 62

5-6. $\quad$ Person trips by mode by destination district of trips made by BMTS residents..........................63

5-7. Occupancy Rates Based on PT/VT of POV Trips by BMTS Household Districts........................ 77

5-8. Occupancy Rates Based on PMT/VMT of POV Trips by BMTS Household Districts ................ 77

6-1. $\quad$ Number of Business by NAICS Located in each SMTC Zone ${ }^{a}$................................................ 80

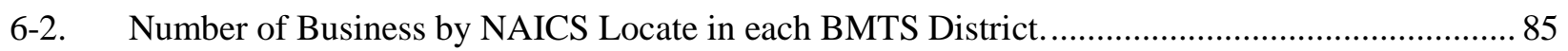

7-1. Total PT Flows Between SMTC Districts (in thousand person-trips) ....................................... 91

7-2. Total PMT Flows Between SMTC Districts (in thousand person-miles. ..................................... 92

7-3. Total VT Flows Between SMTC Districts (in thousand vehicle-trips)....................................... 92

7-4. Total VMT Flows Between SMTC Districts (in thousand vehicle-miles) .................................. 92

7-5. Average Person-trip Distance Between SMTC Districts ......................................................... 93

7-6. Average Vehicle-trip Distance Between SMTC Districts ........................................................ 93

7-7. Person-trips Made for the Purpose of "Earning a Living" (1,000 trips) ....................................... 94

7-8. Vehicle-trips Made for the Purpose of "Earning a Living" (1,000 trips).................................... 94

7-9. Person-trips Made for the Purpose of "Family/Personal Business" (1,000 trips) ........................ 94

7-10. Vehicle-trips Made for the Purpose of "Family/Personal Business" (1,000 trips) ...................... 95

7-11. Person-miles-traveled for the Purpose of "Earning a Living" (1,000 person miles) .................... 96

7-12. Vehicle-miles-traveled for the Purpose of "Earning a Living" (1,000 vehicle miles) .................. 97

7-13. Person-miles-traveled for the Purpose of "Family/person Business" (1,000 person miles) .......... 97

7-14. Vehicle-miles-traveled for the Purpose of "Family/person Business" (1,000 person miles)......... 97

7-15. Origin-destination Flows from District 7 to All SMTC Districts (1,000 person trips) ................. 98

7-16. Person-trips by POV Between SMTC Districts (1,000 trips) ................................................... 99

7-17. Person-miles-travel Flows by POV Between SMTC Districts (1,000 person-miles) .................. 100

7-18. Average Auto Occupancy Rates between SMTC Districts..................................................... 100

7-19. Average Auto Occupancy Rates between SMTC Districts for Other ${ }^{\mathrm{a}}$ Trip Purposes ................. 101

7-20. Total Person Trip Flows between BMTS Districts (in 1,000 person-trips) ................................ 101 
7-21. Total Personal-Miles-Traveled Flows between BMTS Districts (in 1,000 person-miles)........... 101

7-22. Total Vehicle-trip Flows between BMTS Districts (in 1,000 vehicle-trips) .............................. 102

7-23. Total Vehicle-Miles-Traveled Flows between BMTS Districts (in 1,000 vehicle-miles) ........... 102

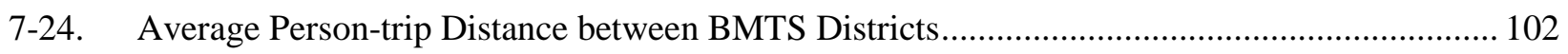

7-25. Average Vehicle-trip Distance between BMTS Districts ...................................................... 103

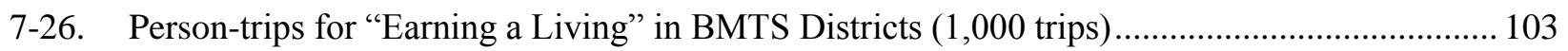

7-27. Vehicle-trips for "Earning a Living" in BMTS Districts (1,000 trips) ...................................... 103

7-28. Person-trips for "Family/Personal Business" in BMTS Districts $(1,000$ trips $)$.......................... 103

7-29. Vehicle-trips for "Family/Personal Business" in BMTS Districts (1,000 trips) ......................... 104

7-30. Person-miles-traveled for "Earning a Living" in BMTS Districts (1,000 person-miles)............ 105

7-31. Vehicle-miles-traveled for "Earning a Living" in BMTS Districts (1,000 vehicle-miles) .......... 105

7-32. Person-miles-traveled for "Family/Personal Business" in BMTS Districts (1,000 person-

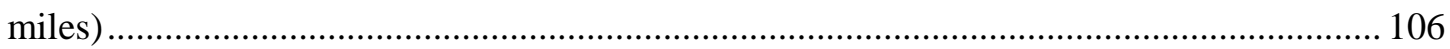

7-33. Vehicle-miles-traveled for "Family/Personal Business" in BMTS Districts (1,000 vehicle-

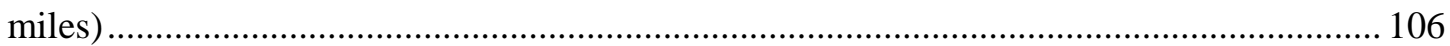

7-34. Origin-destination Flows Originated from District 2 to All BMTS Districts (person trips)........ 106

7-35. Origin-destination Flows from All BMTS Districts and Terminated in District 2 (person

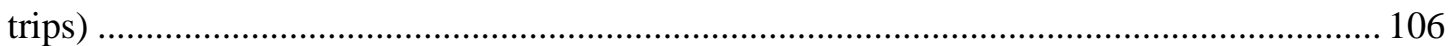

7-36. Person-trip Flows by POV between BMTS Districts (1,000 trips) .......................................... 107

7-37. Person-miles-traveled Flows by POV between BMTS Districts (1,000 person-miles) ............... 107

7-38. Average Auto Occupancy Rates between BMTS Districts (All Purposes) ................................. 107

7-39. Average Auto Occupancy Rates between BMTS districts for Purpose of Other ${ }^{\mathrm{a}}$...................... 107

7-40. Average Auto Occupancy Rates between BMTS Districts for Purpose of Home ....................... 108

8-1. Census Transportation Planning Package Worker Flows between SMTC Districts ................... 115

8-2. Census Transportation Planning Package Worker Flows between BMTS Districts ................... 115 


\section{ACRONYMS}

\begin{tabular}{ll} 
ACS & American Community Survey \\
BMTS & Binghamton Metropolitan Transportation Study \\
CTA & Center for Transportation Analysis \\
CTPP & Census Transportation Planning Package \\
DOE & Department of Energy \\
FEMA & Federal Emergency Management Agency \\
GIS & Geographic Information System \\
HAZUS & Federal Emergency Management Agency's Methodology for Estimating Potential \\
& Losses from Disasters \\
JC & Johnson City \\
JTW & Journey to Work \\
MPA & Metropolitan Planning Area \\
MPO & Metropolitan Planning Organizations \\
NAICS & North American Industry Classification System \\
NHTS & National Household Travel Survey \\
NYC & New York City \\
NYSDOT & New York State Department of Transportation \\
OD & Origin-Destination \\
ORNL & Oak Ridge National Laboratory \\
PA & Pennsylvania \\
PMT & Person-Miles Traveled \\
POV & Privately Owned Vehicles \\
PT & Person Trips \\
SMTC & Syracuse Metropolitan Transportation Council \\
TAD & Traffic Analysis District \\
VMT & Vehicle-Miles Traveled \\
VT & Vehicle Trips \\
& \\
\hline
\end{tabular}




\section{INTRODUCTION}

\subsection{BACKGROUND}

Information on Origin-Destination (OD) based daily travel flow is a vital part of the regional transportation planning process, and is rather challenging to obtain. The OD data specifies traffic flow volumes between geographic zones or specific locations. Traditionally, this data has been difficult to gather due to the expense of manual data collection and entry through license plate surveys and/or traveler interviews. This data is crucial for the calibration of travel demand models, which without OD data, are mainly based on known land use patterns and existing road networks, which only provides generalized travel information. The OD data contributes to the optimization of travel demand models and is used by transportation planners and analysts for all levels of agencies.

As an Add-on participant of the 2009 National Household Travel Survey (NHTS), the New York State Department of Transportation (NYSDOT) received travel data for nearly 16,200 state households. This allows NYSDOT analysts to address transportation planning issues pertinent to geographic areas significantly smaller than what the national NHTS data is intended for. Furthermore, trip ODs in the 2009 NHTS add-on samples were geo-coded, thus enabling NYSDOT to examine specific travel flow patterns.

Under an interagency agreement between the NYSDOT and the Department of Energy (DOE), the Center for Transportation Analysis (CTA) within Oak Ridge National Laboratory (ORNL) was tasked to provide analytical and technical support to the NYSDOT, particularly for the NHTS data. To investigate how data gathered under the 2009 NHTS can be used to produce regional travel flow information critical to support transportation planners in Metropolitan Planning Organizations (MPO), CTA researchers worked closely with transportation analysts from the NYSDOT to identify geographic regions that were most feasible for performing travel flow analysis at a disaggregated sub-county level, as well as identifying regions that could be supported by the 2009 NHTS Add-On data. Traffic Analysis District (TAD)-based regions were considered to be the most feasible and desirable geographic level for summarizing the 2009 NHTS data for transportation planning purposes.

Since this project was intended to be an exploratory pilot study, the project team determined that mediumsized MPOs would be the desired choice, rather than larger-sized ones, such as New York City (NYC), Buffalo, and Albany. Preferably, the selected MPO regions would embody slightly different regional characteristics. An initial examination of the 2009 NHTS OD data for counties within all Add-On MPOs in New York State (NYS) was conducted first to identify whether 2009 NHTS sample sizes were sufficient to support travel flow analysis at a more disaggregated level (i.e., sub-county). As a result from that initial scan, two MPO regions were selected and then used as the proof-of-concept areas for this pilot study.

\subsection{OBJECTIVE OF STUDY}

The goal of this task was to carry out a feasibility study on using NHTS Add-On data to support transportation planning applications in medium-sized MPOs, specifically OD flow patterns in a 
disaggregated sub-county geography. Initially, an overall examination of the OD data as collected under the 2009 NHTS for counties within all add-on MPOs in NYS was conducted. The purpose of this initial task was to identify whether sample sizes were sufficient to support travel flow analysis at a more disaggregated sub-county level. Based on examination of the county-level travel patterns and their corresponding sample sizes using the 2009 NHTS data, two MPOs (Syracuse and Binghamton) were selected as the pilot study regions. The sub-county zones within each of the two selected regions were then defined so that OD travel flow analysis can be conducted at a more disaggregated sub-county level. Note that, in order to produce practical and meaningful travel flow information that could best support MPO planning activities, a proper definition of sub-county zones is extremely crucial.

\subsection{ORGANIZATION OF REPORT}

This report describes the data, analysis method, activity-based OD travel flow patterns, lessons-learned during the process, and comparison results for the selected proof-of-concept areas. Specifically, discussions presented in this report include summaries of OD passenger travel flows among TAD-based zones in the given MPOs; visualization of travel flow patterns; as well as illustrations of potential benefits and impacts of integrating multiple geospatial data/information (e.g., business data, American Community Survey (ACS) data, etc.) to support regional planning and programs in transportation agencies. Although only two MPOs were examined under this pilot study, it is anticipated that the processes and analytical procedures developed here could easily be transferable to other MPOs with addon NHTS samples. This report is concluded with two appendices. Appendix A lists the 62 counties of NYS that were examined in this pilot study. Appendix B is glossary providing the most commonly used terms in the NHTS data and definitions of those terms. 


\section{SCOPE OF GEOGRAPHIC REGIONS}

\subsection{SELECTION PROCESS}

As a first step in defining the geographic region for this study, an initial examination of the 2009 NHTS OD data for all add-on NYS MPOs was conducted. This initial step analyzed detailed OD travel flows at the county level and reviewed travel patterns by activity (i.e., trip purpose) using statistical measures such as person trips (PT), vehicle trips (VT), person-mile traveled (PMT), and vehicle-miles traveled (VMT). The main focus of this effort was to identify areas with sufficient sample sizes to support travel flow analysis at a more disaggregated sub-county level.

From this initial process, an OD matrix showing 2009 NHTS travel flows between counties was created, with cells representing the total number of daily trips made between the given pairs of OD counties in 2009. There are 62 counties in NYS (listed in Appendix A), however not all NYS county pairs have NHTS-captured trips. As an example, Table $2-1$ below shows a portion of this OD matrix. Clearly, many of these cells have zero counts of trips.

Table 2-1. New York State County-to-County Trip Counts (by all modes and all purposes)

\begin{tabular}{|l|c|c|c|c|c|c|}
\hline \multirow{2}{*}{ County name } & \multirow{2}{*}{$\begin{array}{l}\text { Origin } \\
\text { county }\end{array}$} & \multicolumn{6}{|c|}{ Destination county } \\
\cline { 3 - 7 } & 36001 & $\mathbf{3 6 0 0 1}$ & $\mathbf{3 6 0 0 3}$ & $\mathbf{3 6 0 0 5}$ & $\mathbf{3 6 0 0 7}$ & $\mathbf{3 6 0 0 9}$ \\
\hline Albany & $361,300,000$ & 0 & 66,537 & 61,398 & 0 \\
\hline Allegany & 36003 & 0 & $41,900,000$ & 0 & 0 & $3,265,397$ \\
\hline Bronx & 36005 & 66,537 & 0 & $893,200,000$ & 0 & 0 \\
\hline Broome & 36007 & 223,199 & 0 & 0 & $236,200,000$ & 0 \\
\hline Cattaraugus & 36009 & 0 & $2,478,748$ & 0 & 0 & $90,240,000$ \\
\hline Cayuga & 36011 & 58,544 & 0 & 0 & 38,847 & 0 \\
\hline Chautauqua & 36013 & 0 & 85,654 & 0 & 161,801 & $6,010,689$ \\
\hline Chemung & 36015 & 12,171 & 120,507 & 0 & 427,034 & 54,117 \\
\hline Chenango & 36017 & 0 & 0 & 0 & $2,964,373$ & 0 \\
\hline Clinton & 36019 & 0 & 0 & 0 & 0 & 0 \\
\hline Columbia & 36021 & $2,717,328$ & 0 & 0 & 0 & 0 \\
\hline Cortland & 36023 & 15,793 & 0 & 0 & $3,729,843$ & 0 \\
\hline
\end{tabular}

Note that a trip originating from a NYS county could be terminated outside NYS (e.g., trip ends in New Jersey). Likewise, a trip terminating in a NYS county could actually be originating from a county outside NYS (e.g., trip begins in Pennsylvania (PA)). Because NHTS is a household-based travel survey, trips captured in this NYS Add-on database represent travel made during the survey time period by $\underline{\mathrm{NYS}}$ residents. Although NHTS national samples could have included trips made by residents of PA visiting NYS, for example, trip data for non-Add-on locations is not geocoded the same way thus do not provide geographic-specific location information. Because of this, OD-specific flows involving non-NYS residents making trips into/out of NYS were missed; this could have a greater impact on travel pattern analysis involving counties along the state borders. 
In addition to the OD county flow matrix discussed above, these county-level trips are further separated into categories by geographic regions of travel. Specifically, all trips originating from a given county were categorized by their destination locations (see Figure 2-1): within county trips (i.e., trip ended in the same county), destination in other NYS counties, destination in U.S. location but outside NYS, and those with unreported locations (including foreign locations). To show more details for counties around NYC, a separate close-up map is provided in Figure 2-2. Clearly, the majority of NHTS trips (daily travel) were within-county trips.

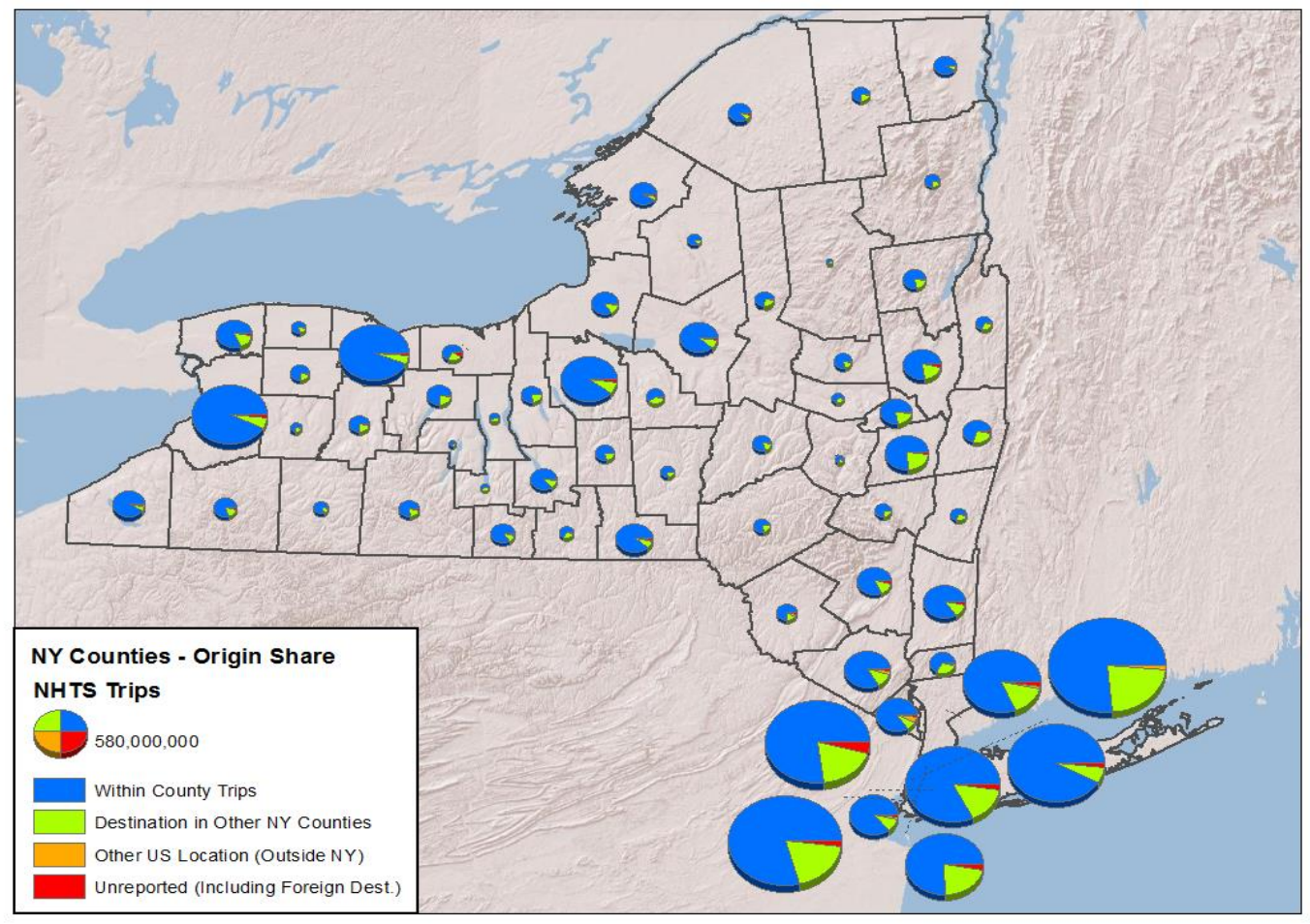

Figure 2-1. Travel geographic region share by trip origin counties (2009 NHTS).

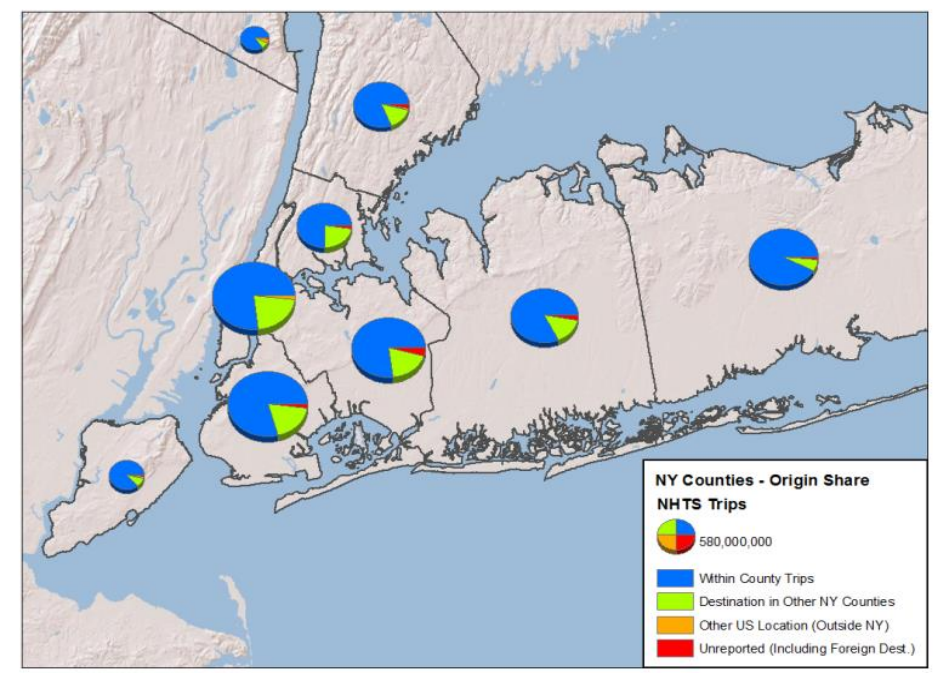

Figure 2-2. Zoom-in view for New York City region. 
Similarly, Figure 2-3 and Figure 2-4 show the share of county-level trip counts by trip destination counties. Higher shares of "unreported" trips are seen than those shown in Figures 2-1 and 2-2, particularly in the NYC area.

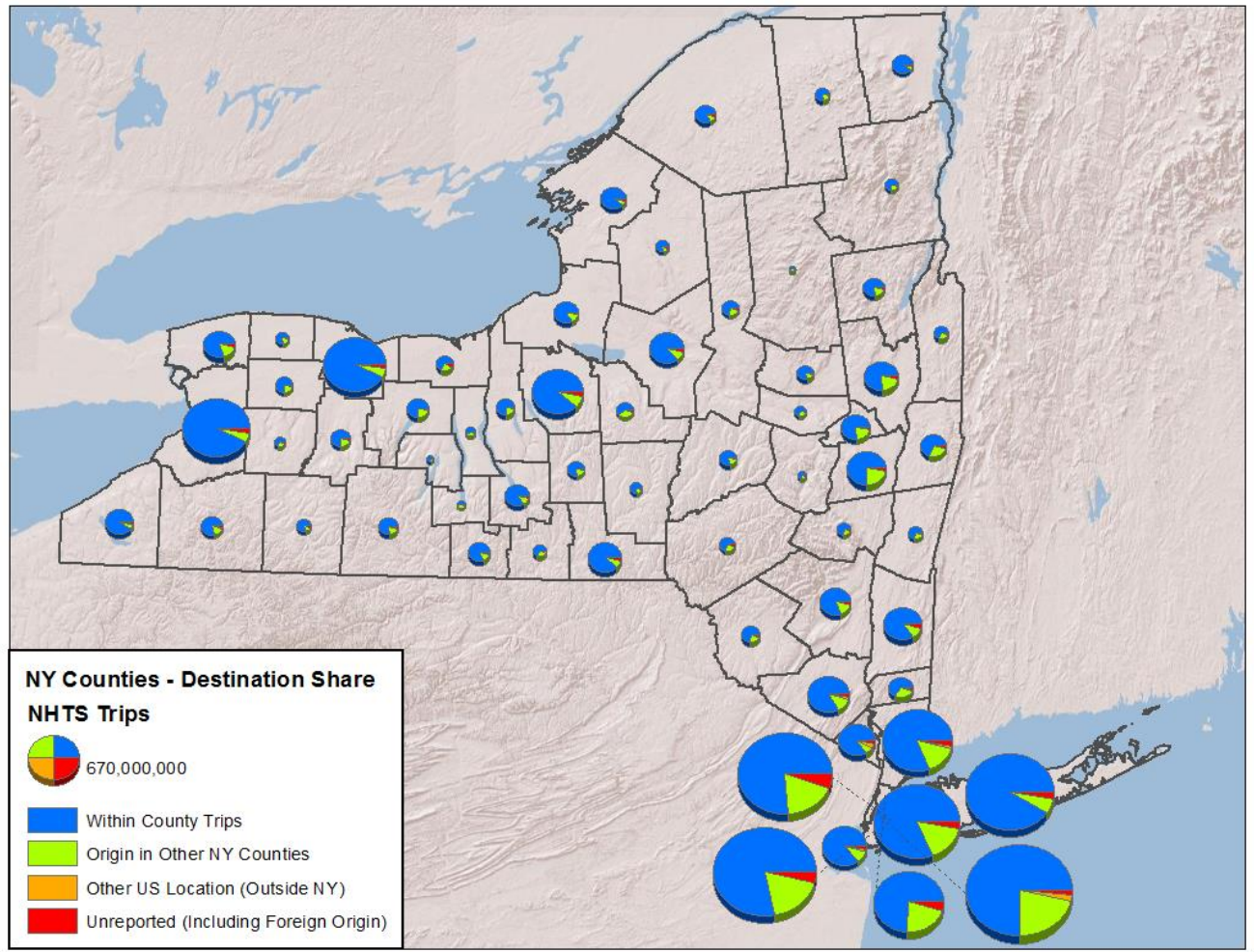

Figure 2-3. Travel geographic region share by trip destination counties (2009NHTS).

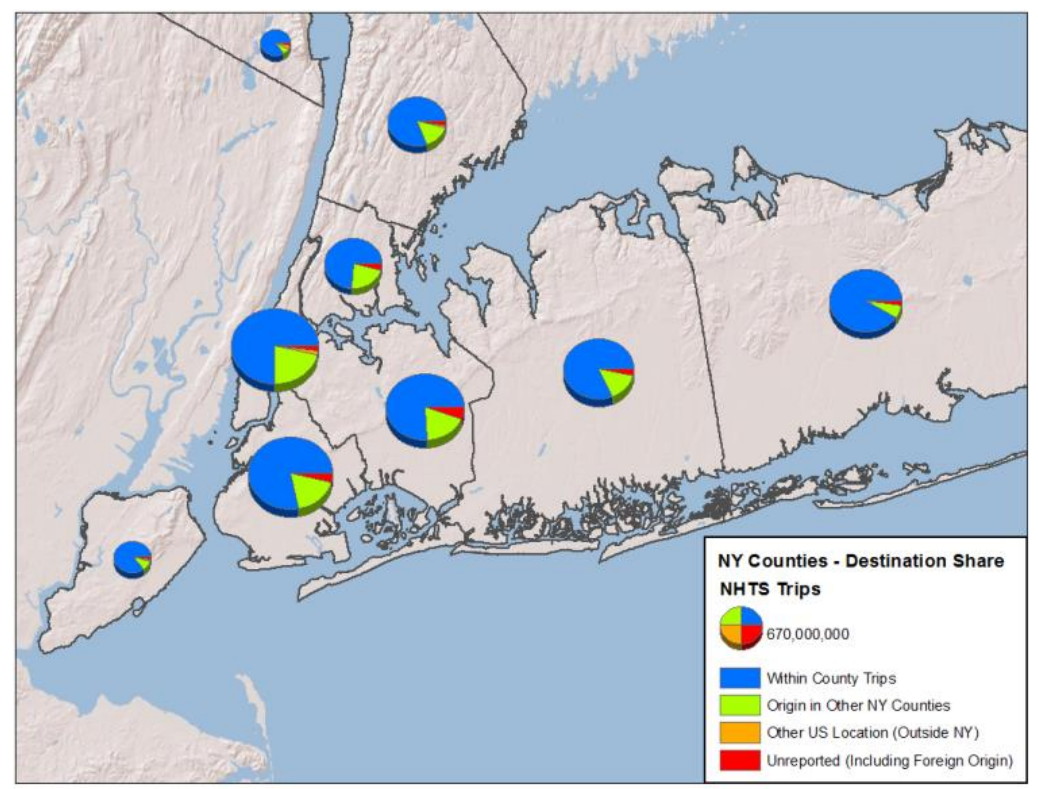

Figure 2-4. Zoom-in view for New York City destinations. 
Note that the NYC area was not selected as a "pilot study area" for this study mainly because of its regional uniqueness in travel behavior and patterns.

\section{$2.2 \quad$ STUDY REGIONS WITH SUB-COUNTY DISTRICTS}

Based on the examination of population sizes and the degree of travel activities within individual NYS counties reviewed under the aforementioned selection process, two MPOs, the Syracuse Metropolitan Transportation Council (SMTC) and the Binghamton Metropolitan Transportation Study (BMTS), were identified as good candidates for this pilot study. A TAD-based region was considered to be the most feasible and desirable geographic level for summarizing the 2009 NHTS data for transportation planning purposes.

The process of defining sub-county level study regions within each of these two selected MPOs involved the use of Geographic Information System (GIS). Explicitly, detailed geospatial data on business establishment locations, regional population size, and the degree of travel activities from NHTS data, and so on, are all considered. Furthermore, a representative from each of the MPOs was also invited to participate in the geographic scoping process to ensure meaningful and practical disaggregatedgeographic regions were produced.

\subsubsection{Syracuse Metropolitan Transportation Council}

The SMTC is the MPO responsible for administering the continuous and comprehensive transportation planning process in Onondaga County, and small portions of Madison and Oswego Counties. Working with a SMTC planner, the research team defined eight TAD-based sub-county zones (districts) for the SMTC region. The decision to divide SMTC into these eight specific districts was made based upon not only having sufficient household travel data to support necessary analyses to be conducted under this study, but also ensure meaningful and useful results were produced that support SMTC's planning needs. The eight districts for SMTC are named below and are shown in Figure 2-5 with color-coded areas:

1. Syracuse West (dark blue)

2. Syracuse East (purple)

3. Syracuse South (light green)

4. SMTC Metropolitan Planning Area (MPA) Northwest (red)

5. SMTC MPA North (yellow)

6. SMTC MPA Northeast (cyan)

7. SMTC MPA Southeast (green)

8. SMTC MPA Southwest (orange)

Districts 1-3 represent parts of the City of Syracuse and are shown in the center of the map. Districts 4-8 include different parts of the MPO region, where Districts 6 and 8 also include some partial TADs outside the Onondaga County. 


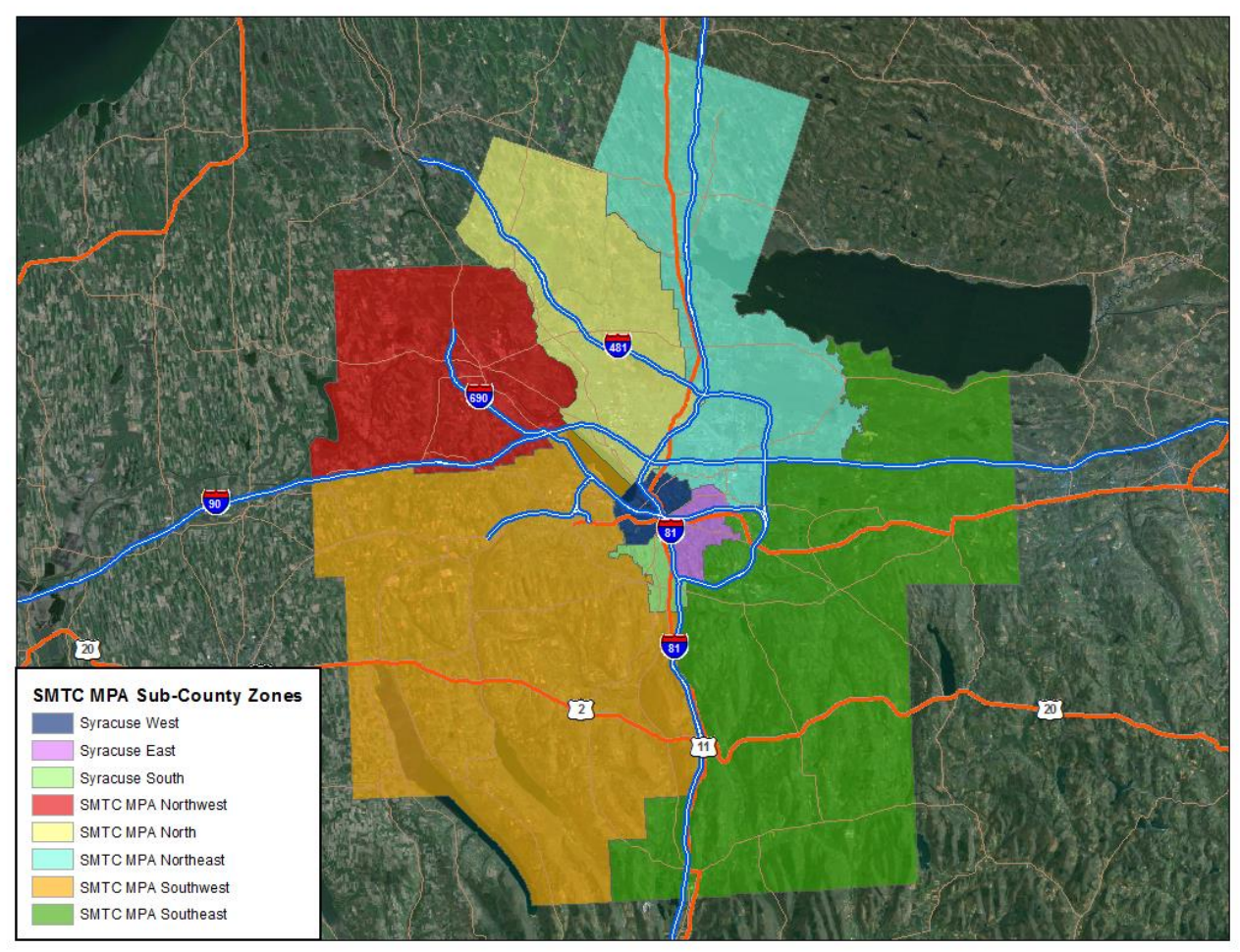

Figure 2-5. Sub-county zones defined for the SMTC region in this study.

\subsubsection{Binghamton Metropolitan Transportation Study}

The BMTS is the MPO for Broome and Tioga Counties along the NY-PA state border. The BMTS is also a much smaller MPO than SMTC, thus allowing for examination of a potentially different aspect of travel patterns from those presented in SMTC. With assistance provided by a BMTS planner, similar effort was conducted to divide the BMTS MPO region into five specific TAD-based districts. The following districts are primarily named by the cities they contain and are presented in Figure 2-6.

1. North/East (yellow)

2. Binghamton (beige)

3. Vestal/Johnson City (Vestal/JC) (green)

4. Endicott (blue)

5. Tioga (pink)

District 1 (North/East) is mainly representing the remainder of the BMTS region, which is outside the 4 city-named regions. 


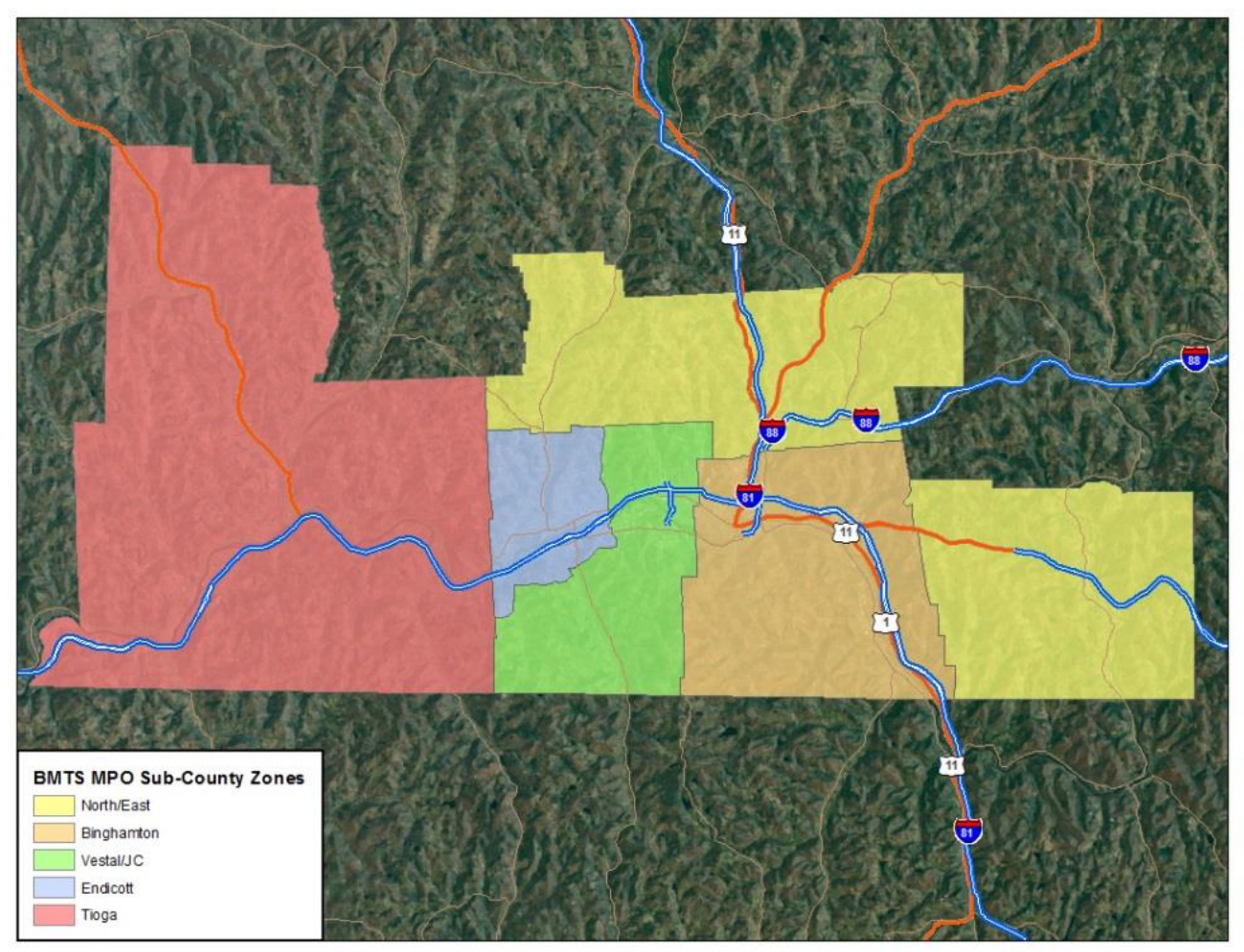

Figure 2-6. Sub-county zones defined for the BMTS region in this study. 


\section{DATA SOURCES AND OVERVIEW}

All data sources used in this pilot study are described in this Section. Clearly the 2009 NYS Add-On NHTS data provides the main source of information associated with characteristics of the traveling households and their travel behaviors for residents in the selected study regions. To better serve NYS MPOs planning needs, other data sources, such as business/employment data and Census data, were used to establish associations and links between travel behavior and regional land-use patterns. Specifically, NYSDOT has a database that contains business employment locations and their associated information for businesses with 10 or more employees. Other data sources examined include the ACS data and other geospatial datasets gathered by the research team. These data sources are discussed below.

\subsection{NATIONAL HOUSEHOLD TRAVEL SURVEY}

The 2009 NHTS is sponsored by the Federal Highway Administration and is a national travel survey of over 150,000 households. ${ }^{1}$ According to the NHTS website, ${ }^{2}$ "The NHTS is the authoritative source of national data on the travel behavior of the American public." The NHTS includes questions about trip frequency, distance, travel time, and modes of transportation.

Although the NTHS is a national survey, its sampling is more concentrated in areas with add-on components, which include individual participating states, cities, and regions. ${ }^{3}$ Sampling weights provided in the NHTS data allow for proper accounting for the add-on sampling, as well as for the nonresponse rates and other adjustments. Of course, estimates (e.g., trips per person) computed for areas with add-on sampling tend to be statistically more precise than estimates from areas without add-on sampling. Furthermore, the NHTS add-on areas not only had higher sampling rates, they also include more detailed information on destinations (i.e., geo-coded locations).

As mentioned previously, as an Add-On participant, NYSDOT received 2009 NHTS travel data for nearly 16,200 of NYS households. This rich dataset allowed analyses to be performed at geographic areas significantly smaller than what the national NHTS data are intended for (typically, at the state level). The geo-coded samples from NHTS also enabled examination of travel flow patterns within specific regions, which was the emphasis of this pilot study.

For the two selected medium-size pilot study regions, 792 households in Syracuse and 560 households in Binghamton were captured by the 2009 NHTS samples. These samples represent about 200,400 households in the SMTC region and over 86,800 households in the BMTS area. Household profiles in terms of household sizes for these two regions are fairly similar. As an example, about $70 \%$ of households in both regions were one- or two-person households (Figure 3-1); although SMTC has a 6\% higher share of single person households, and consequently a significantly lower percent of 2-person households than BMTS.

\footnotetext{
${ }^{1}$ U.S. Territories are not included in the NHTS sampling frame.

${ }^{2}$ http://nhts.ornl.gov/.

${ }^{3}$ The 2009 NHTS add-on areas were California, Cedar Rapids, Iowa, Florida, Georgia, Iowa, Indiana, North Carolina, New York, Omaha, Nebraska, Phoenix, Arizona, Piedmont Region, North Carolina, South Carolina, South Dakota, Tennessee, Tucson, Arizona, Texas, Virginia, Vermont, and Wisconsin.
} 


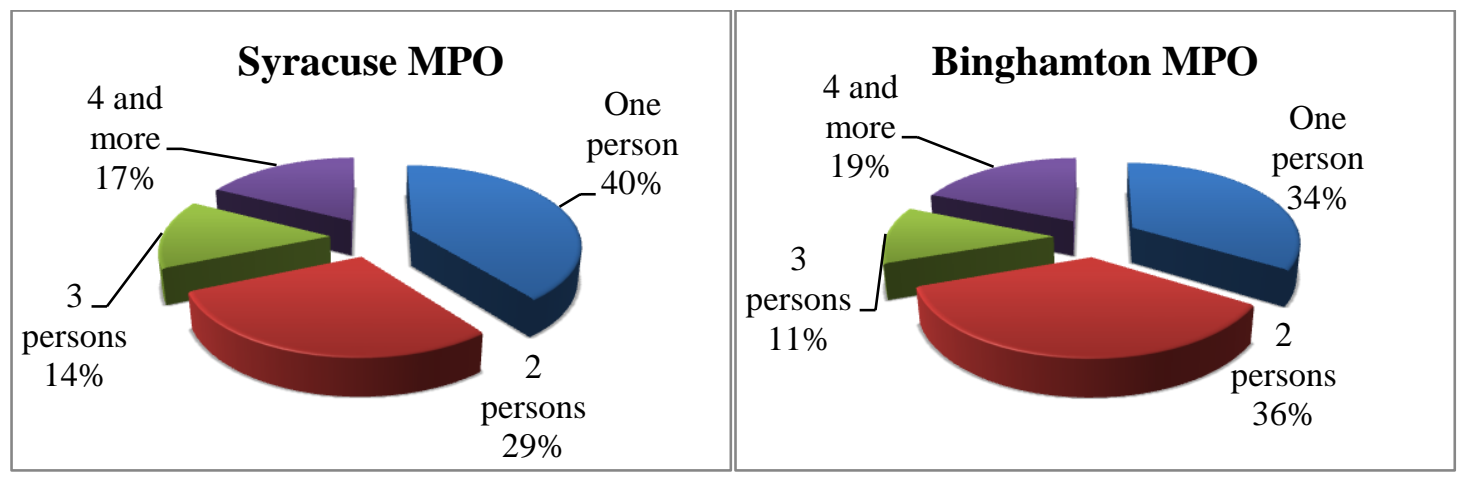

Figure 3-1. Distribution of household sizes in Syracuse and Binghamton MPOs.

Similarly, over $72 \%$ of households in each of the two regions own one or two vehicles. About $12 \%$ of SMTC households do not own any vehicles while $11 \%$ of BMTS households are without any vehicles. Overall, age profiles in the two MPO regions (for persons age 5 and older only) are also very similar; with about $29 \%$ of the region's residents age 55 years old or older and about the same percent for residents that are under age 25 years old.

Using 2009 NHTS daily trips, Figure 3-2 shows the trip origination locations within the three-county region that SMTC is in, and overlay with the 8 districts of SMTC (color-coded area) defined for this study. Clearly visible in Figure 3-2 is a concentration of trips originating around the City of Syracuse area in the center of the map. The pattern of trip originations also shadows major highways in the area (see Figure 2-5). A similar map displaying NHTS trip origins from the BTMS region is presented in Figure 3-3. The concentration of trips starting around the two major cities (Binghamton and Endicott) as well as along major highways (Figure 2-6) can be observed. More detailed NHTS-based statistics and analyses results for SMTC and BMTS are discussed in Sections 4 and 5 of this report. 


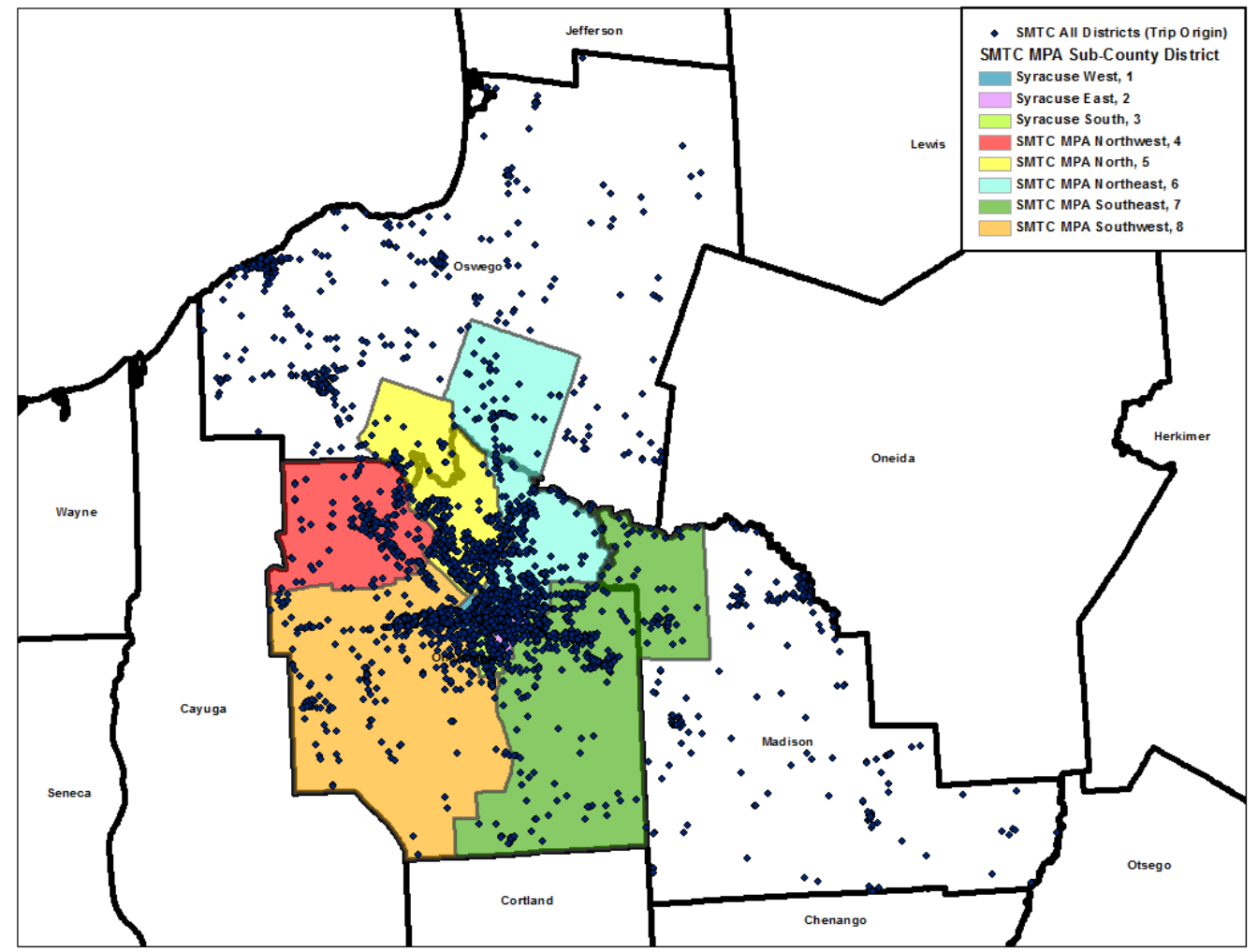

Figure 3-2. NHTS trip origins in the three-county region containing the SMTC. 


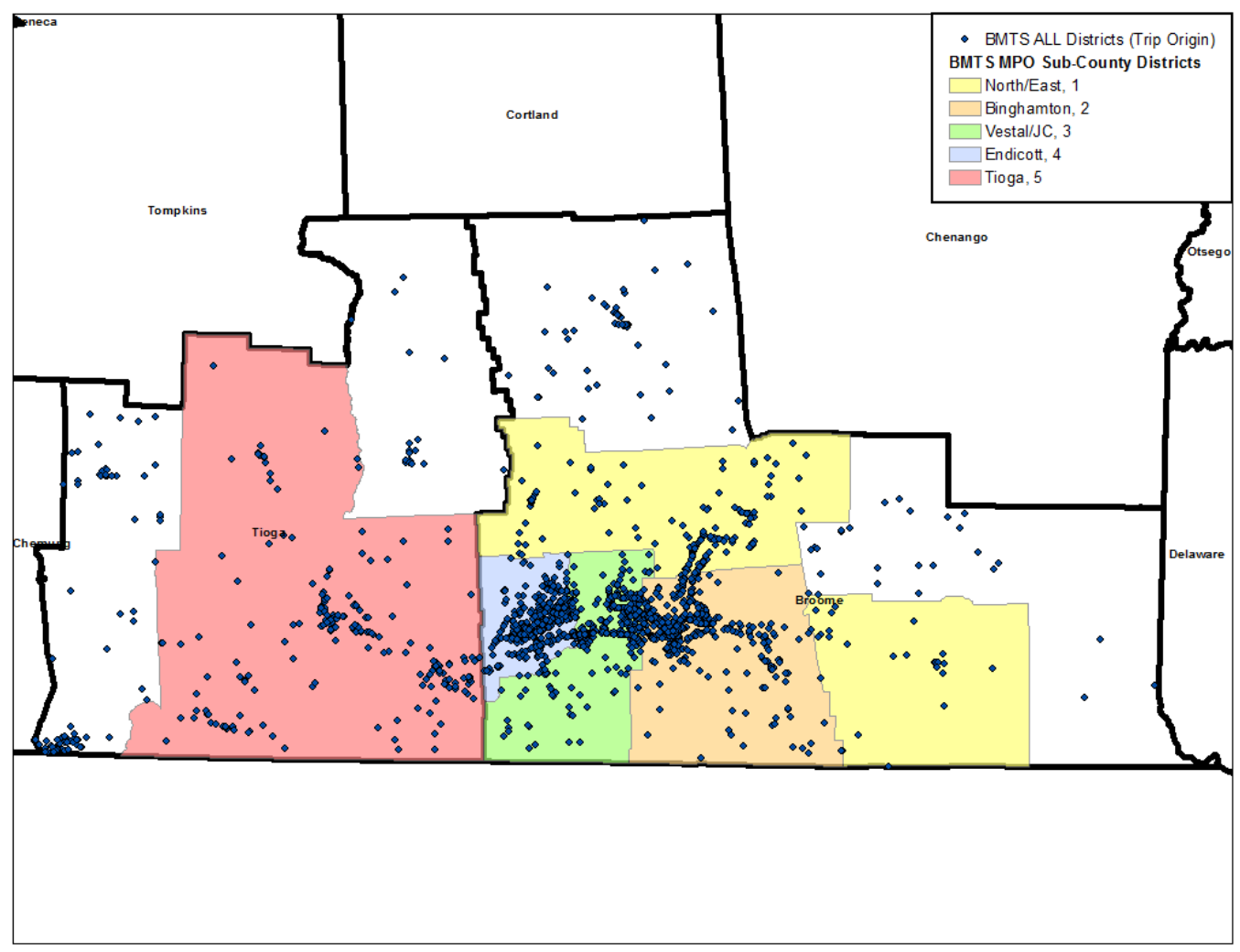

Figure 3-3. NHTS trip origins in the two-county region containing the BMTS.

\subsection{BUSINESS DATA}

The NYSDOT provided the research team with a proprietary business database, namely InfoUSA (a product of the Infogroup), to use as a proxy measure to study the land-use representation or pattern associated with travel. This dataset contained business information (industry category, sales, employment size, etc.) and their locations as of 2011 for businesses with 10 or more employees.

As an initial overview of this database, types of businesses, categorized by the North American Industry Classification System (NAICS) code, are summarized for the selected study regions. Tables 3-1 and 3-2 present the number of businesses (with 10 or more employees), by 2-digit NAICS category, for those located in the SMTC and BMTS regions, respectively. 
Table 3-1. Number of Businesses with 10 or more employees in SMTC region, by NAICS.

\begin{tabular}{|c|l|c|}
\hline NAICS & Description & Number of businesses \\
\hline 11 & Agriculture, Forestry, Fishing and Hunting & 7 \\
\hline 21 & Mining, Quarrying, and Oil and Gas Extraction & 1 \\
\hline 22 & Utilities & 270 \\
\hline 23 & Construction & 239 \\
\hline $31-33$ & Manufacturing & 216 \\
\hline 42 & Wholesale Trade & 614 \\
\hline $44-45$ & Retail Trade & 107 \\
\hline $48-49$ & Transportation and Warehousing & 128 \\
\hline 51 & Information & 193 \\
\hline 52 & Finance and Insurance & 130 \\
\hline 53 & Real Estate and Rental \& Leasing & 285 \\
\hline 54 & Professional, Scientific, and Technical Services & 2 \\
\hline 55 & Management of Companies and Enterprises & 135 \\
\hline 56 & Administrative \& Support, Waste Management \& & 392 \\
\hline 61 & Eemediation Services & 691 \\
\hline 62 & Health Care and Social Assistance & 107 \\
\hline 71 & Arts, Entertainment, and Recreation & 652 \\
\hline 72 & Accommodation and Food Services & 261 \\
\hline 81 & Other Services (except Public Administration) & 260 \\
\hline 92 & Public Administration & 86 \\
\hline 99 & Unknown & \\
\hline & & \\
\hline
\end{tabular}


Table 3-2. Number of Businesses with 10 or More Employees in BMTS Region, by NAICS.

\begin{tabular}{|c|l|c|}
\hline NAICS & Description & Number of businesses \\
\hline 11 & Agriculture, Forestry, Fishing and Hunting & 6 \\
\hline 21 & Mining, Quarrying, and Oil and Gas Extraction & 3 \\
\hline 22 & Utilities & 109 \\
\hline 23 & Construction & 115 \\
\hline $31-33$ & Manufacturing & 80 \\
\hline 42 & Wholesale Trade & 247 \\
\hline $44-45$ & Retail Trade & 54 \\
\hline $48-49$ & Transportation and Warehousing & 46 \\
\hline 51 & Information & 62 \\
\hline 52 & Finance and Insurance & 35 \\
\hline 53 & Real Estate and Rental and Leasing & 74 \\
\hline 54 & Professional, Scientific, and Technical Services & 0 \\
\hline 55 & Management of Companies and Enterprises & 51 \\
\hline 56 & Administrative \& Support and Waste Management \& & 121 \\
\hline 61 & Eemediation Services & 237 \\
\hline 62 & Health Care and Social Assistance & 40 \\
\hline 71 & Arts, Entertainment, and Recreation & 297 \\
\hline 72 & Accommodation and Food Services & 109 \\
\hline 81 & Other Services (except Public Administration) & 114 \\
\hline 92 & Public Administration & 39 \\
\hline 99 & Unknown & \\
\hline & & \\
\hline
\end{tabular}

The locations of these businesses are also displayed in Figures 3-4 and 3-5. Noticeably, most businesses are located along highways; there are some resemblances in their patterns with the NHTS trip origins shown in Figures 3-2 and 3-3. Note that this NYS business data is not available for the same time period as the NHTS travel data which was collected during 2008-2009. Although changes in business dynamics over the two years or so might have occurred for some businesses, it is assumed that the overall impact is small for the purpose of this pilot study. Further discussions on business land-use patterns in the two study regions are presented in later sections of this report. 


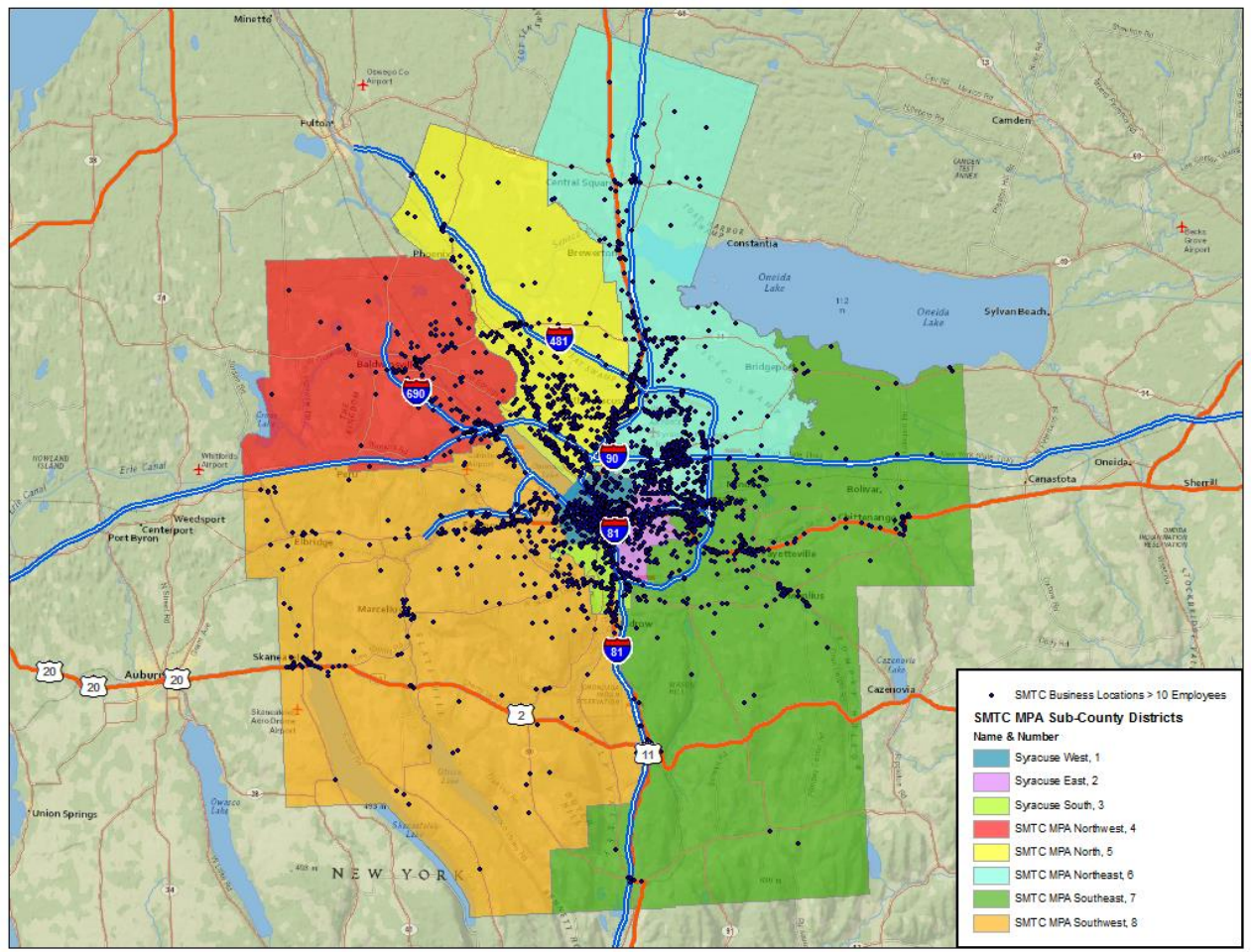

Figure 3-4. Business locations in SMTC 8-district region.

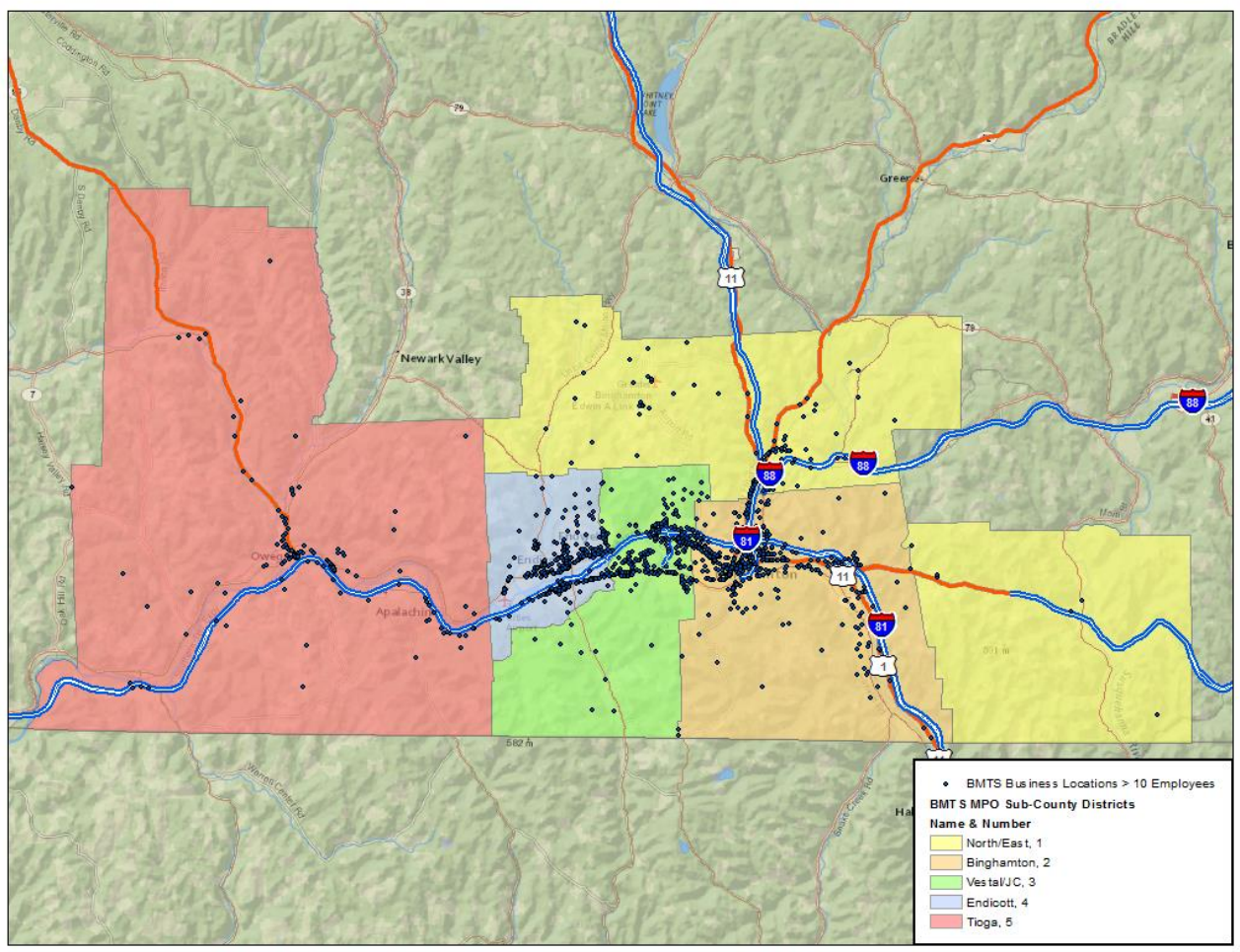

Figure 3-5. Business locations in BMTS 5-district region. 


\subsection{AMERICAN COMMUNITY SURVEY (ACS) DATA}

The $\mathrm{ACS}^{4}$ is a continuous survey conducted by the U.S. Census Bureau of about 3 million households each year (250,000 per month), subject to the constraint that households should not be surveyed more than one time in any five-year period. Thus the ACS is very intensive-about 20 times as big as the NHTS at the national level (3 million versus 150,000)-and it is repeated every year. As the ACS does not have add-on components, it is also geographically more uniform than the NHTS. Each year's ACS sample includes, on average, almost 50 households per Census Tract and almost 15 households per Block Group.

Data on demographic, social, and economic characteristics is collected in the ACS. The ACS also collects data on commuting, i.e., Journey to Work (JTW), including mode of transportation and travel time to work. The 5-year ACS for 2006-2010 is currently available, which is the base for the most recent Census Transportation Planning Package (CTPP) (i.e., JTW) data. Under this study, ACS/CTPP data associated with the two selected MPOs was examined. Benchmark comparisons with results generated from the 2009 NHTS for commute trips were also performed, when possible (i.e., where data is compatible).

It should be noted that, in terms of flows, CTPP provides estimates of annual worker counts between residence and work place; while NHTS-based measures were generally estimated for person-trips or vehicle-trips. Furthermore, NHTS data was "trip segment" based. For example, a worker that leaves home with a child and drops the child off at school and then travels to his/her work place would be coded as two trips under the NHTS. This is considered by the CTPP as one worker between the associated residence location and work place. Consequently, information obtained from these two datasets could be supplementary to each other; but not necessarily be compatible in all situations. Further discussions are summarized in Section 8 of this report.

\subsection{OTHER GEOSPATIAL DATA}

The geospatial nature of a community such as its land-use mix is known to have a direct impact on travel by the residents as well as visitors to the community (e.g., mode choice and trip purposes). In addition to the business data discussed above, which includes businesses with 10 or more employees, the building square-footage occupancy database (entitled HAZUS ${ }^{5}$ ) from the Federal Emergency Management Agency (FEMA) was also used for this study to provide another proxy measure for examining land-use mix of the study regions. The HAZUS data was collected for use in emergency preparedness and response planning purposes. It is a publically accessible database.

Unlike the business data which is coded at a specific point location (i.e., latitude-longitude), the HAZUS data is available at the Census block level, the most detailed geographic region defined by the U.S. Census. The FEMA categorizes the building square-footage occupancy data into seven classes: residential, commercial, industrial, agricultural, religious, government, and education. With the exception

\footnotetext{
${ }^{4}$ http://www.census.gov/acs/www/.

${ }^{5}$ HAZUS, The Federal Emergency Management Agency's Methodology for Estimating Potential Losses from Disasters. http://www.fema.gov/hazus.
} 
of religious and agricultural, further sub-classifications of land use are also provided. For example, the residential class can be expanded further by number of units per residence, temporary lodging, nursing home, etc.

Obviously, the size of square-footage occupied by a sector does not necessarily measure how significant a building's occupant has on "generating" trips (including residents, workers, shoppers, etc.). It could, however, provide supplemental information about the land-use mix in a region; which potentially allows one to examine associations between travel patterns and regional land-use characteristics. More discussions are presented in Section 6 of this report.

\subsection{DATA LIMITATIONS AND CHALLENGES}

As in any sample survey, there were sampling limitations in the NHTS data. Although NYS has a reasonably rich set of Add-On samples, the intent was to provide sufficient data to support MPO-level analyses, (and some major counties) in most cases. The NHTS sample limitations, especially at the more disaggregated district level as in this study, should be carefully considered when making inferences with the data and statistics generated based on the data.

Also, because the NHTS is a household travel survey of U.S. residents, trips made to NYS by foreign visitors (Canadian neighbors, for example) were considered out of scope to the NHTS study. Furthermore, due to resource limitations, geo-coding of trip ODs was only performed for NHTS Add-on samples. This means that no equivalent trip OD details were available for travel made by residents of non-Add-on regions (e.g., PA) into/from NYS. It is anticipated that such impacts on travel flow patterns might be more significant for regions along state borders, such as BMTS, than regions located farther away from the state line. One should keep such data limitations in mind when interpreting results generated from this study. The data should reflect reasonably well with travel behaviors involving NYS households. However, the data might not provide a comprehensive picture of travel flow patterns in all regions, due to a certain number of trips falling out-of-scope (of NHTS) across regions within NYS. 


\section{DEMOGRAPHIC CHARACTERISTICS AND TRAVEL PROFILES IN SMTC REGION}

Various analyses on the household demographic data and travel flow patterns within and between the TAD-based SMTC districts, defined for this study, were conducted using the 2009 NHTS data.

Equivalent ACS demographic data was also reviewed when applicable. Results from these analyses were examined to identify any travel patterns, typically by mode, trip purposes, and time. When feasible, this data and results were integrated into a GIS environment so that regional characteristics can be better visualized; and alongside other geospatial data, if available, to reveal any specific travel flow patterns.

\subsection{REGIONAL DEMOGRAPHIC CHARACTERISTICS}

\subsubsection{Household Size}

Figure 4-1 shows the distribution of household size composition of residents in each SMTC district. The total number of households by size is also included in Figure 4-1. Generally speaking, the more urbanized setting of the City of Syracuse (i.e., districts 1,2, and 3) appears to have a higher percent of single-person households than those in other districts. Recall from Figure 3-1 the overall share of oneperson households in SMTC is about 40\%; districts 4, 7, and 8 are clearly below that average (i.e., having fewer one-person households than overall SMTC region).

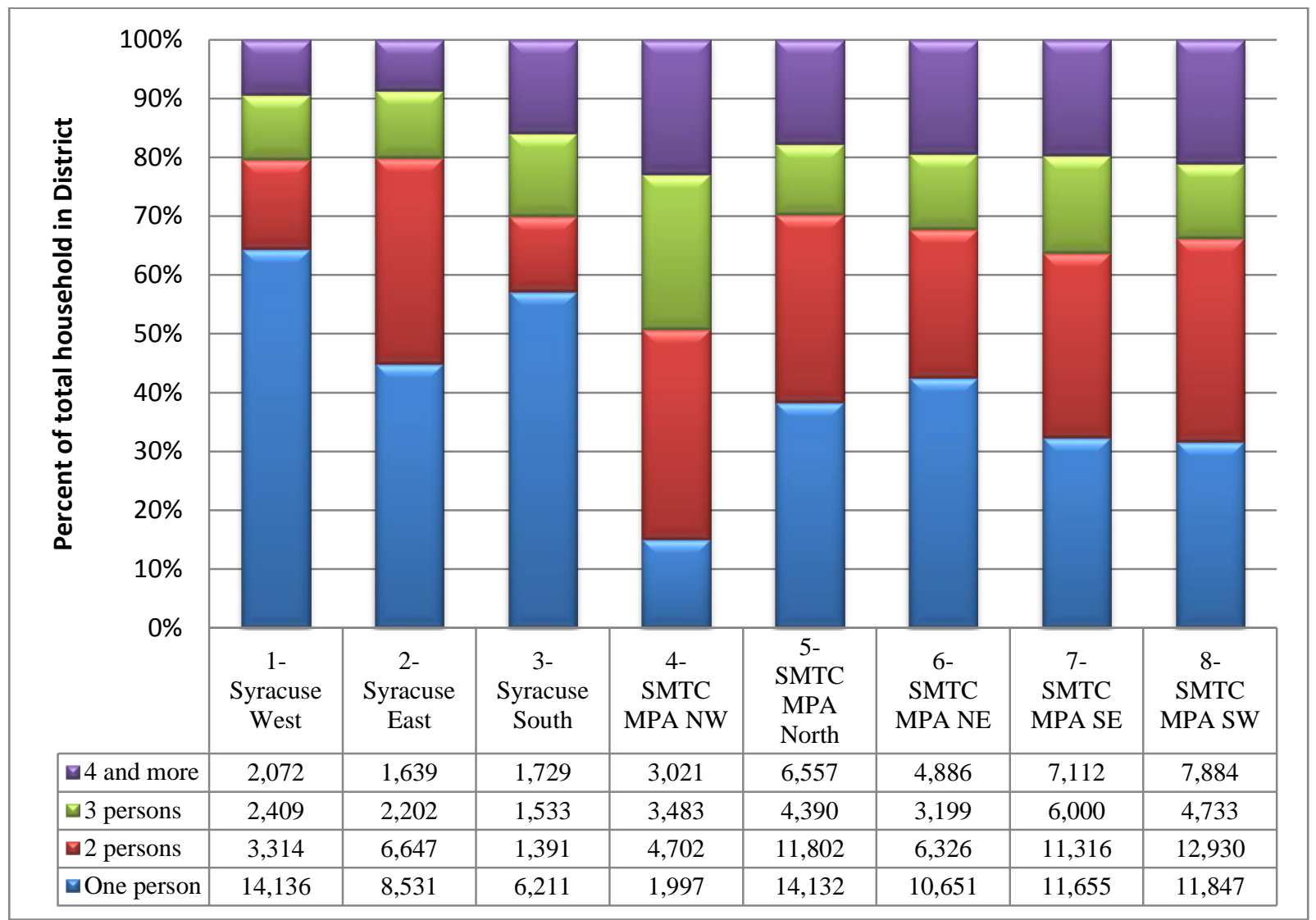

Figure 4-1. Distribution of households in SMTC Districts by household size (2009 NHTS data). 
This information is also displayed geographically as a map shown in Figure 4-2. The advantage of using a map is that it allows geospatial relationships among districts, if any, to be visualized. Note that the size of the pie is in proportion to the total number of households in a district, i.e., the bigger the pie the higher the total number. The number of households in a region has a positive correlation with its population, as expected. Clearly, the higher shares of one-person household (shown in yellow) in the three center districts (i.e., City of Syracuse) can be observed.

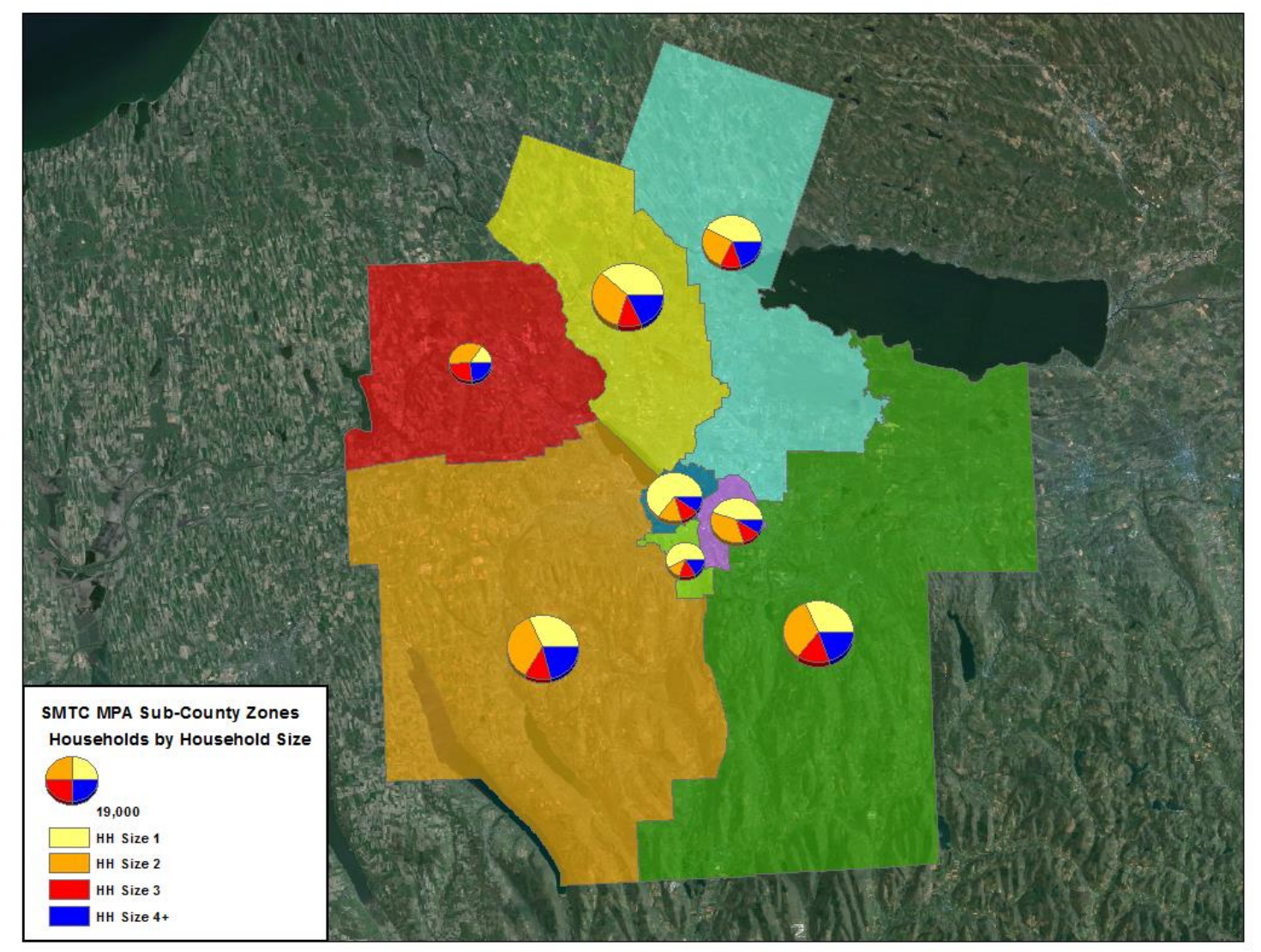

Figure 4-2. Share of households by household size in SMTC districts.

\subsubsection{Age Profile}

The NHTS data covers persons of age 5 year old and older, thus people younger than 5 years old were not included in the survey. Based on age profiles shown in Figure 4-3, the three districts within the City of Syracuse have significantly higher shares of 55+ years old residents, especially in districts 1 and 3 with $49 \%$ and $55 \%$ respectively. 


\begin{tabular}{|l|l|l|l|l|l|l|l|l|}
\hline & \multicolumn{1}{|c|}{$100 \%$} \\
\hline
\end{tabular}

Figure 4-3. Age profile in SMTC districts (2009 NHTS data, age 5 years old and older only).

\subsubsection{Vehicle Ownership}

Figure 4-4 presents the vehicle ownership profile of SMTC districts' households. Not surprisingly, households within the three City of Syracuse districts were more likely to have zero or only one vehicle than those that reside outside the city. In fact, district 1 (Syracuse West) had the highest percent of households with zero vehicles, about 50\% according to the NHTS data. District 3 (Syracuse South) follows, with over $21 \%$ of its households without vehicles. On the other hand, over $70 \%$ of households in district 4 (SMTC MPA NW) owned at least two vehicles.

Geospatially, the distribution of vehicle ownership in each of the SMTC districts is displayed in Figure 45. Clearly, the Syracuse West district in the City of Syracuse has the highest share of zero vehicle households, consistent with what is shown in Figure 4-4. 


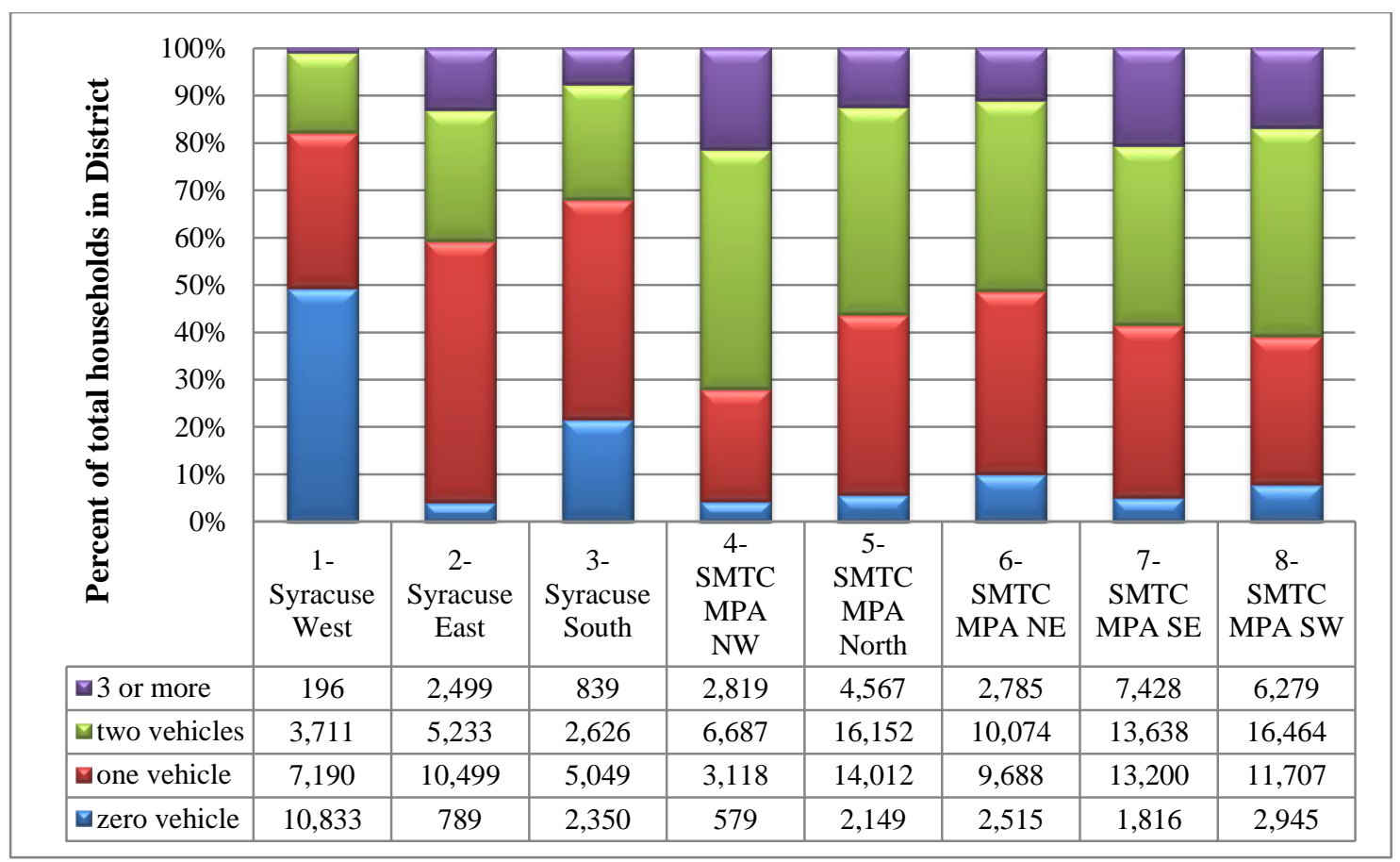

Figure 4-4. Distribution of households by vehicle ownership, SMTC Districts.

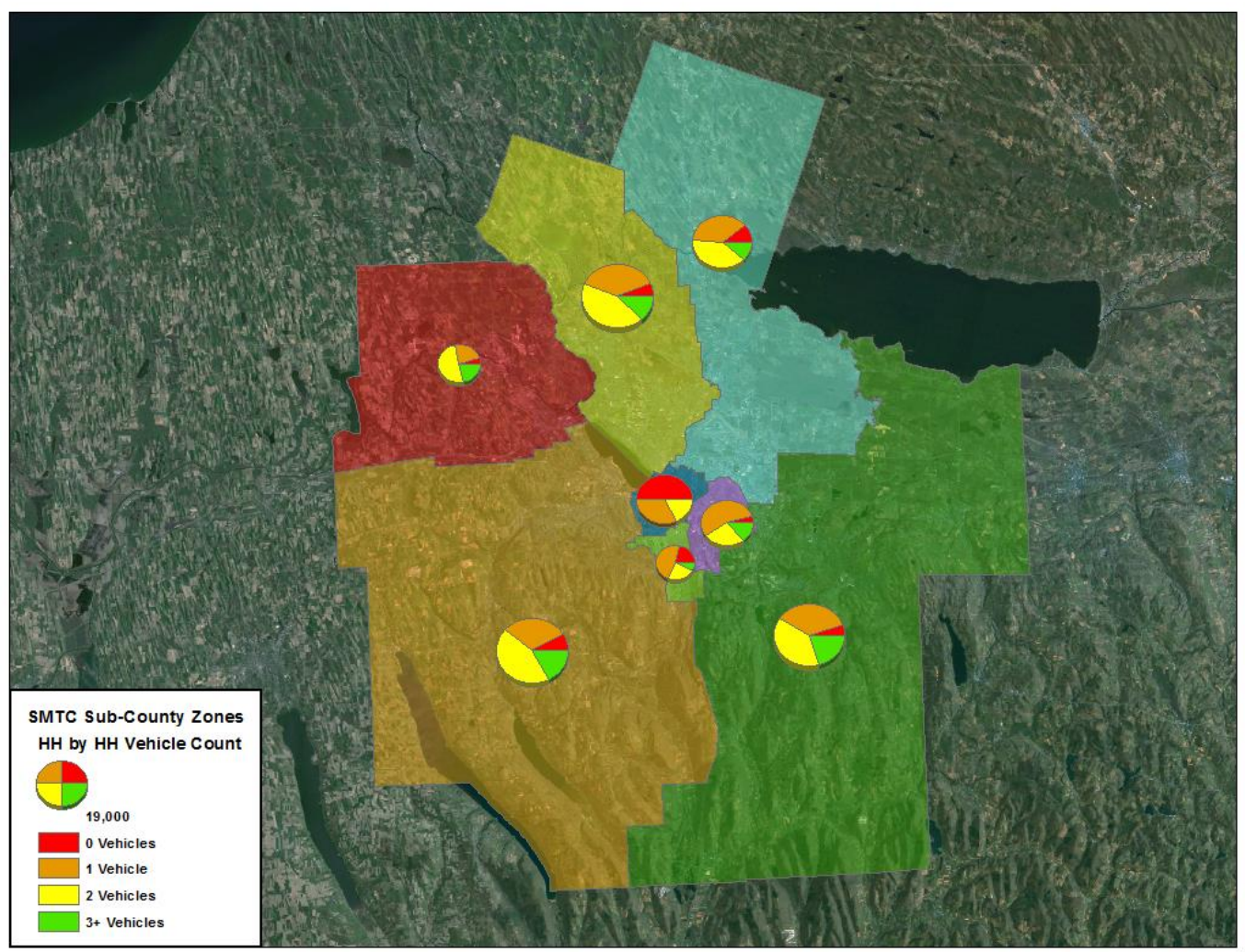

Figure 4-5. Distribution of household by vehicle ownership, SMTC districts. 


\subsubsection{Drivers by Gender}

Based on the 2009 NHTS data, most of the SMTC districts had more female drivers then male drivers. This was especially true for district 1 residents, which has a nearly two-to-one ratio of female drivers to male drivers (seen in Figure 4-6). The more rural districts of 6, 7, and 8, on the other hand, had a slightly higher share of male drivers in their districts.

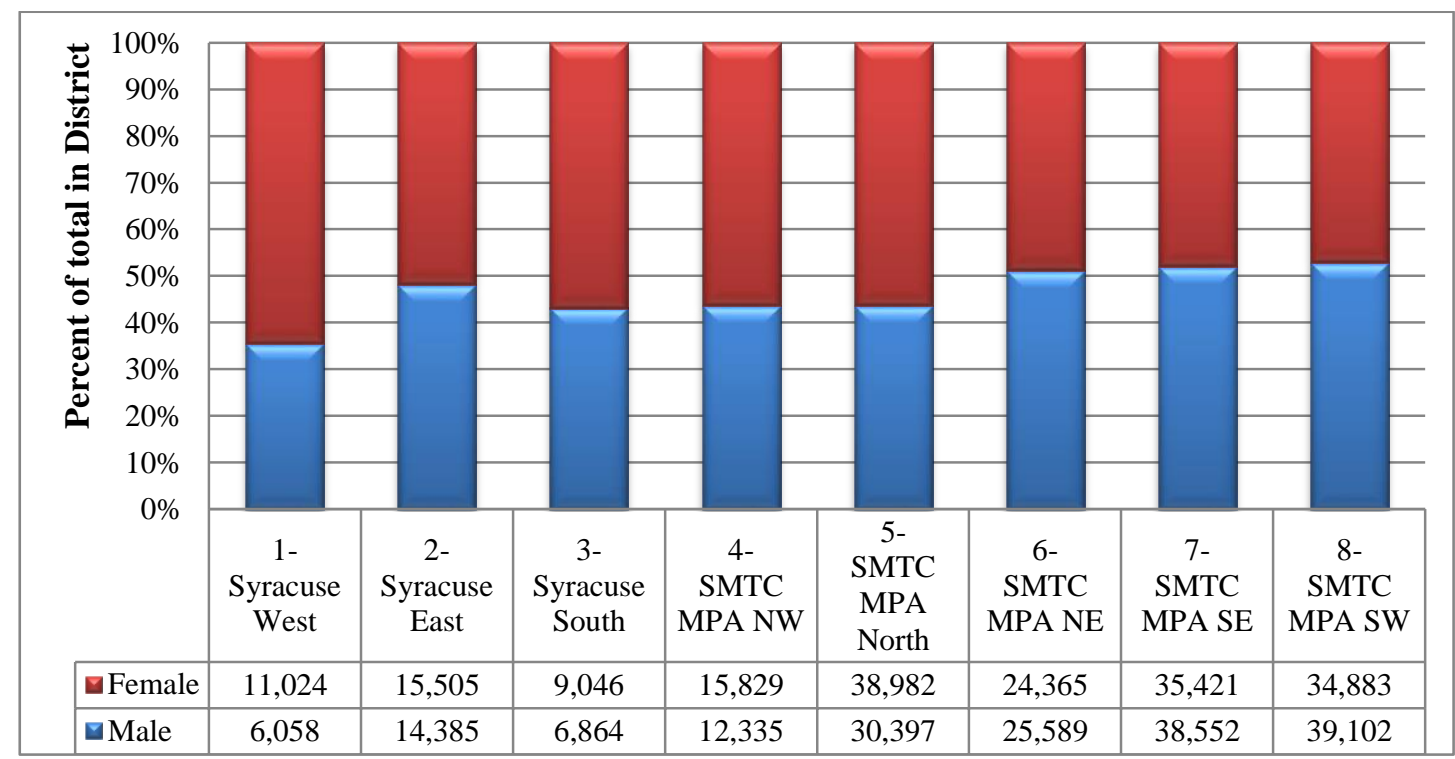

Figure 4-6. Percent of drivers by gender in SMTC districts.

\subsubsection{Workers by Gender}

Similar to the drivers, workers in each of the SMTC districts by gender were also examined using the 2009 NHTS data. As shown in Figure 4-7, half of the SMTC districts (particularly 1, 3, and 5) had higher shares of female workers. Furthermore, Table 4-1 presents worker-to-driver ratios by gender generated from the 2009 NHTS data for the SMTC regions. This could also be viewed as an estimate of "the portion of drivers that are workers." District 3 (Syracuse South) clearly had a significantly lower worker per driver ratio (regardless of gender difference) when compared to all other districts. Note that not all workers were necessarily drivers, and likewise, not all drivers worked. 


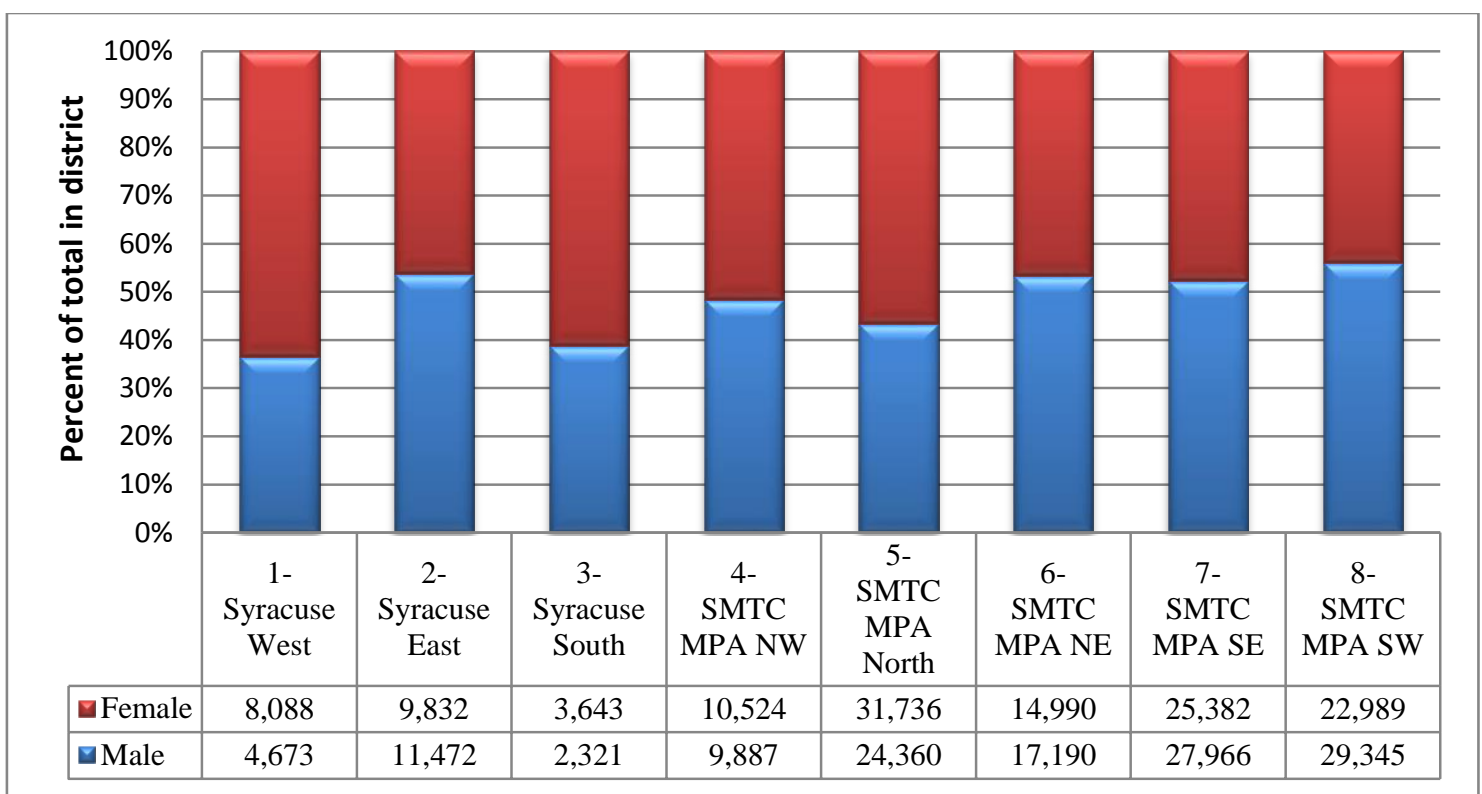

Figure 4-7. Percent of workers by gender for SMTC districts.

Table 4-1. Worker per driver ratio by SMTC districts

\begin{tabular}{|c|c|c|c|c|c|c|c|c|}
\hline \multirow{3}{*}{ Gender } & \multicolumn{9}{|c|}{ SMTC districts } \\
\cline { 2 - 9 } & $\begin{array}{c}\text { Syracuse } \\
\text { West }\end{array}$ & $\begin{array}{c}\mathbf{2 -} \\
\text { Syracuse } \\
\text { East }\end{array}$ & $\begin{array}{c}\text { 3- } \\
\text { Syracuse } \\
\text { South }\end{array}$ & $\begin{array}{c}\text { 4- } \\
\text { SMTC } \\
\text { MPA } \\
\text { NW }\end{array}$ & $\begin{array}{c}\text { 5- } \\
\text { SMTC } \\
\text { MPA } \\
\text { North }\end{array}$ & $\begin{array}{c}\text { 6- } \\
\text { SMTC } \\
\text { MPA } \\
\text { NE }\end{array}$ & $\begin{array}{c}\text { 7- } \\
\text { SMTC } \\
\text { MPA } \\
\text { SE }\end{array}$ & $\begin{array}{c}\text { 8- } \\
\text { SMTC } \\
\text { MPA } \\
\text { SW }\end{array}$ \\
\hline Male & 0.77 & 0.80 & 0.34 & 0.80 & 0.80 & 0.67 & 0.73 & 0.75 \\
\hline Female & 0.73 & 0.63 & 0.40 & 0.66 & 0.81 & 0.62 & 0.72 & 0.66 \\
\hline All & 0.75 & 0.71 & 0.37 & 0.72 & 0.81 & 0.64 & 0.72 & 0.71 \\
\hline
\end{tabular}

\subsection{REGIONAL TRAVEL BEHAVIORS}

\subsubsection{How Much Travel Activity Is in SMTC?}

As a household-based travel survey, NHTS collected travel information from sampled residents, in this case residents of SMTC. Since most trips occur with a corresponding reverse-order return trip, counting the total number of PT based on their origin or destination districts was likely to result in similar volume counts (seen in Table 4-2). Those not presented in Table 4-2 were trips made by SMTC residents traveling between SMTC districts and other regions (i.e., other NYS locations and locations outside of NYS, including foreign locations). The table also does not include trips made by SMTC residents that fall entirely outside the eight SMTC districts. As a whole, NHTS data showed that SMTC residents made a total of nearly 927 million trips (measured in person trips) in 2009. Based on information presented in Table 4.3, about $80 \%$ of these 927 million trips have at least one end (either origin or destination) located in one of the eight SMTC districts (based on [668+674-602]/927=0.80).

Clearly, all districts had significant amounts of within-district PT (i.e., trips begin and end in the same district; or intra-district trips). Using data presented in column 2 (trips originated from district) and the 
rightmost column (intra-district trips) of Table 4-2 to examine shares of intra-district trips, districts in the City of Syracuse appeared to have lower shares, ranging from $37 \%$ to $42 \%$, while districts outside the City ranged from the lowest of $48 \%$ in District 6 (SMTC MPA Northeast) to the highest at about $70 \%$ in District 8 (SMTC Southwest).

Table 4-2. Trip Volumes by SMTC District

\begin{tabular}{|l|c|c|c|c|}
\hline \multicolumn{1}{|c|}{ District } & $\begin{array}{c}\text { Number of trips } \\
\text { originated from } \\
\text { district }\end{array}$ & $\begin{array}{c}\text { Number of trips } \\
\text { terminated in } \\
\text { district }\end{array}$ & $\begin{array}{c}\text { Number of } \\
\text { trips start \& } \\
\text { end in SMTC }\end{array}$ & $\begin{array}{c}\text { Number of } \\
\text { intra-district } \\
\text { trips only }\end{array}$ \\
\hline 1- Syracuse West & $81,158,765$ & $82,054,739$ & $68,994,003$ & $31,333,245$ \\
\hline 2- Syracuse East & $60,624,390$ & $61,724,998$ & $57,230,615$ & $25,509,223$ \\
\hline 3- Syracuse South & $27,182,925$ & $26,733,019$ & $25,278,605$ & $10,105,671$ \\
\hline 4- SMTC MPA Northwest & $42,642,184$ & $42,225,849$ & $37,737,812$ & $24,290,815$ \\
\hline 5- SMTC MPA North & $109,027,577$ & $109,745,370$ & $101,995,550$ & $63,828,232$ \\
\hline 6- SMTC MPA Northeast & $108,843,930$ & $109,617,525$ & $94,970,400$ & $52,260,687$ \\
\hline 7- SMTC MPA Southeast & $125,855,689$ & $127,859,632$ & $113,704,211$ & $77,044,574$ \\
\hline 8- SMTC MPA Southwest & $112,860,832$ & $113,918,818$ & $102,410,6116$ & $75,565,199$ \\
\hline Total & $\mathbf{6 6 8 , 1 9 6 , 2 9 3}$ & $\mathbf{6 7 3 , 8 7 9 , 9 4 8}$ & $\mathbf{6 0 2 , 3 2 1 , 8 1 2}$ & $\mathbf{3 5 9 , 9 3 7 , 6 4 6}$ \\
\hline
\end{tabular}

Figures 4-8 and 4-9 display the total volumes of vehicle-trips that originate and terminate in each SMTC districts, respectively. Generally speaking, these two maps are very similar, reinforcing the nature of "round trips" where an outgoing trip typically is followed by an inbound trip occurring at a later time of the travel day. This is also true when examining VMT by trip-origin and by trip-destination districts, and is seen in Figures 4-10 and 4-11, respectively.

Note that the total number of trips that occurred within a district (either originated or terminated), by itself, generally is not a good measure for comparing regional differences. This is because the number of daily trips generated from a region, could simply be a reflection of its population size, or its geographic region size in some cases. To allow for proper comparisons, several "average per household" estimates were produced for each of the districts. These statistics are discussed in next section of this report. 


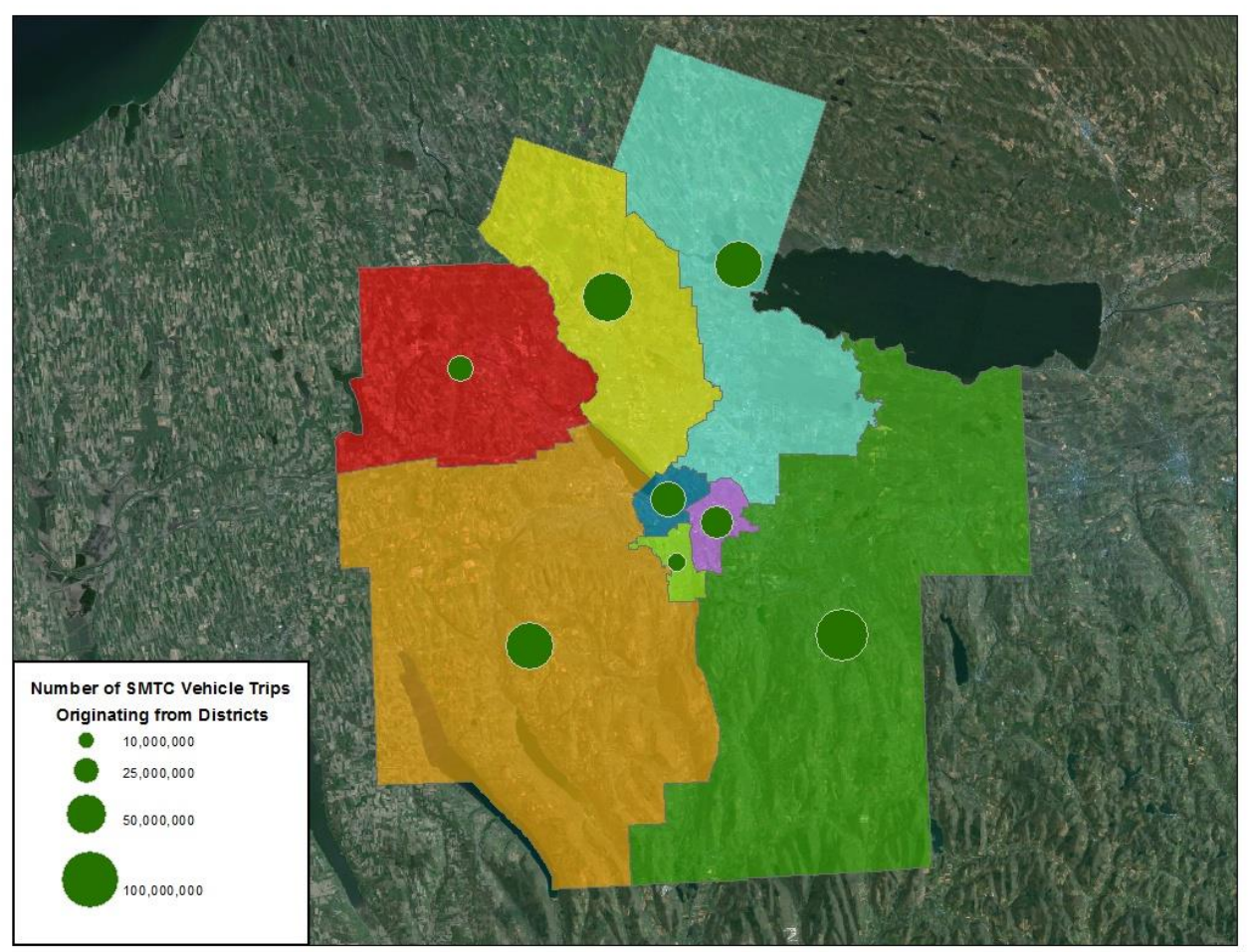

Figure 4-8. Vehicle trips (VT) originating from SMTC districts.

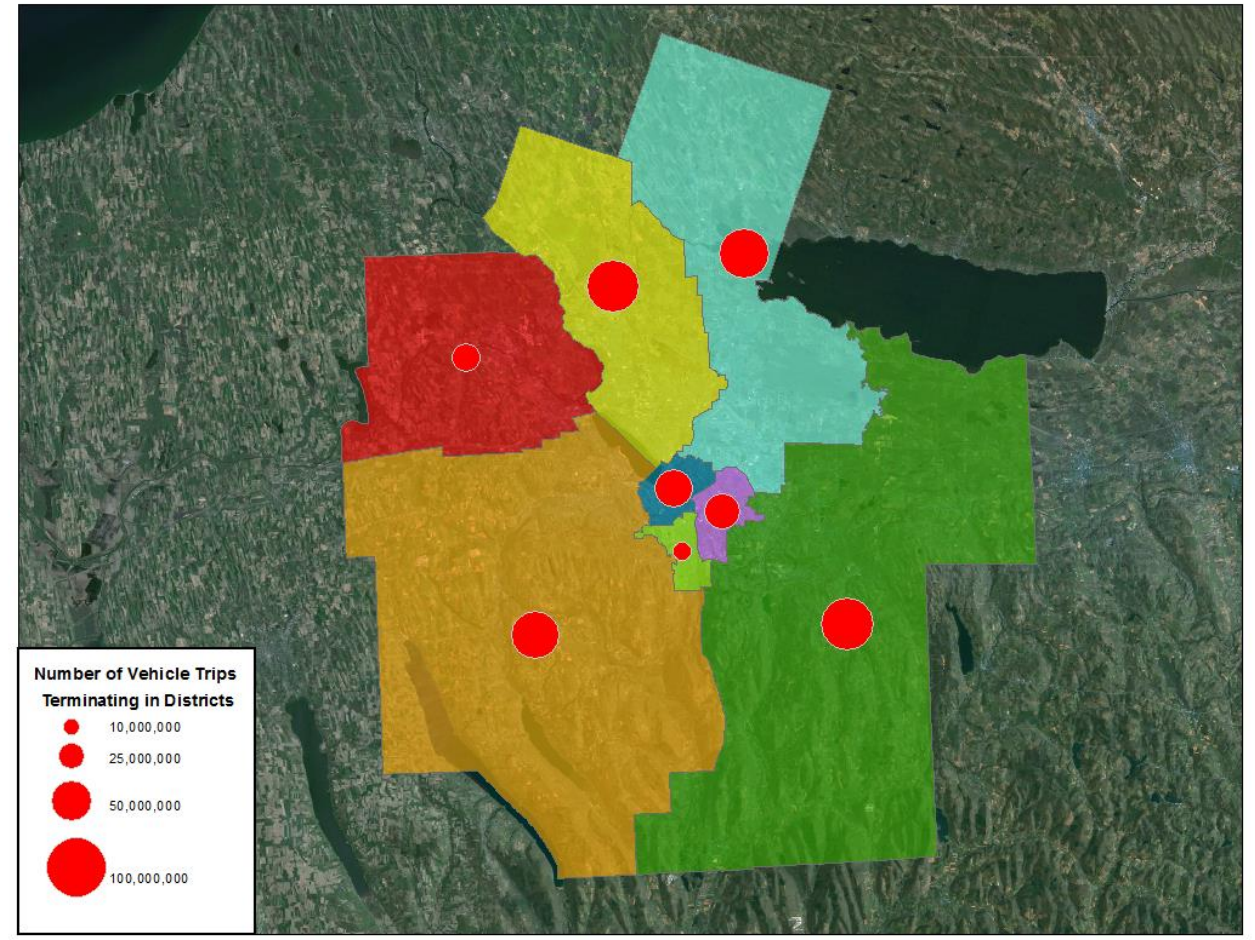

Figure 4-9. Vehicle trips (VT) terminating in SMTC districts. 


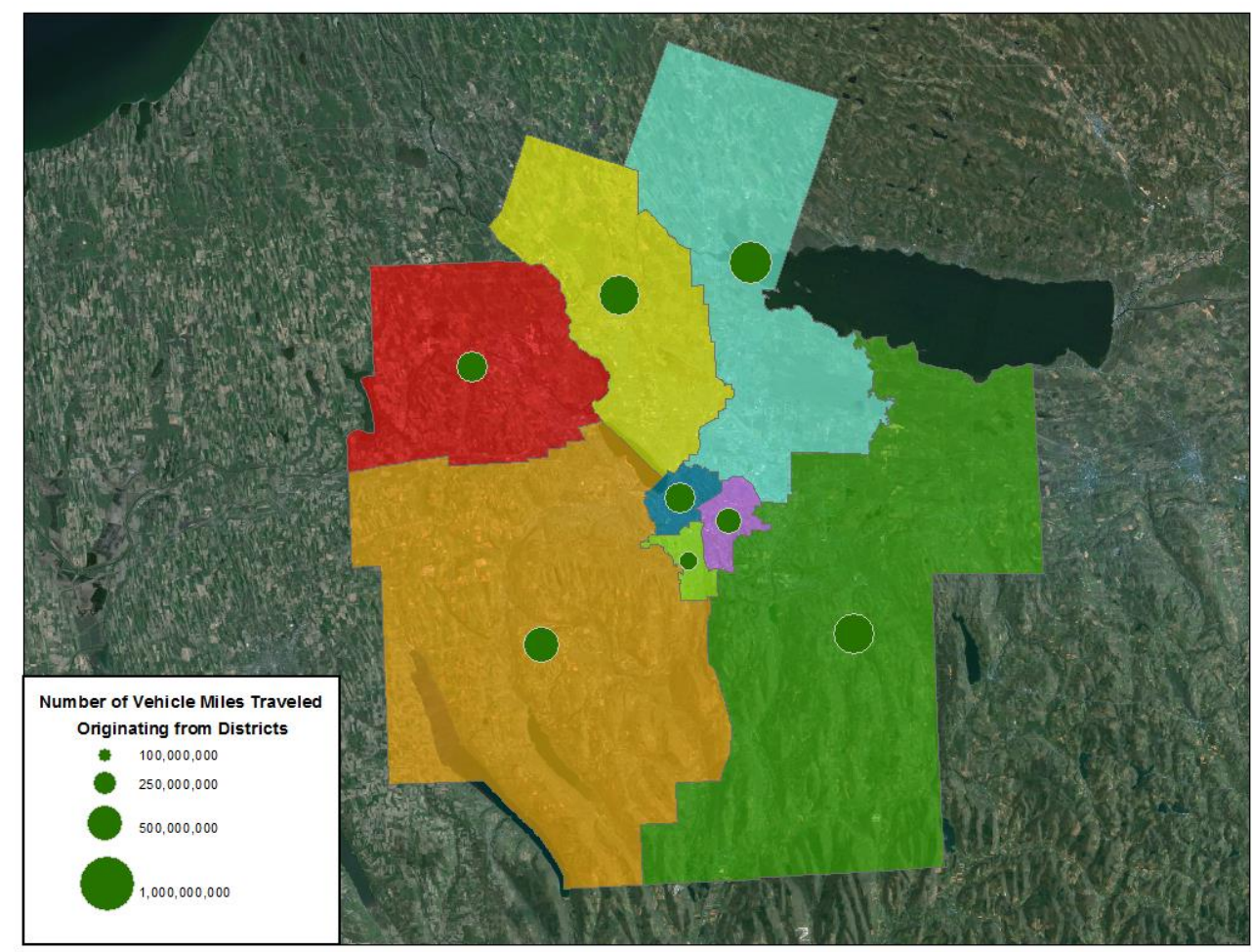

Figure 4-10. Vehicle-miles traveled (VMT) originating in SMTC districts.

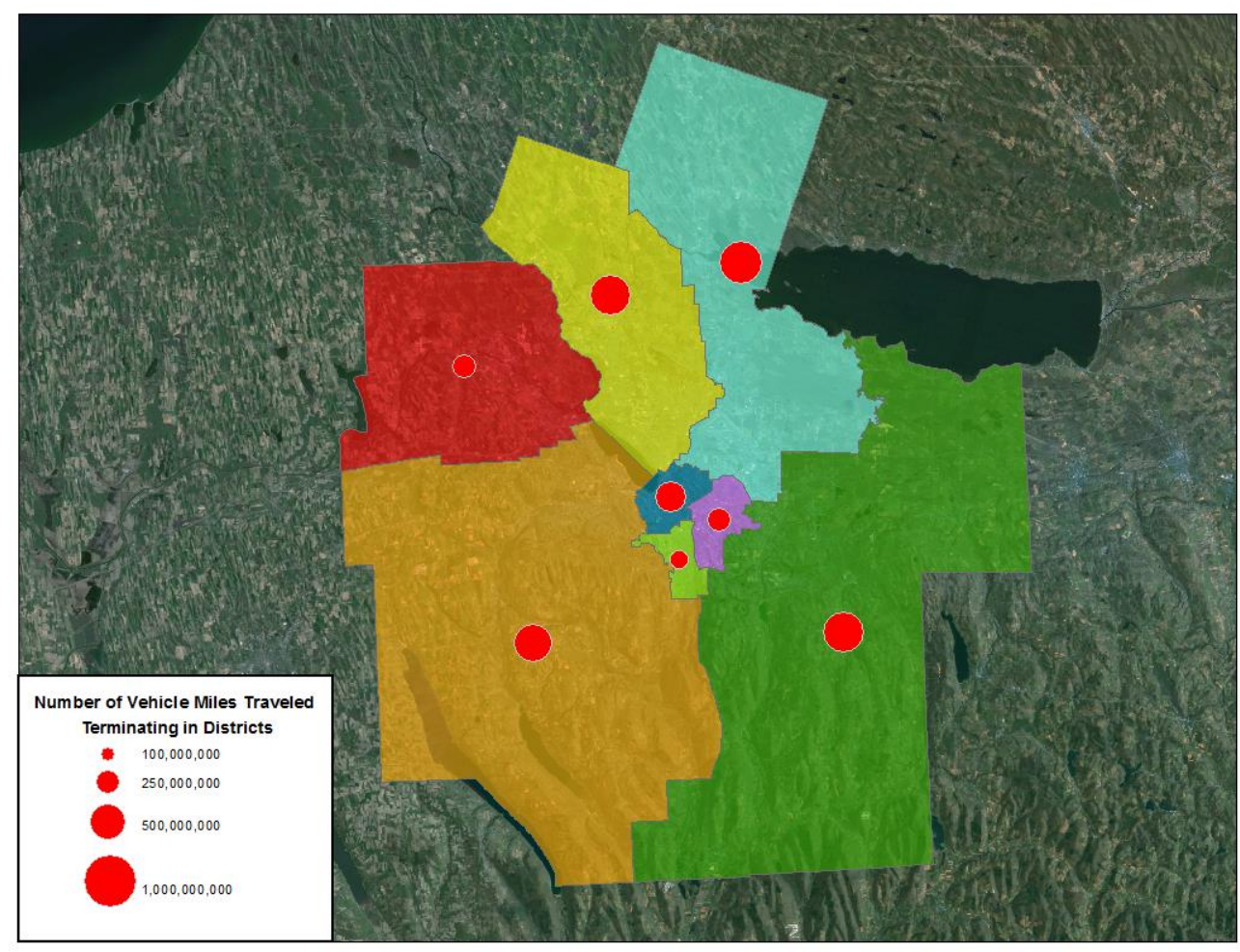

Figure 4-11. Vehicle-miles traveled (VMT) terminating in SMTC Districts. 


\subsubsection{How Frequently Do SMTC Households Travel? - Measure of per Household Averages}

As shown in Figure 4-12, the three downtown Syracuse districts all have lower averages for perhousehold PT and VT than districts outside the City of Syracuse. Recall that VT considers only trips made in privately-owned vehicles (POV); the relatively lower averages on VT in Districts 1 and 3 might be associated with their higher shares of zero-vehicle households, as well as higher proportions of oneperson households (see Figures 4-4 and 4-5). Corresponding per-household averages on PMT and VMT are presented in Figure 4-13. Similarly, districts within the City of Syracuse tend to have lower PMTs and VMT than those located outside the city. It was suspected that the much higher volume for District 4 might be due to outliers within the NHTS sample.

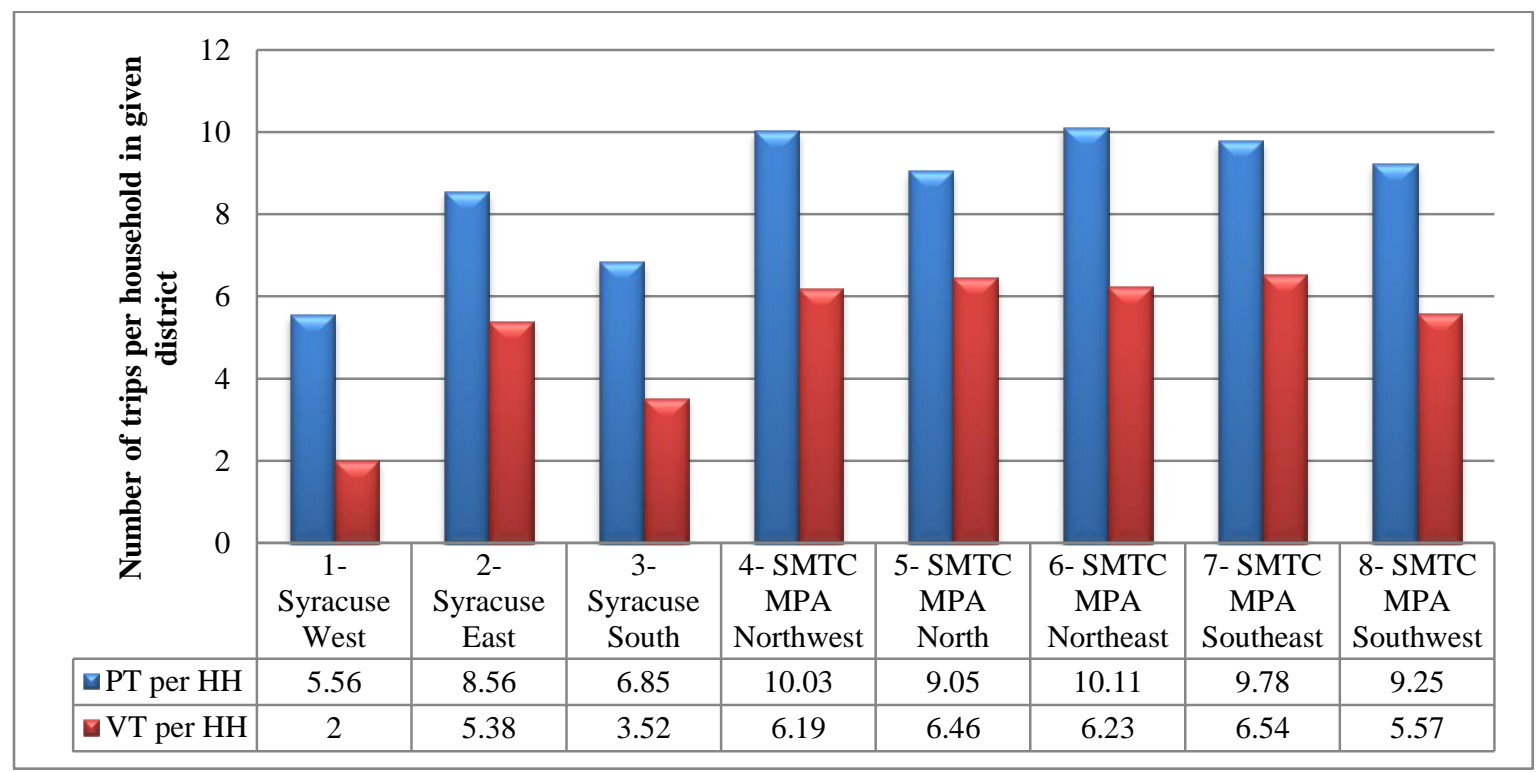

Figure 4-12. Average person-trip and vehicle-trip per household in SMTC districts.

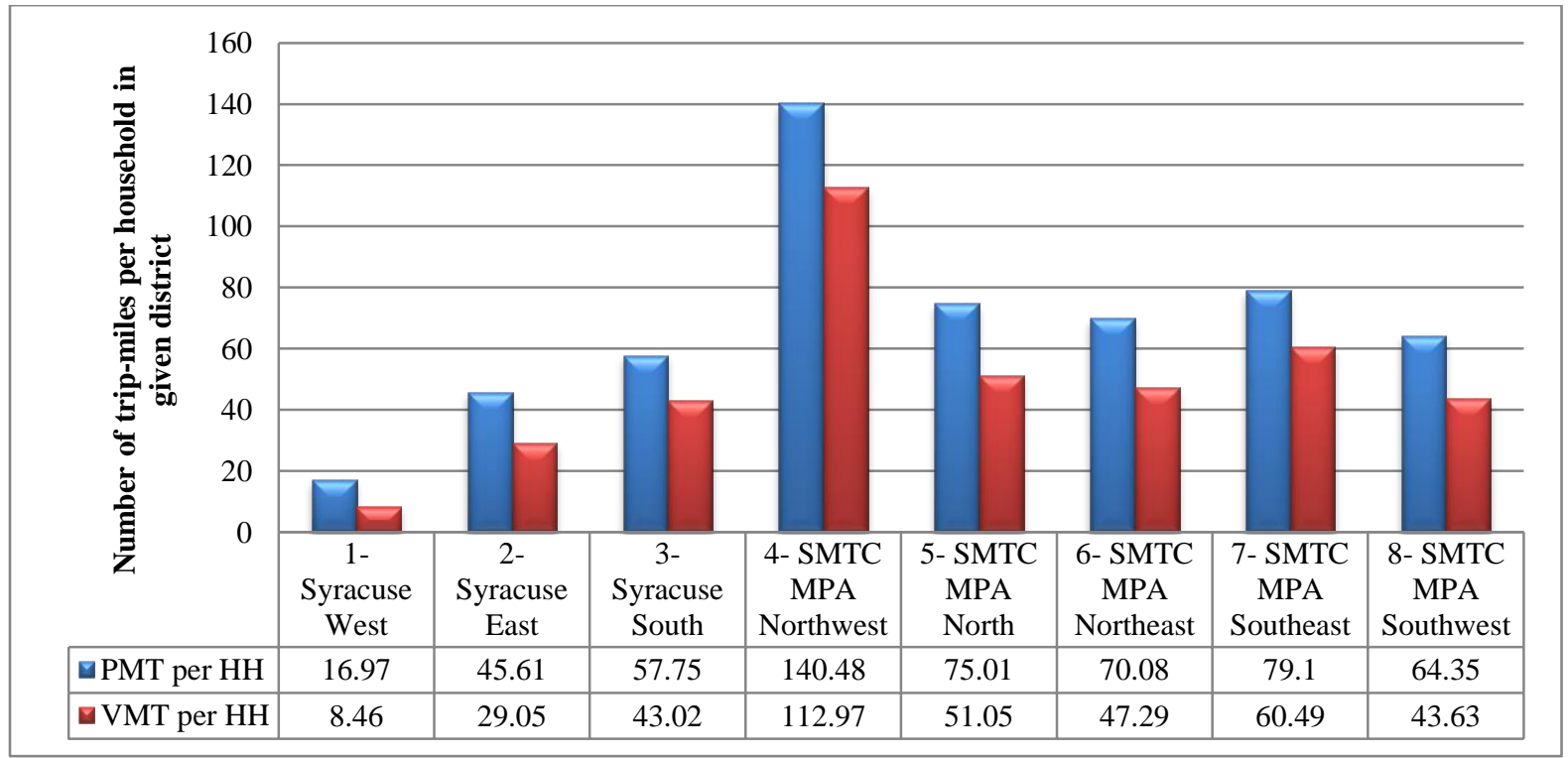

Figure 4-13. Average PMT and VMT per household in SMTC districts. 
Further investigation of District 4 data identified an extreme value (1,400 mile) in one of the trips; with another three trips found with distances between 100 to 200 miles. The average PMT per household dropped to 120.6 (from about 140) and VMT per household reduced to 91.0 (from about 110) when the extreme value was removed. When all 4 outliers (those with distances over 100 mile) were eliminated, the average PMT per household and VMT per household was further reduced to about 94.8 and 69.6, respectively; still higher but much more in line with the averages from other districts.

\subsubsection{Average person trips by household size}

Figure 4-14 shows that districts are generally consistent in their averages by household size; the larger a household size the higher the average PT are. In most cases, this pattern is similar for the average numbers of VT (see Figure 4-15); although districts within the city appear to be a little different (in terms of larger size households) from the rest of the SMTC districts. Note that a relatively high value of average PT (and VT) for the "4+" group in SMTC District 2 in the City of Syracuse is suspected to be caused by small sample sizes.

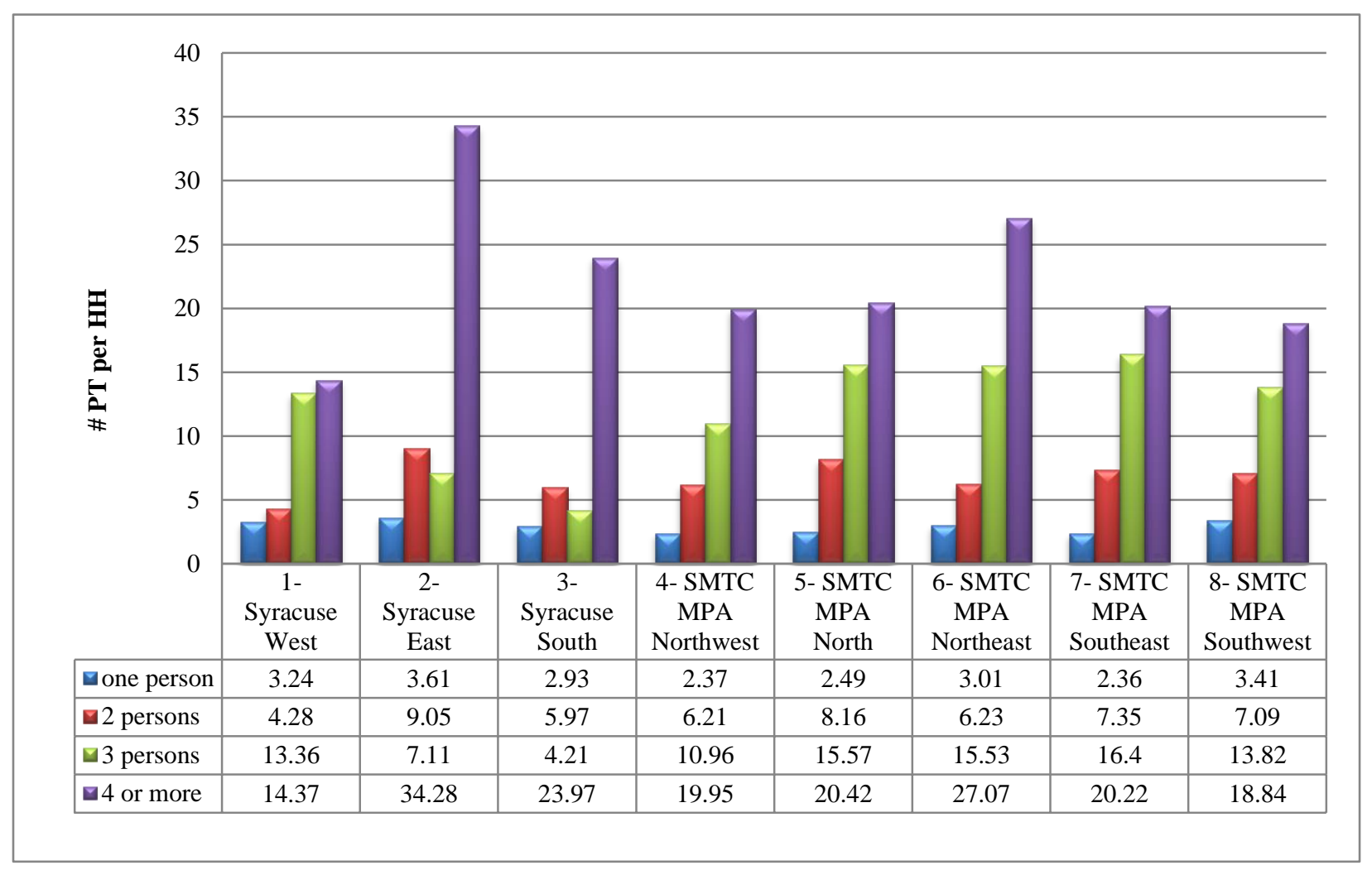

Figure 4-14. Average person-trips per household by household size by household district in SMTC. 


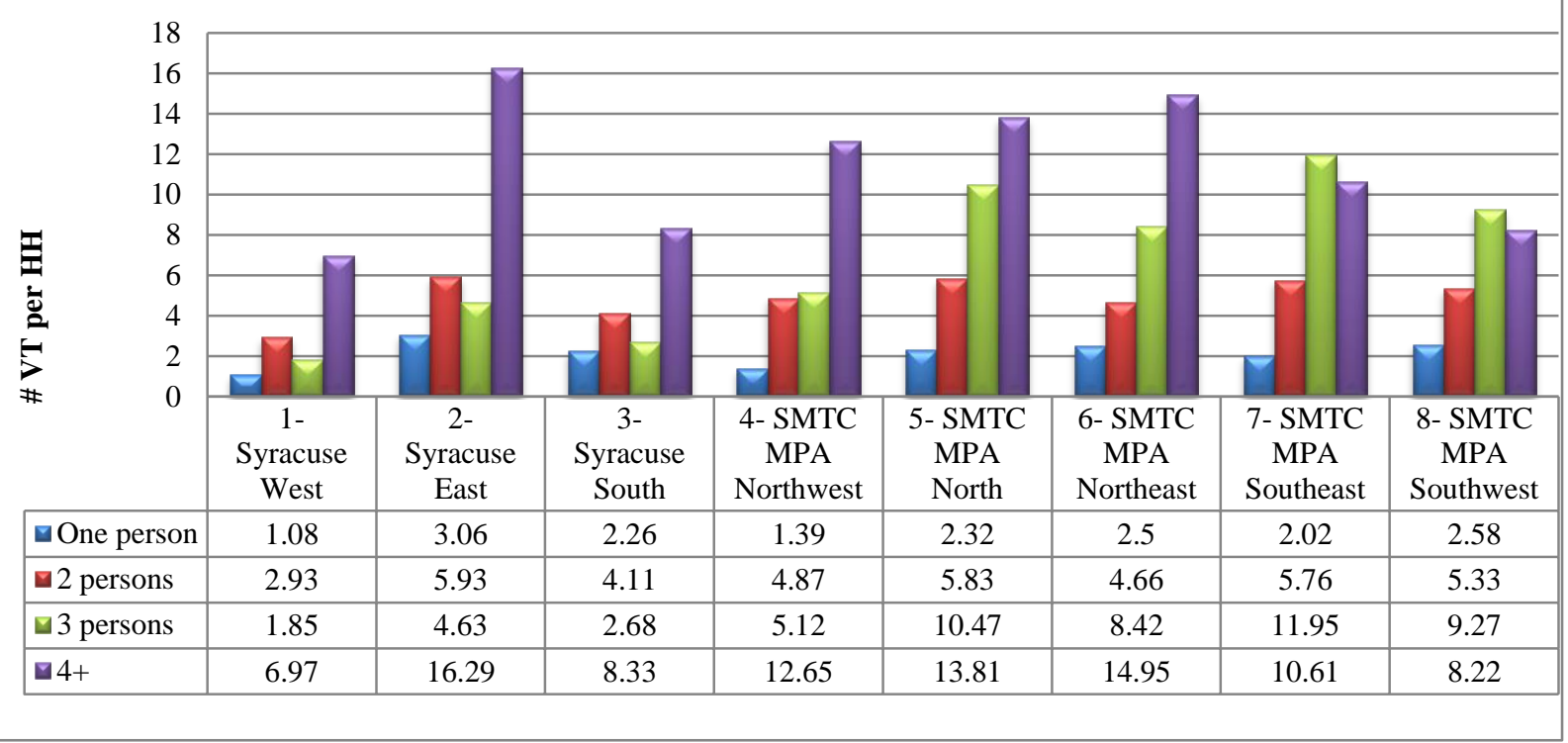

Figure 4-15. Average vehicle-trips per household by household size and household district in SMTC.

\subsubsection{Vehicle Ownership}

Not surprisingly, households without vehicles traveled the least and the average PT per household generally increases where more vehicles were owned (see Figure 4-16). Note that the majority of the households within the SMTC districts own one or two vehicles (see Figure 4-4), therefore likely having sufficient data to obtain more reliable estimates (averages in this case). Estimates based on small samples are subject to a higher degree of variation (or standard error), making them less reliable. The average number of VT per household by SMTC district is presented in Figure 4-17. Again, in most cases, the average number of trips gets higher as the number of vehicle owned increases.

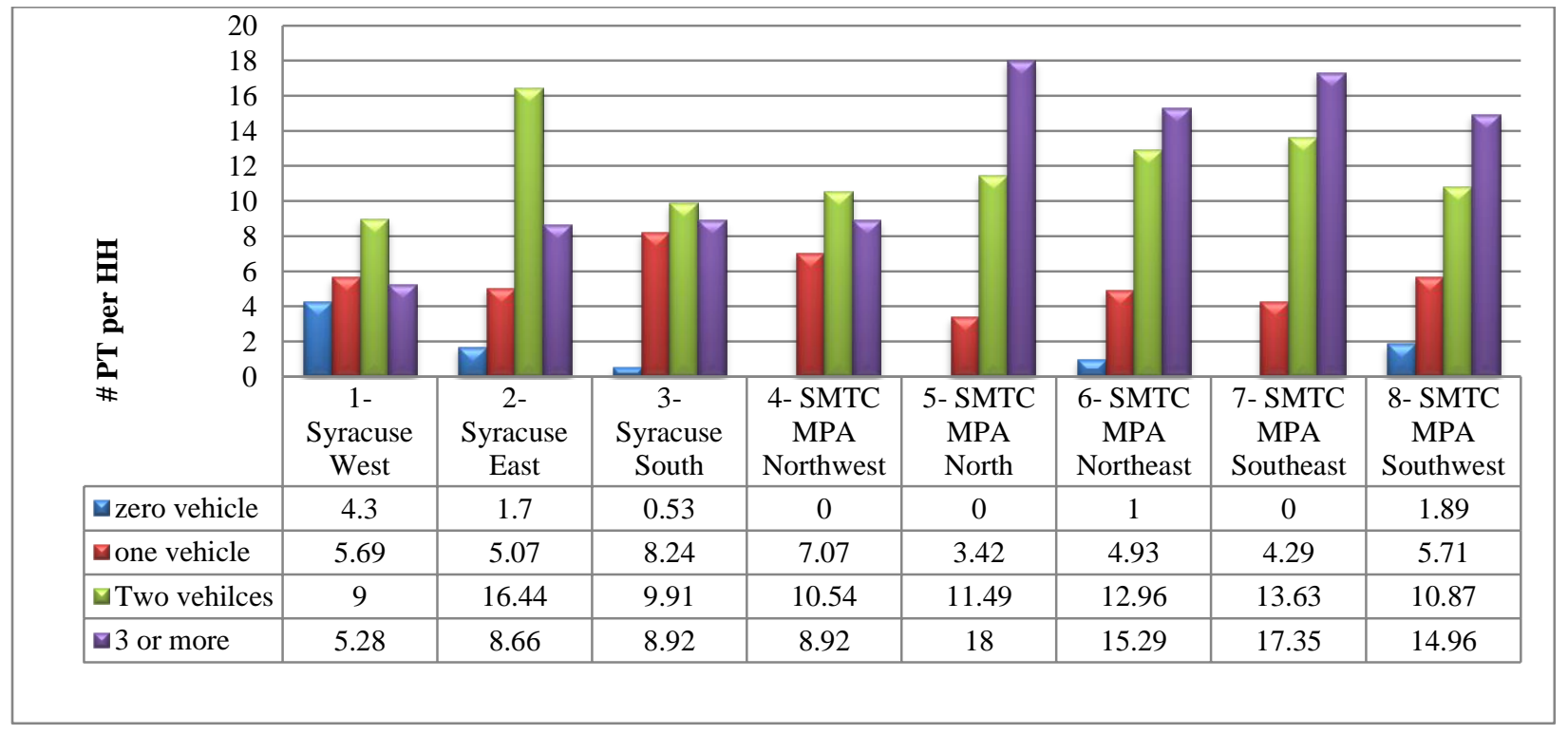

Figure 4-16. Average person-trips (PT) per household by vehicle ownership by household district in SMTC. 


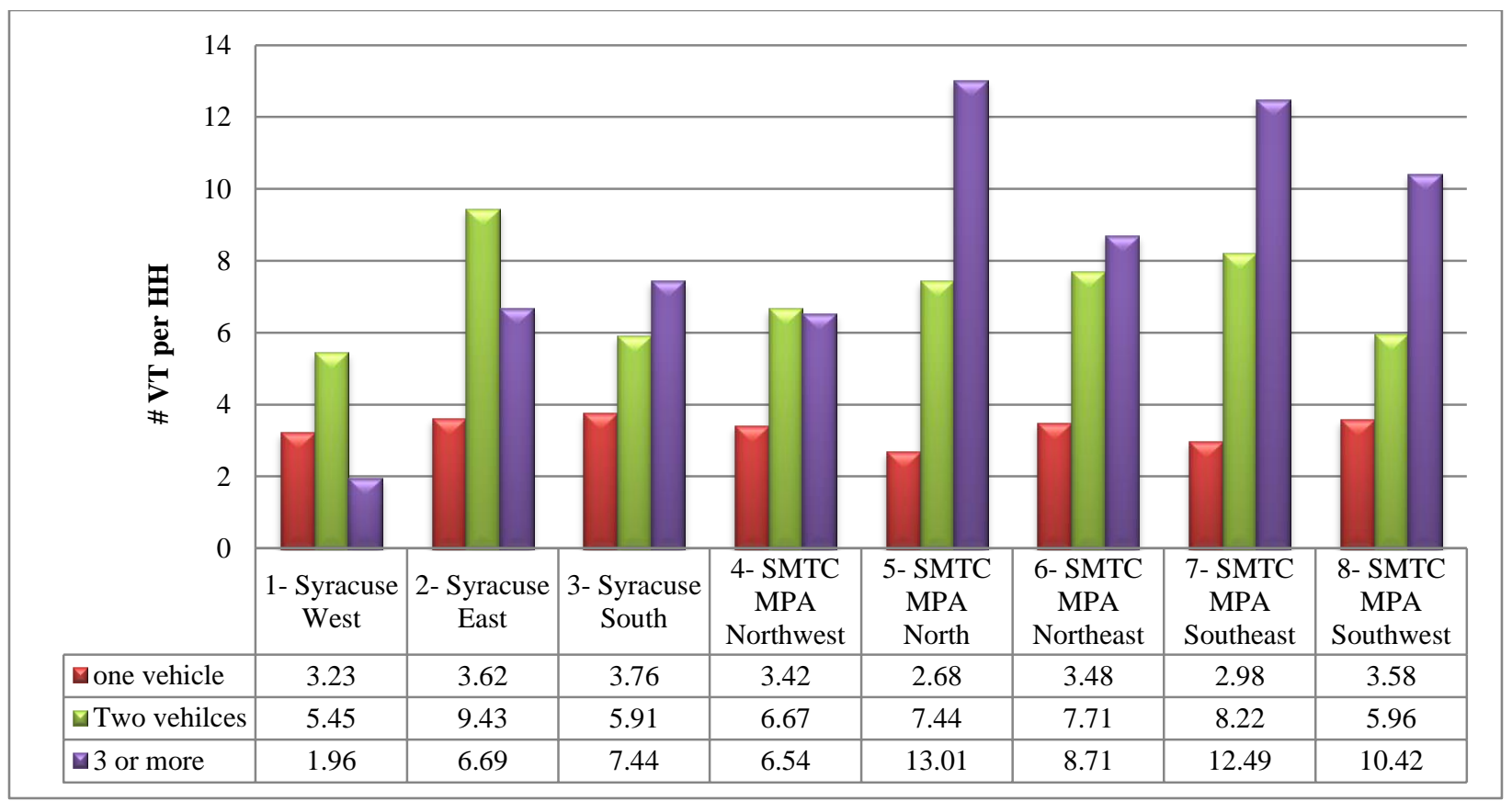

Figure 4-17. Average vehicle-trips (VT) per household by vehicle ownership for SMTC districts.

\subsubsection{Why Do SMTC Residents Travel? - A Look at Trip Purposes}

Overall, most of the PT that started from a SMTC district were made for the three trip purposes: family/personal business, social/recreational, and earning a living (i.e., commute). Travel made for these three purposes accounts for over $90 \%$ of total PT made in all but one district. Only about $80 \%$ of trips originating from District 3 (Syracuse South) were for the abovementioned three purposes. A relatively large share of trips originating from District 3 were for school/church activities, accounting for about $15 \%$ of its total PT, slightly higher than the share for "earning a living" trips.

Figure 4-18 shows the total number of PT originating from each given SMTC district by trip purpose. As mentioned previously, most daily trips have a reversed return trip; thus, the pattern is quite similar if summarizing these PT by their destination district instead. However, it is expected that travel purposes could differ during different periods of time within a day, as well as during weekends. These subjects are further examined and discussed later in Section 4.2.5 of this report. 


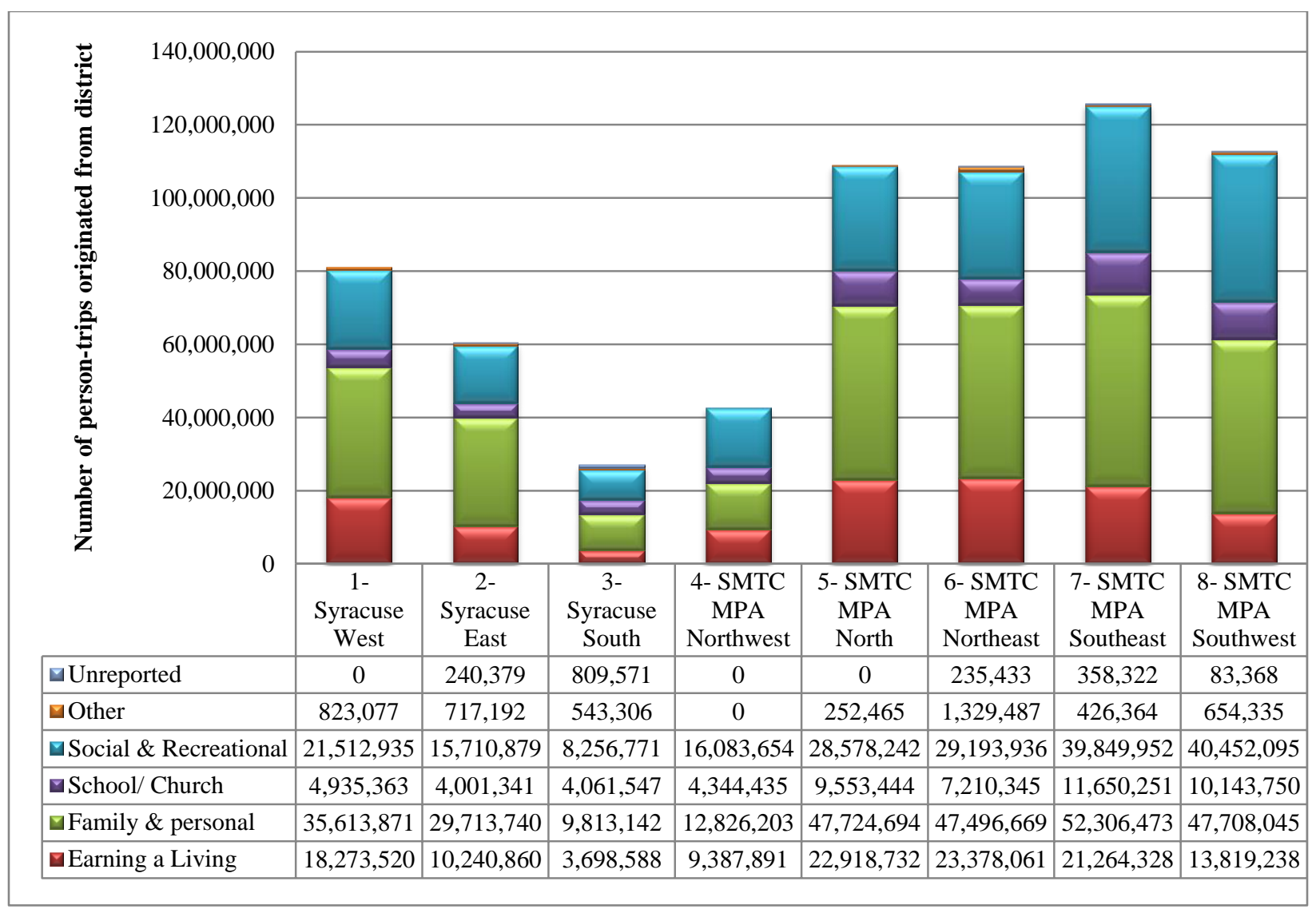

Figure 4-18. Total number of person-trips originated from SMTC districts by trip purposes.

Since the total number of trips cannot be directly compared between districts, average per household measures were generated by trip purpose for households within each of the SMTC districts. As shown in Table 4-3, on average, households in the districts outside the City of Syracuse had higher averages perhousehold trips, ranging from around 9 to over 10 trips, than districts within the city. More commonly, trips conducted for family/personal business and social/recreational purposes were more frequently made by residents of the SMTC districts. The general pattern by trip purpose as presented in Table 4.3 stays about the same when considering only PT made with POV (see Figure 4-19). This is likely due to the fact that the majority of trips were made in POVs. Mode choice is further discussed in the next section. 
Table 4-3. Average Number of Person-trips per Household by Trip Purpose for SMTC Districts

\begin{tabular}{|l|c|c|c|c|c|}
\hline \multicolumn{1}{|c|}{ Household District } & $\begin{array}{c}\text { Earning a } \\
\text { Living }\end{array}$ & $\begin{array}{c}\text { Family \& } \\
\text { Personal } \\
\text { Business }\end{array}$ & $\begin{array}{c}\text { School/ } \\
\text { Church }\end{array}$ & $\begin{array}{c}\text { Social and } \\
\text { Recreational }\end{array}$ & $\begin{array}{c}\text { All } \\
\text { purposes }\end{array}$ \\
\hline 1- Syracuse West & 0.70 & 2.80 & 0.61 & 1.28 & 5.56 \\
\hline 2- Syracuse East & 1.01 & 4.55 & 0.62 & 2.19 & 8.56 \\
\hline 3- Syracuse South & 0.83 & 2.31 & 0.91 & 2.31 & 6.85 \\
\hline 4- SMTC MPA Northwest & 2.90 & 2.88 & 1.08 & 3.17 & 10.03 \\
\hline 5- SMTC MPA North & 2.35 & 3.73 & 0.82 & 2.06 & 9.05 \\
\hline 6- SMTC MPA Northeast & 1.92 & 4.20 & 0.87 & 3.04 & 10.11 \\
\hline 7- SMTC MPA Southeast & 1.91 & 3.99 & 0.70 & 3.08 & 9.78 \\
\hline 8- SMTC MPA Southwest & 1.64 & 4.22 & 0.97 & 2.55 & 9.47 \\
\hline
\end{tabular}

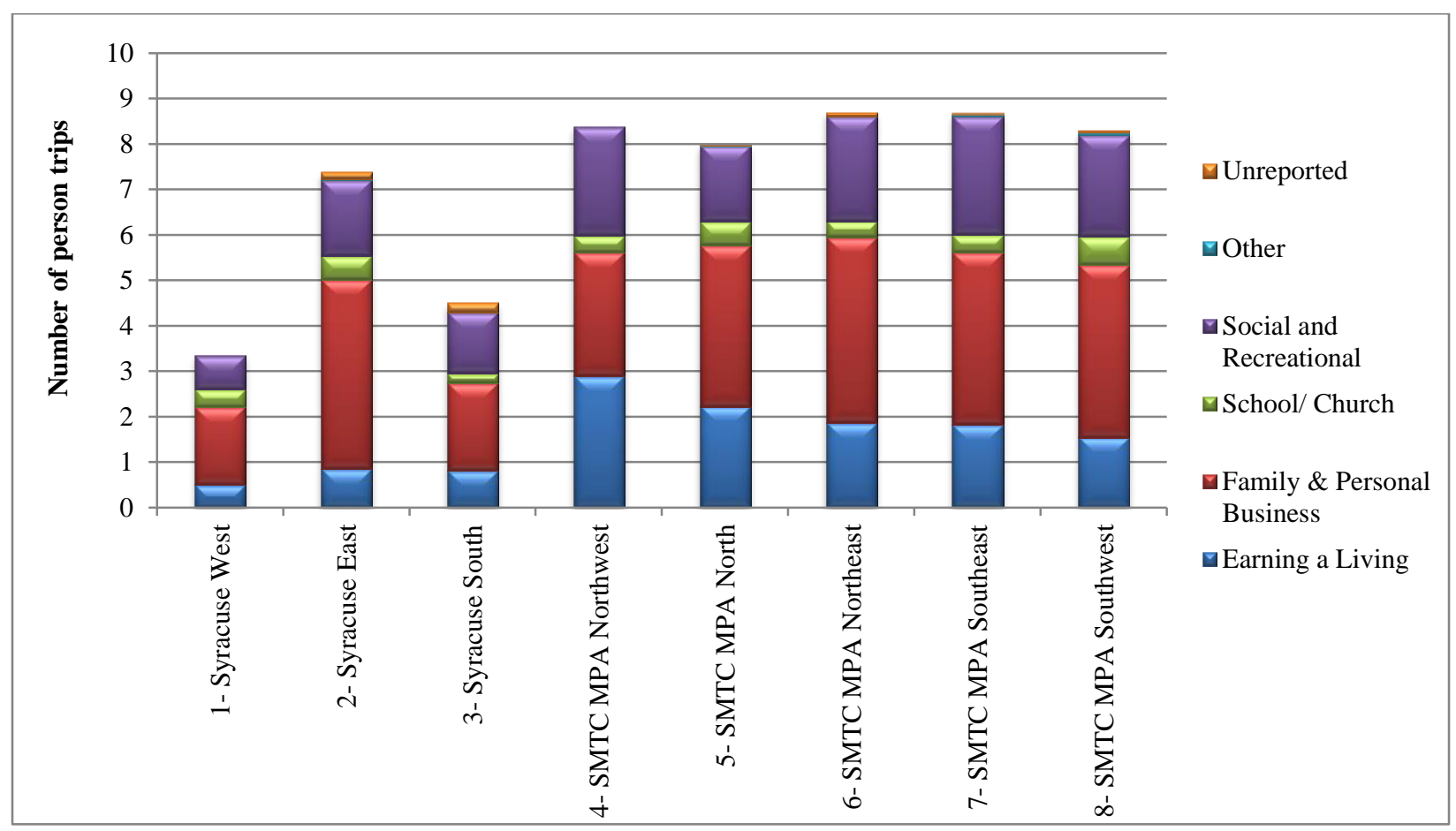

Figure 4-19. Average number of POV person-trips per household by trip purpose for SMTC districts.

Furthermore, the average number of vehicle-trips per household also varies among districts in SMTC (see Figure 4-20). Clearly, districts outside the City of Syracuse had higher average trip counts per household. Besides the difference in scale, patterns of trip purposes as presented in Figures 4-19 and 4-20 were very consistent (both are based on POV). 


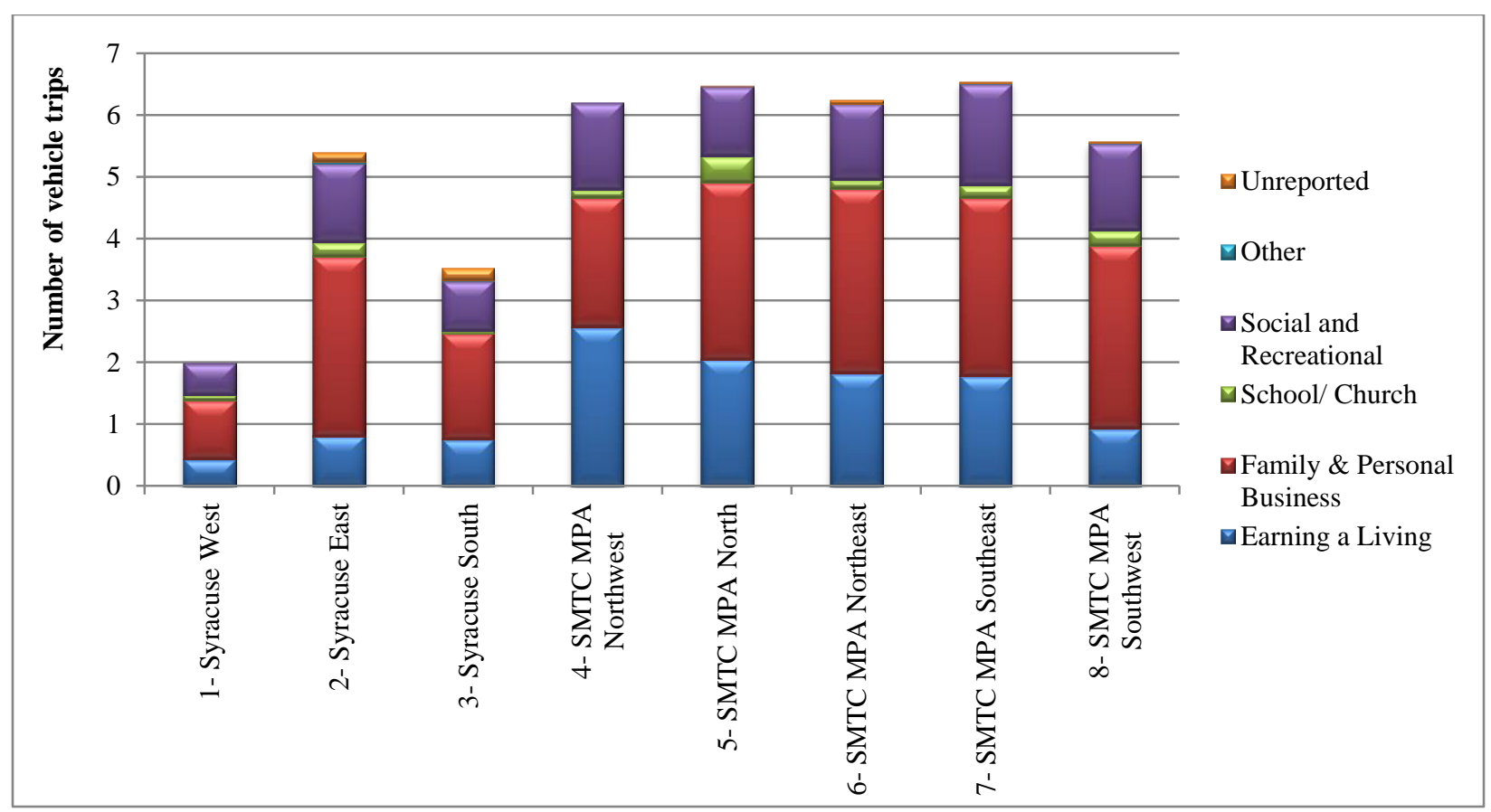

Figure 4-20. Average number of vehicle-trips per household by trip purpose for SMTC districts.

\subsubsection{Mode Choices for SMTC Residents}

Of the nearly 927 million total PT, about 792 million ( 86\%) were made in a POV; this includes all trips made by SMTC residents, thus containing trips departing from locations outside the eight district regions (i.e, SMTC MPA) as well. Table 4-4 presents a summary of total PT by mode and by origin district. Overall, about $9 \%$ of trips made by SMTC residents were walk/bike trips; public transit accounted for only about $1 \%$. Note that the "other" mode includes taxi/cab, ferry, airplane, etc.

Table 4-4. Person Trips by Mode Based on Origin District of Trips Made by SMTC Residents.

\begin{tabular}{|l|r|r|r|r|r|r|}
\hline \multicolumn{1}{|c|}{ Origin District } & \multicolumn{1}{c|}{ POV } & $\begin{array}{c}\text { Public } \\
\text { Transit }\end{array}$ & Walk/Bike & \multicolumn{1}{c|}{ Other } & $\begin{array}{c}\text { Not } \\
\text { reported }\end{array}$ & \multicolumn{1}{c|}{ All } \\
\hline 1- Syracuse West & $59,089,567$ & $3,463,833$ & $15,302,297$ & $2,541,316$ & 761,753 & $81,158,766$ \\
\hline 2- Syracuse East & $50,669,261$ & 915,932 & $6,869,205$ & $1,985,418$ & 184,575 & $60,624,391$ \\
\hline 3- Syracuse South & $19,239,454$ & 435,224 & $4,959,984$ & $2,548,263$ & 0 & $27,182,925$ \\
\hline 4- SMTC MPA Northwest & $33,924,364$ & 531,486 & $4,717,200$ & $3,469,135$ & 0 & $42,642,185$ \\
\hline 5- SMTC MPA North & $97,171,649$ & 52,055 & $7,199,098$ & $4,223,899$ & 380,877 & $109,027,578$ \\
\hline 6- SMTC MPA Northeast & $96,513,982$ &. & $6,394,171$ & $5,935,777$ & 0 & $108,843,930$ \\
\hline 7- SMTC MPA Southeast & $111,765,503$ & 171,531 & $8,453,681$ & $5,464,974$ & 0 & $125,855,689$ \\
\hline 8- SMTC MPA Southwest & $92,293,837$ & $1,145,140$ & $16,462,907$ & $2,958,949$ & 0 & $112,860,833$ \\
\hline \multicolumn{1}{|c|}{ Others $^{a}$} & $231,232,218$ & $1,659,663$ & $16,987,478$ & $8,820,832$ & 48,799 & $258,748,990$ \\
\hline \multicolumn{1}{|c|}{ All } & $791,899,835$ & $8,374,864$ & $87,346,021$ & $37,948,563$ & $1,376,004$ & $926,945,287$ \\
\hline
\end{tabular}

Note: A "." Indicates that no samples were in the category.

${ }^{a}$ All other locations outside the eight SMTC districts. 
Using information from Table 4-4, mode share statistics by trip-origin district are displayed geographically in Figure 4-21. Clearly, POV is the most commonly used mode of transportation for the majority of PT, regardless which district the trips originated from. As expected, trips originating from the City of Syracuse districts (three pies in the center of the SMTC region) were more likely taken as walking/biking or public transit than other districts. Walk/bike mode share was the highest (19\%) on trips originating from District-1 (Syracuse West), closely followed by District-3 (Syracuse South) with 18\%. District-8 (SMTC MPA Southwest) had a 14\% mode share for walk/bike, which is the highest among districts outside the City of Syracuse.

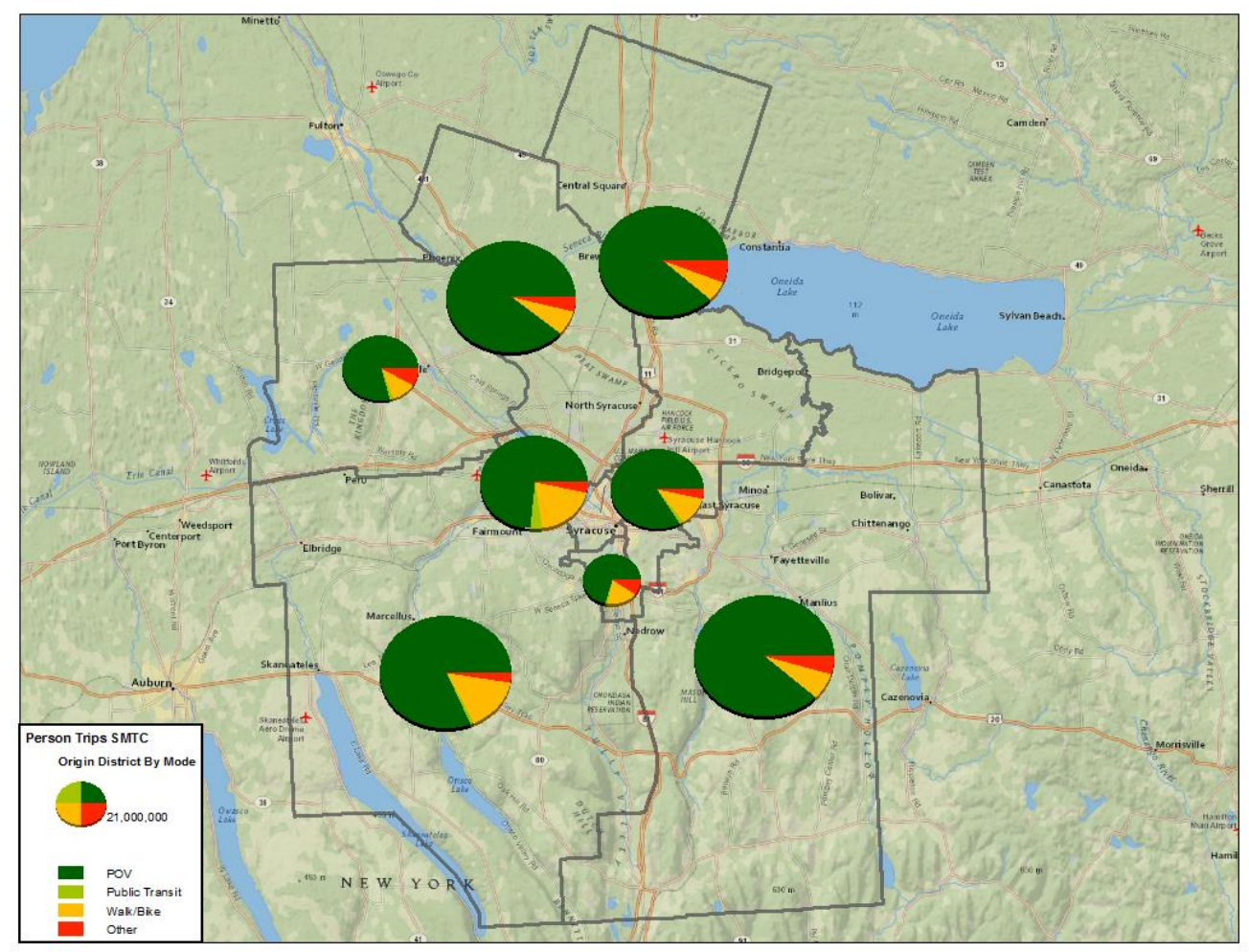

Figure 4-21. Mode shares of person-trips by SMTC district.

Little change in statistics can be seen when examining mode shares by trip-destination districts, i.e., trip termination locations. As mentioned previously, most daily travel was "symmetric" - i.e., a trip from point $\mathrm{A}$ to point $\mathrm{B}$, followed by a later return trip from point $\mathrm{B}$ to point $\mathrm{A}$ - especially on POV trips. Thus the overall mode shares based on all trips made by SMTC residents were not significantly changed; staying roughly at $86 \%$ by POV, $9 \%$ by walk/bike, and about $1 \%$ by public transit. Some variations among trip-destination districts can be seen in Table 4-5, when compared with Table 4-4. 
Table 4-5. Person Trips by Mode on Destination District of Trips Made by SMTC Residents.

\begin{tabular}{|c|c|c|c|c|c|c|}
\hline Destination District & POV & $\begin{array}{c}\text { Public } \\
\text { Transit }\end{array}$ & Walk/Bike & Other & $\begin{array}{c}\text { Not } \\
\text { reported }\end{array}$ & All \\
\hline 1- Syracuse West & $59,510,894$ & $2,346,038$ & $16,240,988$ & $3,195,065$ & 761,753 & $82,054,738$ \\
\hline 2- Syracuse East & $52,931,276$ & 785,414 & $6,377,074$ & $1,582,434$ & 48,799 & $61,724,997$ \\
\hline 3- Syracuse South & $18,185,553$ & 978,530 & $5,160,994$ & $2,407,941$ & 0 & $26,733,018$ \\
\hline 4- SMTC MPA Northwest & $33,482,583$ & 531,486 & $4,717,200$ & $3,494,580$ & 0 & $42,225,849$ \\
\hline 5- SMTC MPA North & $97,986,647$ & 52,055 & $7,228,079$ & $4,097,712$ & 380,877 & $109,745,370$ \\
\hline 6- SMTC MPA Northeast & $96,569,533$ & $1,002,117$ & $6,394,171$ & $5,515,928$ & 135,776 & $109,617,525$ \\
\hline 7- SMTC MPA Southeast & $113,148,471$ & 574,516 & $8,364,634$ & $5,772,011$ & 0 & $127,859,632$ \\
\hline 8- SMTC MPA Southwest & $93,053,777$ & $1,362,275$ & $16,561,644$ & $2,941,121$ & 0 & $113,918,817$ \\
\hline Others $^{a}$ & $227,031,098$ & 742,432 & $16,301,236$ & $8,941,770$ & 48,799 & $253,065,335$ \\
\hline All & $791,899,832$ & $8,374,863$ & $87,346,020$ & $37,948,562$ & $1,376,004$ & $926,945,281$ \\
\hline
\end{tabular}

${ }^{a}$ All other locations outside the eight SMTC districts

Further investigation on intra-district trips (trips that begin and end in the same district) revealed significant changes in mode share patterns for SMTC districts. Clearly visible from Figure 4-22 was the increase for the share of walking/biking trips in all districts, especially those within the downtown area. Since most of the walk/bike trips were for short distance activities, traveling within a close proximity of a location, it is reasonable to expect walk/bike to be a more commonly used mode for intra-district travel.

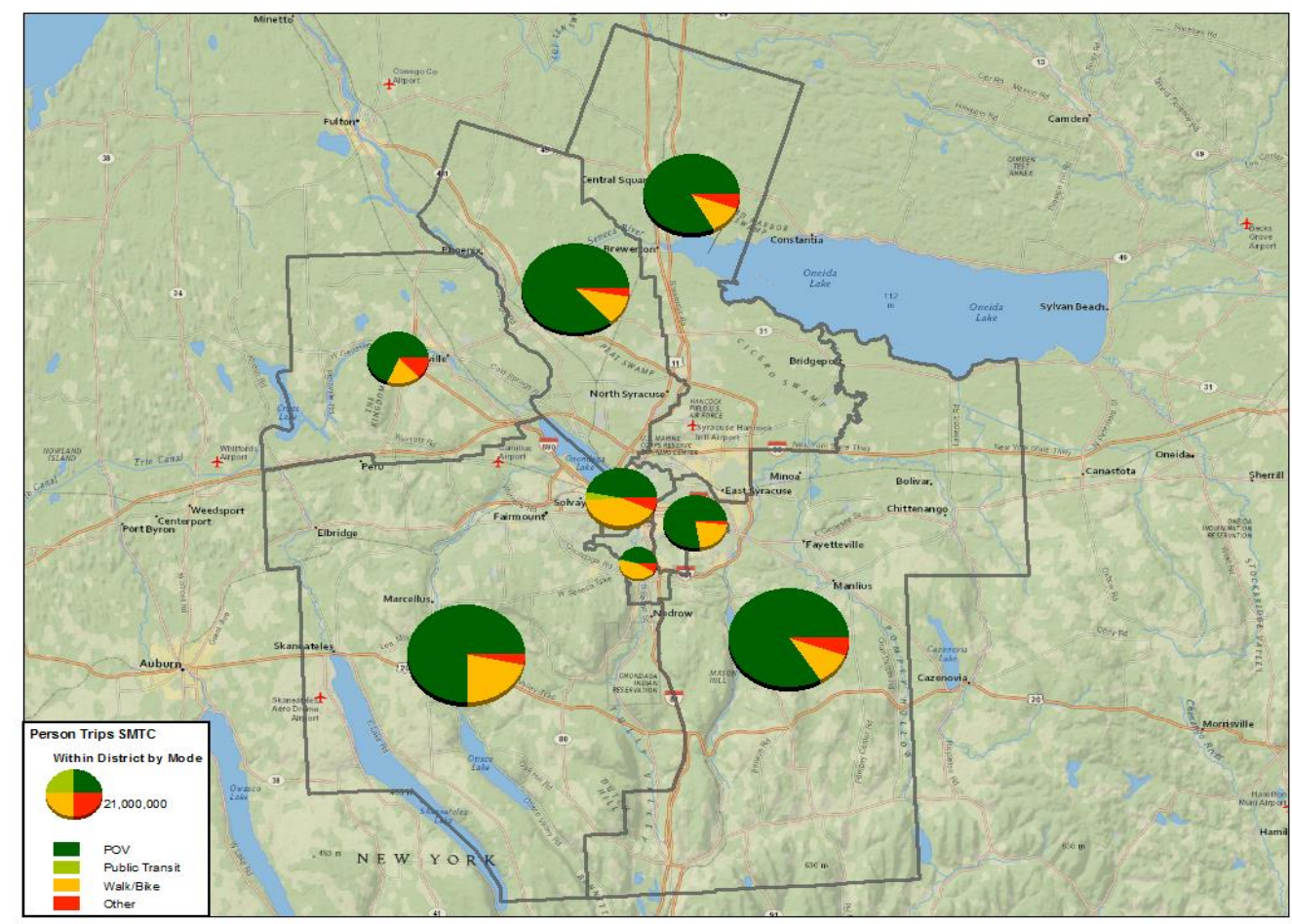

Figure 4-22. Mode share of person trips for intra-district travels in SMTC districts.

\subsubsection{Travel Start Times by SMTC Residents}

To explore whether there is a geographic difference in regional travel patterns, trips made by SMTC residents (measured by PT) were categorized into three groups: within (trips that originate and terminate 
within a given district), outbound (trips that start from a given district and terminate in all other districts), and inbound (trips that originate from other districts and terminate in the given district). Note that travel patterns were known to vary between weekdays and weekends, as well as during different time periods of a day particularly on weekday travels. Thus, using trip start times reported by NHTS respondents, specific travel periods of interest were extracted for a more detailed examination. These time periods are defined as:

- AM peak: from 6:00 to 9:00 in the morning,

- Midday peak: from 11:00 a.m. to 2:00 p.m., and

- PM peak: from 4:00 to 7:00 in the afternoon.

\subsubsection{AM peak travel}

As expected, trips made by SMTC households during the AM peak on weekdays were mostly for commuting (i.e., earning a living), family/personal business (e.g., doctor appointment), and attending school, in descending order. This was clearly evident using the NHTS data (see top chart in Figure 4-23); about $88 \%$ of trips made by SMTC residents during the period from AM peak on weekdays were for these three purposes.

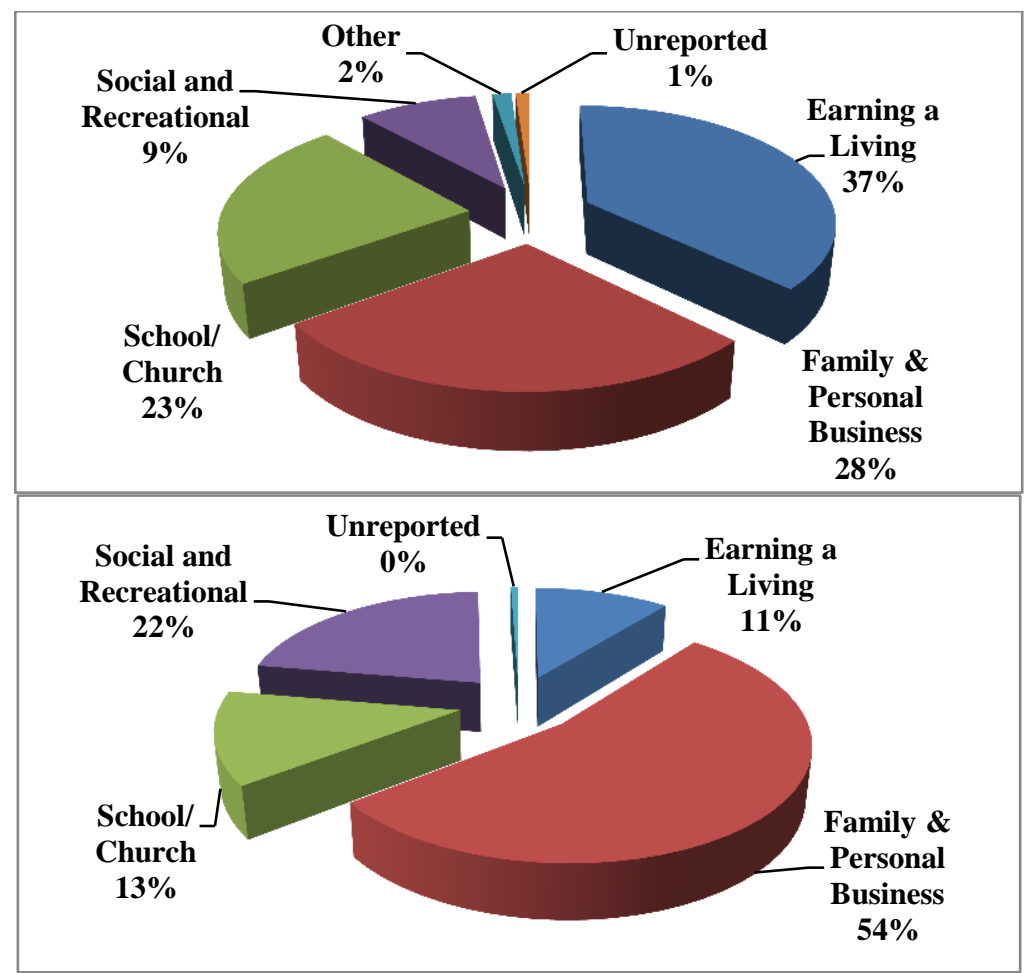

Figure 4-23. Person trips made by SMTC households during AM peak hours by trip purpose (Top: weekdays; bottom: weekends).

On the contrary, as shown in the bottom chart of Figure 4-23, only $11 \%$ of trips made by SMTC households during the time period of AM peak on weekends were for earning a living (i.e., work trips). 
In fact, over half of the weekend trips made in this time period were for family/personal business reasons; and another $22 \%$ of trips are for social and recreational purposes (e.g., shopping).

Considering the geospatial relationship of travel between SMTC districts, Figure 4-24 presents travel patterns during the weekday AM peak period by SMTC district, measured in PT. Again, the size of the pies reflects the total volume of PT in each district and the color of slides represents different trip categories: yellow for intra-region travel (within), green for outbound trips, and red is for inbound travel.

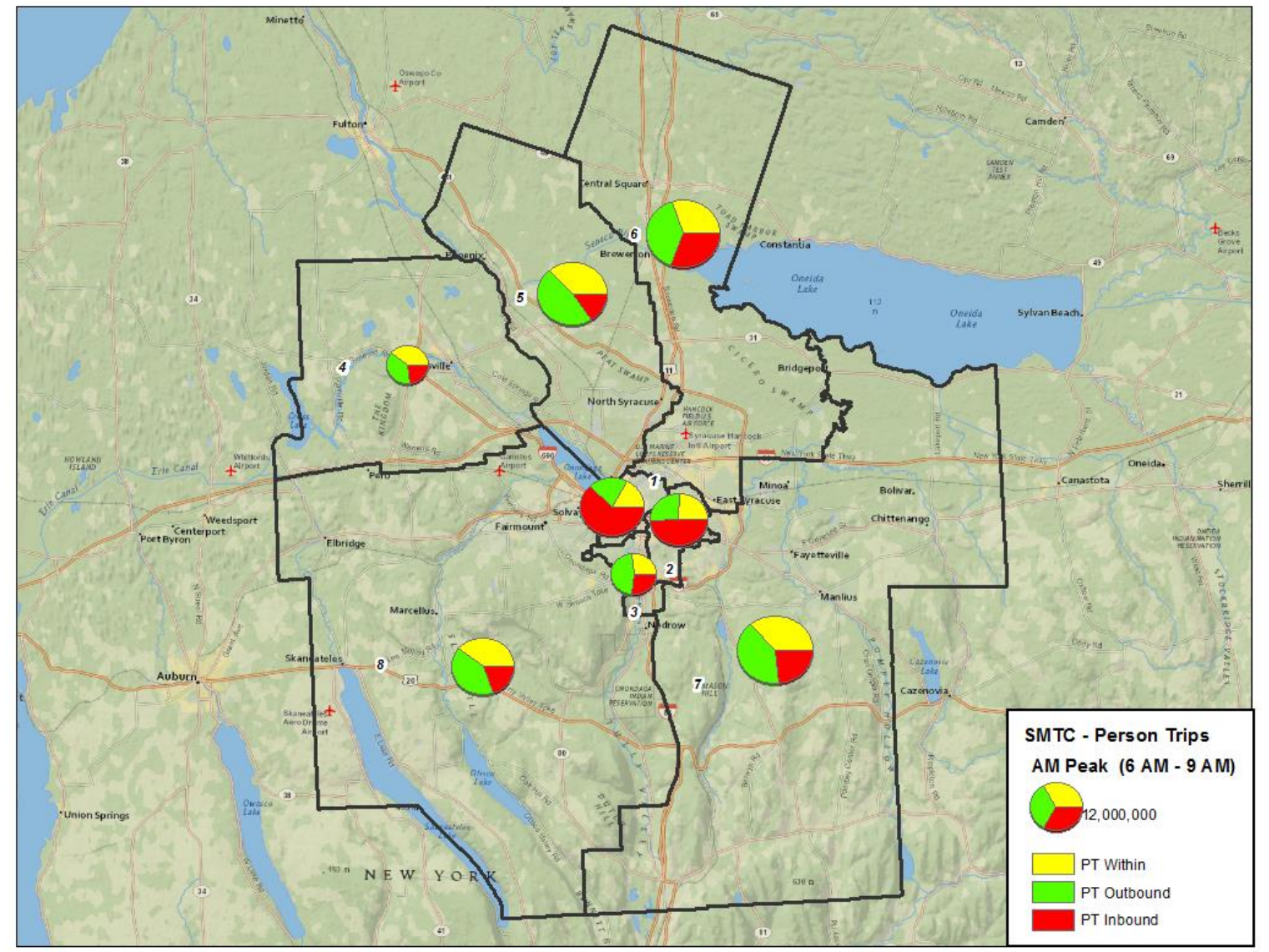

Figure 4-24. Travel patterns during weekday morning peak hours (6:00-9:00 am) in SMTC districts.

Clearly, the two Syracuse downtown districts, specifically Syracuse West and Syracuse East, had much higher shares of inbound trips (shown in red) than those of other SMTC districts during the weekday morning peak hours. This was anticipated since these two regions contain several major employment centers such as university, hospital, government office buildings, etc., which attracts many travel activities (i.e., as trip destinations) particularly for morning commuting. As for all other SMTC districts (outside the two downtown districts), Figure 4-24 indicates that they had more outbound than inbound trips during those AM peak hours. These regions also contained significant shares of "within trips" (in yellow) especially in comparison to the downtown districts.

Specifically, when considering weekday AM-peak hour travels made solely within a SMTC district (i.e., intra-district trips), over one-third of these trips were conducted for the purpose of family/personal 
business (e.g., bank, doctor, etc.) and another $29 \%$ for school/church activities (see top chart in Figure 425). Only $22 \%$ of the intra-district trips are for the purpose of earning a living. On the other hand, as shown in the bottom chart of Figure 4-25, over half of the inter-district trips made during the weekday morning peak hours were for commuting; follow by $21 \%$ for family/personal business and $17 \%$ for school/church activities.

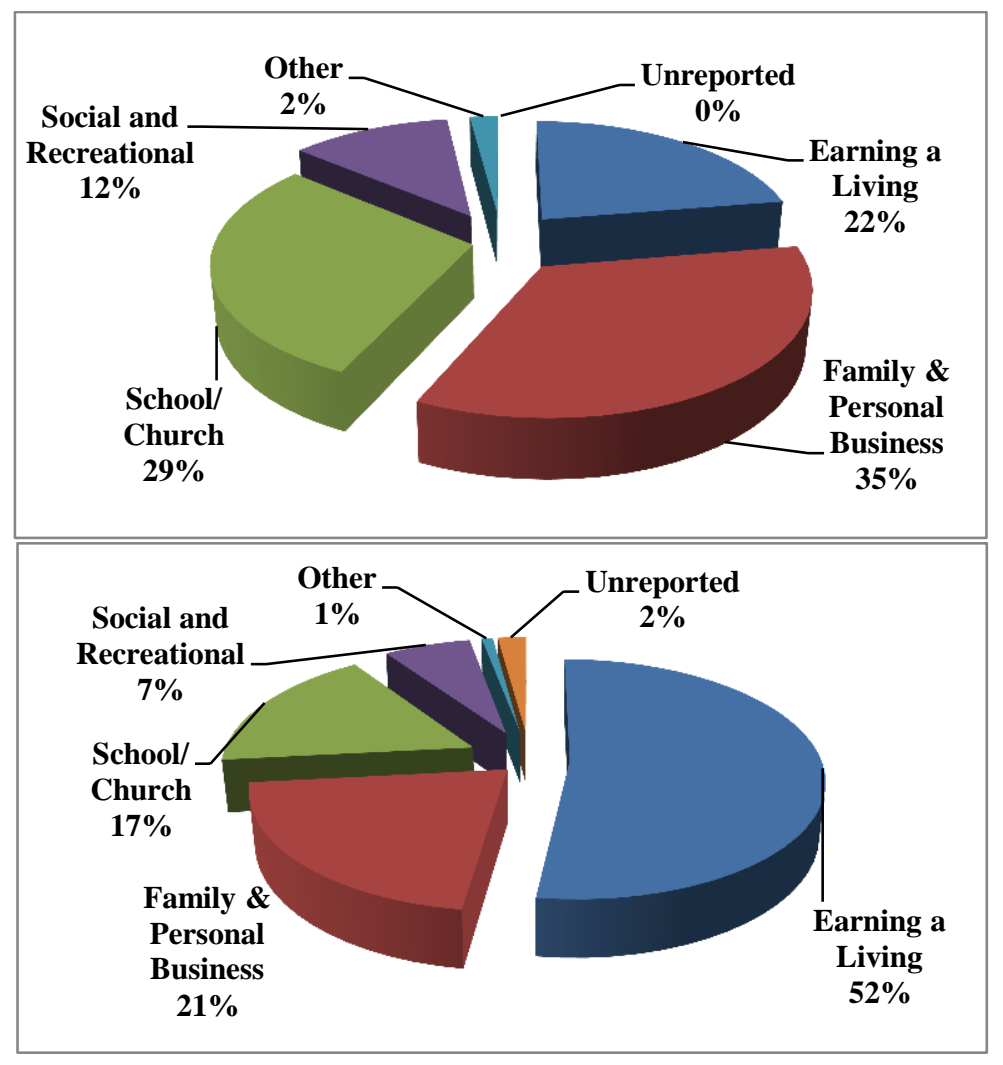

Figure 4-25. Travel purpose for trips made during weekday AM peak hours (6:00-9:00) in SMTC (Top: intradistrict trips; bottom: inter-district trips).

Review of weekend morning travel activities in SMTC, for both intra- and inter-district trips revealed a rather similar pattern as that shown in the bottom chart of Figure 4-23. The majority of those trips were made for the purpose of family/personal business, accounting for 50\% of intra-district travel and 58\% for inter-district trips. The most visible difference, however, appeared to be on "earning a living" trips; accounting for $16 \%$ of intra-district trips and only $5 \%$ for inter-district travel. In other words, weekend morning commute seems to be a more "local" (i.e., within a given SMTC district) activity.

\subsubsection{Midday peak travel}

Unlike morning travel, trips made by SMTC households during midday peak hours (from 11:00 a.m. to 2:00 p.m.) on weekdays were mostly for family/personal business (56\%) and social/recreational (20\%) activities. As presented in Figure 4-26, only 15\% of SMTC person trips made during midday peak hours on weekdays were for work purposes (i.e., earning a living). Still, on weekends, over half of the SMTC person trips made during midday were for family/personal business reasons. There was a clear jump on 
travel activities for social and recreational purposes (e.g., shopping, dining out, etc.) on weekends (increased from $20 \%$ on a typical weekday to $37 \%$ on a weekend).

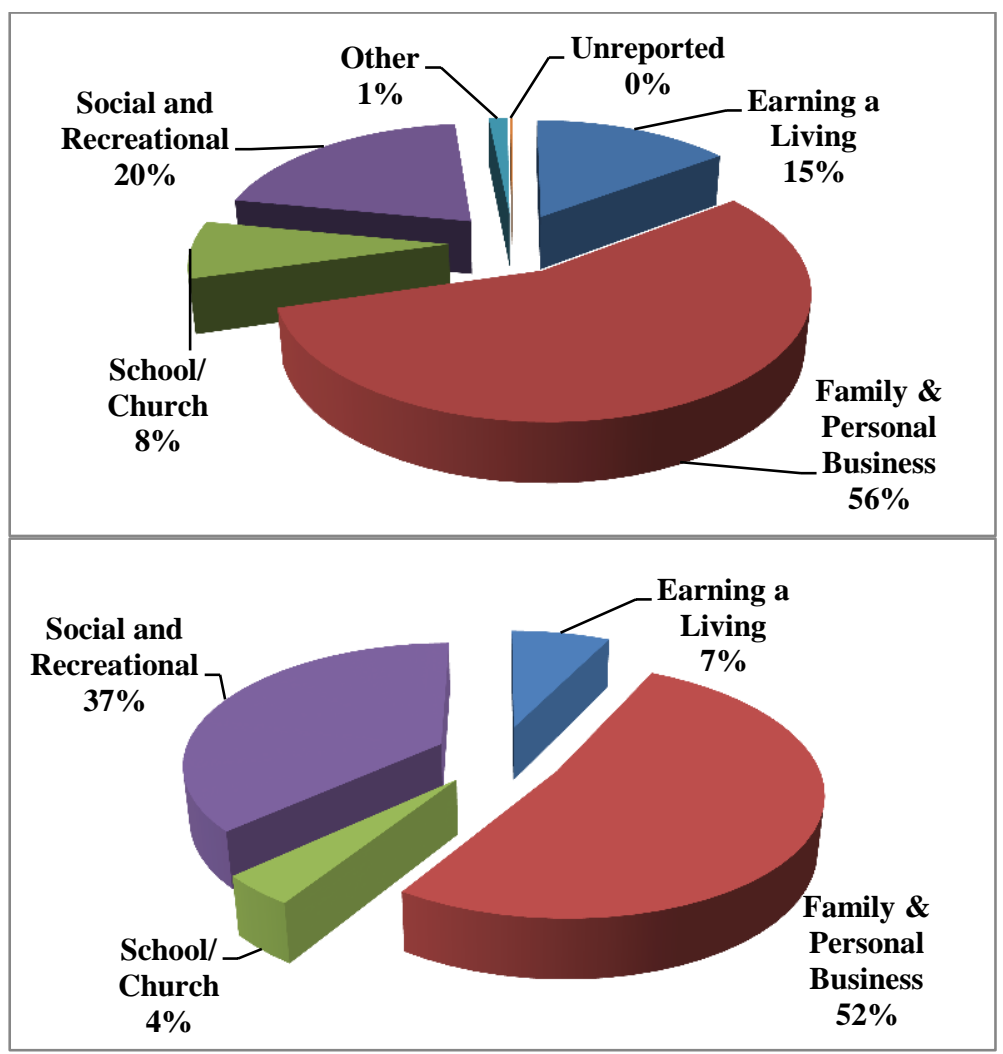

Figure 4-26. Travel during midday peak hours (11:00 a.m. to 2:00 p.m.) in SMTC districts (Top: weekday travel; bottom: weekend travel).

A similar examination for geospatial relationships on trips made among SMTC districts for weekday travel during the midday peak hours also revealed a visible different pattern from the AM-peak pattern (see Figure 4-27 versus Figure 4-24). Most of the SMTC districts have shown an increased share of within-region trips for midday peak hours travel on weekdays, particularly in districts shown in the bottom half of the map in Figure 4-27. The only exception is in Syracuse South district, a mostly residential area within the City of Syracuse. 


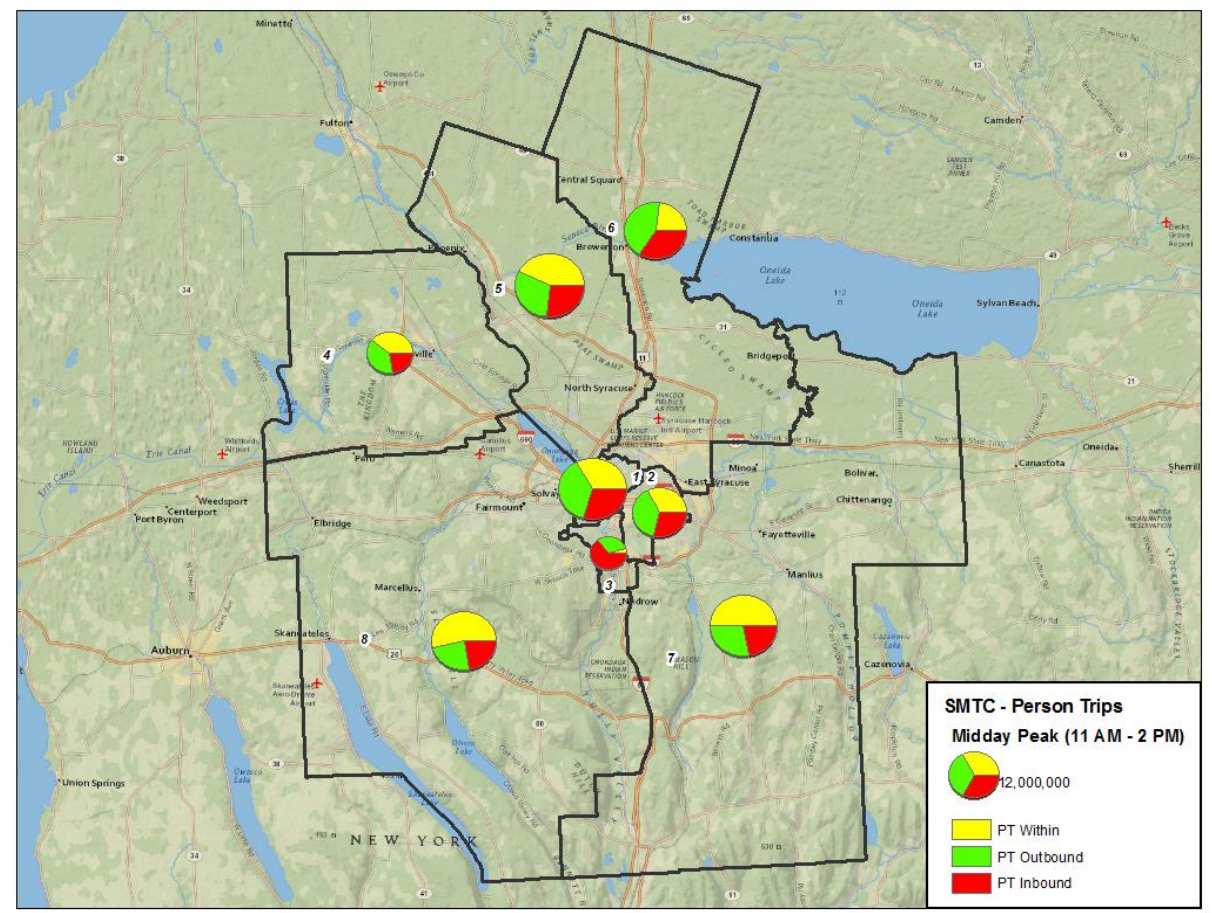

Figure 4-27. Travel patterns during midday peak hours (11:00 am to 2:00 pm) on weekdays for the SMTC districts, in person-trips.

It is speculated that the higher share for intra-district travel during midday hours, as observed in several districts shown in Figure 4-27, might be due to SMTC residents making midday trips for meals, running errands, and/or conducting personal business. To confirm this, travel purpose for both intra- and interdistrict midday trips were reviewed and the results are summarized in Figure 4-28. Clearly, Family/personal business is the primary reason for trips made during this time period, followed by trips made for social/recreational purposes, regardless if they were for intra- or inter-district activities. This is very different from the AM-peak hour travel patterns shown in Figure 4-25.

A review of NHTS data on midday travel activities on weekends reveals a similar pattern between the intra- and inter-district travels. As in Figure 4-25, most of the midday weekend trips were for family/personal business purposes, accounting for $49 \%$ of intra-district travel and 56\% for inter-district trips. Midday travel for social/recreational purpose was nearly twice as much on weekends than those conducted during weekdays, however. About $40 \%$ of midday intra-district weekend trips by SMTC residents were made for social/recreational activities, versus $22 \%$ on weekdays. About $32 \%$ of midday inter-district weekend trips were conducted for the same reason versus $18 \%$ for weekdays. 

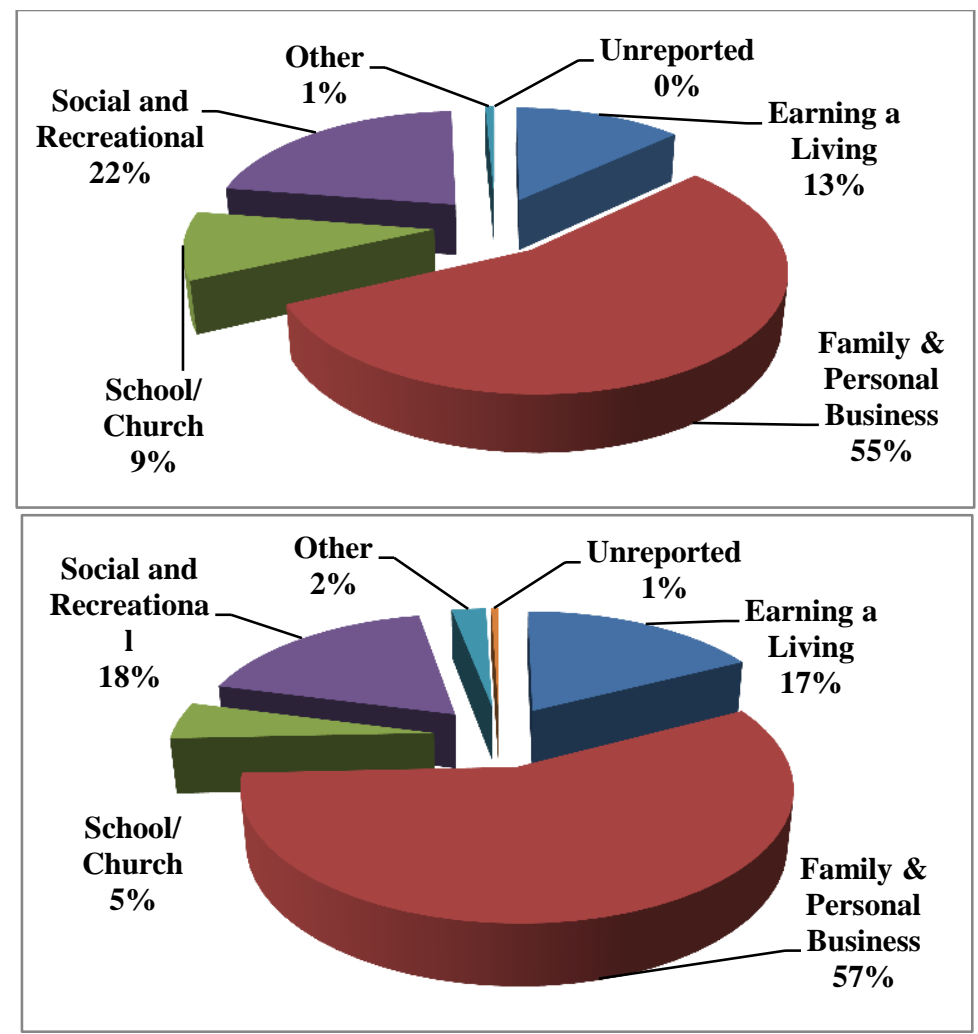

Figure 4-28. Travel made during weekday midday-peak hours (11 a.m. to 2 p.m.) in SMTC districts (Top chart for intra-district trips; bottom chart for interdistrict trips).

\subsubsection{PM peak travels}

Figure 4-29 indicates that trips made by SMTC households during afternoon peak hours (from 4:00 to 7:00 p.m.) on weekdays were mostly for social/recreational (37\%) and family/personal business (34\%) activities. Only $23 \%$ of SMTC person trips that start during the weekday afternoon peak hours were for work purposes. On weekends, however, over half of the SMTC person trips made during the afternoon hours were for family/personal business reasons (52\%); while trips made for social/recreational activities during the same time period on weekends dropped only slightly to a $35 \%$ share. 


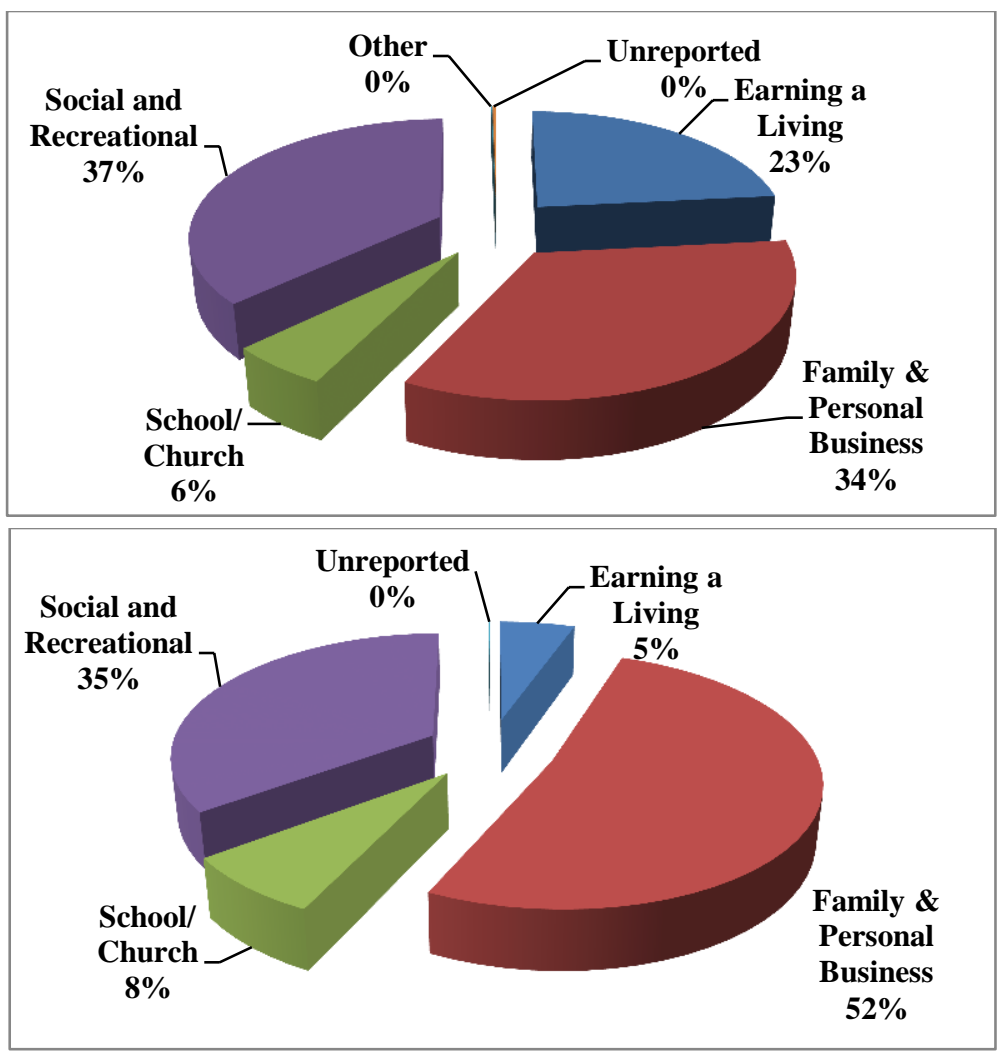

Figure 4-29. Travel during PM peak hours (4:00 to 7:00 p.m.) in SMTC districts (Top: weekday travel; bottom: weekend travel).

Geospatial travel patterns of weekday PT during the afternoon peak period are shown in Figure 4-30. A higher share of outbound trips for the two Syracuse downtown districts was clearly observed. This displays a reverse pattern of the morning travel as shown in Figure 4-24, which reflects more trips made leaving the two major employment districts to return to other districts. Intra-district trip shares were noticeably higher for districts outside the City of Syracuse and in the more residential-oriented Syracuse South district. In general, travel patterns outside the City of Syracuse were relatively similar between the PM peak and the midday peak hours for weekdays. 


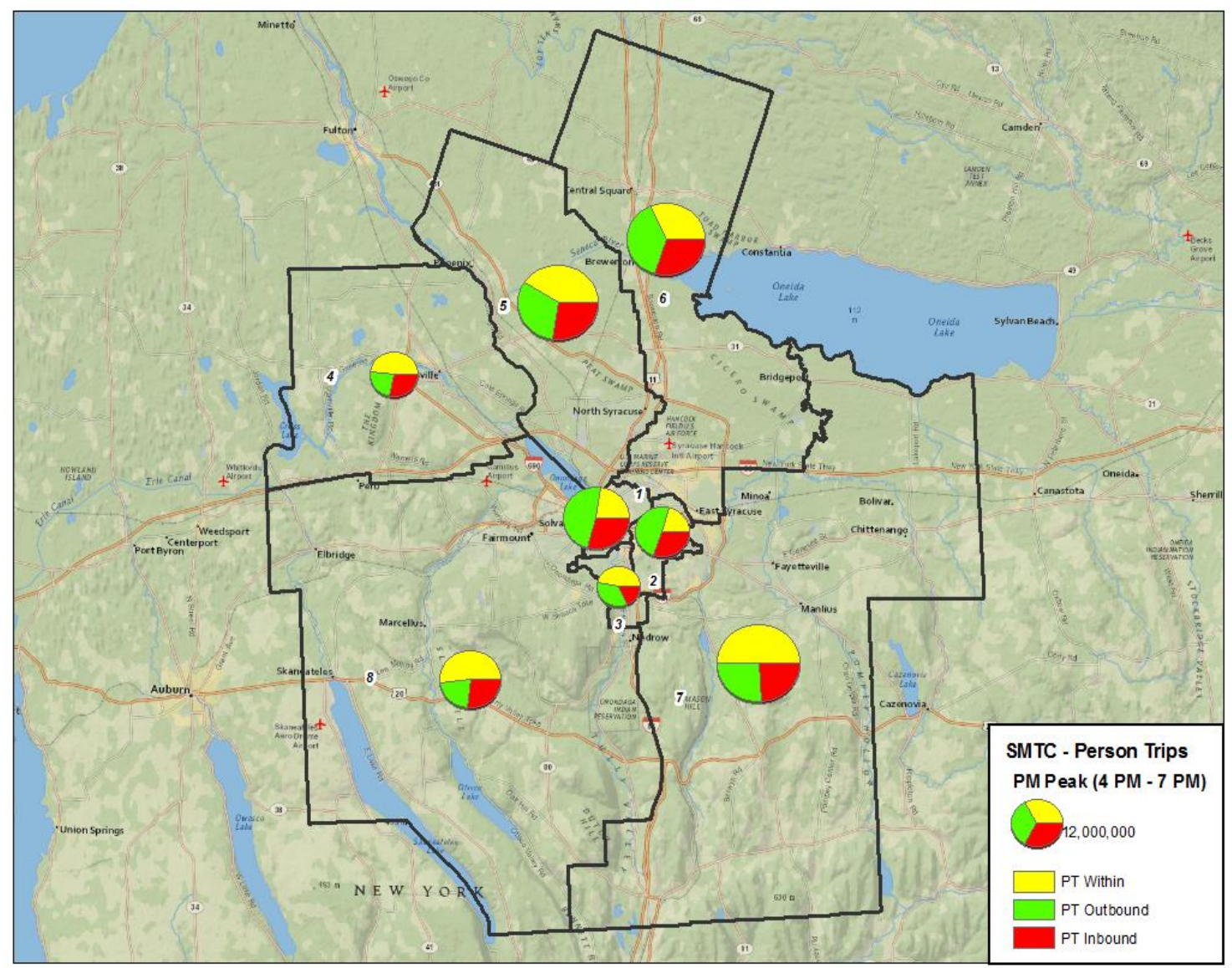

Figure 4-30. Travel patterns during weekday PM peak hours (4:00 to 7:00 pm) in SMTC districts.

As shown in Figure 4-31, intra-district travel by SMTC residents was most likely made to conduct social/recreational activities, accounting for $42 \%$ of the total intra-district trips that start during weekday afternoon peak hours. Intra-district family/personal business trip was another major reason for travel during weekday PM peak hours in SMTC districts, accounting for 35\% of the total SMTC intra-district trips. By comparison, inter-district traveling for family/personal business activities stayed with the same share (35\%) during the afternoon peak hours on weekdays, while social/recreational inter-district trips dropped to a $29 \%$ share. A noticeable significant portion (32\%) of inter-district trips made during the afternoon peak hours on weekdays were work trips (i.e., earning a living).

A similar examination of weekend trips for travel made during the 4:00 to 7:00 p.m. time period showed no significant differences between intra- and inter-district travel patterns by trip purposes for the SMTC districts. The primary reason for making either intra- or inter-district trips during this time period on weekends remained to be for family/personal business, $51 \%$ of total person trips on intra-district travel and 53\% for inter-district trips. Social/recreational activities accounted for 35\% of total PM weekend trips under both intra- and inter-district cases. 


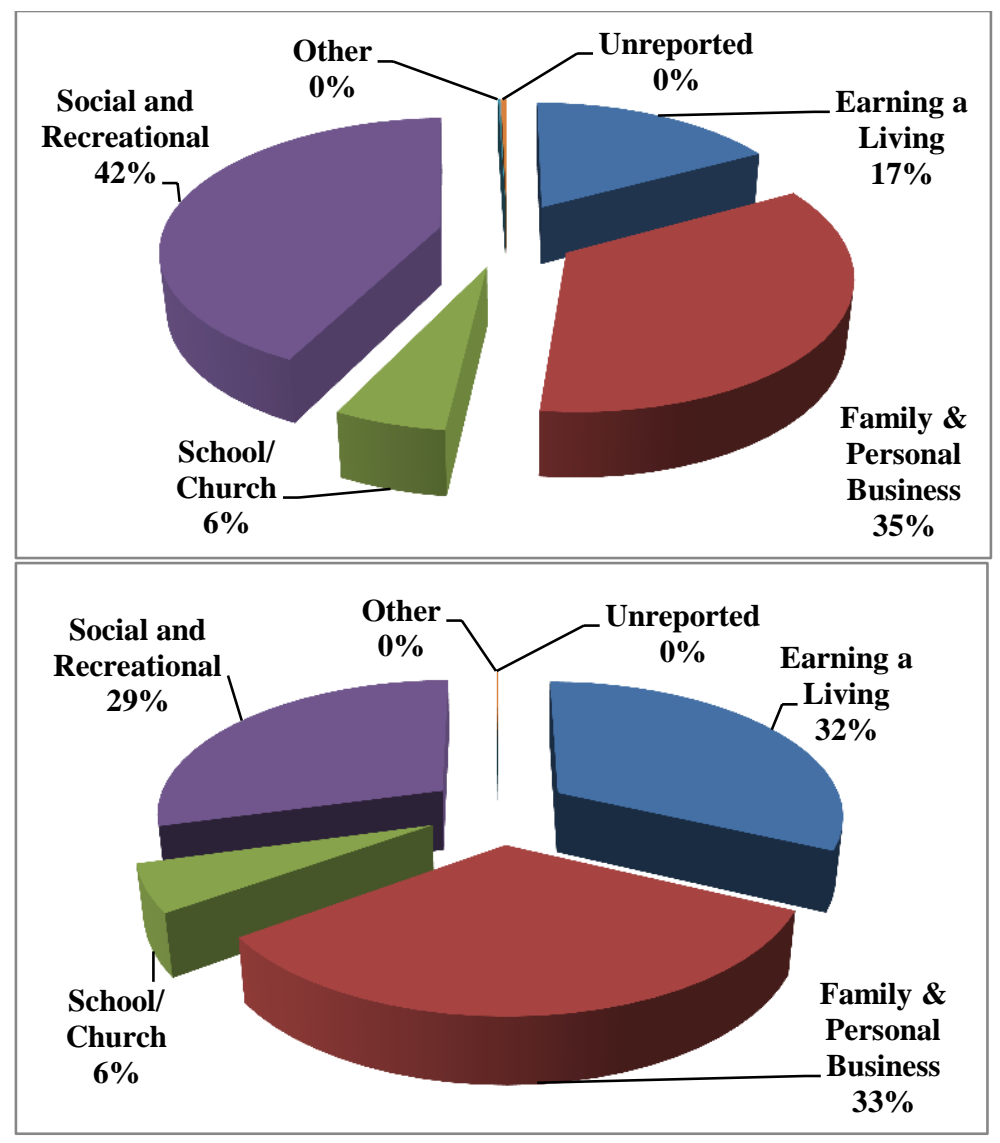

Figure 4-31. Trips made during weekday PM-peak hours (4 to 7 p.m.) in SMTC districts (Top chart for intra-district trips; bottom chart for inter-district trips).

\subsubsection{Other remarks}

Although similar geospatial maps for travel patterns on weekends by SMTC districts (as in Figures 4-24, 4-27, 4-30) might be of interest, sample size limitations in NTHS data unfortunately prevented adequate estimates to be generated at such a level of detail. Considering all hours on a weekend, as shown in Figure 4-32, higher shares of intra-district person trips on weekends were observed in all districts outside the City of Syracuse. Generally speaking, the shares of inbound and outbound travel volumes (measured by PT) were about equal within each district in the SMTC; this is probably because most daily trips were "symmetric" - meaning an outbound trip typically incurs a reversed return trip. 


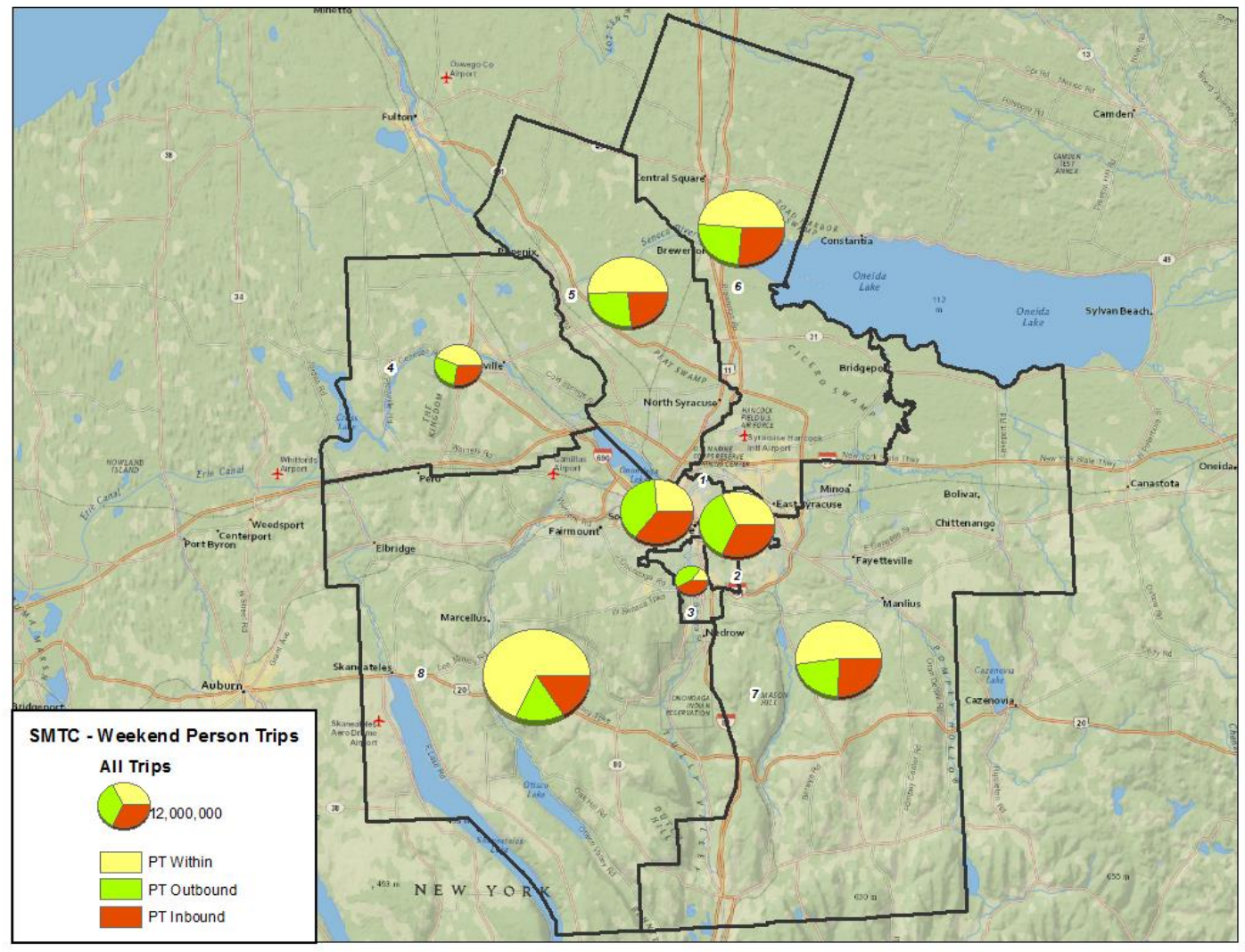

Figure 4-32. Travel patterns of person trips during weekend (all hours) in SMTC districts.

Weekday travel patterns, measured by VT, in the SMTC districts were very similar to those measured by PT, likely due to the fact that the majority of daily travels were vehicle-based (i.e., use of POV). The exact same argument can be made with VMT and PMT distributions in SMTC districts with respect to their travel patterns.

\subsubsection{Average Trip Distance and Average Occupancy Rate in the SMTC Region}

Based on NHTS data, average travel distance by SMTC district residents were examined. Figure 4-33 compares average PT distances by trip-origin district as well as by trip-destination district on trips made by residents of SMTC region. Again, since most trips were symmetric, the difference in average distances was not expected to be significant in most cases. However, a return trip may or may not mirror the initial outbound trip,. For example, one could drop off dry-cleaning on the way to work in the morning, but return directly home from work at the end of the day. Although Figure 4-33 shows that trips starting in District 4 (SMTC MPA Northwest) have, on average, a longer distance than those trips terminating in the same district, after removing an extreme outlier (discussed in Section 4.2.2), the average was reduced to 8.4 instead which is much more consistent with all other districts. 


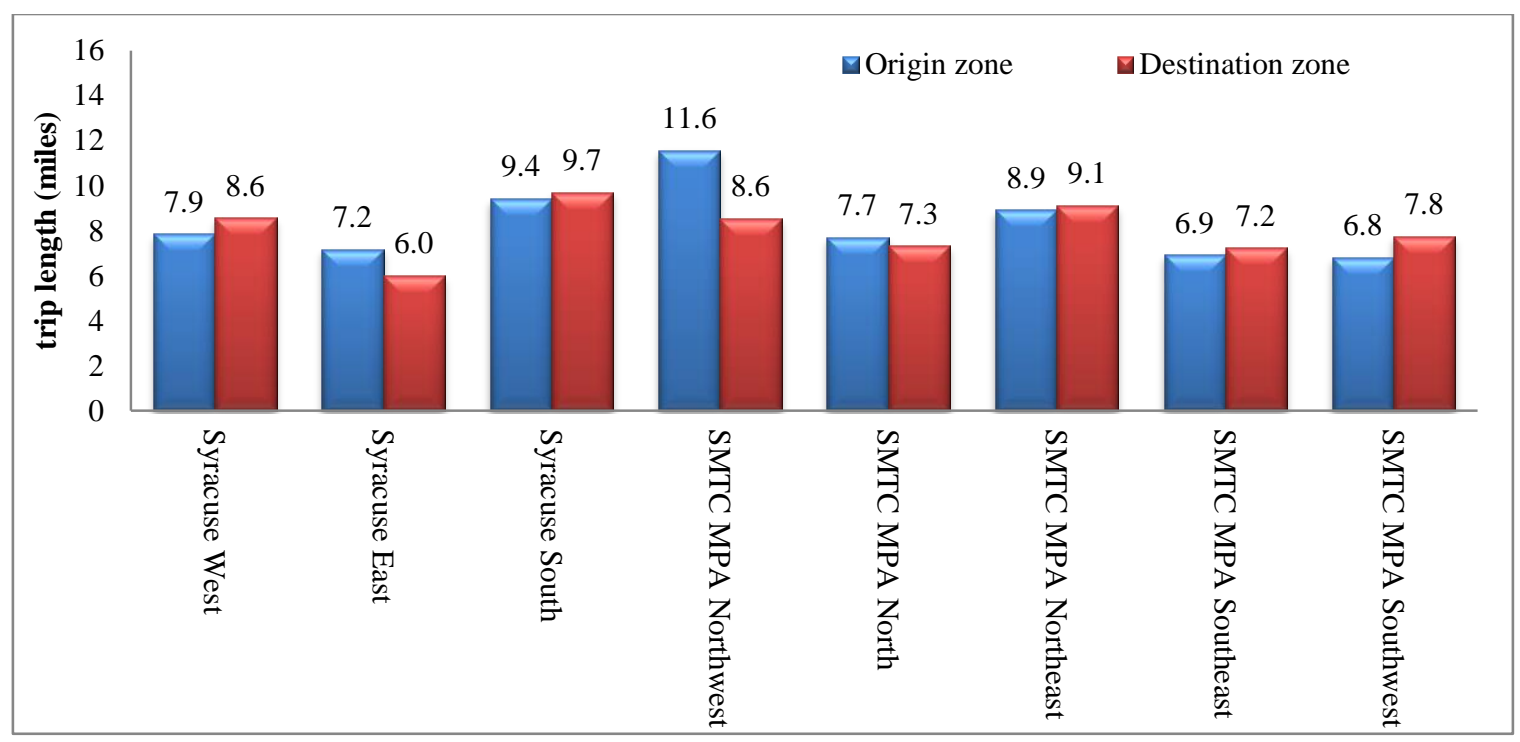

Figure 4-33. Average distance of a person-trip in SMTC district by trip-origin and trip-destination.

Similarly, average distances of VT by SMTC district are presented in Figure 4-34. On average, a VT travels a longer distance than a typical PT (which includes trips made by walk/bike, transit, etc.). General patterns among the districts are fairly consistent in both figures.

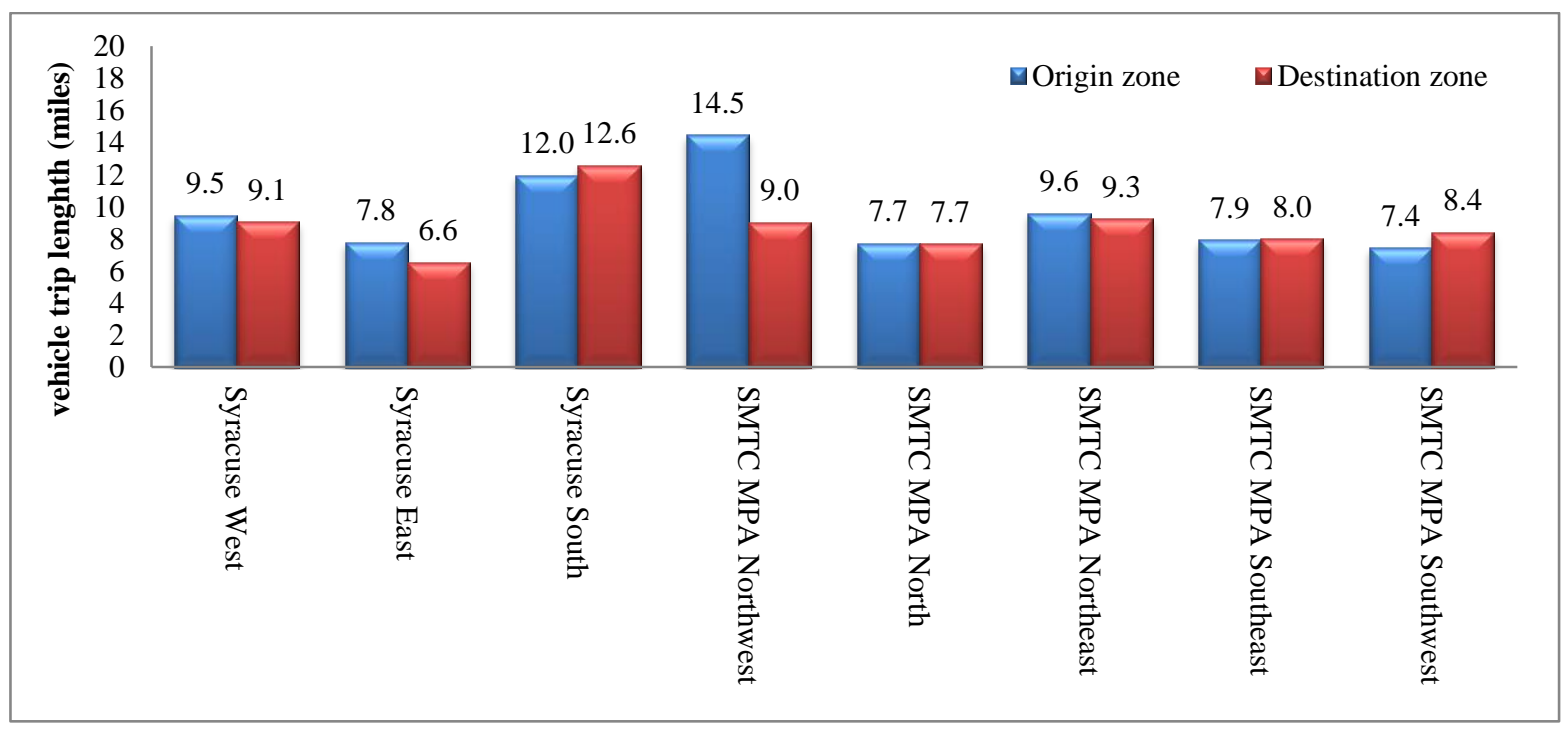

Figure 4-34. Average distance of a vehicle-trip in SMTC district by trip-origin and trip-destination.

Another way of examining average PT distance by district is presented in Figure 4-35. A "home-bound" trip is defined as any trip with a purpose of going home; this could include trips from work place or shopping trips. The "work-bound" trip is traveling to a work place, which could be from home (more typical) or other locations. And, trips assigned under the "other purpose" group are for those non-home and non-work trips. In this figure, work trips out of SMTC districts (i.e., originated from the given district) are displayed in red, while home-bound trips are displayed in blue. 


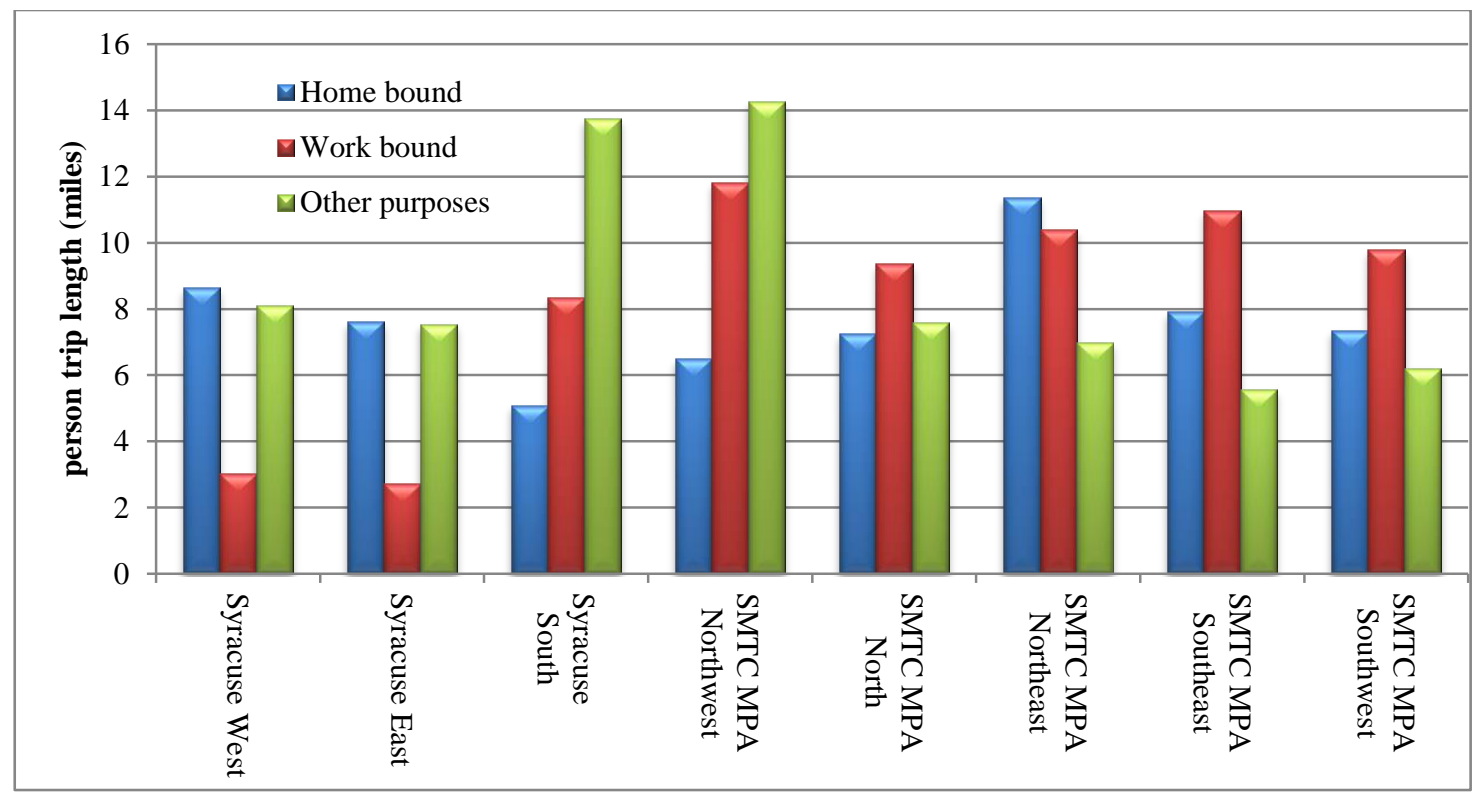

Figure 4-35. Average distance of a person-trip by originated SMTC district by trip type.

Using data on VT (travel made by POV only), average occupancy rates for trips associated with each SMTC district were estimated. Figure 4-36 illustrates that, for most districts, average occupancy rates by trip-origin district and trip-destination district are fairly similar with the exception of an outlier in District 4 (Syracuse MPA Northwest) data causing the spike in the average. An occupancy rate can be computed by dividing the total PT (POV only) in a region by its corresponding number of VT (i.e., PT/VT), as well as it can be obtained from dividing PMT (POV only) by its corresponding VMT. Results from the two calculation methods could vary by some degrees.

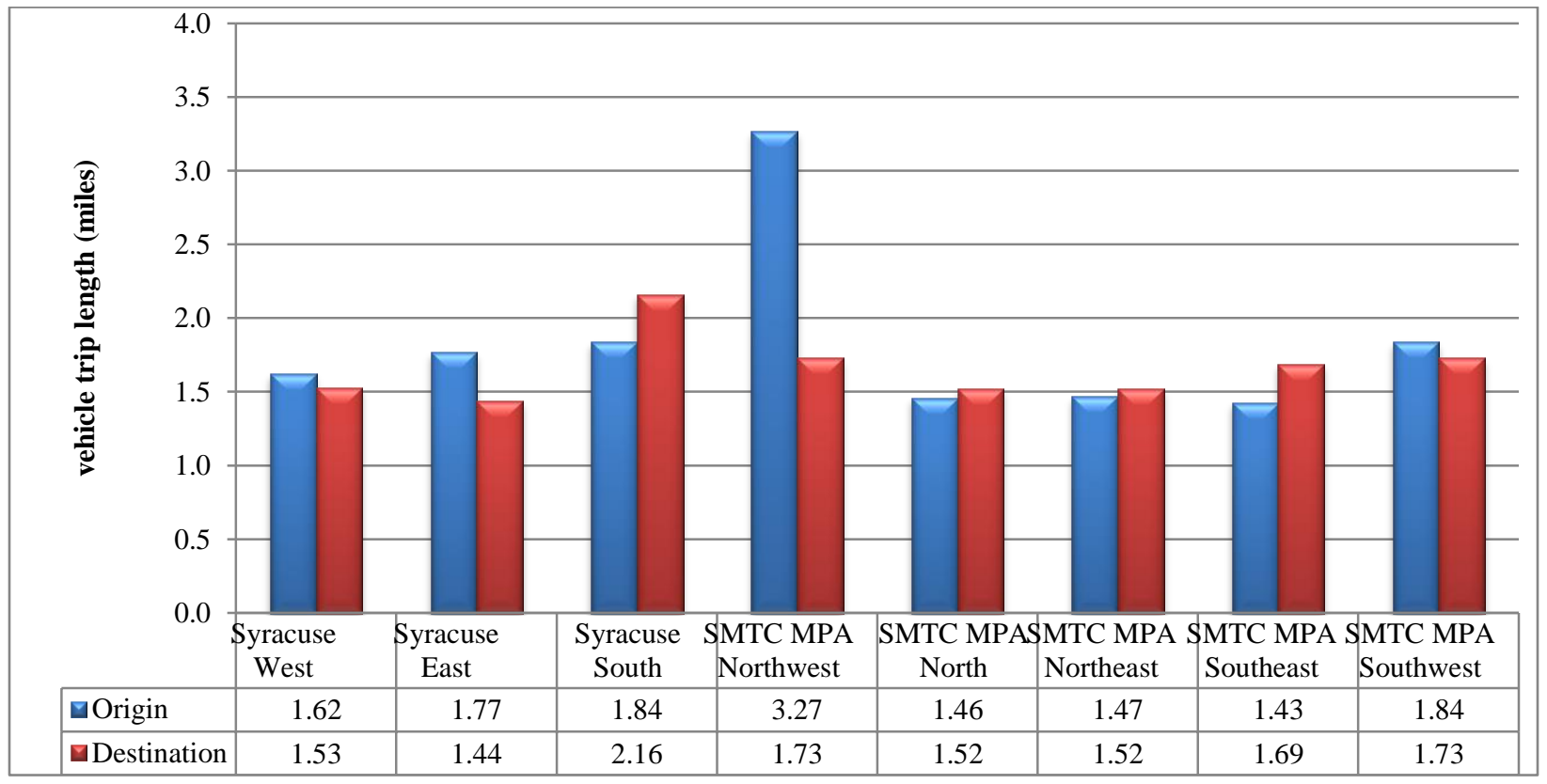

Figure 4-36. Average occupancy rate for vehicle trips in SMTC districts. 
Table 4-6 summarizes occupancy rate estimates based on PT/VT of POV trips by SMTC household district by the trip purpose. The result reflected that work-related VT by SMTC residents was mostly single-occupancy, except in District 8 (SMTC Southwest). On the other hand, VT made for other purposes were more likely to be shared rides (with a higher occupancy rate), particularly those made for school/church activities. The two shaded rates noted in Table 4-6 are likely caused by extreme values among the small sample sizes-mainly due to divisions of very small VT values.

Table 4-6. Occupancy Rates Based on PT/VT of POV Trips by SMTC Household District.

\begin{tabular}{|l|c|c|c|c|c|}
\hline \multicolumn{1}{|c|}{ Household District } & $\begin{array}{c}\text { Earning a } \\
\text { Living }\end{array}$ & $\begin{array}{c}\text { Family \& } \\
\text { Personal } \\
\text { Business }\end{array}$ & $\begin{array}{c}\text { School/ } \\
\text { Church }\end{array}$ & $\begin{array}{c}\text { Social and } \\
\text { Recreational }\end{array}$ & $\begin{array}{c}\text { All } \\
\text { Purposes }\end{array}$ \\
\hline 1- Syracuse West & 1.2 & 1.8 & 4.3 & 1.5 & 1.7 \\
\hline 2- Syracuse East & 1.1 & 1.4 & 2.3 & 1.3 & 1.4 \\
\hline 3- Syracuse South & 1.1 & 1.1 & 5.3 & 1.7 & 1.3 \\
\hline 4- SMTC MPA Northwest & 1.1 & 1.3 & 2.9 & 1.7 & 1.6 \\
\hline 5- SMTC MPA North & 1.1 & 1.2 & 1.2 & 1.5 & 1.2 \\
\hline 6- SMTC MPA Northeast & 1.0 & 1.4 & 2.4 & 1.9 & 1.4 \\
\hline 7- SMTC MPA Southeast & 1.0 & 1.3 & 1.9 & 1.6 & 1.3 \\
\hline 8- SMTC MPA Southwest & 1.7 & 1.3 & 2.5 & 1.6 & 1.5 \\
\hline
\end{tabular}

Similar results are seen in Table 4-7 where the occupancy rates are computed from PMT/VMT of VT made by SMTC district residents. The shaded rates "deteriorate" more-again due to divisions of very small VMT estimates. Other than that, results from Table 4.7 are consistent with findings from Table 4-6 in that work trips via POVs were mostly single occupancy vehicles while other types of trips were more likely to have multiple occupants in the same vehicles.

Table 4-7. Occupancy rates based on PMT/VMT of POV trips by SMTC household districts.

\begin{tabular}{|l|c|c|c|c|c|}
\hline \multicolumn{1}{|c|}{ HH District } & $\begin{array}{c}\text { Earning a } \\
\text { Living }\end{array}$ & $\begin{array}{c}\text { Family \& Personal } \\
\text { Business }\end{array}$ & $\begin{array}{c}\text { School/ } \\
\text { Church }\end{array}$ & $\begin{array}{c}\text { Social and } \\
\text { Recreational }\end{array}$ & $\begin{array}{c}\text { All } \\
\text { Purposes }\end{array}$ \\
\hline 1- Syracuse West & 1.1 & 2.0 & 12.1 & 1.4 & 1.7 \\
\hline 2- Syracuse East & 1.1 & 1.5 & 2.6 & 1.6 & 1.5 \\
\hline 3- Syracuse South & 1.0 & 1.1 & 9.0 & 1.2 & 1.2 \\
\hline 4- SMTC MPA Northwest & 1.1 & 1.5 & 1.7 & 1.2 & 1.2 \\
\hline 5- SMTC MPA North & 1.1 & 1.3 & 1.2 & 1.6 & 1.3 \\
\hline 6- SMTC MPA Northeast & 1.0 & 1.4 & 1.8 & 2.2 & 1.4 \\
\hline 7- SMTC MPA Southeast & 1.0 & 1.3 & 1.3 & 1.7 & 1.3 \\
\hline 8- SMTC MPA Southwest & 1.1 & 1.3 & 1.5 & 1.9 & 1.4 \\
\hline
\end{tabular}




\section{DEMOGRAPHIC CHARACTERISTICS AND TRAVEL PATTERNS IN BMTS REGION}

\subsection{REGIONAL DEMOGRAPHIC CHARACTERISTICS IN BMTS DISTRICTS}

A similar review of demographic characteristics summarized in Section 4 was also performed for the five BMTS districts. This section discusses findings from the data analysis of NHTS, and other data when applicable, for the BMTS region. Based on estimates from the 2009 NHTS data, a total of nearly 87,000 households reside in the BMTS region. As seen in Figure 5-1, about 31\% of the BMTS household population resides in the district of Binghamton.

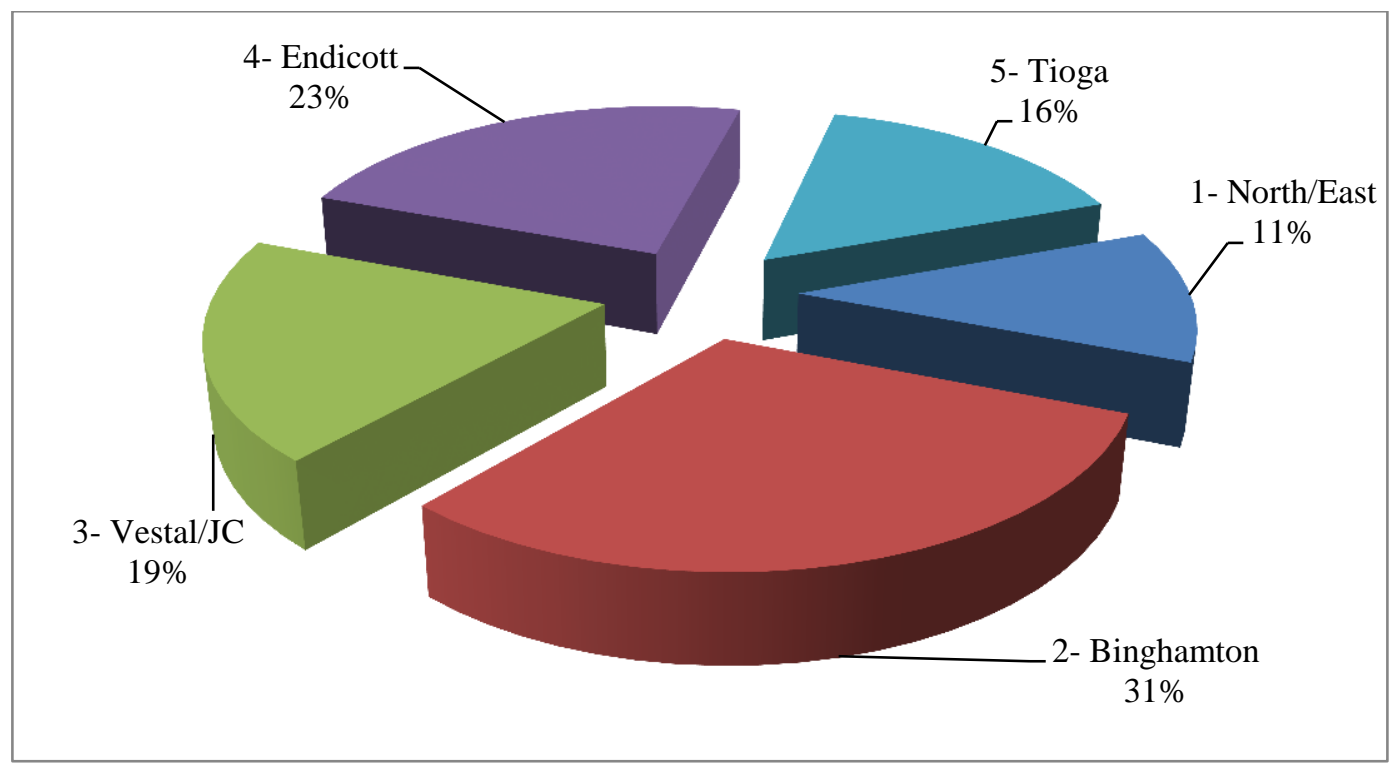

Figure 5-1. Distribution of households by BMTS district.

\subsubsection{Household Size}

Overall, single-person households were approximately $34 \%$ of all households in the BMTS region; that number is $40 \%$ of total households in the SMTC region (see Figure 3-1). The distribution of householdsize composition of residents in each of the five BMTS districts is presented in Figure 5-2, with their number of households by household-size shown under the chart.

Unlike SMTC, there is no major urban downtown area (e.g., City of Syracuse) in the BMTS region. Generally speaking, BMTS household size profiles appear to be more "uniform" among the districts than those within the SMTC region (see Figure 4-1 for comparison). With the exception of the more rural North/East district which has only about $26 \%$ single-person households, all other districts in the BMTS have a $30 \%$ or higher single-person household shares. Specifically, Binghamton (district 2) contains the largest number of single-person households among BMTS districts, accounting for $40 \%$ of its household population. A geospatial view of the household size profile is also presented in Figure 5-3. As in earlier maps, the size of each "pie" reflects the total number of households in a given district. 


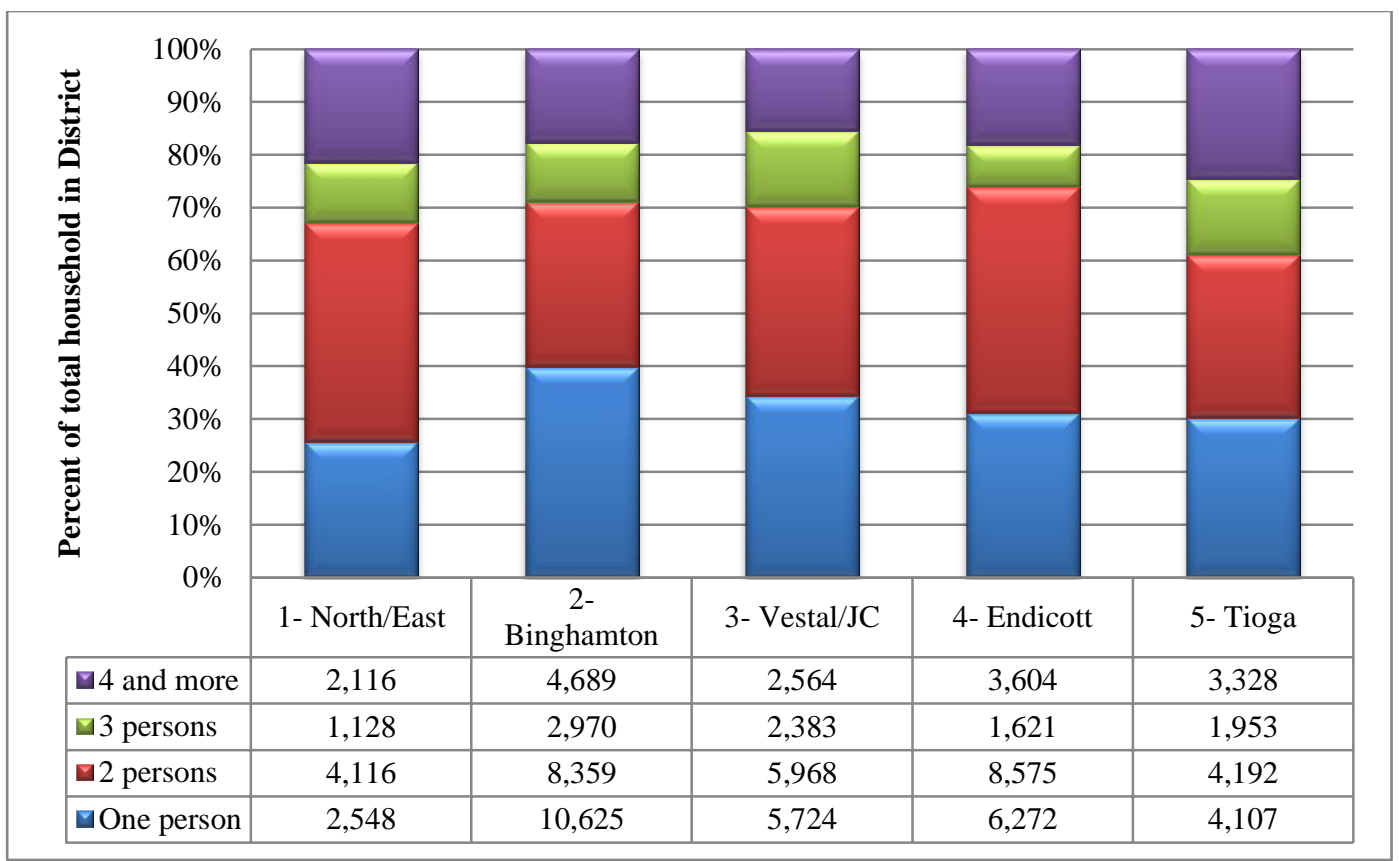

Figure 5-2. Distribution of household size by district in BMTS region.

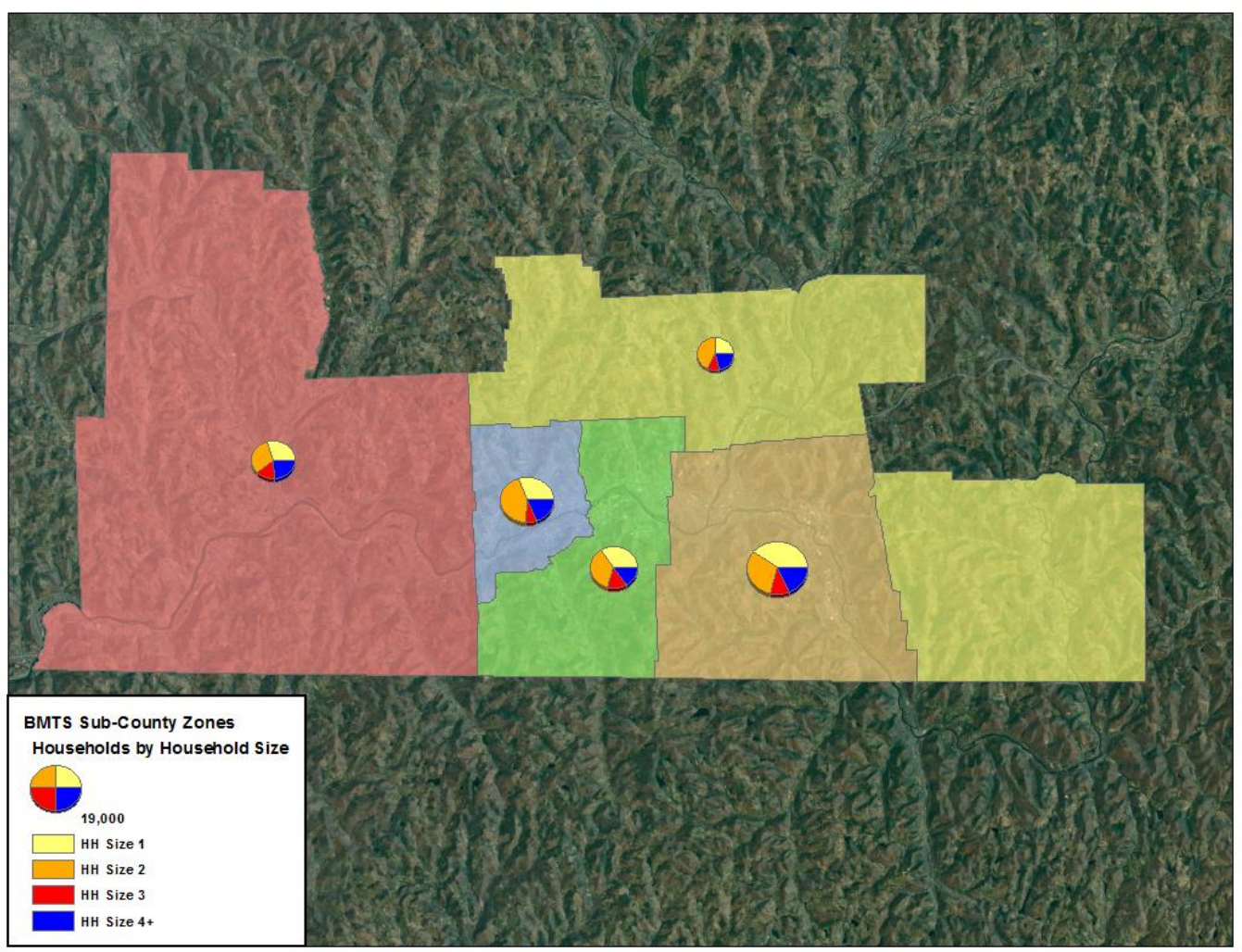

Figure 5-3. Profile of household sizes by district in BMTS region. 


\subsubsection{Age Profile}

Recall that 2009 NHTS data covers persons 5 years old and older; therefore, people younger than 5 years old are not included in the survey. When comparing age profiles for BMTS (shown in Figures 5-4) with the one for SMTC (Figure 4-3), no significantly higher share of 55+ years old residents was observed among BMTS districts. Note that the two relatively small shares for age group 25-34 year olds for district 1 and for age group 15-24 year olds for district 5 (in Figure 5-4) were likely a result from their corresponding small sample sizes (under 10 samples each in this case)- a consequence resulting from "stretching" data beyond survey sampling limitations. Nevertheless, the more rural North/East (district 1) region appeared to have a smaller share of "younger" (under 45 year olds) population (considering 5 years old and older population only) when compared with other BMTS districts. Specifically, less than $45 \%$ of North/East district's 5 year olds and older population are in the "under-45" group; while the shares were over $52 \%$ in all other districts in BMTS.

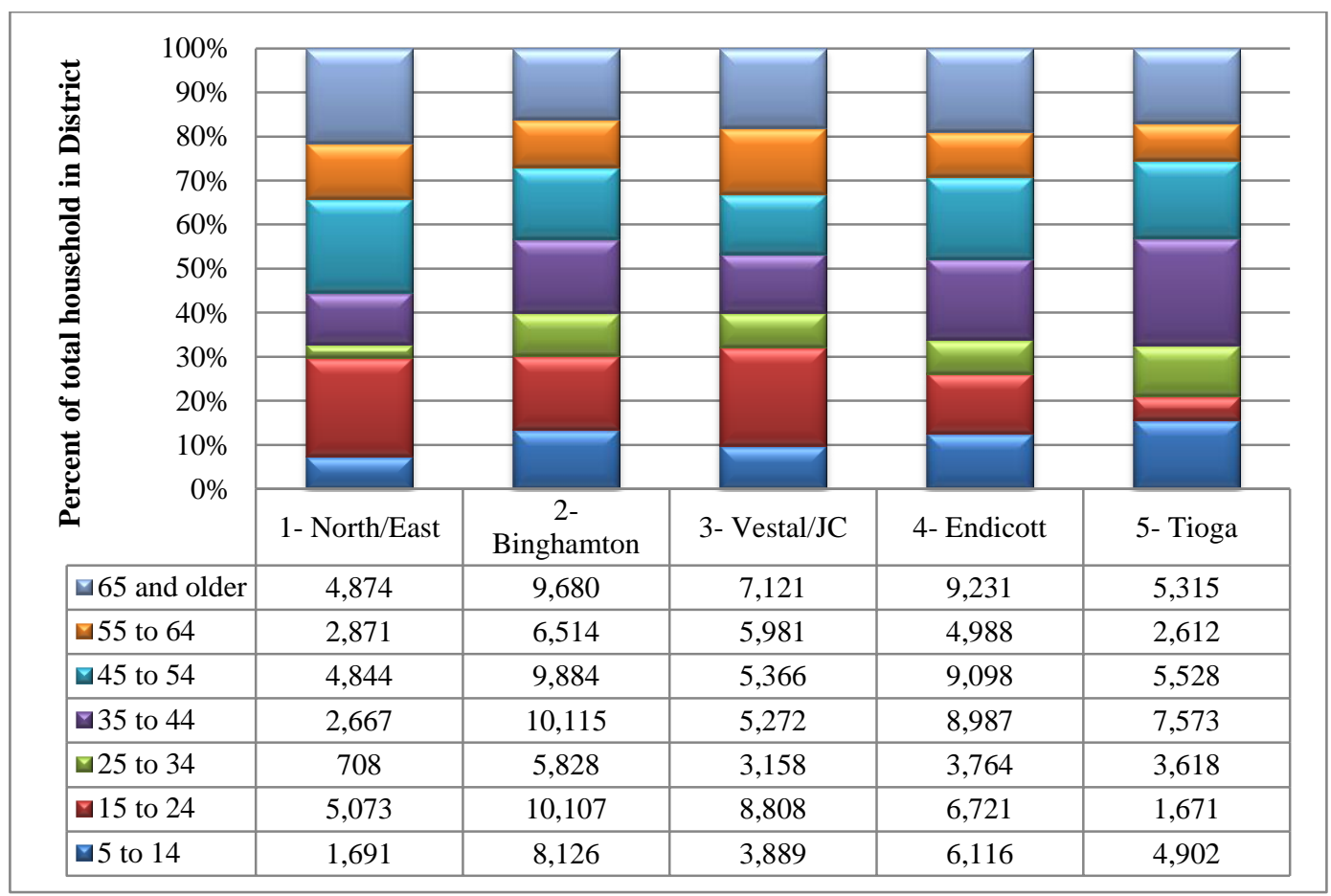

Figure 5-4. Distribution of households by age for the BMTS districts.

\subsubsection{Vehicle Ownership}

As a whole, about $11 \%$ of BMTS households did not own any vehicles (see Figure 5-5). Unfortunately, the smaller sample sizes of zero-vehicle households in the North/East district, and in a slightly lesser degree for Endicott and Tioga, made the estimation of zero-vehicle shares rather unreliable at the district level. Still, the North/East district did show a much lower share of less than two-vehicle (i.e., either zero or one) households than all other BMTS districts. Among the five BMTS districts, district 2 (i.e., Binghamton) had the largest proportion of households with less than two vehicles. Overall however, all BMTS districts had an $80 \%$ or higher portion of their households who own two or fewer vehicles, a much "flatter" pattern than that seen in the SMTC region. 


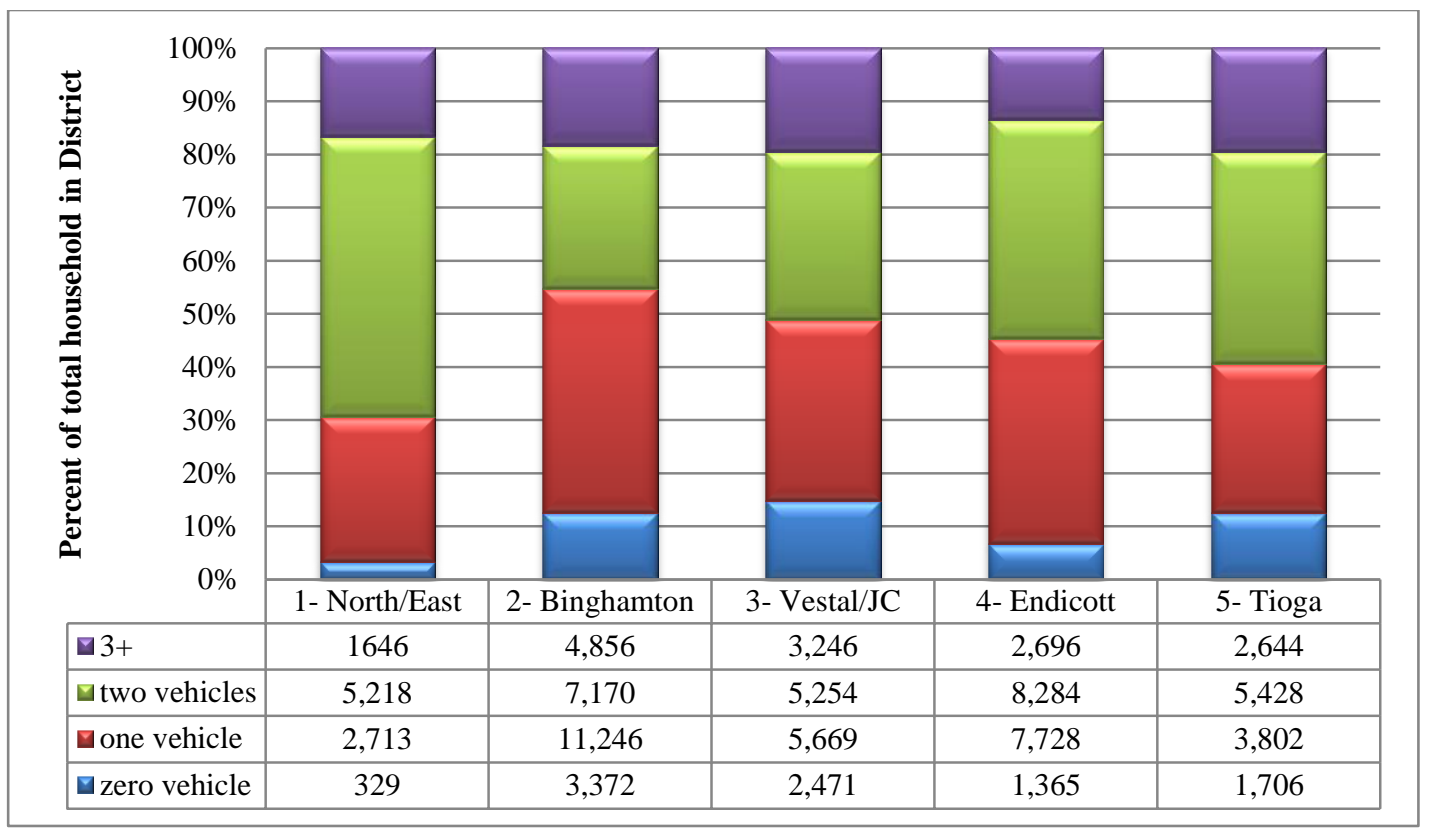

Figure 5-5. Distribution of household vehicle ownership by BMTS districts.

\subsubsection{Drivers and Workers}

No significant variations in drivers and workers, by gender, among BMTS districts was identified, although a slightly higher number of female drivers in Binghamton (district 2), and a higher share of male workers in North/East and Vestal/JC (Table 5-1), were observed.

Table 5-1. BMTS Driver and Worker Populations by Gender and by District.

\begin{tabular}{|c|c|r|r|r|r|r|}
\hline \multirow{2}{*}{ Population group } & \multicolumn{5}{|c|}{ BMTS District } \\
\cline { 2 - 7 } Driver & Male & 10,178 & 20,892 & 14,857 & 19,518 & \multicolumn{1}{c|}{ Tioga } \\
\cline { 2 - 7 } & Female & 9,794 & 24,241 & 15,998 & 19,356 \\
\cline { 2 - 7 } & Total driver & $\mathbf{1 9 , 9 7 2}$ & $\mathbf{4 5 , 1 3 3}$ & $\mathbf{3 0 , 8 5 5}$ & $\mathbf{3 8 , 8 6 7}$ & 12,075 \\
\hline \multirow{3}{*}{ Worker } & Male & 7,813 & 15,670 & 11,401 & 13,989 & 7,431 \\
\cline { 2 - 7 } & Female & 6,046 & 17,542 & 9,580 & 14,146 & 7,639 \\
\cline { 2 - 7 } & Total worker & $\mathbf{1 3 , 8 5 9}$ & $\mathbf{3 3 , 2 1 2}$ & $\mathbf{2 0 , 9 8 1}$ & $\mathbf{2 8 , 1 3 5}$ & $\mathbf{1 5 , 1 7 2}$ \\
\hline
\end{tabular}

Using information provided in Table 5-1, a worker-to-driver ratio in each of the BMTS districts was computed and presented in Table 5-2. Again, a more uniform pattern among BMTS districts were observed (when compared to Table 4-1); with overall worker-to-driver ratios rounded to about 0.7 for all five BMTS districts, verses a wider spread from 0.4 to 0.8 for the eight SMTC districts. In most BMTS districts, a male driver had a higher ratio of being a worker than his female counterpart. This is consistent with what was observed in the SMTC district in Table 4-1. 
Table 5-2. Worker per Driver Ratio by BMTS Districts.

\begin{tabular}{|l|c|c|c|c|c|}
\hline Gender & North/East & Binghamton & Vestal/JC & Endicott & Tioga \\
\hline Male & 0.77 & 0.75 & 0.77 & 0.72 & 0.66 \\
\hline Female & 0.62 & 0.72 & 0.60 & 0.73 & 0.63 \\
\hline All & 0.69 & 0.74 & 0.68 & 0.72 & 0.65 \\
\hline
\end{tabular}

\subsection{REGIONAL TRAVEL BEHAVIORS}

\subsubsection{How Much Travel Activity Is in The BMTS?}

Because most daily trips occurred with a corresponding reverse-order return trip, counting the total number of person trips based on their origin or destination districts was likely to result in similar volume counts (see Table 5-3). Note that trips not captured in Table 5-3 were trips made by BMTS residents that fall entirely outside its five BMTS districts. Based on information presented in Table 5-3, a total of approximately 312 million person trips had at least one end (either origin or destination) located in the five-district BMTS region (i.e., with rounded numbers from the table below, 280+284-252=312).

Table 5-3. Trip Volumes by BMTS District (in number of person-trips)

\begin{tabular}{|c|c|c|c|}
\hline District & $\begin{array}{c}\text { Number of trips } \\
\text { originated from } \\
\text { district }\end{array}$ & $\begin{array}{c}\text { Number of trips } \\
\text { terminated in district }\end{array}$ & $\begin{array}{c}\text { Number of trips began } \\
\text { and ended in BMTS } \\
\text { districts }\end{array}$ \\
\hline North/East & $29,443,338$ & $29,336,848$ & $24,197,876$ \\
\hline Binghamton & $89,838,532$ & $92,387,946$ & $80,360,917$ \\
\hline Vestal/JC & $64,233,011$ & $65,317,915$ & $59,011,330$ \\
\hline Endicott & $65,970,508$ & $66,383,983$ & $62,363,871$ \\
\hline Tioga & $30,372,573$ & $30,110,445$ & $26,278,070$ \\
\hline ALL & $\mathbf{2 7 9 , 8 5 7 , 9 6 2}$ & $\mathbf{2 8 3 , 5 3 7 , 1 3 7}$ & $\mathbf{2 5 2 , 2 1 2 , 0 6 4}$ \\
\hline
\end{tabular}

Based on household locations, the total number of PT and VT made by residents of the five BMTS districts are shown in Figure 5-6. Residents of the Binghamton district made the highest total number of PT, as well as VT (Figure 5-6). On the other hand, households in the more rural North/East district made a lower number of trips in total. Recall only $11 \%$ of the total households in BMTS live in the North/East district while about $31 \%$ were in the Binghamton district (Figure 5-1).

Note that trips made by residents of a given district do not always originate or terminate in the district he/she resides in. For example, a resident of the Vestal/JC district, working in Binghamton, could take a shopping trip during a lunch break that falls entirely outside the Vestal/JC region. Thus, trip counts shown in the chart in Figure 5-6 are clearly different from those summarized in Table 5.3, which was based on trip origin/destination locations. In this study, especially when travel flows were considered, trip statistics are generally categorized by district where the trip origin/destination is located. 


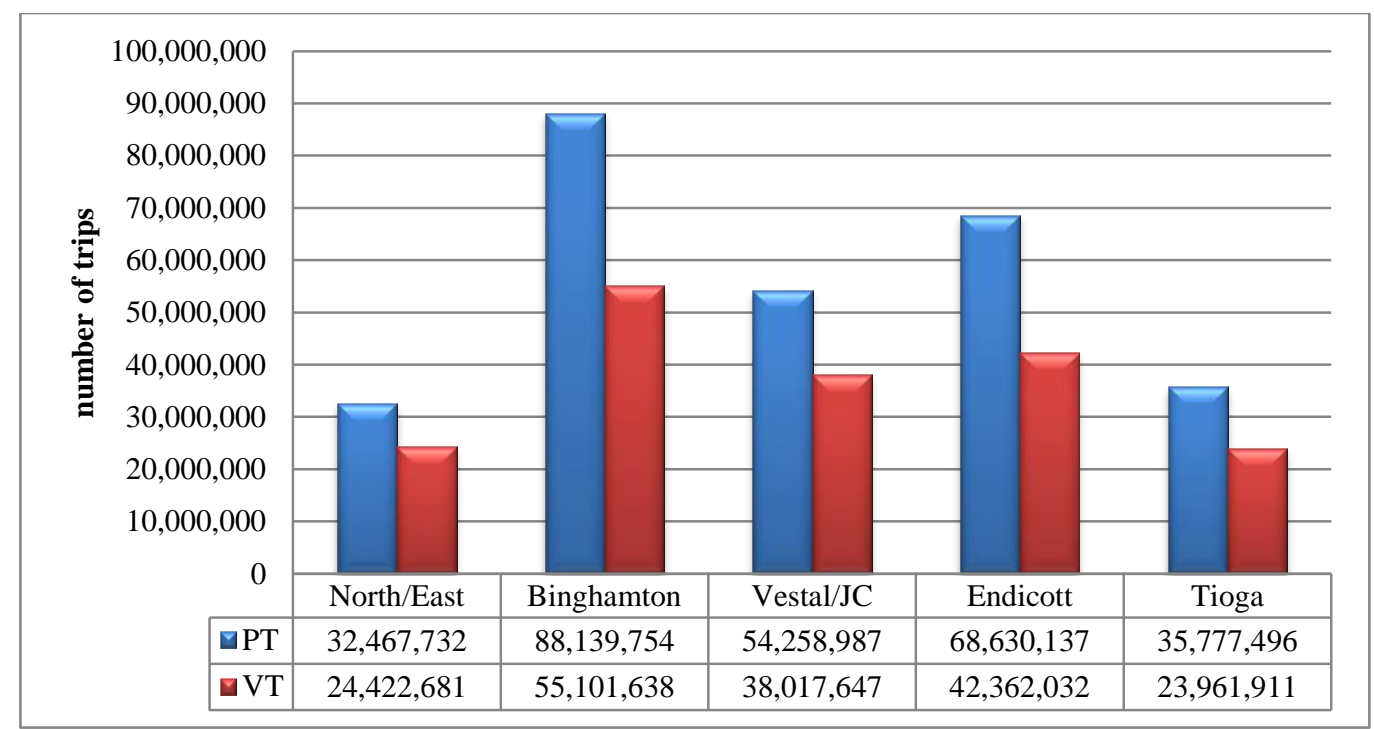

Figure 5-6. Total number of person-trips and vehicle-trips by household location.

\subsubsection{How Frequently Do BMTS Households Travel? - Measure of per Household Averages}

As shown in Figure 5-7, PT per household measured by household-district was generally consistent among BMTS districts, around 9 trips on average. The only exception was in the Tioga district (averaged about 7 PT per household). Recall that VT only consists of trips made in POV, thus the average VT per household counts are expected to be smaller than those PT measures. Based on Figure 5-7, the North/East district had a slightly higher average with nearly 7 VT per household; compared to about 6 in the three "major city" districts (i.e., Binghamton, Vestal/JC, and Endicott). As for the PT per-household, district 5 (Tioga) had the lowest average for VT, about 5 trips per household. Nevertheless, BMTS districts were more homogeneous than SMTC districts in terms of average number of trips made on a household basis.

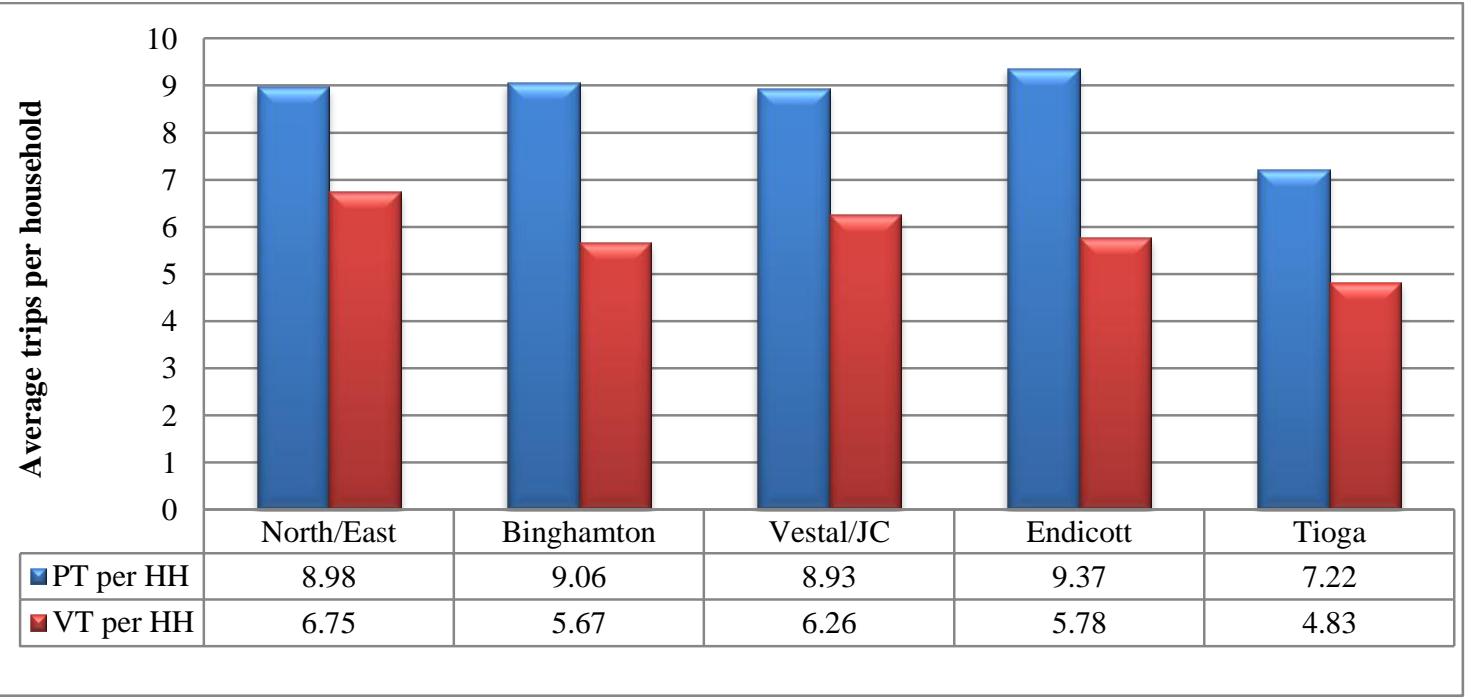

Figure 5-7. Average person-trip (PT) and vehicle-trip (VT) per household by BMTS household-district. 
Associated per-household averages on PMT and VMT for the BMTS districts are presented in Figure 5-8. Residents of the North/East district appeared to have a significantly higher PMT per household measure than those in other BMTS districts; an average of nearly 89 person-miles-traveled per household compared to less than 71 person-miles-traveled per household in all other BMTS districts. Similar comparisons also held on VMT per household: about 72 VMT on average per the North/East district household verses 50 or less VMT for typical households in other districts of the BMTS. Basically, this North/East district was "created" to represent the remaining BMTS region outside the 4 city-named districts; which includes two geographically disconnected areas. A longer distance to drive on average for households in this mostly rural region might be an explanation.

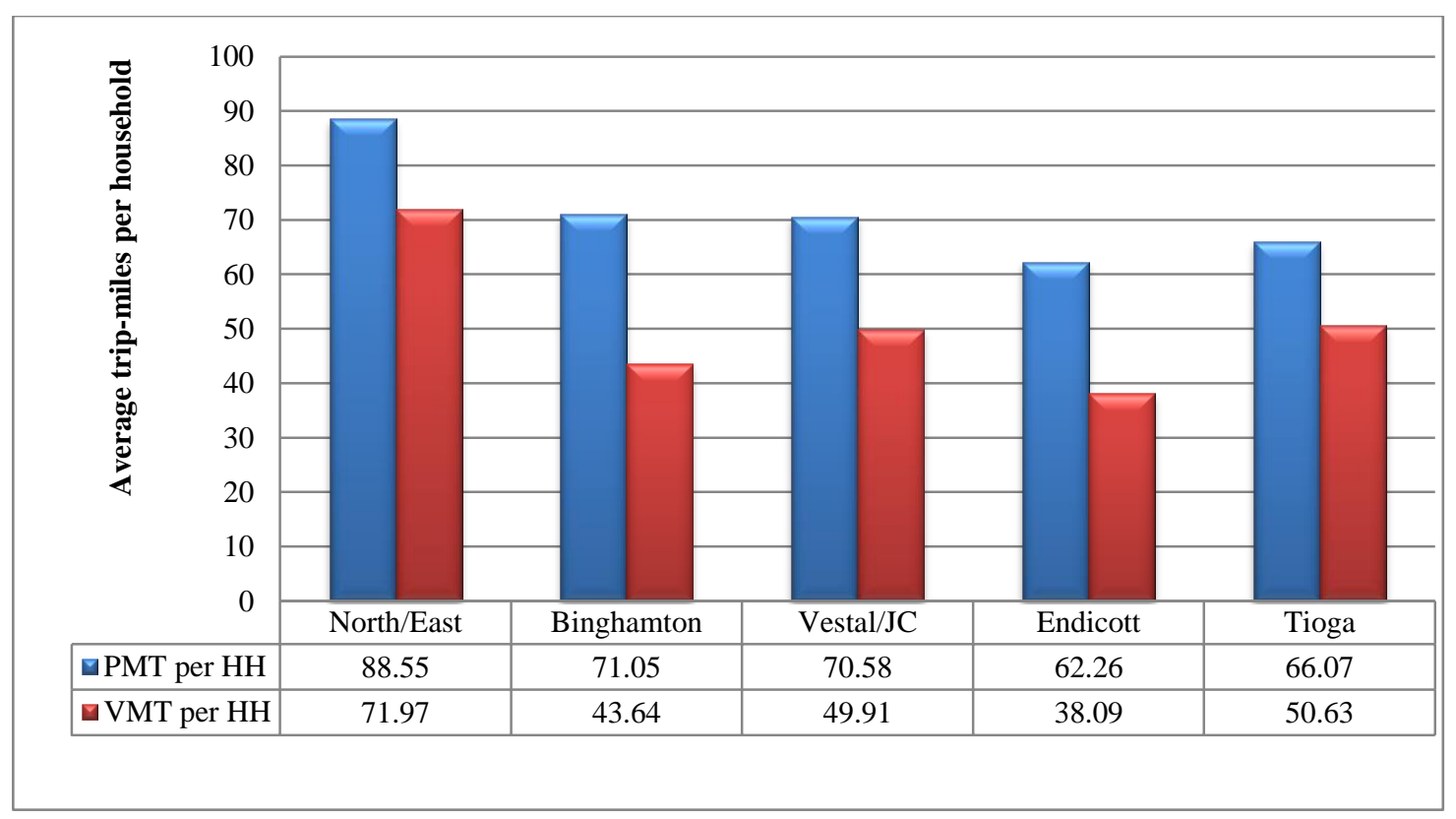

Figure 5-8. Average PMT and VMT per household by BMTS household-district.

\subsubsection{Average by Household Size}

Figure 5-9 indicates that districts were generally consistent with PT averages by household size; generally showing that the larger a household size was the higher the average number of PT. This general pattern was similar to the average number of VT (presented in Figure 5-10); although the Tioga district appeared to be a little different on the largest household-size group in both figures. 


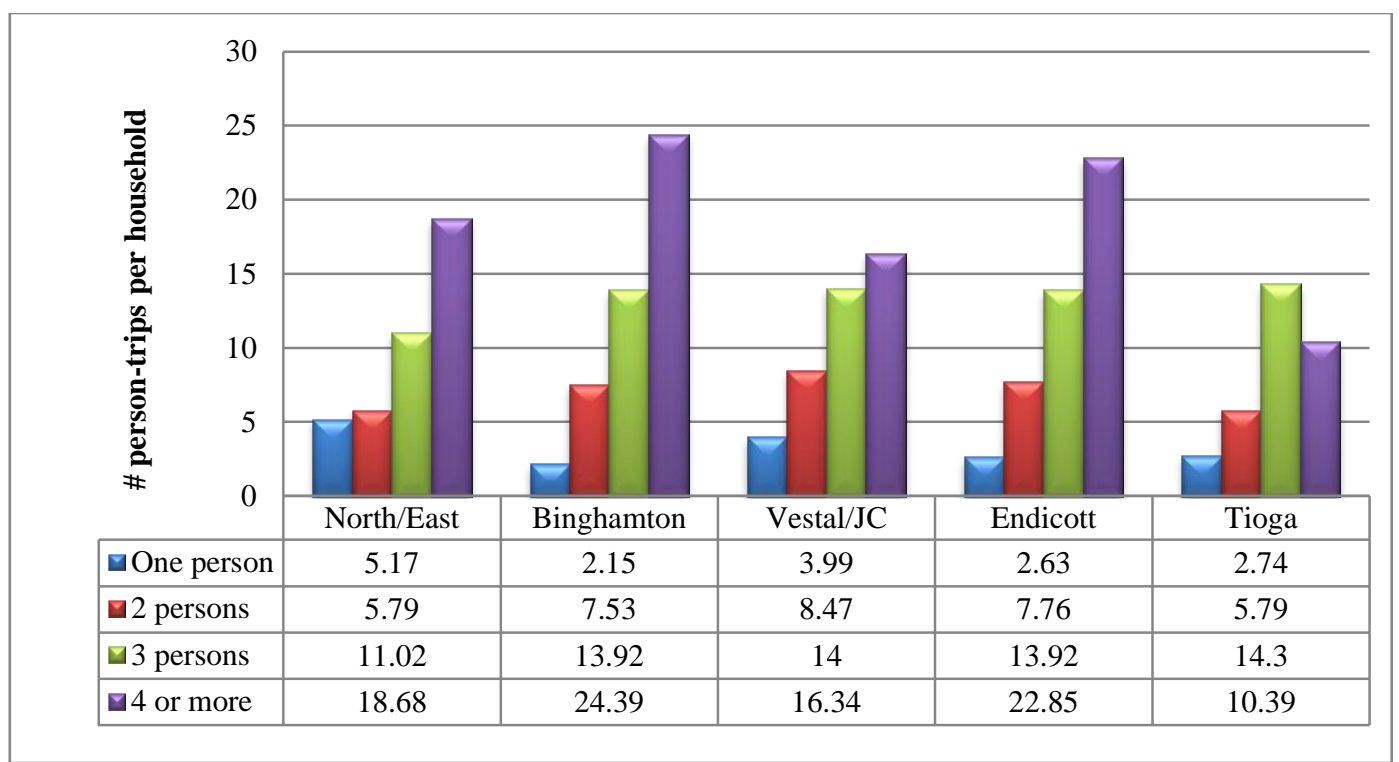

Figure 5-9. Average per-household PT by household size by BMTS household-districts.

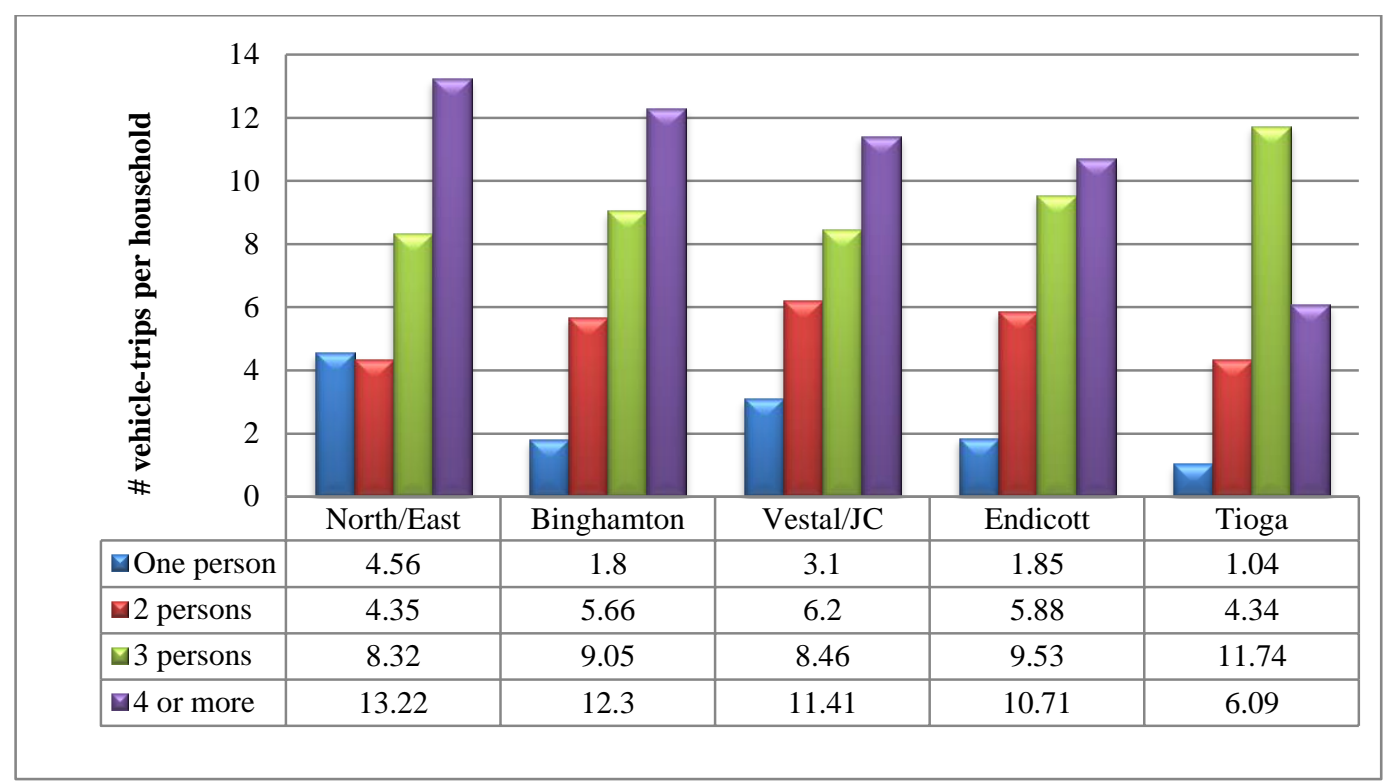

Figure 5-10. Average per-household VT by household size for BMTS household-districts.

\subsubsection{Vehicle Ownership}

Not surprisingly, households with zero vehicles traveled the least and the average PT per household generally increased as more vehicles were available to the household (see Figure 5-11). As observed in Figure 5-5, the majority of households within the BMTS districts own one or two vehicles; thus likely having sufficient data to obtain more reliable estimates (averages in this case). Note that estimates based on small samples are subject to a higher degree of variation (or standard error), making it difficult to determine their reliability. One should exercise caution when using estimates based on small samples. In this case, estimates based on NHTS data for the zero-vehicle household groups are certainly subject to this concern. 


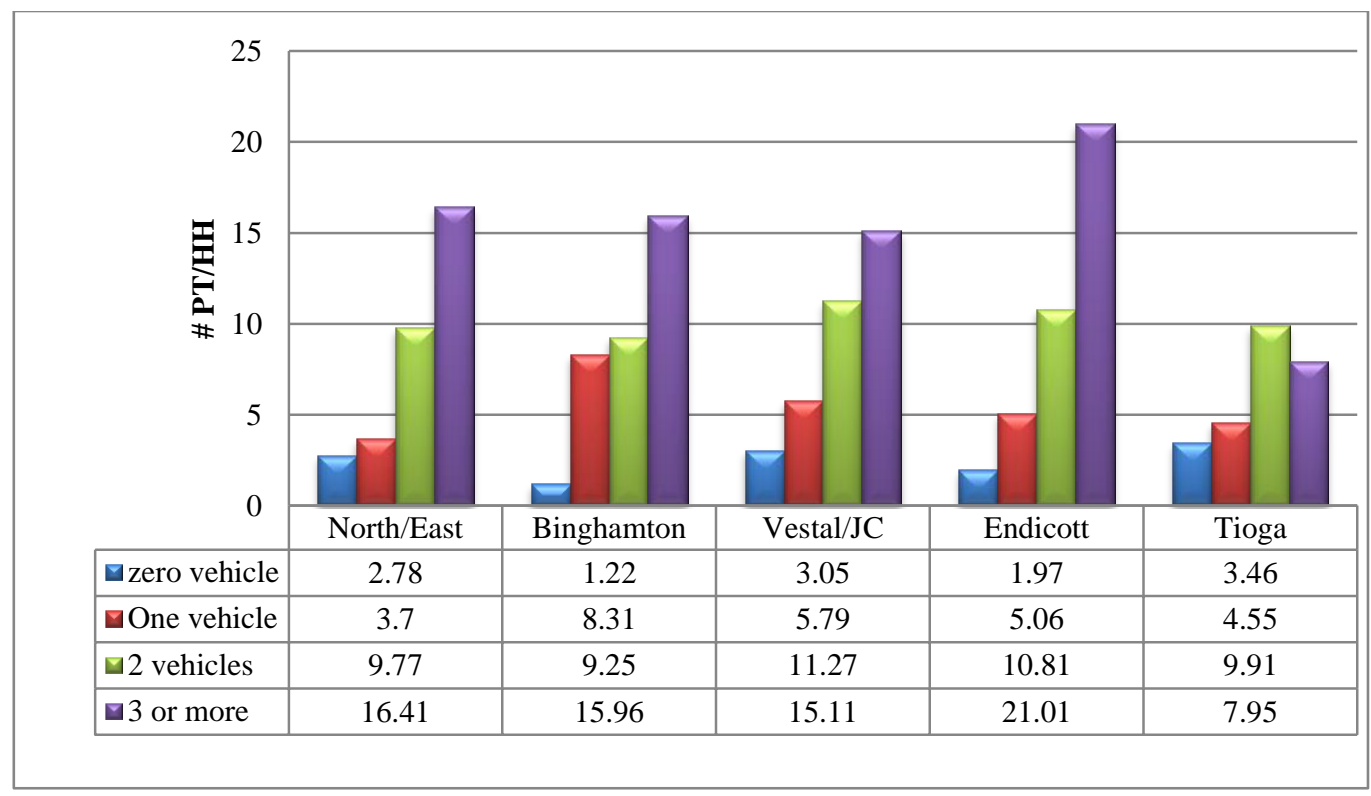

Figure 5-11. Average number of person-trips per BMTS household by vehicle ownership.

The average number of VT per household by BMTS district is presented in Figure 5-12. Again, in most cases, the average number of trips grew higher as the number of vehicles owned increased. Similar to the household-size numbers, the Tioga district showed a much lower per-household trip counts (both PT and VT) in the "highest" category (i.e., 3 or more vehicles) than all other BMTS districts. The consistency among BMTS districts was clearly visible in Figure 5-12, with the only exception in the " 3 or more" group for the Tioga district.

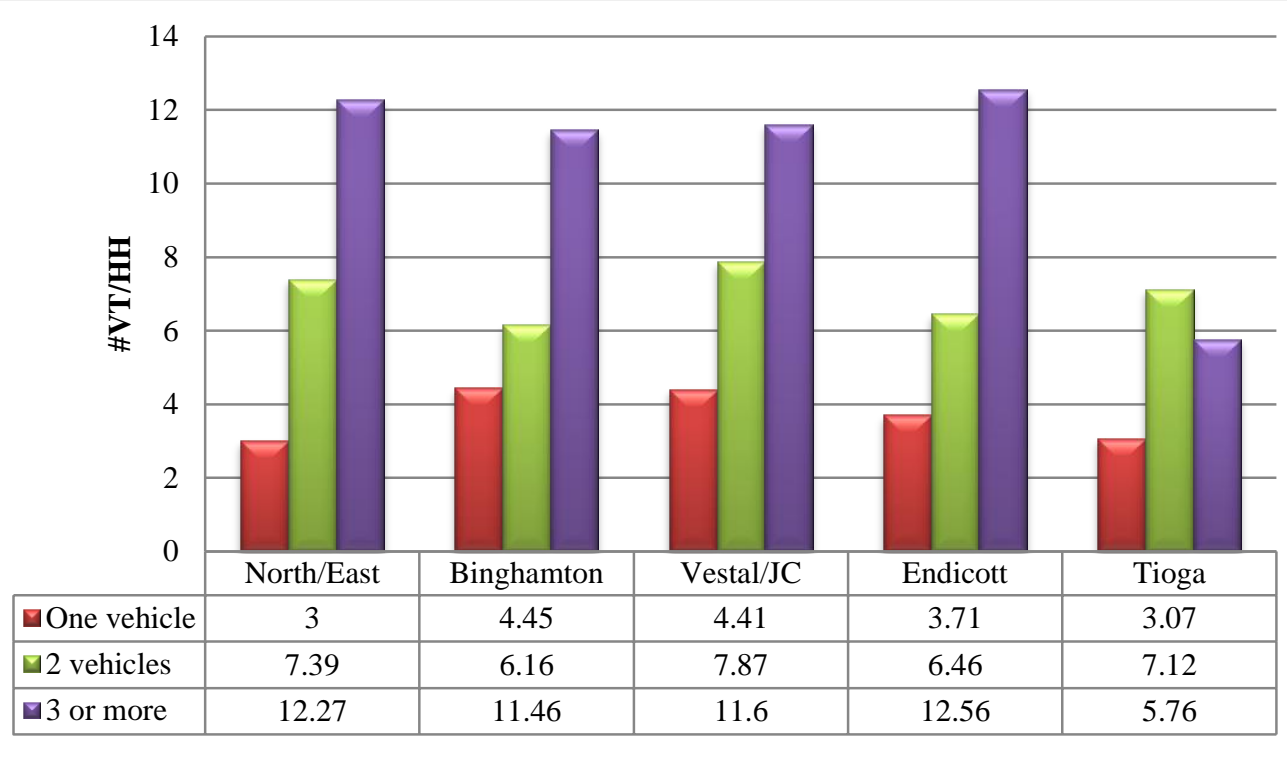

Figure 5-12. Average number of vehicle-trips per BMTS household by vehicle ownership. 


\subsubsection{Why Do BMTS Residents Travel? - A Look at Trip Purposes}

Overall, most of the PT made by residents of BMTS districts were for the purposes of: family/personal business, social/recreational, and earning a living (i.e., commute). As shown in Figure 513, travel made for these three purposes accounted for nearly all person-trips. The patterns for VT were very similar, since most trips were made in POVs. The patterns of trip purposes by trip origins (or destinations) are expected to be similar to what was observed in Figure 5-13. However, it was anticipated that trip purposes could differ during different periods of time within a day, as well as during weekends. These subjects are further examined and discussed separately in the latter part of this section.

\begin{tabular}{|c|c|c|c|c|c|}
\hline \multirow{10}{*}{$\begin{array}{l}70 \% \\
60 \% \\
50 \% \\
40 \% \\
30 \% \\
20 \% \\
10 \%\end{array}$} & & & & & \\
\hline & & & & & \\
\hline & & & & & \\
\hline & & & & & \\
\hline & & & & & \\
\hline & & & & & \\
\hline & & & & & \\
\hline & & & & & \\
\hline & & & & & \\
\hline & North/East & Binghamton & Vestal/JC & Endicott & Tioga \\
\hline QUnreported & 398,029 & 699,315 & 191,156 & 330,219 & 112,428 \\
\hline 甲Other & 161,390 & $1,278,632$ & 163,799 & 79,269 & 57,465 \\
\hline 口Social and Recreational & $8,345,576$ & $23,472,547$ & $16,113,520$ & $16,431,777$ & $9,076,819$ \\
\hline$\square$ School/ Church & $2,471,418$ & $6,690,584$ & $5,751,709$ & $7,775,815$ & $2,759,672$ \\
\hline 口Family \& Personal Business & $12,987,162$ & $43,716,627$ & $21,516,217$ & $30,040,936$ & $15,434,250$ \\
\hline 口Earning a Living & $8,104,157$ & $12,282,050$ & $10,522,587$ & $13,972,121$ & $8,336,862$ \\
\hline
\end{tabular}

Figure 5-13. Total number of person trips by trip purpose by household district.

In addition to examining the total number of trips, average per-household measures were also generated by trip purpose to allow comparisons between the five BMTS districts. As shown in Table 5-4, households in the Tioga district, with an average count of 7 PT per household, traveled less than households in all other BMTS districts, about 9 trips per household. Clearly, family/personal business and social/recreational purposes were the two most frequently cited reasons for making trips by residents in BMTS districts. This is consistent with the findings from Figure 5-13. 
Table 5-4. Average Person-Trips per Household by Trip Purpose by Household-District

\begin{tabular}{|l|c|c|c|c|c|c|c|}
\hline \multicolumn{1}{|c|}{$\begin{array}{c}\text { BMTS } \\
\text { District }\end{array}$} & $\begin{array}{c}\text { Earning } \\
\text { a Living }\end{array}$ & $\begin{array}{c}\text { Family \& } \\
\text { Personal } \\
\text { Business }\end{array}$ & $\begin{array}{c}\text { School/ } \\
\text { Church }\end{array}$ & $\begin{array}{c}\text { Social and } \\
\text { Recreational }\end{array}$ & Other & Unreported & Total \\
\hline North/East & 2.24 & 3.59 & 0.68 & 2.31 & 0.04 & 0.11 & 8.98 \\
\hline Binghamton & 1.26 & 4.5 & 0.69 & 2.41 & 0.13 & 0.07 & 9.06 \\
\hline Vestal/JC & 1.73 & 3.54 & 0.95 & 2.65 & 0.03 & 0.03 & 8.93 \\
\hline Endicott & 1.91 & 4.1 & 1.06 & 2.24 & 0.01 & 0.05 & 9.37 \\
\hline Tioga & 1.68 & 3.11 & 0.56 & 1.83 & 0.01 & 0.02 & 7.22 \\
\hline
\end{tabular}

This consistency is also observed from Figure 5-14, where the average numbers of VT per household, in BMTS districts, are shown. Again, since POV is the primary mode used for daily travel, the pattern in PT and VT were generally similar. Further discussion on mode choice is presented in next subsection.

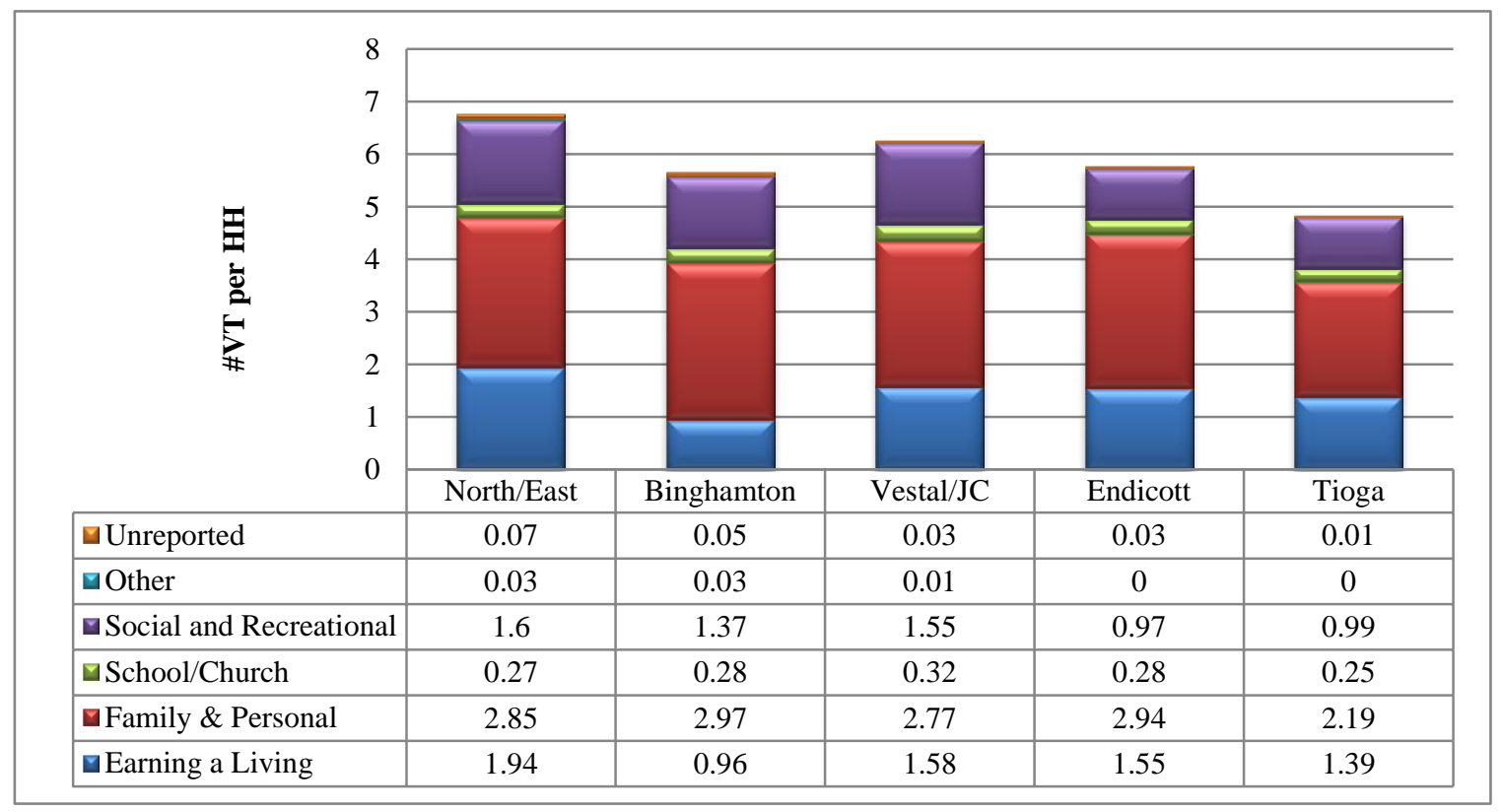

Figure 5-14. Average vehicle-trips per household by trip purpose in BMTS districts.

\subsubsection{Mode Choices for BMTS Residents}

Table 5-5 provides a summary of total PT by mode and by trip-origin district. Note that the "All" listed at the bottom row of Table 5-5 includes all trips made by residents of the BMTS region; i.e., it contains trips that departed from locations outside the five districts of BMTS. Of the nearly 342 million trips captured by the 2009 NHTS data, about 306 millions (90\%) trips were made in a POV. About $7 \%$ of total trips made by BMTS residents were walk/bike trips; while public transit accounted for less than $1 \%$. As mentioned before, "other" mode includes taxi/cab, ferry, airplane, etc. 
Table 5-5. Person Trips by Mode Based on Origin District of Trips Made by BMTS Residents

\begin{tabular}{|c|c|c|c|c|c|}
\hline Origin & POV & $\begin{array}{c}\text { Public } \\
\text { Transit }\end{array}$ & Walk/Bike & Other & All Modes \\
\hline North/East & $26,416,494$ & . & $1,459,675$ & $1,567,168$ & $29,443,337$ \\
\hline Binghamton & $82,821,505$ & 601,292 & $5,321,254$ & $1,094,482$ & $89,838,533$ \\
\hline Vestal/JC & $57,037,137$ & 689,747 & $4,034,737$ & $2,471,389$ & $64,233,010$ \\
\hline Endicott & $57,603,117$ & 203,443 & $6,668,374$ & $1,495,573$ & $65,970,507$ \\
\hline Tioga & $23,800,909$ & 86,082 & $4,466,008$ & $2,019,574$ & $30,372,573$ \\
\hline $\mathbf{A l l}^{a}$ & $305,679,190$ & $1,681,351$ & $23,289,678$ & $11,020,734$ & $341,670,953$ \\
\hline
\end{tabular}

Note: “.” Indicates no samples in the category.

${ }^{a}$ Including trips with origins outside the 5 districts

Based on information from Table 5-5, mode share statistics by trip-origin district are displayed geographically in Figure 5-15. Clearly, POV was the most commonly used mode of transportation regardless of where trips originated from, and accounted for about $90 \%$ share in all districts but the Tioga region (which has less than $80 \%$ share of POV). As can be seen in Figure 5-15, trips originating from the four city-named districts were more likely to use walking/biking than the more rural North/East district. Specifically, the highest walk/bike mode share based on trip-origin was in the Tioga district (nearly 15\%), followed by the Endicott district at 10\%, then the Binghamton and Vestal/JC districts, both with about $6 \%$ of walk/bike share. Walk/bike share for the North/East district was about $5 \%$.

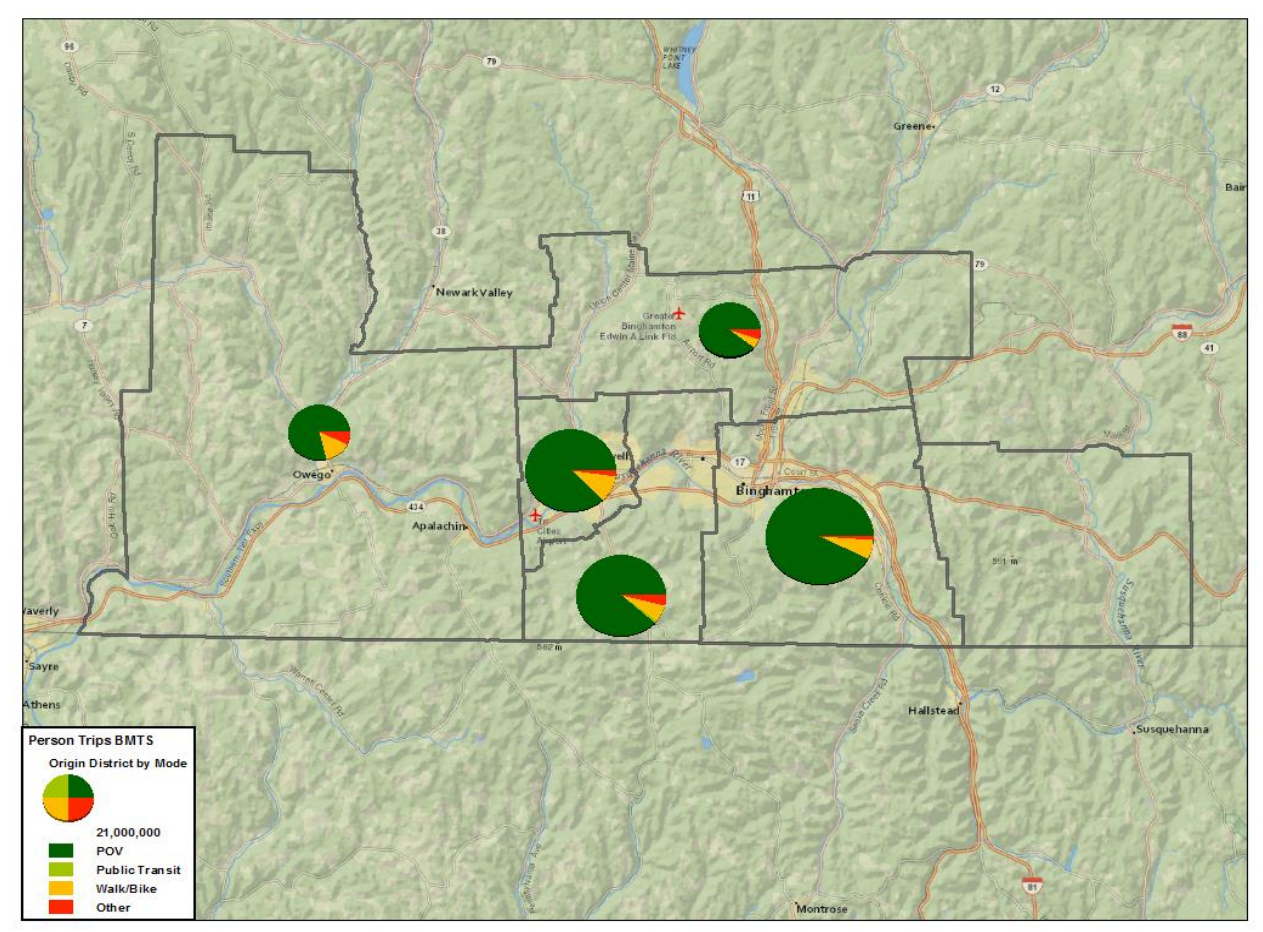

Figure 5-15. Mode share by trip-origin district in BMTS (based on person-trips).

Little difference was seen when examining mode shares by trip-destination districts, i.e., considering trip end locations. As previously mentioned, most daily travels were symmetrical-especially for POV trips. Thus the overall mode shares based on all trips made by residents of the region did not significantly 
change when categorizing the trips by destination districts; staying roughly the same for mode shares. Only small variations among trip-destination districts can be seen in Table 5-6, when compared with Table 5-5.

Table 5-6. Person trips by mode by destination district of trips made by BMTS residents.

\begin{tabular}{|l|r|r|r|r|r|}
\hline \multicolumn{1}{|c|}{ Origin } & POV & $\begin{array}{c}\text { Public } \\
\text { Transit }\end{array}$ & Walk/Bike & \multicolumn{1}{c|}{ Other } & \multicolumn{1}{c|}{ All Modes } \\
\hline North/East & $26,778,910$ &. & $1,445,133$ & $1,112,804$ & $29,336,847$ \\
\hline Binghamton & $84,693,703$ & 726,404 & $5,316,974$ & $1,650,865$ & $92,387,946$ \\
\hline Vestal/JC & $58,366,969$ & 488,659 & $3,932,386$ & $2,529,902$ & $65,317,916$ \\
\hline Endicott & $57,602,755$ & 203,443 & $6,792,622$ & $1,785,163$ & $66,383,983$ \\
\hline Tioga & $23,533,455$ & 86,082 & $4,466,008$ & $2,024,900$ & $30,110,445$ \\
\hline All $^{a}$ & $305,679,191$ & $1,681,352$ & $23,289,678$ & $11,021,732$ & $341,671,953$ \\
\hline
\end{tabular}

Note: "." Indicates no samples in the category.

${ }^{a}$ Including trips with origins outside the 5 districts

Further investigation on intra-district trips (trips that begin and end within the same district) revealed significant changes in mode share patterns for several BMTS districts. Clearly visible from Figure 5-16 is the increased share of walking/biking trips in all city-named districts (i.e., other than the North/East district). Since most walk/bike trips are for activities within close proximity of a location, it is reasonable to expect walk/bike as a more commonly utilized mode for intra-district travel.

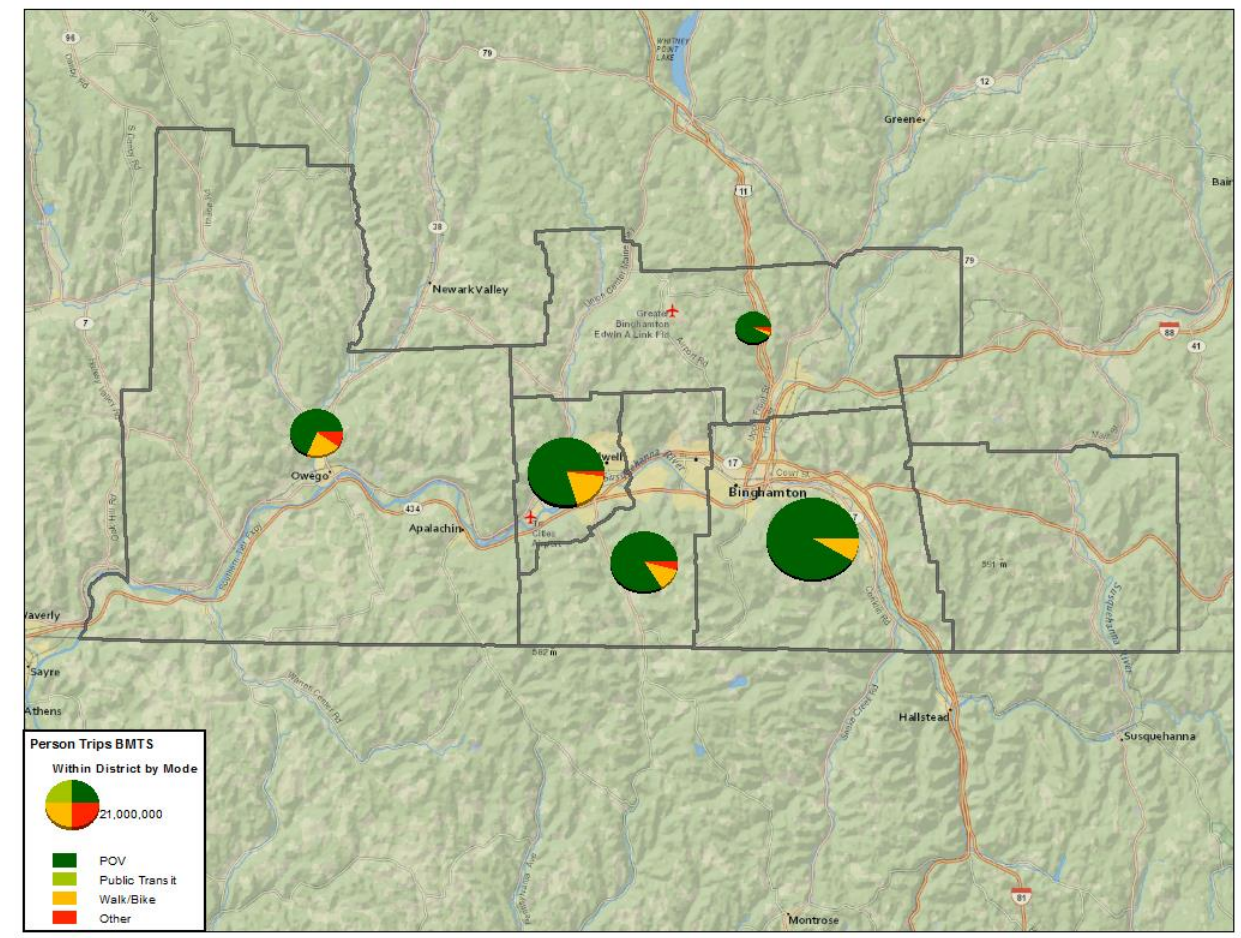

Figure 5-16. Mode shares for within district person-trips in BMTS. 


\subsubsection{Travel Start Times in BMTS Districts}

As examined in the SMTC districts, geographic differences in BMTS regional travel patterns were also examined. Trips made by BMTS residents (measured by PT) were categorized into within (trips staying entirely within a given district), outbound (trips starting from a given district and terminated in all other districts), and inbound (trips starting from other districts and terminated in the given district) categories. The same time periods as used in Section 4 were also applied when examining weekday/weekend and time of day differences in BMTS travel patterns. Recall these time periods are defined as:

- AM peak: from 6:00 to 9:00 in the morning,

- Midday peak: from 11:00 a.m. to 2:00 p.m., and

- PM peak: from 4:00 to 7:00 in the afternoon.

\subsubsection{AM Peak Travel}

As in the SMTC region, trips made by BMTS households during the AM peak on weekdays were mostly for commuting (i.e., earning a living), family/personal business (e.g., doctor appointment), and attending school, in descending order. This was clearly evident in the NHTS data (see top chart in Figure 5-17); nearly 90\% of trips made by BMTS residents during the period from 6:00 to 9:00 a.m. on weekdays were for these three purposes. On the contrary, as shown in the bottom chart of Figure 5-17, the same three purposes accounted for about $67 \%$ of total weekend AM-peak-hour trips, and only $15 \%$ of trips made by BMTS households during this time period on weekends were for the reason of earning a living (i.e., work trips). In fact, 30\% of trips made during 6:00-9:00 a.m. on weekends were for social and recreational purposes (e.g., shopping); while only $10 \%$ travel for the same reason on weekday mornings.

Considering the geospatial relationship of travel between BMTS districts, Figure 5-18 presents travel patterns during the weekday AM peak period by BMTS district, measured in PT. Again, the size of the pies reflects the total volume of PT in each district and the color of slides represents different trip categories: yellow for intra-region travel (within), green for outbound trips, and red is for inbound travel.

No major downtown activities for the City of Syracuse districts was observed in the BMTS districts during the weekday morning peak hours; although Binghamton and Vestal/JC districts clearly showed significant portions of "inbound" trips. Figure 5-18 indicates that BMTS regions also contain significant shares of "within trips" (intra district trips, shown in yellow) especially in the Tioga, Binghamton, and Endicott districts. 

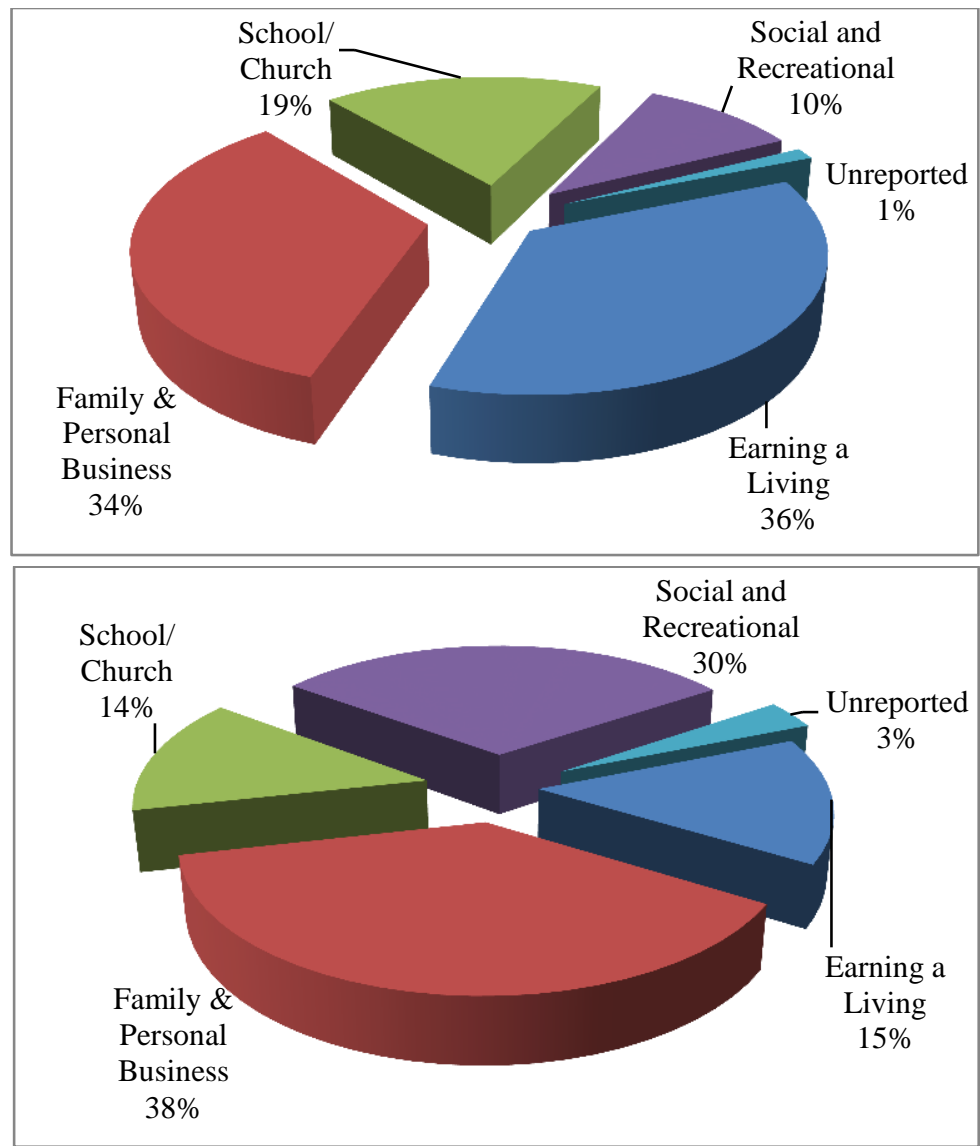

Figure 5-17. Person trips made by BMTS households during AM peak hours by trip purpose (Top: weekday; bottom: weekend). 


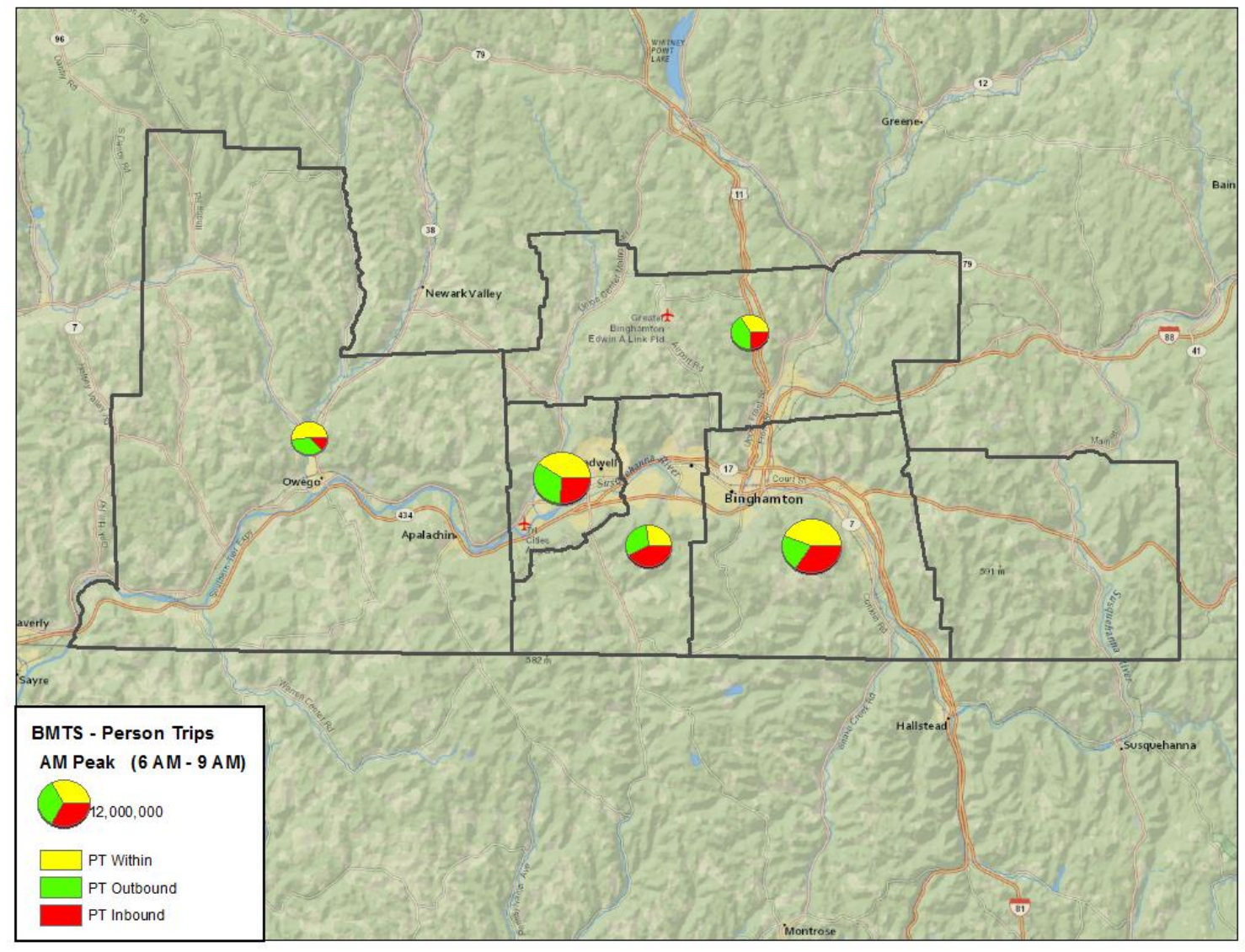

Figure 5-18. Travel patterns during weekday AM peak hours (6:00-9:00 am) in BMTS districts.

Specifically, when considering weekday AM-peak hour travel made solely within a BMTS district (i.e., intra-district trips), over $40 \%$ of those trips were conducted for the purpose of family/personal business (e.g., bank, doctor, etc.), while $29 \%$ for earning a living (commute trips) and $18 \%$ for school/church activities (see top chart in Figure 5-19). On the other hand, as shown in the bottom chart of Figure 5-19, nearly half of the inter-district trips made during the weekday AM peak hours were for commuting; followed by $26 \%$ for family/personal business and $19 \%$ for school/church activities. 


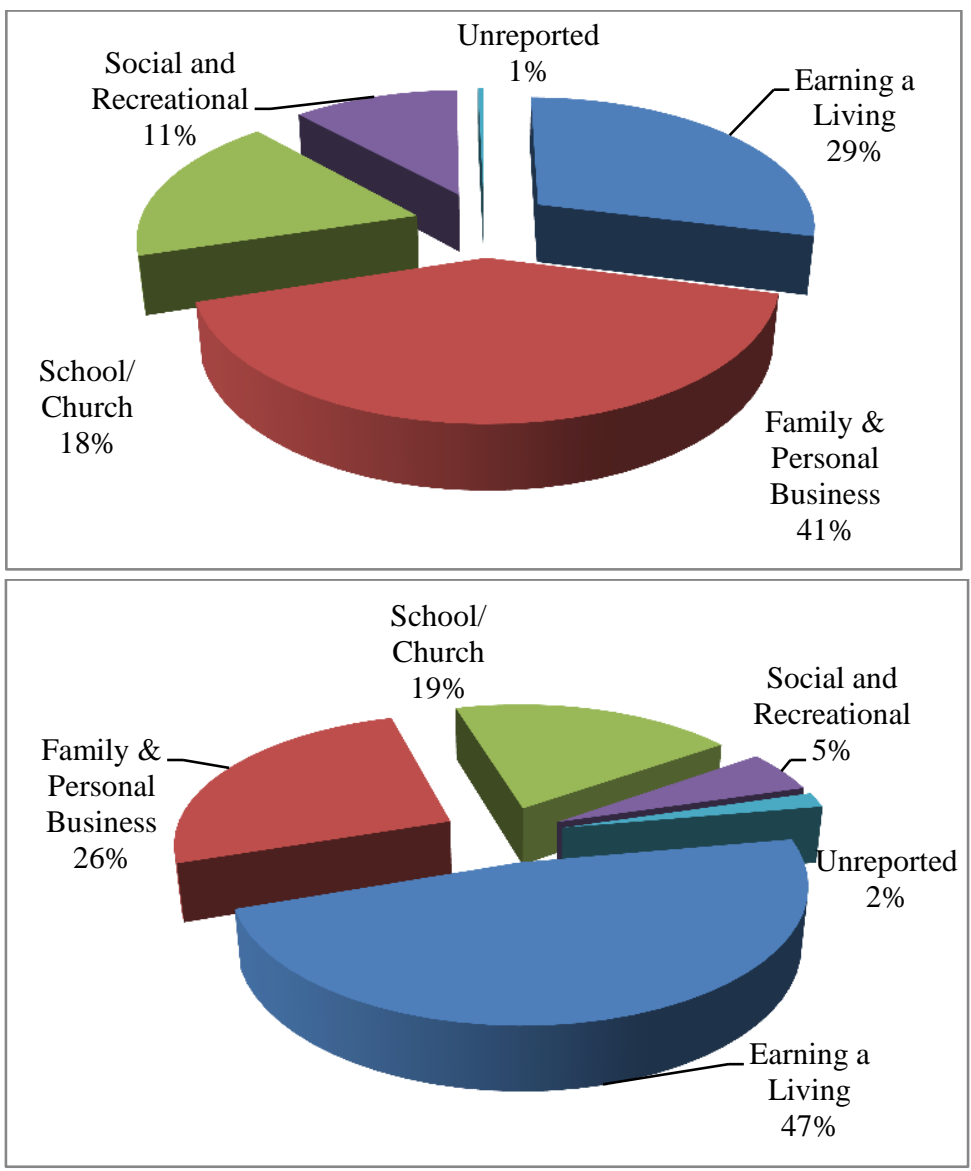

Figure 5-19. Travel purpose for trips made during weekday AM peak hours (6:00-9:00) in BMTS (top chart for intra-district trips; bottom chart for inter-district trips).

A review of morning travel activities in BMTS on weekends for both intra- and inter-district trips revealed a rather different pattern as that shown in the bottom chart of Figure 5-17. While the majority of weekend AM-peak hour inter-district trips were made for the purpose of family/personal business, accounting for $46 \%$ of weekend morning inter-district trips, family/personal trips () only accounted for $29 \%$ of weekend morning intra-district travel (see Figure 5-20). In fact, intra-district weekend morning trips were mostly (46\%) made for social/recreational purposes. Another visible difference appears to be on "earning a living" trips, which accounted for $20 \%$ of inter-district trips and only $9 \%$ for intra-district travel during weekend morning hours from 6:00 to 9:00. This is different from those presented for the SMTC region as discussed in Section 4 of this report. 

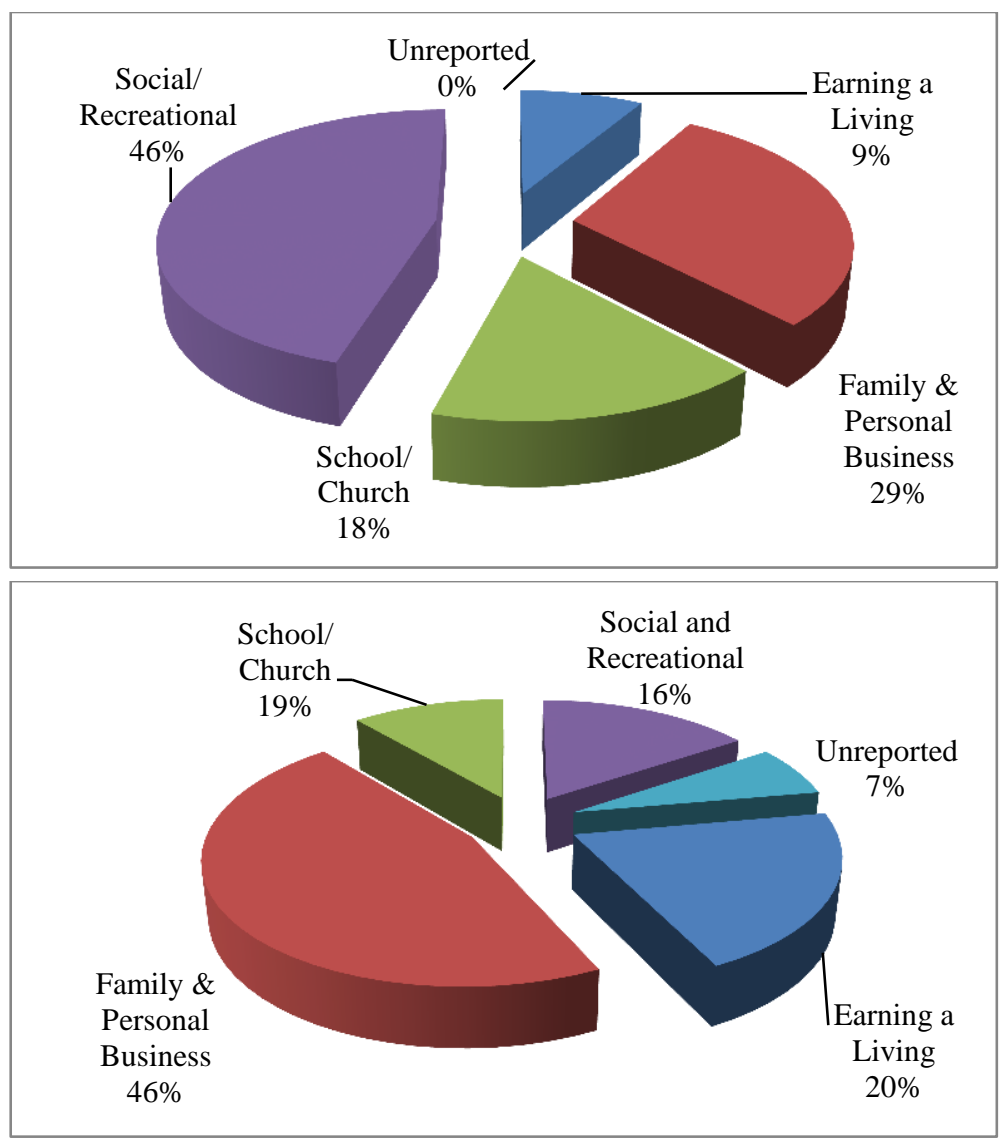

Figure 5-20. Travel purpose for trips made during weekend AM peak hours (6:00-9:00) in BMTS (top chart for intra-district trips; bottom chart for inter-district trips).

\subsubsection{Midday Peak Travel}

Unlike morning travel, trips made by BMTS households during midday peak hours (from 11:00 a.m. to 2:00 p.m.) on weekdays were mostly for family/personal business (59\%) and social/recreational (20\%) activities. As presented in Figure 5-21, only 14\% of BMTS PT made during midday peak hours on a weekday were for work purposes (i.e., earning a living). This pattern, in fact, is very similar to those observed from the SMTC region (Section 4). Furthermore, over a half of the BMTS PT made during midday on weekends were also for family/personal business reasons. Figure 5-21 also shows that, there was a clear jump on travel activities for social and recreational activities (e.g., shopping, eating out, etc.) on weekends (increasing from $20 \%$ on a typical weekday to $31 \%$ over weekends). This again is fairly consistent with patterns seen in SMTC.

The geospatial relationship of trips made among BMTS districts during midday peak hours on a weekday showed very little difference in patterns from the AM-peak hours. The size of the pies in Figure 5-22, in most districts, is slightly smaller than its corresponding pie in Figure 5-18, indicating less travel volumes occurred during the midday peak hours. The only exception is in the Vestal/JC district where the total trip volume in midday is higher than that in the morning. 


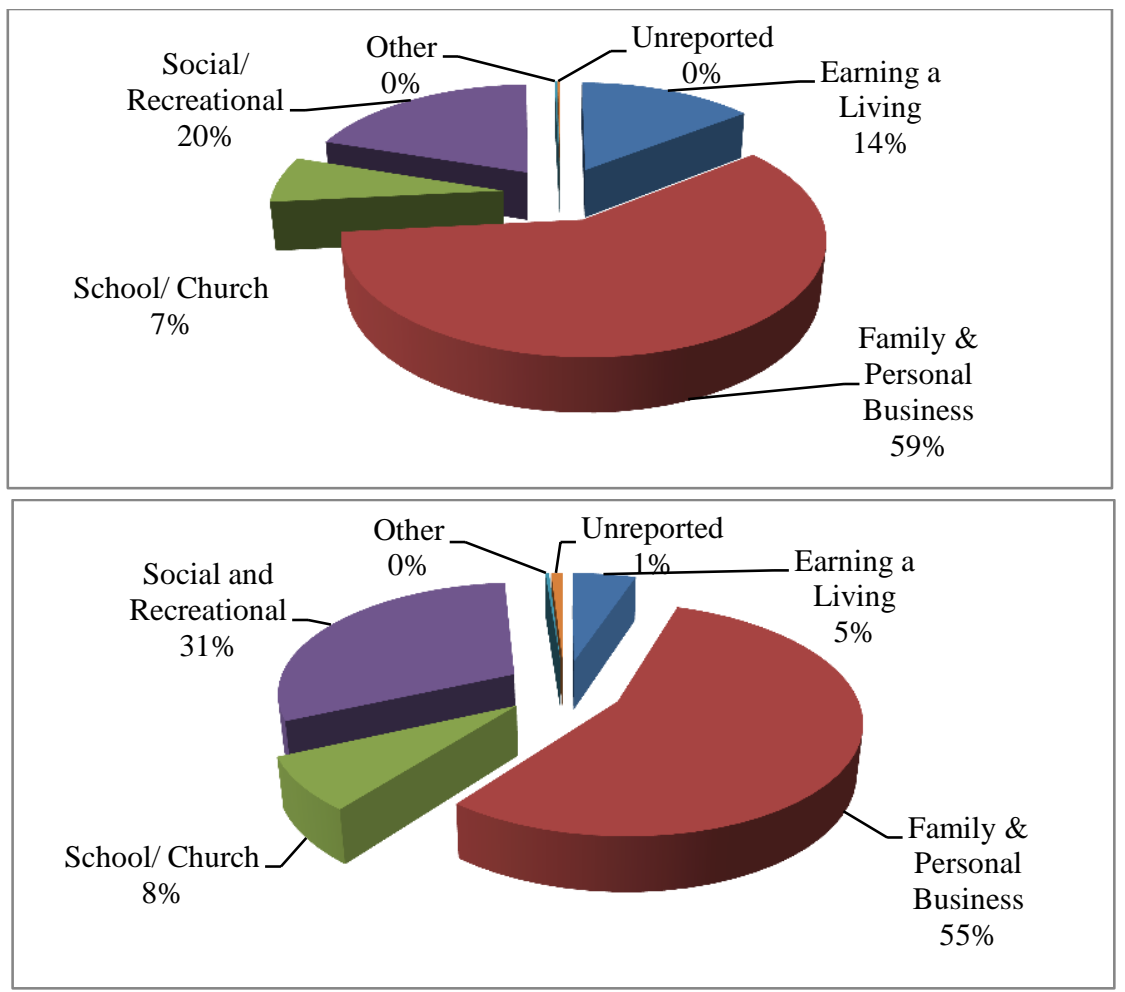

Figure 5-21. Travel during midday peak hours (11:00 a.m. to 2:00 p.m.) in BMTS districts (Top: weekday travel; bottom: weekend travel).

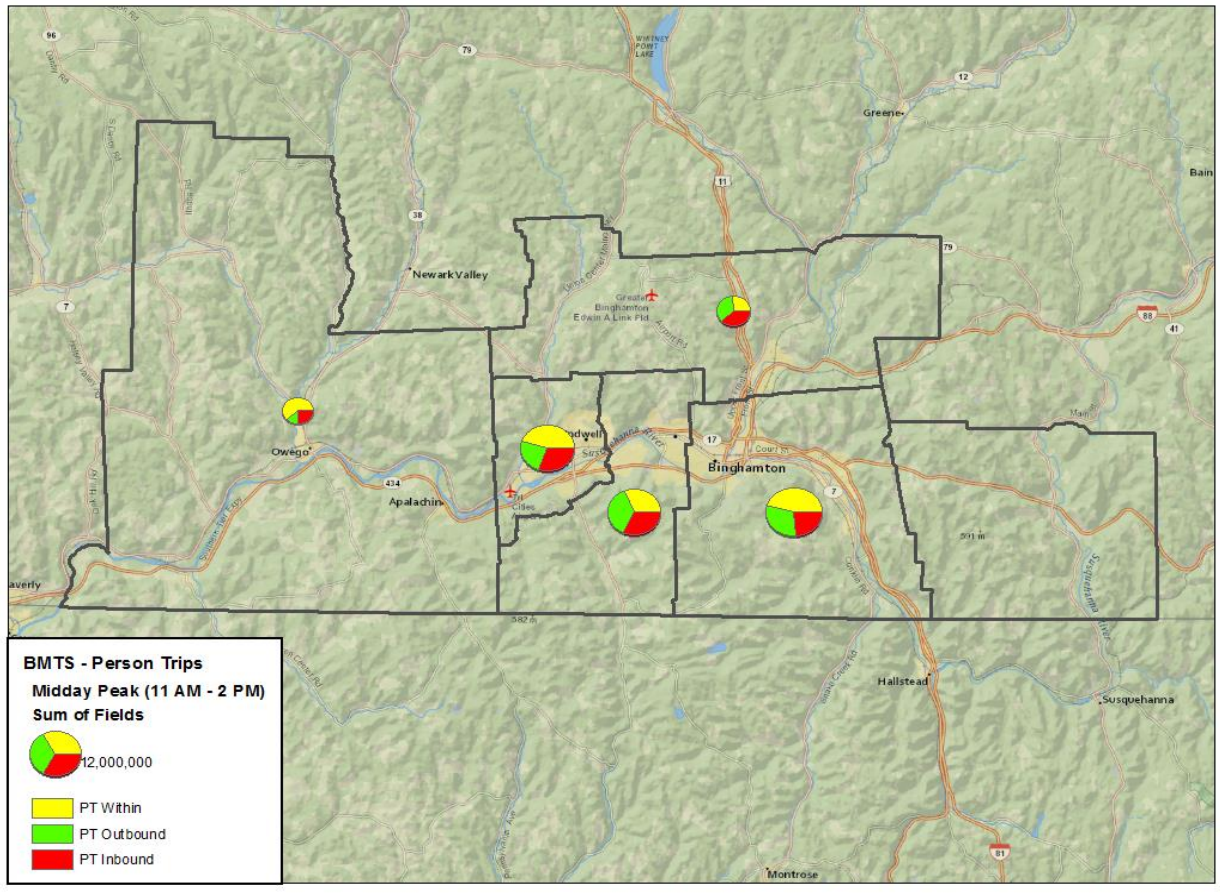

Figure 5-22. Travel patterns during midday peak hours (11:00 am to 2:00 pm) on weekdays for the BMTS districts, in person-trips. 
Travel purposes for both intra- and inter-district midday trips in BMTS districts results are summarized in Figure 5-23. Clearly, family/personal business was the primary reason for trips made within districts during this midday time period, followed by trips made for social/recreational purposes. This is true regardless of whether these trips were made for intra- or inter-district activities, although intra-district trips have a significantly higher likelihood of being made for family/personal business activities.

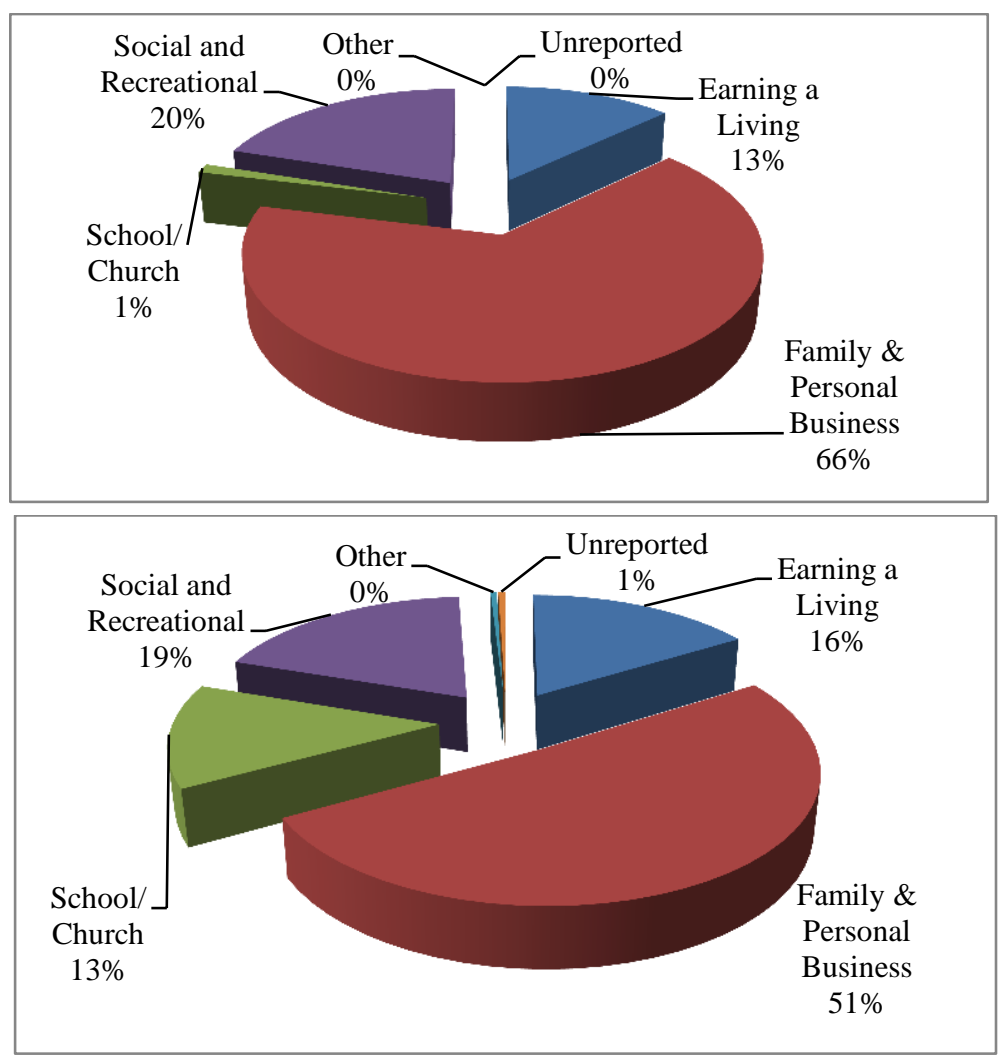

Figure 5-23. Travel purpose for trips made during weekday midday-peak hours (11 a.m. to 2 p.m.) in BMTS districts (Top chart for intra-district trips; bottom chart for inter-district trips).

A review of midday travel activities on weekends reveals a similar pattern between the intra- and interdistrict travels. The majority of midday weekend trips were for family/personal business; accounting for $54 \%$ of intra-district travel and 56\% for inter-district trips. Midday travel for social/recreational purposes also significantly increased on weekends where approximately $36 \%$ of midday intra-district weekend trips by BMTS residents were made for social/recreational activities compared to $20 \%$ on weekdays. And about $26 \%$ of midday inter-district weekend trips were conducted for the same reason verses $19 \%$ for weekdays.

\subsubsection{PM Peak Travel}

Similar to above, Figure 5-24 shows trips made by BMTS households during afternoon peak hours (from 4:00 to 7:00 p.m.) on weekdays were mostly for family/personal business (35\%) and social/recreational (32\%) activities. About 27\% of BMTS PT started during the weekday afternoon peak hours were for 
work purposes. On weekends, however, nearly a half of the BMTS PT made during the afternoon hours were for family/personal business reasons (47\%); while trips made for social/recreational activities during the same time period on weekends was about $42 \%$ share.

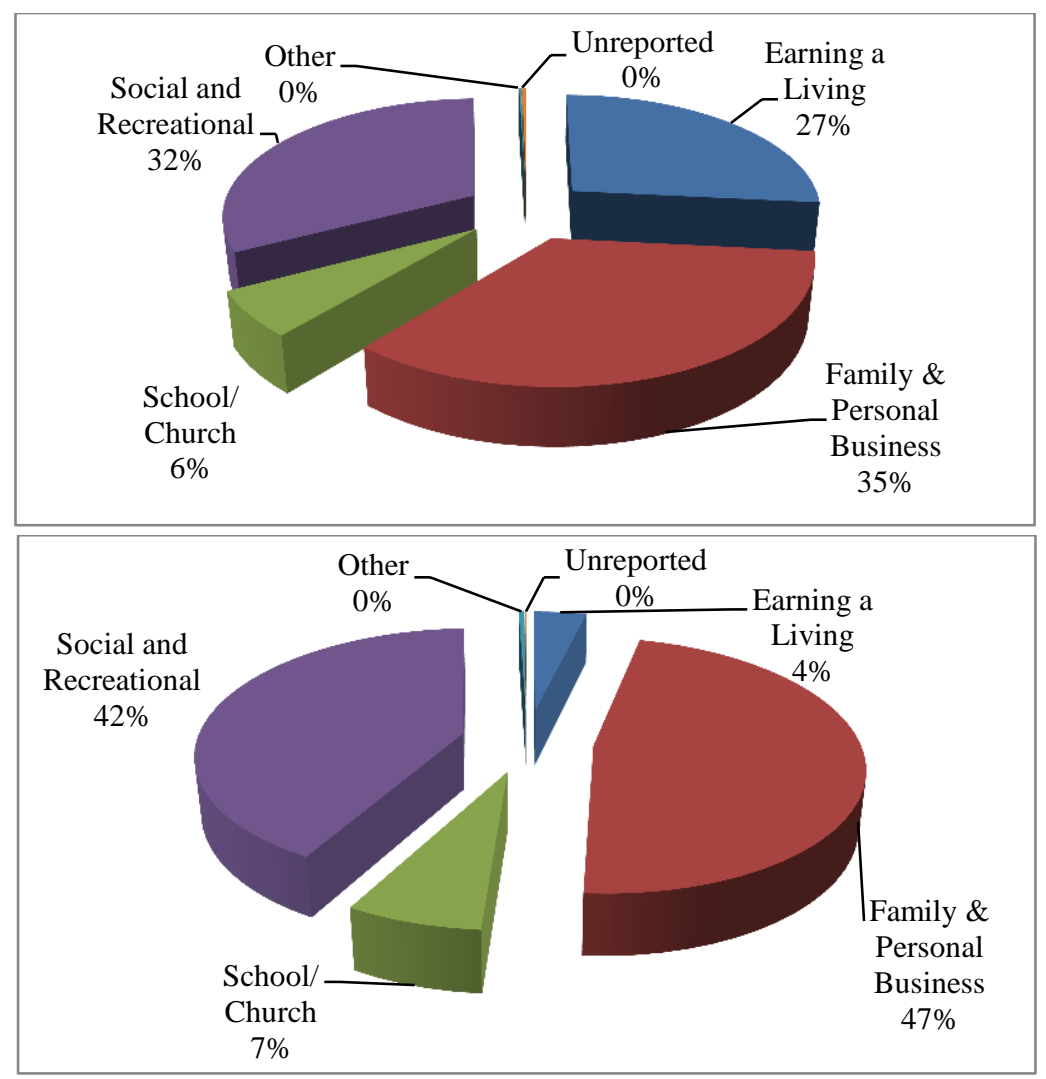

Figure 5-24. Travel during PM peak hours (4:00 to 7:00 p.m.) in BMTS districts (Top: weekday travel; bottom: weekend travel).

Geospatial travel patterns of weekday PT during the PM peak period are shown in Figure 5-25. This is very similar to the midday patterns shown in Figure 5-22; i.e., no clearly noticeable differences were observed from these maps.

As shown in Figure 5-26, intra-district travel by BMTS residents was most likely made for conducting family/personal business and social/recreational activities, accounting for $36 \%$ each in shares of the total intra-district trips starting during weekday PM peak hours. Unlike districts in the SMTC region, a noticeably significant portion (24\%) of intra-district trips made during the PM peak hours on weekdays were work trips (i.e., earning a living). Work trip share is also significant for inter-district travel, accounting for $29 \%$ of total inter-districts trips made during the afternoon peak hours on weekdays. Although slightly decreased in volume, family/personal business and social/recreational trips still accounted for the majority of trips made during this afternoon time period. 


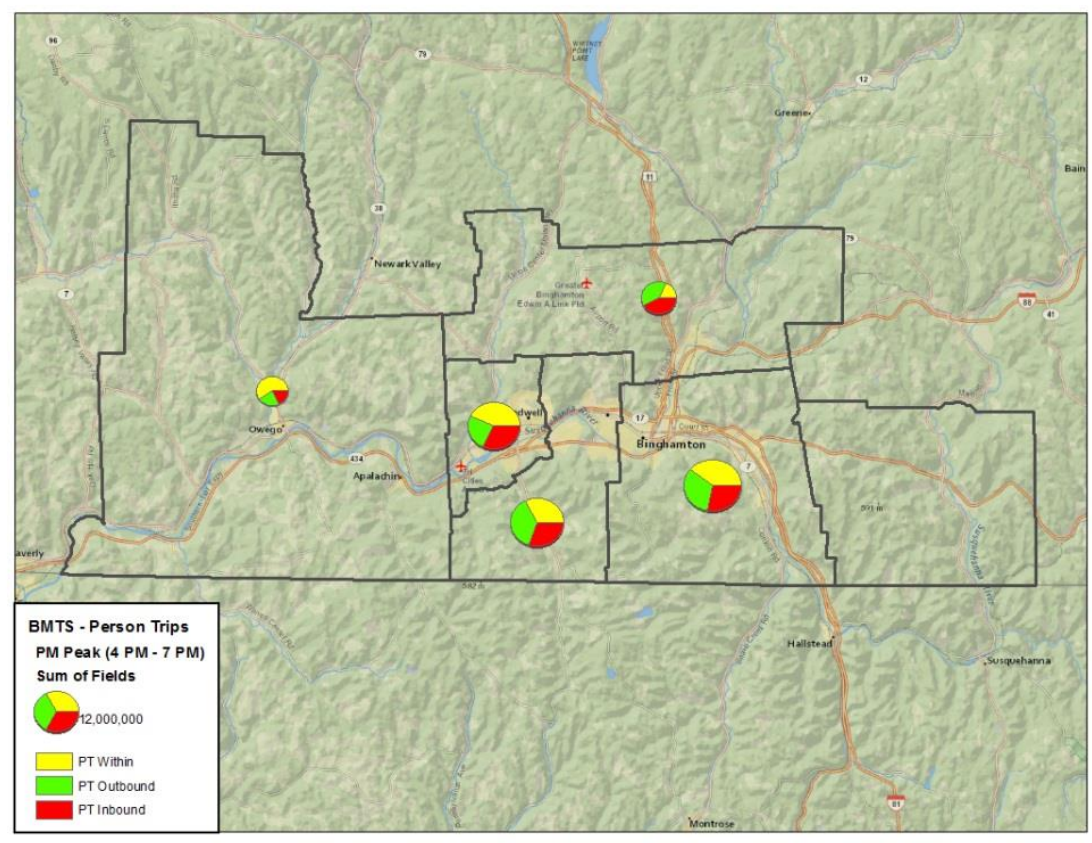

Figure 5-25. Travel patterns during weekday PM peak hours (4:00 to 7:00 pm) in BMTS districts.

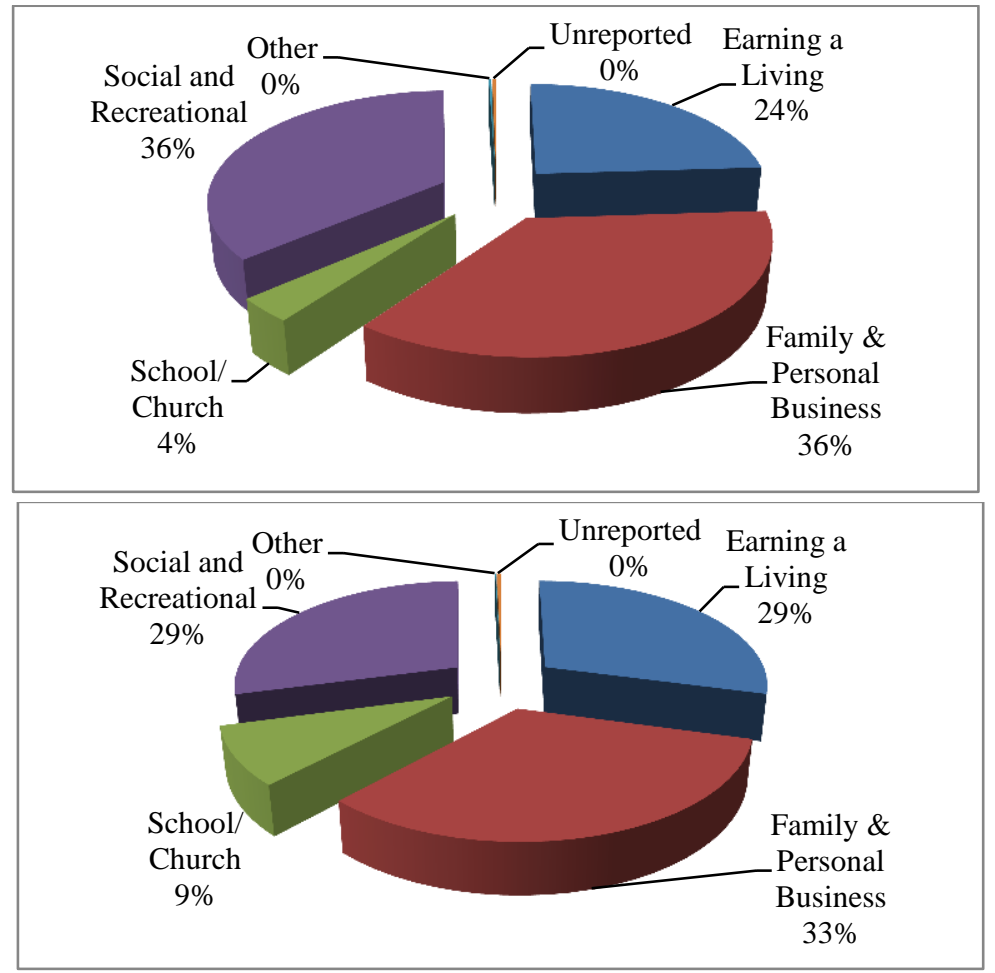

Figure 5-26. Travel purpose for trips made during weekday PM-peak hours (4 to 7 p.m.) in BMTS districts (Top chart for intra-district trips; bottom chart for interdistrict trips). 
The primary reasons for making either intra- or inter-district trips during the PM peak time period on weekends remained the same as those during weekdays: mostly for family/personal business and social/recreational activities.

\subsubsection{Weekend Travel Patterns}

Although a similar geospatial map for travel patterns on weekends by BMTS district residents might be of interest, sample size limitations in NTHS data unfortunately prevented adequate estimates to be generated at such a level of detail. Considering all hours of a weekend day, shown in Figure 5-27, relatively high shares of intra-district PT were observed in all districts. Generally speaking, the shares of inbound and outbound travel volumes (measured by PT) were about equal within each district in the BMTS districtprobably because most daily trips were symmetric.

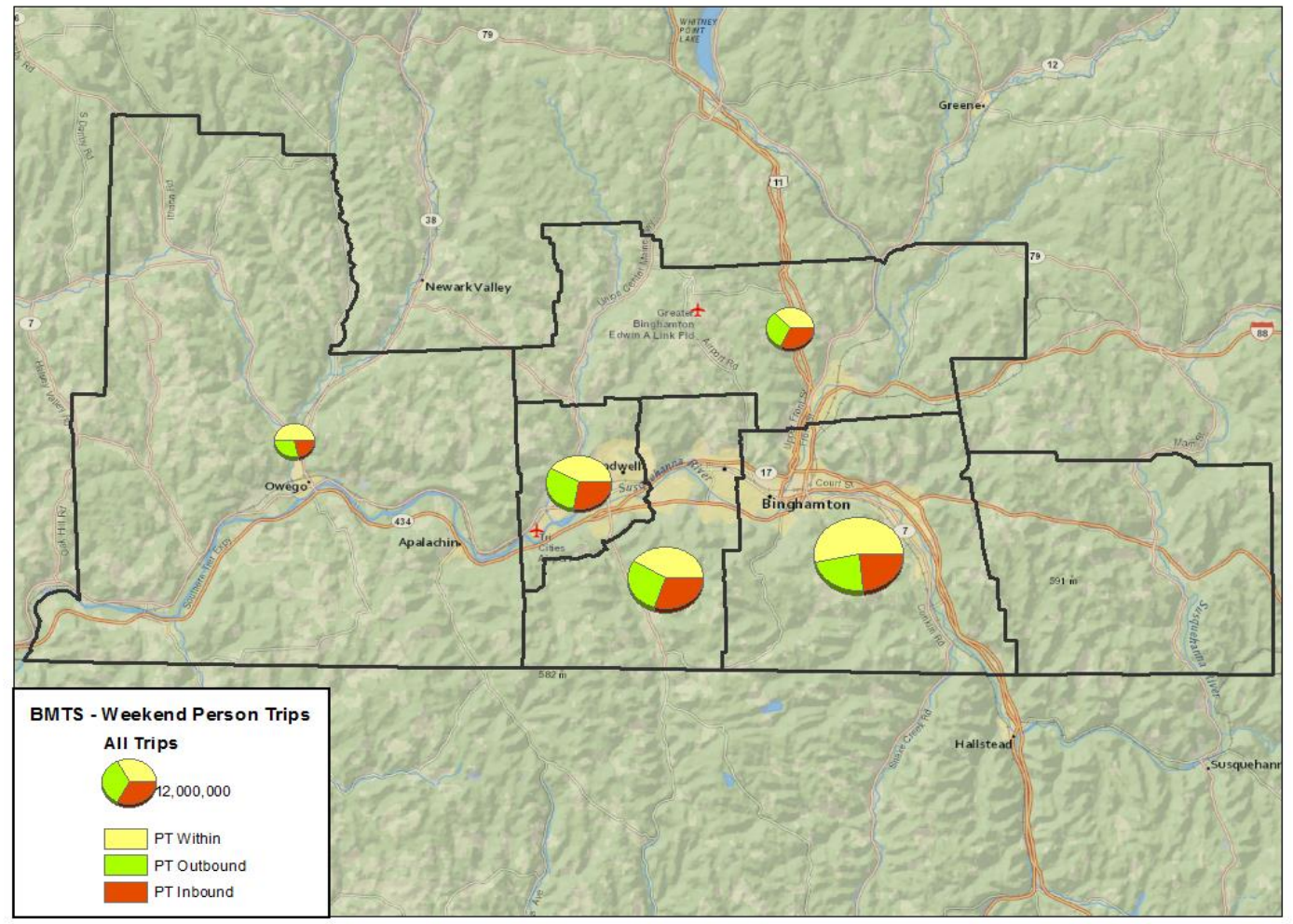

Figure 5-27. Travel patterns of person trips during weekend (all hours) in BMTS districts.

\subsubsection{Trip Rates by Time of Day}

In addition to overall trip rates measured by PT and VT per household, shown previously in Figure 5-5, trip rates by time of the day were also examined. Figure 5-28 provides weekday per-household PT rates by the time periods defined above; i.e., AM peak (red), mid-day peak (green), PM peak (purple), and other (rest of the day, in blue). Since the "other" category includes many more hours than those 3-hour peak periods, it should not be a surprise to see higher per-household trip rates during this time period. Generally, the PM peak period has a higher per-household trip rate than the other two peak periods; except for the Tioga region. A relatively similar pattern is also seen in Figure 5-29 for the per-household VT rates on weekdays. 


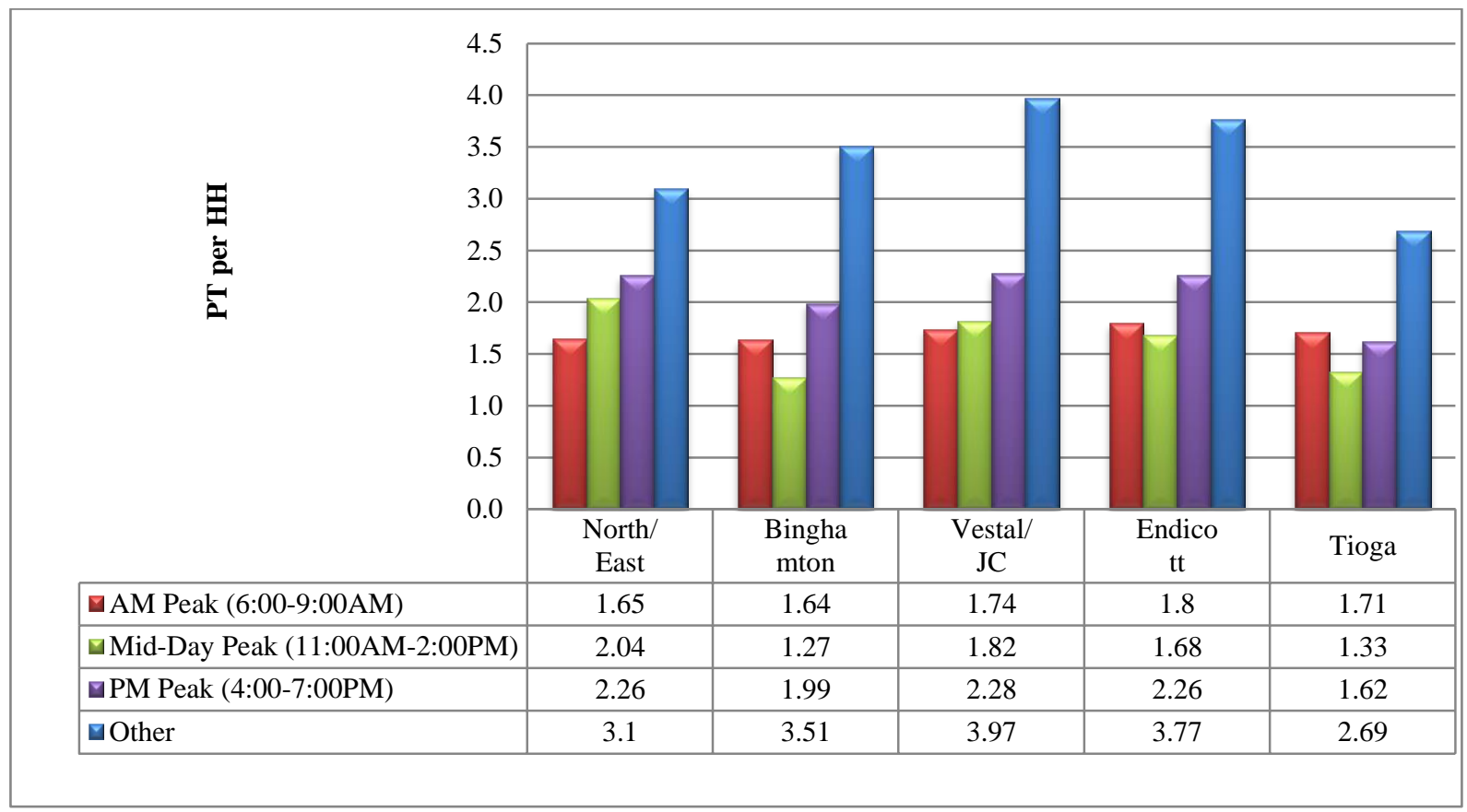

Figure 5-28. Weekday average number of person-trips per household by time period and BMTS household district.

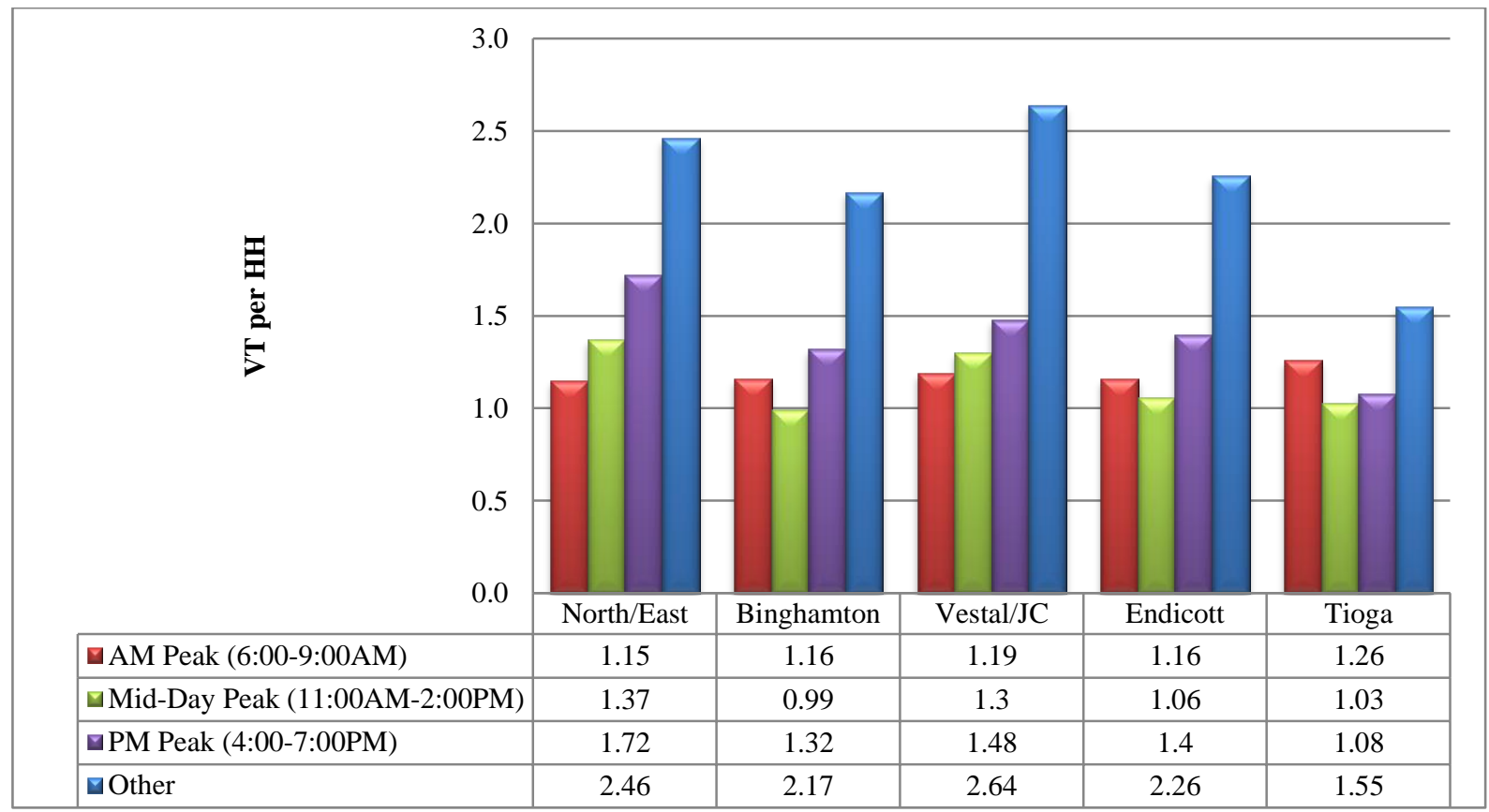

Figure 5-29. Weekday average number of vehicle-trips per household by time period and BMTS household district. 


\subsubsection{Average Trip Distance and Average Occupancy Rate in BMTS Regions}

Based on NHTS data, average travel distance in the BMTS districts were examined. Figure 5-30 compares average PT distances by trip-origin district as well as by trip-destination district. Again, since most trips have a reverse return trip, the difference in average distances is not expected to be too significant in most cases. A return trip may or may not mirror the initial outbound trip, however. For example, one could drop off dry-cleaning on the way to work in the morning, but return home from work directly at the end of the day.

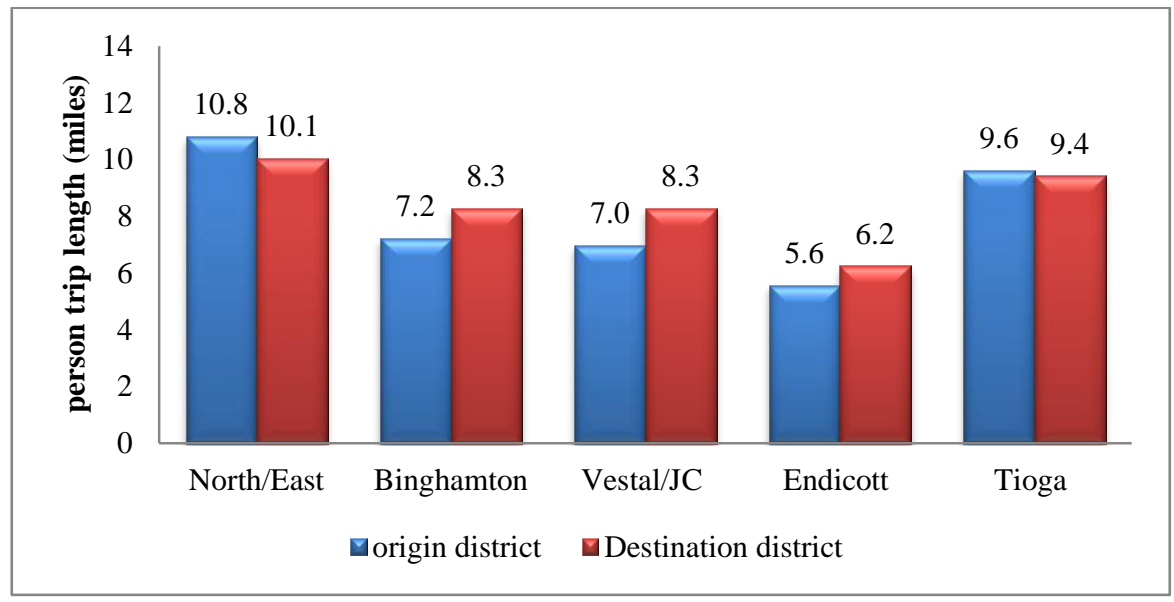

Figure 5-30. Average person-trip distance in BMTS district.

Similarly, average distances of VT in the BMTS districts are presented in Figure 5-31. With the exception of the more rural North/East district, a VT generally traveled greater distance than a typical PT (which includes trips made by walk/bike, transit, etc.). Overall patterns among the districts were fairly consistent in both figures.

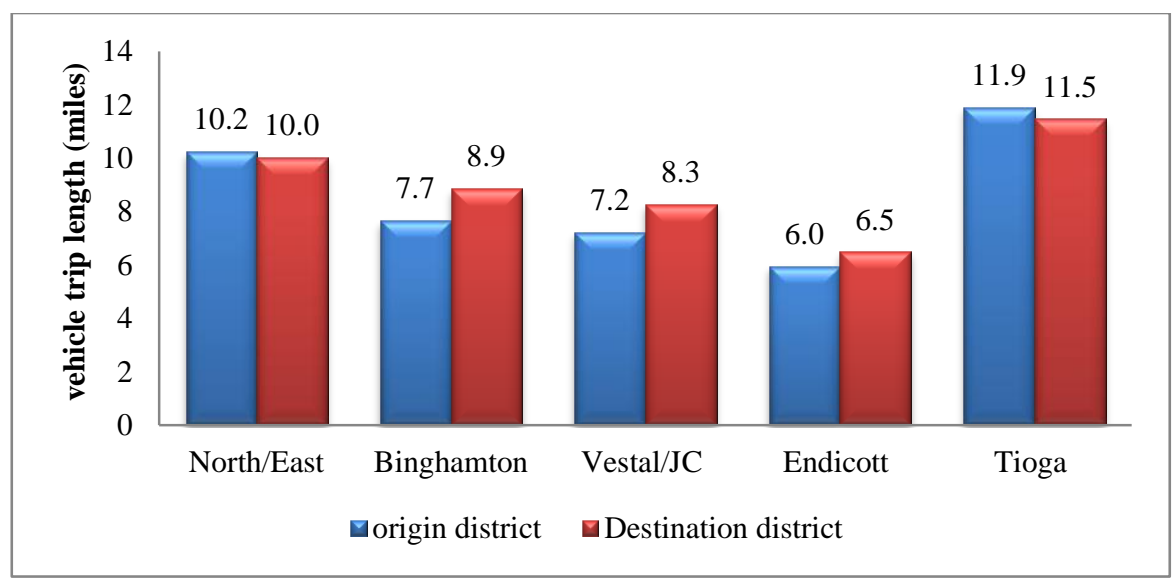

Figure 5-31. Average vehicle-trip distance in BMTS districts.

Another way of examining average PT distance by district is presented in Figure 5-32, where work trips out of BMTS districts (i.e., originating from the given district) are displayed in red and while home-bound trips are displayed in blue. Note that a "home-bound" trip is defined as any trip with a purpose of going 
home; this could include trips from work place or shopping trips. The "work-bound" trip is going to the work place, which could be from home (more typical) or other locations. And, trips assigned under the "other purposes" group were for those non-home and non-work trips. Except for trips originating from the Binghamton district, on average, all work-bound trips traveled a greater distance than home-bound trips.

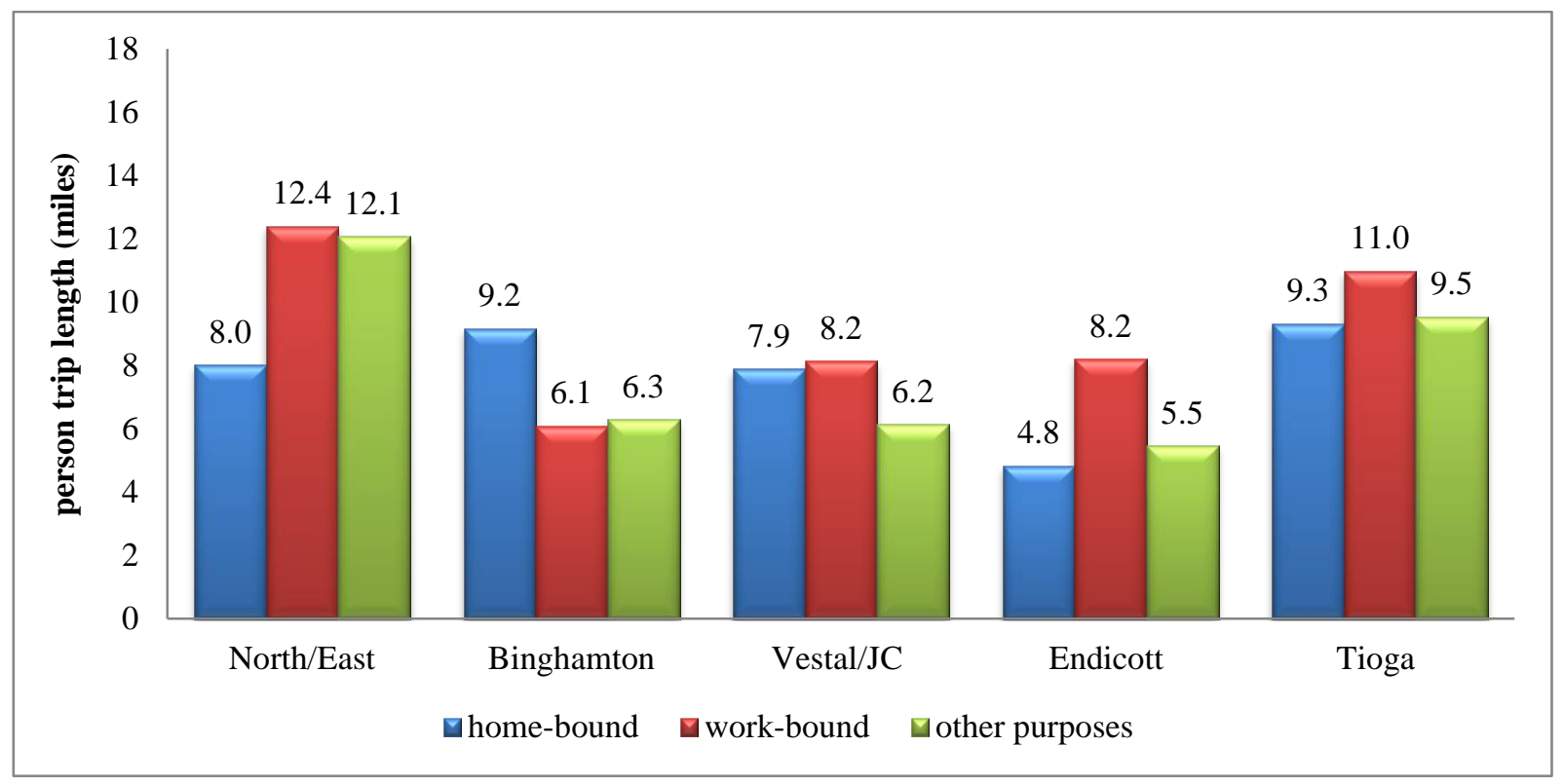

Figure 5-32. Average person-trip distance by trip purpose type by trip-origin district in BMTS districts.

Using data on VT (travel made by POV only), average occupancy rates for trips associated with each BMTS district were estimated. Figure 5-33 illustrates that, for most districts, average occupancy rates by trip-origin district and trip-destination district are fairly similar. Two districts that show slight differences between trip-origin based and trip-destination based occupancy rates were the North/East district (1.8 vs. 1.7 respectively) and the Binghamton district (1.6 vs 1.7 respectively). Trips involving these two districts (either originating/terminating) also had higher occupancy rates than those within the other three districts. Overall in the BMTS districts, the occupancy rates ranged from about 1.3 for trips originating/terminating in the Tioga district to around 1.8 for trips originating/terminating in the North/East district.

Note that occupancy rate can be computed by dividing the total PT in POV in a region by its corresponding number of VT (i.e., PT/VT); as well as it can be obtained from dividing PMT in POV by its corresponding VMT. Results from the two calculations could vary in some degrees due to the calculation method used. Table 5-7 summarizes occupancy rate estimates based on PT/VT of POV trips by BMTS household district by their trip purposes. The results reflected that work-related vehicle trips were mostly single-occupancy. On the other hand, vehicle travels made for other purposes were more likely be shared rides (with a higher occupancy rate), particularly those made for school/church activities. 


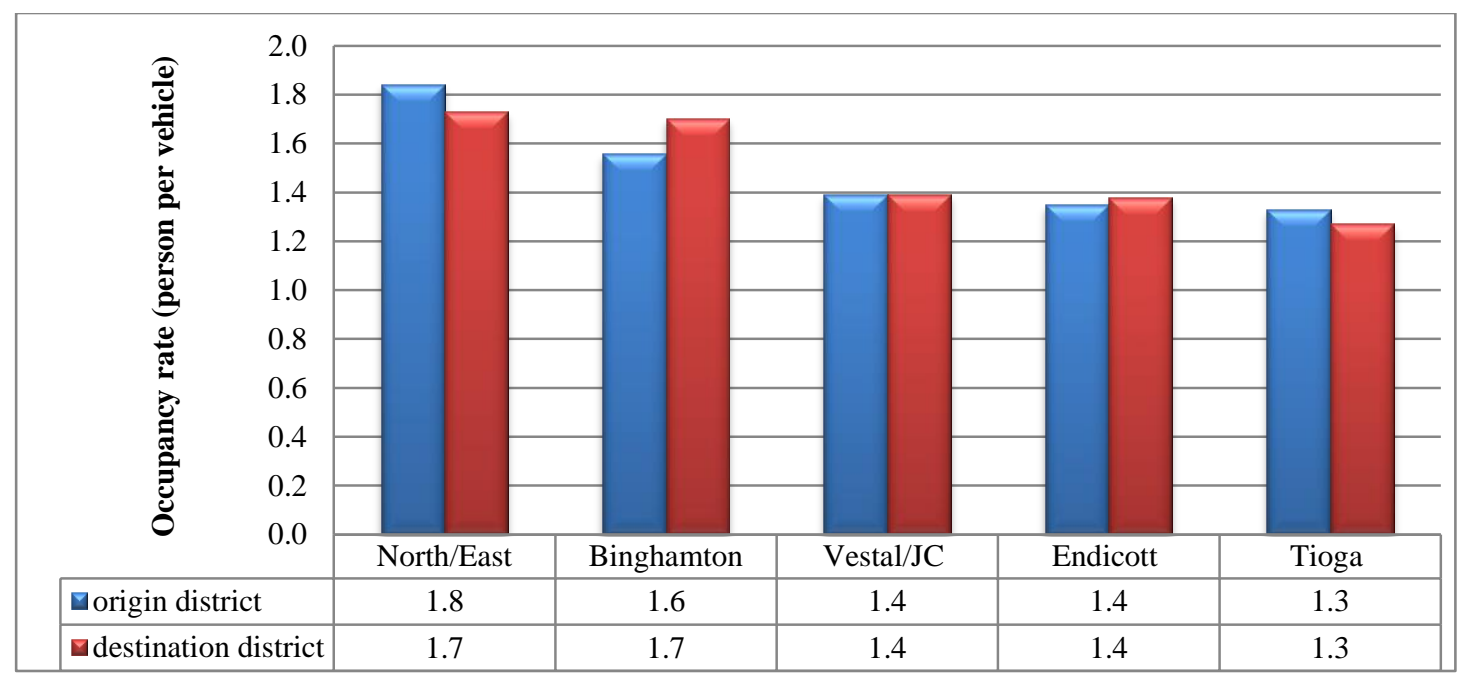

Figure 5-33 Average occupancy rate by trip-origin and trip-destination in the BMTS districts.

Table 5-7. Occupancy Rates Based on PT/VT of POV Trips by BMTS Household Districts

\begin{tabular}{|l|c|c|c|c|c|}
\hline $\begin{array}{c}\text { BMTS } \\
\text { household } \\
\text { district }\end{array}$ & $\begin{array}{c}\text { Earning a } \\
\text { Living }\end{array}$ & $\begin{array}{c}\text { Family \& } \\
\text { Personal } \\
\text { Business }\end{array}$ & School/ Church & $\begin{array}{c}\text { Social and } \\
\text { Recreational }\end{array}$ & $\begin{array}{c}\text { All } \\
\text { purposes }\end{array}$ \\
\hline North/East & 1.1 & 1.2 & 2.0 & 1.3 & 1.2 \\
\hline Binghamton & 1.1 & 1.4 & 1.9 & 1.6 & 1.4 \\
\hline Vestal/JC & 1.1 & 1.2 & 1.9 & 1.3 & 1.2 \\
\hline Endicott & 1.2 & 1.3 & 3.4 & 1.7 & 1.4 \\
\hline Tioga & 1.0 & 1.2 & 1.4 & 1.5 & 1.2 \\
\hline
\end{tabular}

Similar results are seen from Table 5-8 where the occupancy rates are computed from PMT/VMT of VT made by BMTS district residents. Results from Table 5.8 are consistent with estimates presented Table 5-7 in that work trips via POVs were mostly single occupancy while other types of trips were more likely to have multiple occupants in the same vehicles.

Table 5-8. Occupancy Rates Based on PMT/VMT of POV Trips by BMTS Household Districts

\begin{tabular}{|l|c|c|c|c|c|}
\hline $\begin{array}{c}\text { Household } \\
\text { District }\end{array}$ & $\begin{array}{c}\text { Earning a } \\
\text { Living }\end{array}$ & $\begin{array}{c}\text { Family \& } \\
\text { Personal } \\
\text { Business }\end{array}$ & $\begin{array}{c}\text { School/ } \\
\text { Church }\end{array}$ & $\begin{array}{c}\text { Social and } \\
\text { Recreational }\end{array}$ & $\begin{array}{c}\text { All } \\
\text { purposes }\end{array}$ \\
\hline North/East & 1.1 & 1.2 & 2.0 & 1.3 & 1.2 \\
\hline Binghamton & 1.0 & 1.7 & 1.8 & 1.6 & 1.5 \\
\hline Vestal/JC & 1.0 & 1.2 & 4.4 & 1.2 & 1.4 \\
\hline Endicott & 1.1 & 1.2 & 4.8 & 1.9 & 1.6 \\
\hline Tioga & 1.0 & 1.2 & 1.5 & 1.6 & 1.3 \\
\hline
\end{tabular}




\section{LAND-USE PATTERNS IN SMTC AND BMTS REGIONS}

Regional land-use patterns are known to have significant impacts on travel patterns (e.g., trip generation, mode choice, trip purposes, etc.). Although no direct measures of land-use mix are produced from this study, two proxy geospatial data sources were briefly examined for this pilot study. Note that the purpose of this review was not to conduct a formal analytical or modeling effort, but rather as an attempt to visualize any possible associations between land-use mix and travel patterns.

The Business Location data described in Section 3 was examined further and summarized in this section. Recall this dataset includes businesses with at least 10 employees only; i.e., small businesses are excluded from this set.

\subsection{BUSINESS LOCATIONS IN SMTC REGION}

Using the Business Location data, Table 6-1 lists the number of businesses by SMTC district in each industry based on their 2-digit NAICS code. Considering their geographic sizes, districts of Syracuse West and East clearly had significant shares of businesses located within their regions. Figure 6-1 presents a visual display of the regional business-mix using slightly aggregated information. Instead of using the 21 NAICS codes as presented in Table 6-1, businesses were grouped by their one-digit NAICS code except those with NAICS codes of 42, 44-45, and 48-49. Also, NAICS codes that start with 8 and 9 were grouped together. This produced a total of 10 categories and allowed for a clearer view with the pie charts.

As seen from Figure 6-1, business types within the SMTC districts are all well mixed. Businesses categorized as "educational services /health care" (purple) generally accounted for a significant share in each district; the highest one being in the Syracuse East District where a major university is located. The more residential region of Syracuse South also has a significant share of educational/health related businesses.

Other noticeable observations from Figure 6-1 include:

- a significant share of "Other" NAICS sector (shown in white color) in Syracuse West District which could be due to many government agencies residing in this downtown area;

- SMTC MPA Southwest, a neighboring district to the downtown Syracuse, also has a significant share of "Other" type of industry;

- all districts have a similar share for "entertainment, recreational, restaurants" sector; and

- more "manufacturing and construction, etc." businesses are located in District 6 (SMTC MPA Northeast). 
Table 6-1. Number of Businesses by NAICS Located in each SMTC Zone ${ }^{a}$

\begin{tabular}{|c|c|c|c|c|c|c|c|c|c|}
\hline NAICS & Description & 1 & 2 & 3 & 4 & 5 & 6 & 7 & 8 \\
\hline 11 & $\begin{array}{l}\text { Agriculture, Forestry, Fishing and } \\
\text { Hunting }\end{array}$ & 1 & 0 & 1 & 0 & 0 & 2 & 1 & 2 \\
\hline 21 & $\begin{array}{l}\text { Mining, Quarrying, and Oil and Gas } \\
\text { Extraction }\end{array}$ & 0 & 0 & 0 & 0 & 0 & 0 & 1 & 0 \\
\hline 22 & Utilities & 1 & 2 & 0 & 0 & 3 & 3 & 2 & 1 \\
\hline 23 & Construction & 40 & 21 & 3 & 11 & 35 & 105 & 31 & 24 \\
\hline $31-33$ & Manufacturing & 32 & 15 & 9 & 10 & 41 & 88 & 14 & 30 \\
\hline 42 & Wholesale Trade & 30 & 11 & 1 & 9 & 31 & 95 & 17 & 22 \\
\hline $44-45$ & Retail Trade & 112 & 40 & 20 & 27 & 112 & 131 & 97 & 75 \\
\hline $48-49$ & Transportation and Warehousing & 10 & 9 & 8 & 11 & 6 & 49 & 5 & 9 \\
\hline 51 & Information & 29 & 25 & 3 & 2 & 11 & 28 & 18 & 12 \\
\hline 52 & Finance and Insurance & 55 & 7 & 1 & 6 & 39 & 42 & 33 & 10 \\
\hline 53 & Real Estate and Rental and Leasing & 10 & 14 & 8 & 3 & 30 & 18 & 28 & 19 \\
\hline 54 & $\begin{array}{l}\text { Professional, Scientific, and } \\
\text { Technical Services }\end{array}$ & 101 & 22 & 4 & 7 & 42 & 67 & 36 & 6 \\
\hline 55 & $\begin{array}{l}\text { Management of Companies and } \\
\text { Enterprises }\end{array}$ & 1 & 0 & 0 & 0 & 0 & 0 & 1 & \\
\hline 56 & $\begin{array}{l}\text { Administrative and Support and } \\
\text { Waste Management and } \\
\text { Remediation Services }\end{array}$ & 22 & 10 & 2 & 8 & 21 & 36 & 22 & 14 \\
\hline 61 & Educational Services & 41 & 111 & 32 & 13 & 52 & 40 & 43 & 60 \\
\hline 62 & Health Care and Social Assistance & 134 & 153 & 51 & 14 & 113 & 68 & 79 & 79 \\
\hline 71 & Arts, Entertainment, and Recreation & 14 & 6 & 2 & 10 & 13 & 27 & 20 & 15 \\
\hline 72 & Accommodation and Food Services & 132 & 83 & 31 & 25 & 121 & 108 & 78 & 74 \\
\hline 81 & $\begin{array}{l}\text { Other Services (except Public } \\
\text { Administration) }\end{array}$ & 55 & 30 & 18 & 12 & 45 & 36 & 35 & 30 \\
\hline 92 & Public Administration & 119 & 14 & 2 & 12 & 27 & 24 & 13 & 49 \\
\hline 99 & Unknown & 20 & 23 & 5 & 0 & 10 & 10 & 10 & 8 \\
\hline & All Businesses & 959 & 596 & 201 & 180 & 752 & 977 & 584 & 539 \\
\hline
\end{tabular}

Note: ${ }^{a}$ SMTC zones are: 1. Syracuse West, 2. Syracuse East, 3. Syracuse South, 4. SMTC MPA Northwest, 5. SMTC MPA North, 6. SMTC MPA Northeast, 7. SMTC MPA Southeast, 8. SMTC MPA Southwest. 


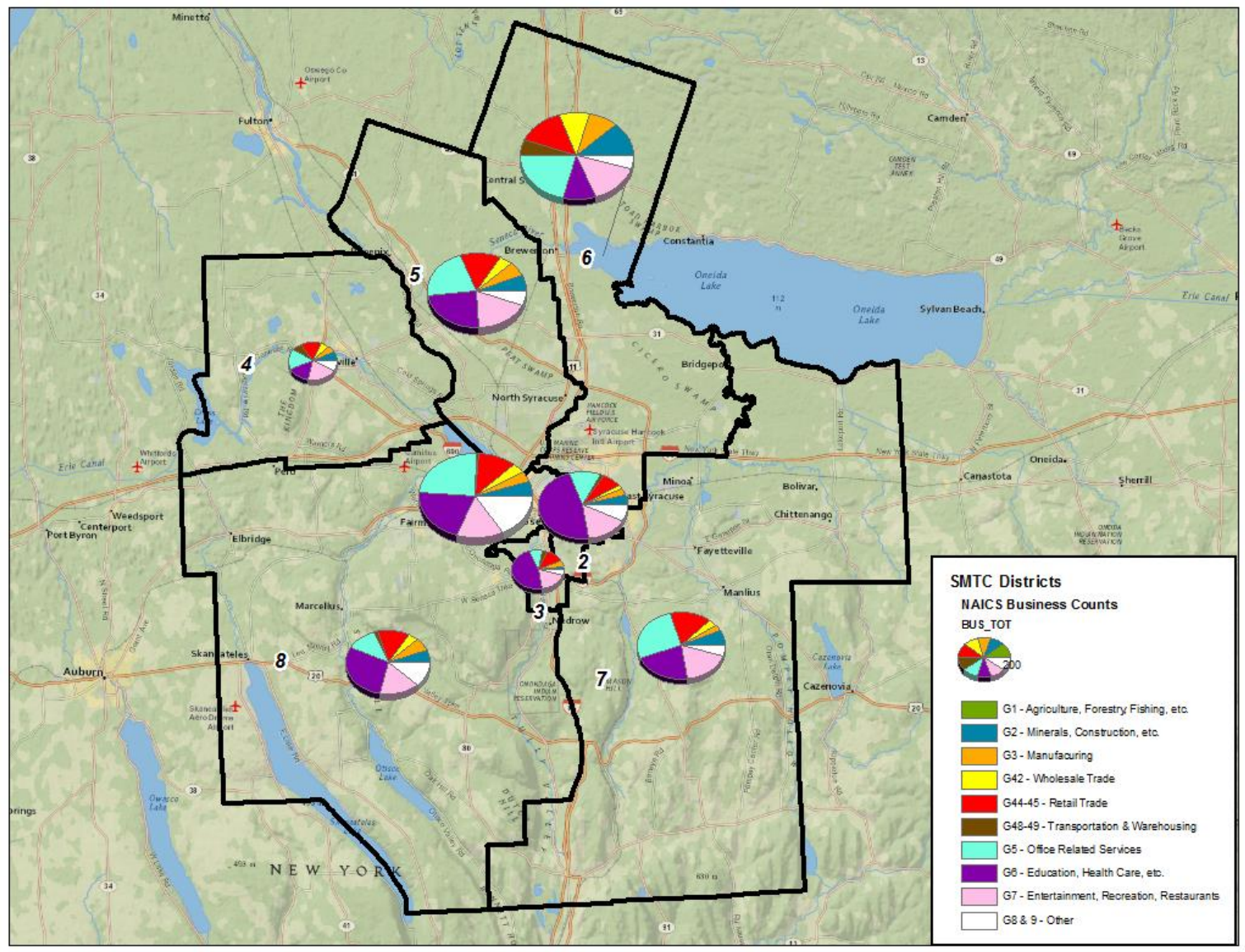

Figure 6-1. Number of businesses (10 or more employees) by industry type in SMTC districts.

The number of businesses in a district by itself, however, does not provide sufficient information for making associations with travel patterns or volumes in the given region. For example, a large hospital or university would employee a lot more people thus generating more commute trips along with attracting more trips from "visitors" (e.g., patients, students, or parents) than those of smaller clinics or smaller schools.

Using the number of employees for businesses within each district by the same 10 aggregated-NAICS categories, Figure 6-2 shows a slightly different view of the business mix from the previous map. Clearly visible is the share of educational/health in Syracuse East (District 2); reflecting the employment size from the major university and the hospital located in this region. Shares of manufacturing (orange color slices) are more significant in all areas outside the City of Syracuse, when measured by the number of employees instead of the number of businesses. 


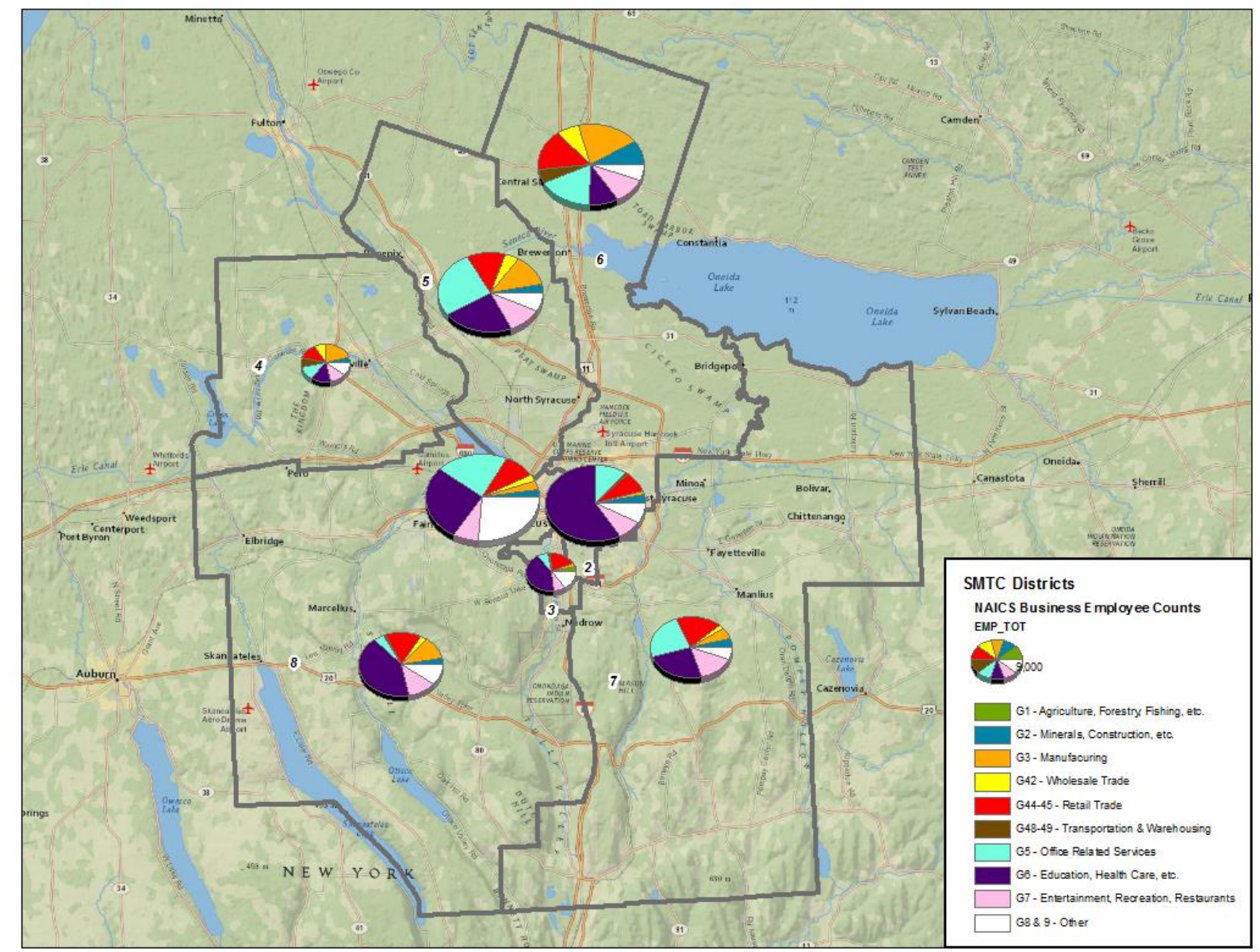

Figure 6-2. Number of Employees for businesses (10 or more employees) by industry type in SMTC districts.

Another different view of the business mix is based on the total annual sales, as shown in Figure 6-3. Naturally, wholesale and retail trades are more directly involved with "sales" thus it is not a surprise to see much larger shares are attributed to these two sectors in all districts. Specifically, the combined annual sales from businesses in wholesale and retail sectors in most SMTC districts represent over half of the individual total sales; except the sales are slightly lower for the two major downtown districts. The rationale of considering business sales is that sales might be associated with travel-induced activities such as shopping (including groceries), eating out, etc. more than the number of businesses or employees, particularly for businesses of wholesales, retails, entertainment, restaurants, etc. 


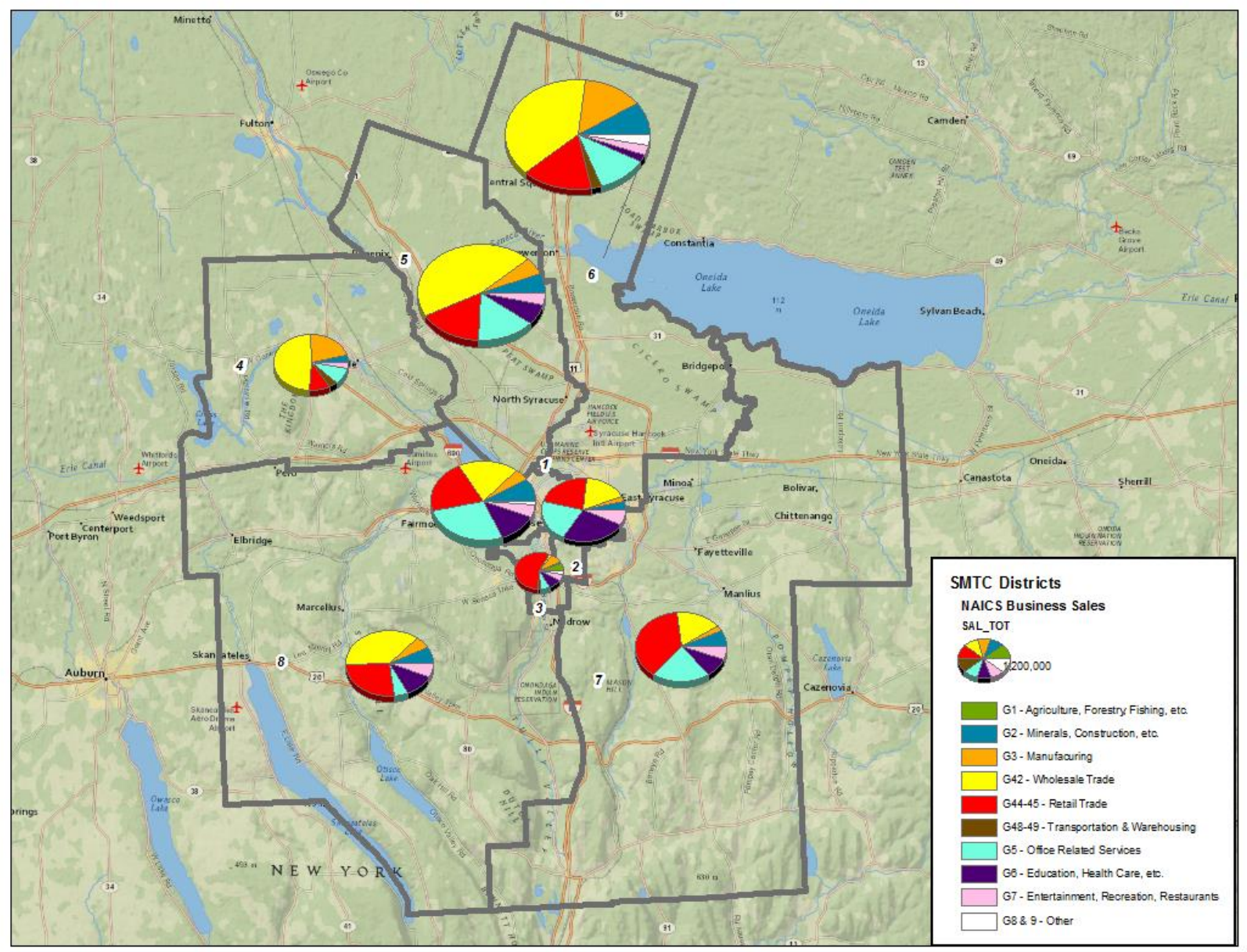

Figure 6-3. Sales share of businesses (10 or more employees) by industry type in SMTC districts.

\subsection{BUILDING OCCUPANCY IN SMTC}

As pointed out in Section 3 of this report, the building square-footage occupancy database from FEMA provides a different angle to view the land-use mix of a region. Because building occupancy information is based on the usage of a "building" within a Census block, it is different from the point-based business location data. This data is not categorized by NAICS, thus not exactly in the same grouping as the Business data. In addition, the FEMA data also includes residential buildings and in most cases residential space is the largest component by square-footage (occupancy) within a region. Figure 6-4 shows the distribution of building occupancy (by square-footage) in each SMTC district, including residential buildings.

Clearly, downtown Syracuse districts had higher shares of commercial (yellow) and educational (orange) occupied buildings, as measured by building square-footage. Because space used by the residential sector is significantly higher than those used by other sectors, the residential sector was removed to create a nonresidential map (shown in Figure 6-5) which allows for an easier distinction among other sectors. 


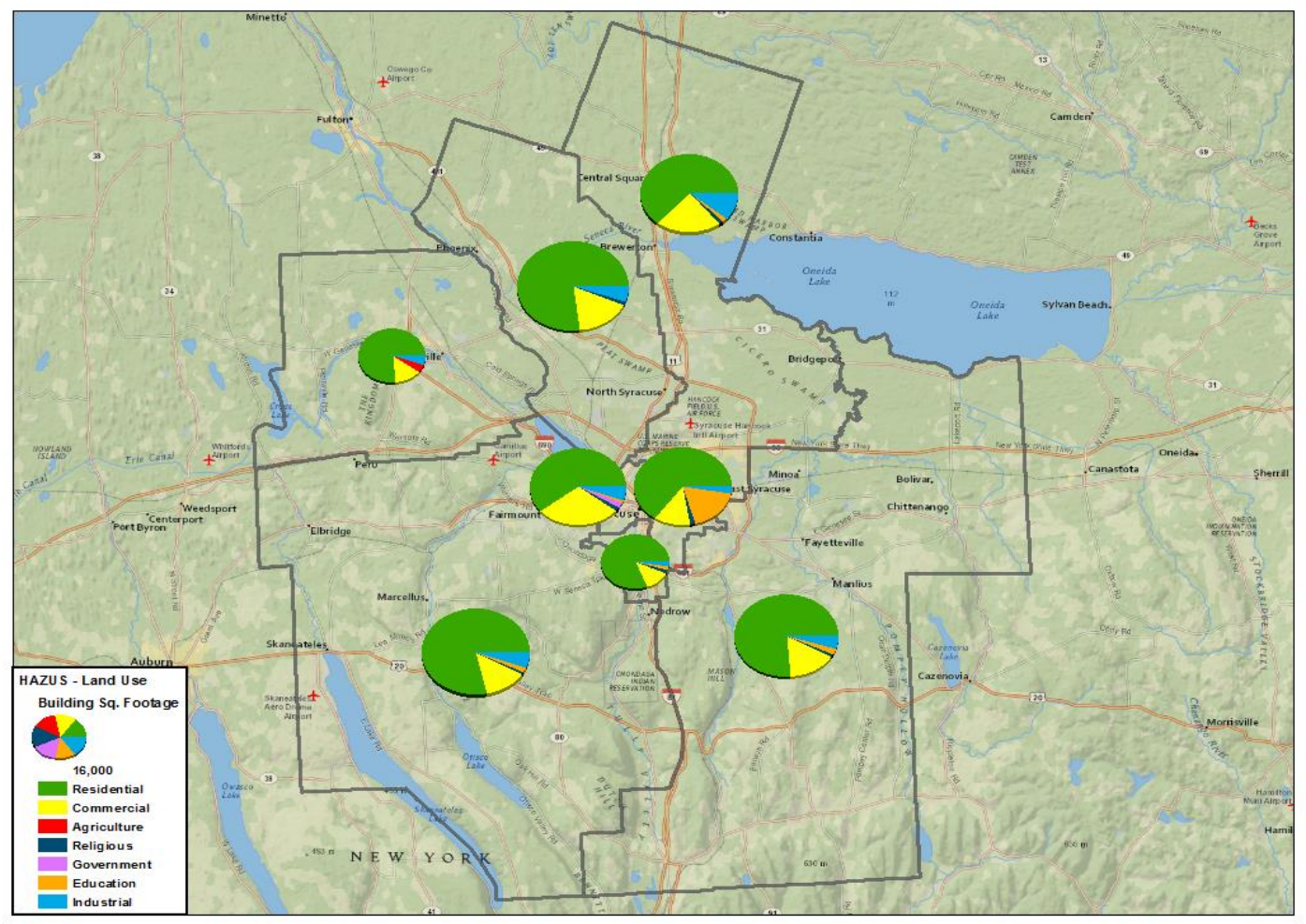

Figure 6-4. Share of sectors using FEMA's building square-footage occupancy data.

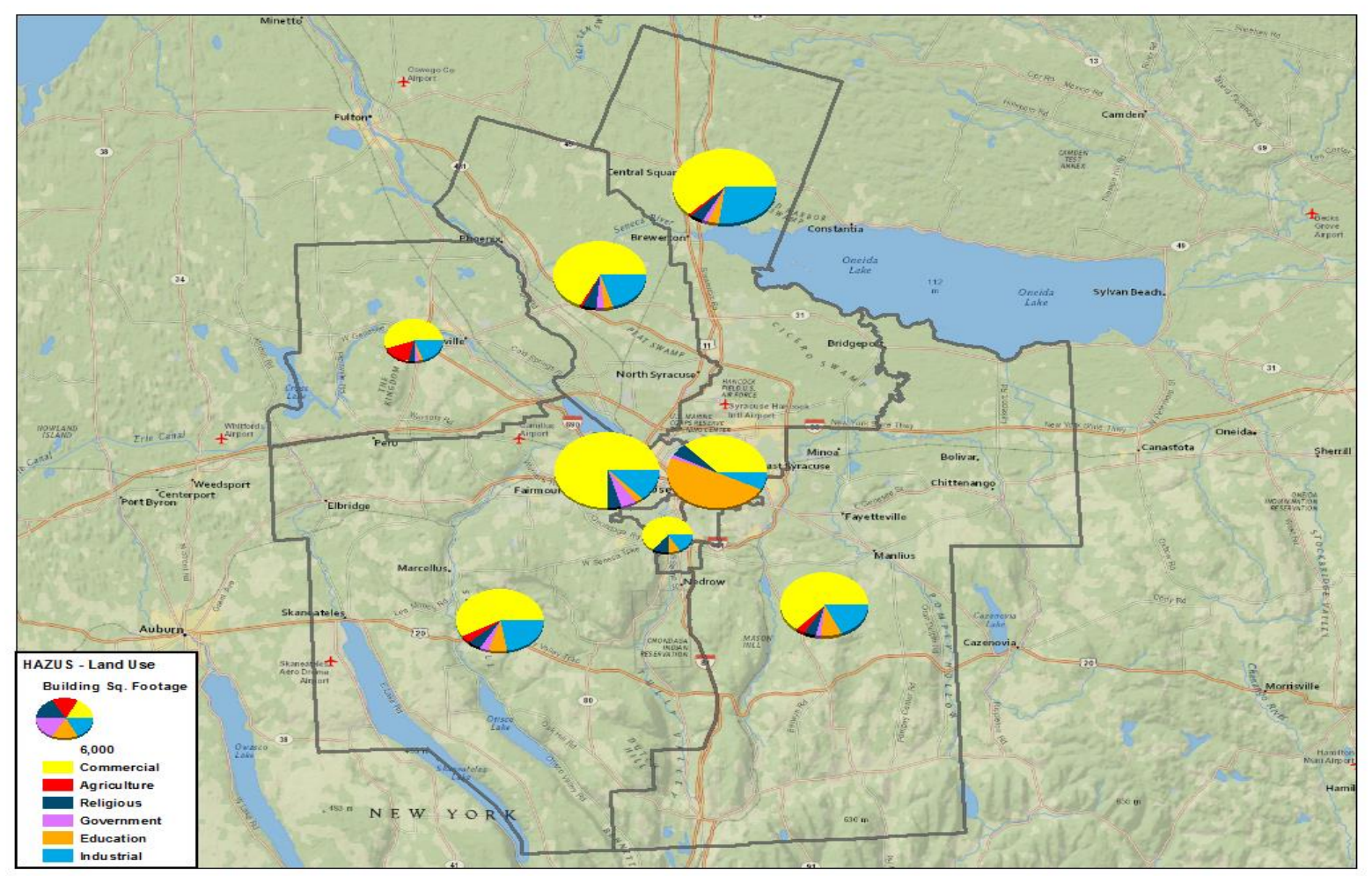

Figure 6-5. Share of non-residential sectors using FEMA's building square-footage occupancy data. 
Note that it might be reasonable to assume that the "commercial sector" includes businesses in wholesale, retail, office related services, entertainment/restaurants; while mining/construction, manufacturing, and transportation and warehousing might be reflected as "industries." Again, this building occupancy-based land-use data could be used to provide supplemental information about the districts.

\subsection{BUSINESS LOCATIONS IN BMTS REGION}

Similar to SMTC, Table 6-2 lists the number of businesses in BMTS districts for each industry based on their 2-digit NAICS code. The districts of Binghamton, Vestal/JC, and Endicott clearly have more businesses located within those regions than the more rural districts of Tioga and North/East.

Table 6-2. Number of Businesses by NAICS Located in each BMTS District ${ }^{\text {a }}$

\begin{tabular}{|l|l|r|r|r|r|r|}
\hline NAICS & Description & $\mathbf{1}$ & $\mathbf{2}$ & $\mathbf{3}$ & $\mathbf{4}$ & $\mathbf{5}$ \\
\hline 11 & Agriculture, Forestry, Fishing and Hunting & 2 & 1 & 0 & 0 & 3 \\
\hline 21 & Mining, Quarrying, and Oil and Gas Extraction & 1 & 2 & 0 & 0 & 0 \\
\hline 22 & Utilities & 1 & 3 & 1 & 2 & 0 \\
\hline 23 & Construction & 14 & 32 & 19 & 32 & 12 \\
\hline $31-33$ & Manufacturing & 8 & 47 & 30 & 21 & 9 \\
\hline 42 & Wholesale Trade & 4 & 42 & 14 & 15 & 5 \\
\hline $44-45$ & Retail Trade & 25 & 57 & 95 & 48 & 22 \\
\hline $48-49$ & Transportation and Warehousing & 8 & 25 & 6 & 8 & 7 \\
\hline 51 & Information & 1 & 16 & 18 & 10 & 1 \\
\hline 52 & Finance and Insurance & 1 & 22 & 21 & 17 & 1 \\
\hline 53 & Real Estate and Rental and Leasing & 2 & 17 & 11 & 5 & 0 \\
\hline 54 & Professional, Scientific, and Technical Services & 4 & 33 & 13 & 17 & 7 \\
\hline 55 & Management of Companies and Enterprises & 0 & 0 & 0 & 0 & 0 \\
\hline 56 & Administrative and Support and Waste & & & & & \\
& Management and Remediation Services & 1 & 21 & 16 & 11 & 2 \\
\hline 61 & Educational Services & 11 & 50 & 18 & 29 & 13 \\
\hline 62 & Health Care and Social Assistance & 11 & 95 & 76 & 43 & 12 \\
\hline 71 & Arts, Entertainment, and Recreation & 2 & 16 & 9 & 9 & 4 \\
\hline 72 & Accommodation and Food Services & 31 & 90 & 97 & 56 & 23 \\
\hline 81 & Other Services (except Public Administration) & 7 & 42 & 28 & 24 & 8 \\
\hline 92 & Public Administration & 7 & 63 & 7 & 21 & 16 \\
\hline 99 & Unknown & 7 & 13 & 9 & 9 & 1 \\
\hline \multicolumn{2}{|c|}{ All Businesses } & $\mathbf{1 4 8}$ & $\mathbf{6 8 7}$ & $\mathbf{4 8 8}$ & $\mathbf{3 7 7}$ & $\mathbf{1 4 6}$ \\
\hline
\end{tabular}

Note: ${ }^{a}$ BMTS districts are: 1. North/East, 2. Binghamton, 3. Vestal/JC, 4. Endicott, 5. Tioga.

Figure 6-6 presents a visual display of the BMTC regional business-mix using the aggregated 10-sector NAICS categories as described above (Section 6.1). Business types within the BMTS districts are all well-mixed and sector shares are fairly similar across districts. Most businesses within the BMTS districts are in educational/health (purple), entertainment/recreation/restaurants (pink), office-related services (cyan), and retail (red). 


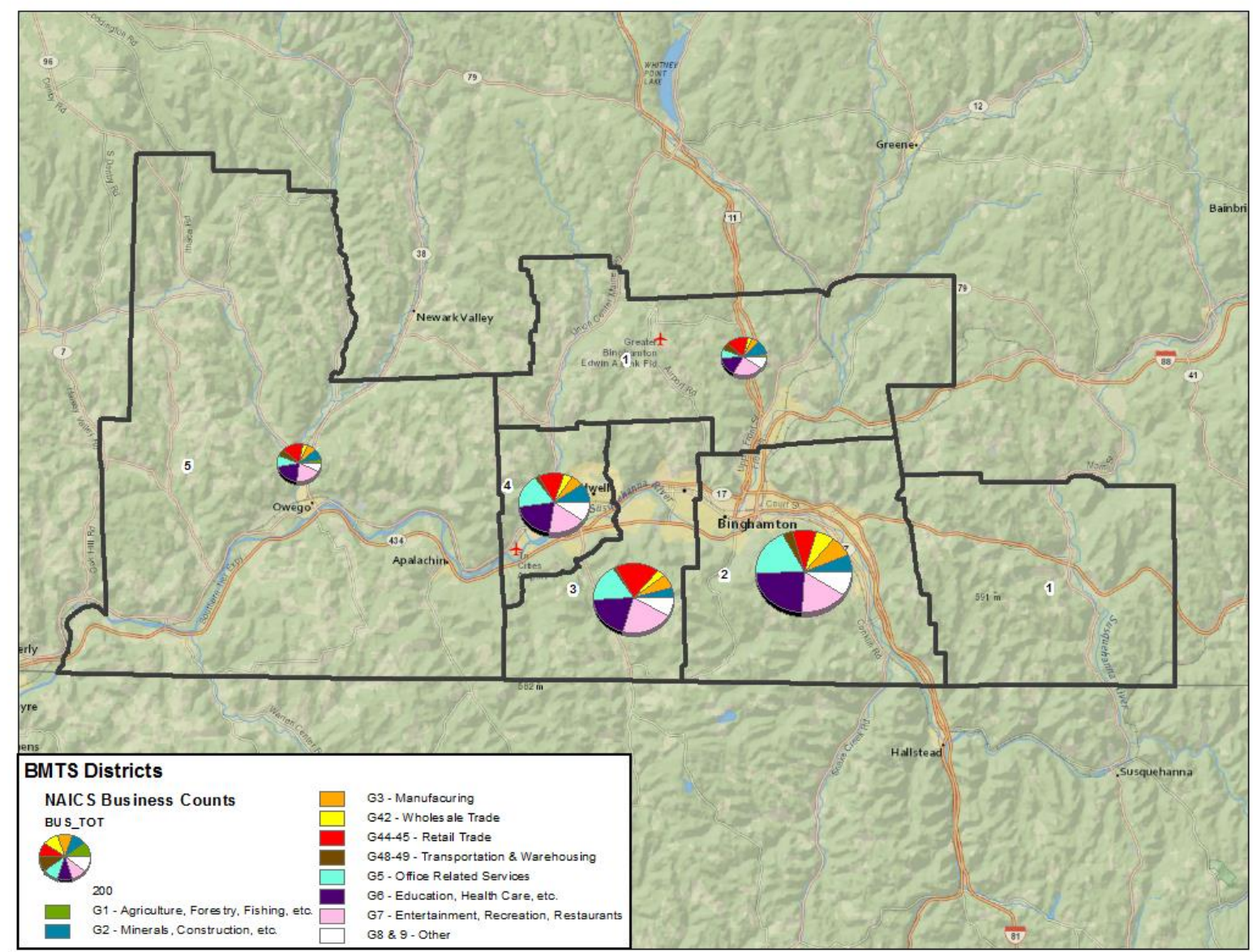

Figure 6-6. Number of businesses (10 or more employees) by industry type in BMTS districts.

Using the number of employees for businesses within each district by the same 10 aggregated-NAICS categories, Figure 6-7 shows a different view of the business mix from the previous map. Clearly visible are the significantly larger shares of educational/health sector (by employee counts) in Binghamton (District 2) and Vestal/JC (District 3). Further investigation confirmed that several medical facilities and universities/colleges are located in these two districts. Furthermore, Binghamton is the largest city in this region, where many public administration facilities are located (including large courthouses), thus explaining the relatively large share of "Other" group (shaded with white).

Also, the share of manufacturing (orange color slice) was significantly higher in the Tioga District when measured by the number of employees instead of the number of businesses. Further investigation of local businesses by the research team found that the most likely reason was the proximity of Tioga residents to an IBM manufacturing facility, along with several other very large facilities that appeared to be related to manufacturing. 


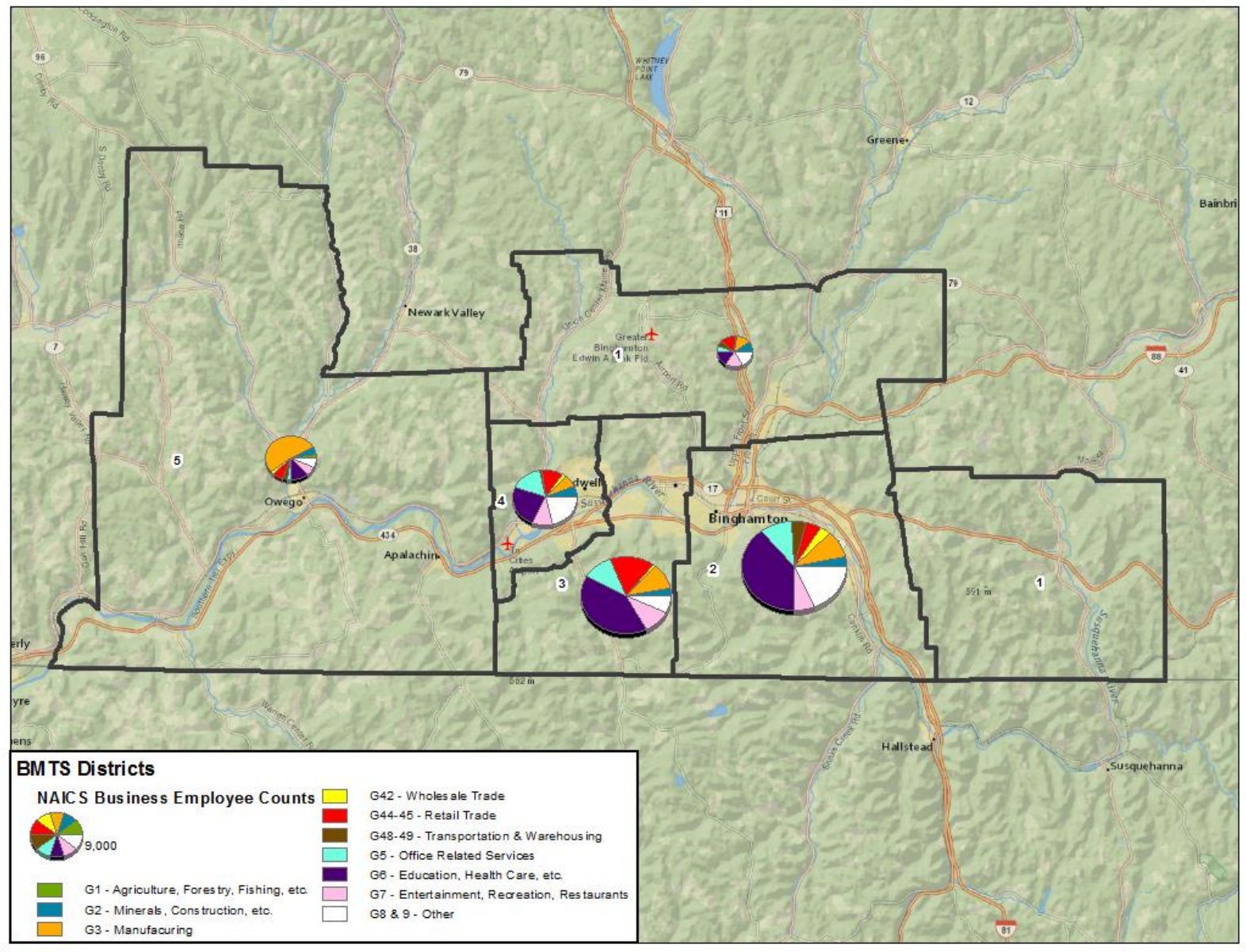

Figure 6-7. Share of businesses (10 or more employees) by employee counts in BMTS districts.

As for the SMTC districts, business shares in wholesale and retail stand out in all districts of the BMTS region (see Figure 6-8) when annual sales in the 10 NAICS-sectors are considered. Again, as pointed out previously, employee-count could have a more direct relationship with commute trips while business sales might be associated more closely with activities such as shopping, eating out, etc. A formal analytical analysis to examine correlations among these factors was beyond the scope of this project and thus was not conducted. 


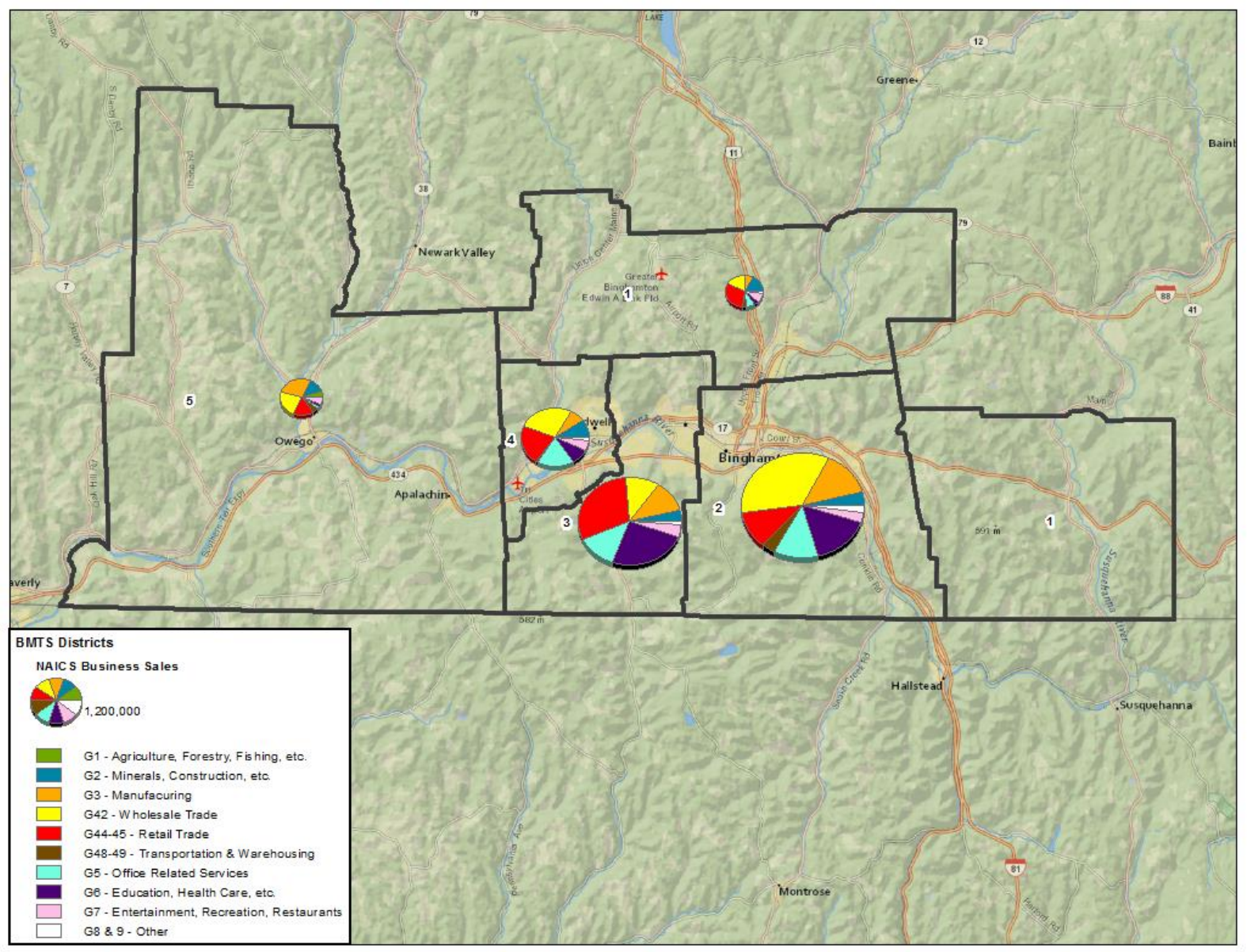

Figure 6-8. Shares of businesses (with 10 or more employees) by annual sales for BMTS districts.

\subsection{BUILDING OCCUPANCY IN BMTS}

Figure 6-9 shows the distribution of building occupancy (by square-footage) in each BMTS district, including residential buildings. Clearly, the Binghamton and Vestal/JC districts had higher shares of commercial (yellow) occupied buildings, measured by building square-footage. Also noticeable, the North/East district showed a significant share of educational building occupancy; a pattern not seen in other BMTS districts.

When the residential sector was eliminated from the total shares, this educational-occupied sector became more visibly dominate than building spaces occupied by all other sectors in the North/East district (see Figure 6-10). The North/East district is a more rural area; it is suspected that, aside from residential spaces, school buildings might occupy more spaces than other businesses in the area. Note that the scale used in Figure 6-10 is much smaller than the scale used in Figure 6-9. Also seen in Figure 6-10, the commercial sector occupies the largest share of building square-footage in all districts, except for the North/East district. 


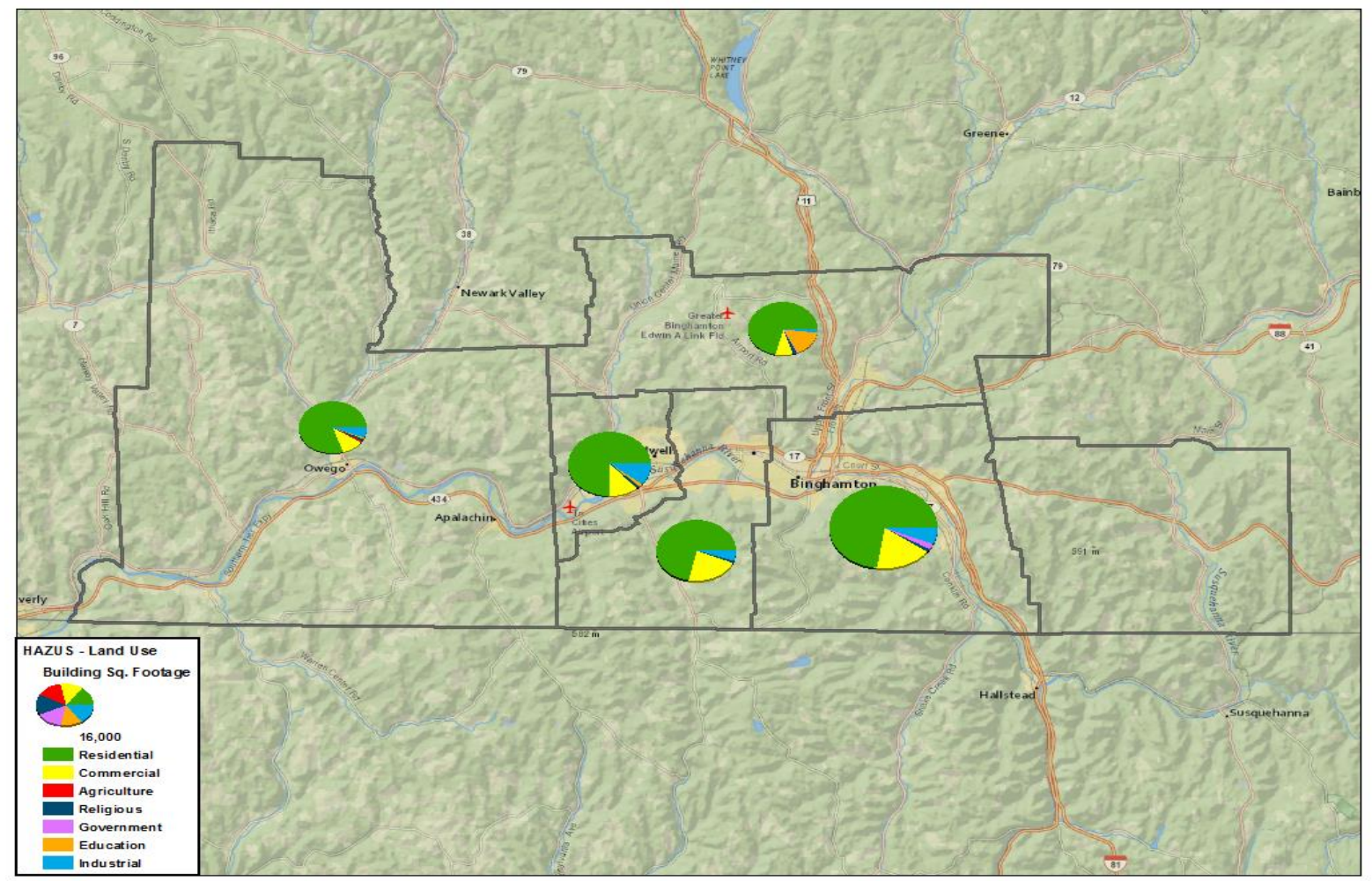

Figure 6-9. Share of sectors using FEMA's building square-footage occupancy data in BMTS districts.

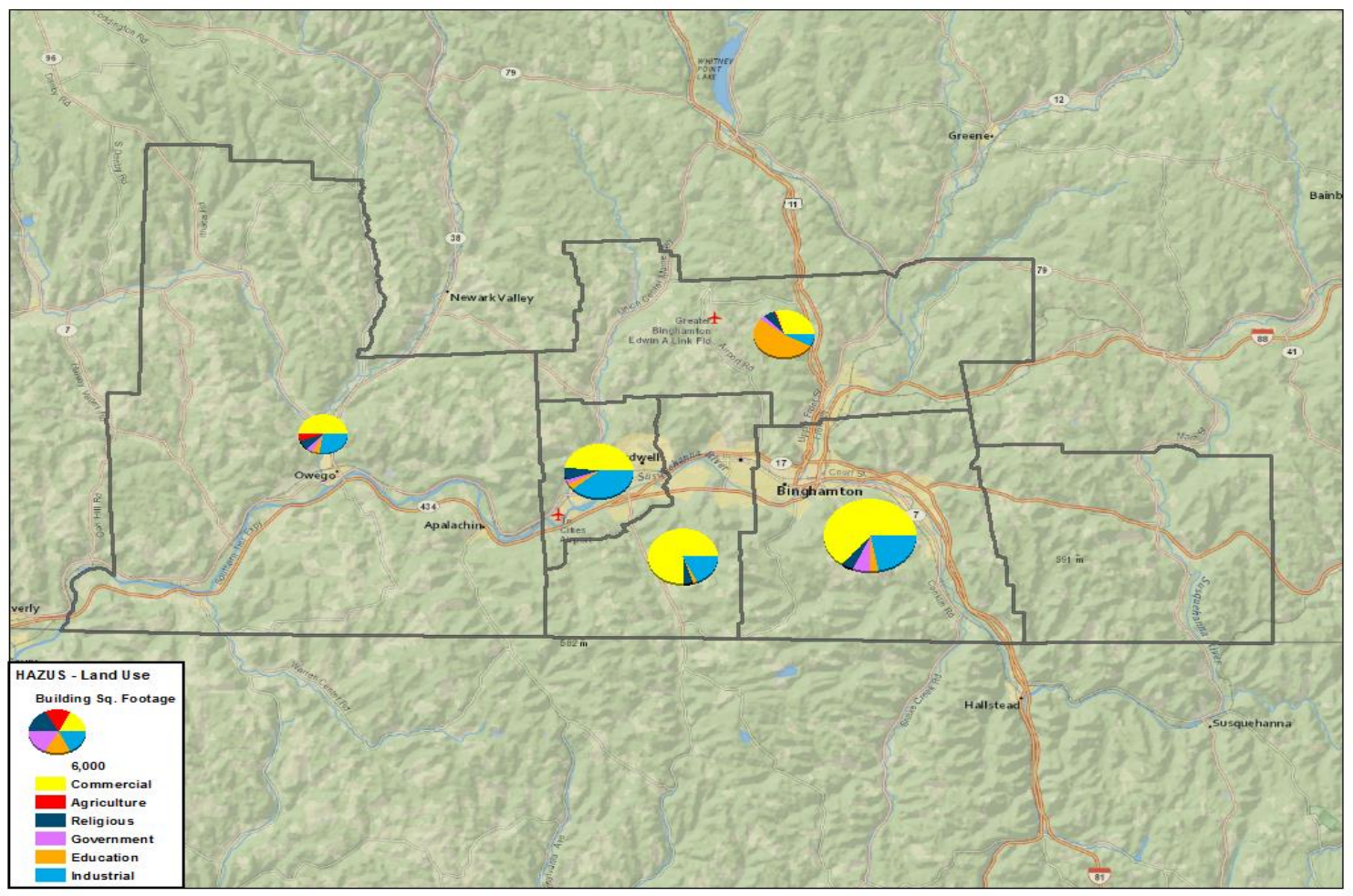

Figure 6-10. Share of non-residential sectors by building square-footage occupancy in BMTS districts. 


\section{INVESTIGATING DISTRICT OD FLOWS}

Many discussions already covered in Sections 4 and 5 were OD-flow based, although typically they were offered at an aggregated level of intra, outbound, and inbound for each district in the two study regions (i.e., SMTC and BMTS districts). This section provides additional in-depth district-level examples of OD-flow patterns examined during this pilot study.

\subsection{SMTC REGION}

\subsubsection{Volume of Travel Activities among SMTC Districts}

Using 2009 NHTS trip data, Table 7-1 through Table 7-4 provide travel volume estimates for PT, PMT, VT, and VMT, respectively. Trips are summarized based on a trip's origin district and its associated destination district. Intra-district travel statistics are highlighted in each table. Note that these tables do not include trips that started from outside the 8 districts of SMTC, or trips that terminated outside these SMTC regions.

Table 7-1. Total Person Trip Flows Between SMTC Districts (in thousand person-trips)

\begin{tabular}{|c|r|r|r|r|r|r|r|r|}
\hline \multirow{2}{*}{$\begin{array}{c}\text { Origin } \\
\text { district }\end{array}$} & \multicolumn{7}{|c|}{ Destination district $^{\mathrm{a}}$} \\
\cline { 2 - 9 } & $\mathbf{1}$ & $\mathbf{2}$ & $\mathbf{3}$ & $\mathbf{4}$ & $\mathbf{5}$ & $\mathbf{6}$ & $\mathbf{7}$ & $\mathbf{8}$ \\
\hline $\mathbf{1}$ & $\mathbf{3 1 , 3 3 3}$ & 8,017 & 2,810 & 1,630 & 6,361 & 6,483 & 5,300 & 7,060 \\
\hline $\mathbf{2}$ & 7,944 & $\mathbf{2 5 , 5 0 9}$ & 3,228 & 650 & 2,270 & 4,891 & 9,232 & 3,507 \\
\hline $\mathbf{3}$ & 3,211 & 3,254 & $\mathbf{1 0 , 1 0 6}$ & 239 & 1,369 & 694 & 2,428 & 3,978 \\
\hline $\mathbf{4}$ & 1,009 & 978 & 90 & $\mathbf{2 4 , 2 9 1}$ & 6,131 & 1,295 & 688 & 3,256 \\
\hline $\mathbf{5}$ & 6,212 & 3,262 & 1,588 & 5,964 & $\mathbf{6 3 , 8 2 8}$ & 14,832 & 2,812 & 3,498 \\
\hline $\mathbf{6}$ & 5,449 & 5,070 & 747 & 1,340 & 14,384 & $\mathbf{5 2 , 2 6 1}$ & 13,433 & 2,287 \\
\hline $\mathbf{7}$ & 5,761 & 9,076 & 2,025 & 1,028 & 2,502 & 13,184 & $\mathbf{7 7 , 0 4 5}$ & 3,083 \\
\hline $\mathbf{8}$ & 8,093 & 2,092 & 4,165 & 2,746 & 4,496 & 1,873 & 3,380 & $\mathbf{7 5 , 5 6 5}$ \\
\hline
\end{tabular}

Note: ${ }^{a}$ Destination districts are: 1. Syracuse West, 2. Syracuse East, 3. Syracuse South, 4. SMTC MPA Northwest, 5. SMTC MPA North, 6. SMTC MPA Northeast, 7. SMTC MPA Southeast, 8. SMTC MPA Southwest. 
Table 7-2. Total Person-Miles of Travel Flows Between SMTC Districts (in thousand person-miles.

\begin{tabular}{|c|r|r|r|r|r|r|r|r|}
\hline \multirow{2}{*}{$\begin{array}{c}\text { Origin } \\
\text { district }\end{array}$} & \multicolumn{10}{|c|}{${\text { Destination } \text { district }^{\mathrm{a}}}^{\mathbf{1}}$} & $\mathbf{2}$ & $\mathbf{3}$ & $\mathbf{4}$ & $\mathbf{5}$ & $\mathbf{6}$ & $\mathbf{7}$ & $\mathbf{8}$ \\
\hline $\mathbf{1}$ & $\mathbf{4 7 , 7 5 7}$ & 22,873 & 7,178 & 26,998 & 45,972 & 75,057 & 53,464 & 55,761 \\
\hline $\mathbf{2}$ & 23,400 & $\mathbf{4 2 , 1 3 2}$ & 22,479 & 10,263 & 43,397 & 34,077 & 41,609 & 29,048 \\
\hline $\mathbf{3}$ & 7,589 & 21,783 & $\mathbf{9 , 0 3 2}$ & 5,486 & 14,050 & 7,368 & 31,463 & 22,220 \\
\hline $\mathbf{4}$ & 15,321 & 18,634 & 863 & $\mathbf{8 2 , 7 3 0}$ & 56,666 & 21,126 & 18,534 & 26,441 \\
\hline $\mathbf{5}$ & 41,913 & 49,225 & 16,270 & 50,810 & $\mathbf{2 2 4 , 0 5 9}$ & 121,794 & 48,494 & 50,187 \\
\hline $\mathbf{6}$ & 58,465 & 36,202 & 8,879 & 21,264 & 117,594 & $\mathbf{1 8 6 , 2 1 3}$ & 94,578 & 35,736 \\
\hline $\mathbf{7}$ & 60,010 & 37,220 & 20,149 & 25,795 & 45,134 & 96,112 & $\mathbf{2 6 6 , 7 5 5}$ & 51,250 \\
\hline $\mathbf{8}$ & 50,585 & 16,678 & 32,091 & 21,685 & 57,900 & 25,564 & 53,298 & $\mathbf{2 1 5 , 1 4 8}$ \\
\hline
\end{tabular}

Table 7-3. Total Vehicle Trip Flows Between SMTC Districts (in thousand vehicle-trips)

\begin{tabular}{|c|r|r|r|r|r|r|r|r|}
\hline \multirow{2}{*}{$\begin{array}{c}\text { Origin } \\
\text { district }\end{array}$} & \multicolumn{10}{|c|}{ Destination district $^{\mathrm{a}}$} \\
\cline { 2 - 9 } & $\mathbf{1}$ & $\mathbf{2}$ & $\mathbf{3}$ & $\mathbf{4}$ & $\mathbf{5}$ & \multicolumn{1}{c|}{$\mathbf{7}$} & $\mathbf{7}$ & $\mathbf{8}$ \\
\hline $\mathbf{1}$ & $\mathbf{1 1 , 2 9 7}$ & 5,971 & 1,355 & 1,545 & 4,932 & 3,440 & 3,801 & 4,679 \\
\hline $\mathbf{2}$ & 5,651 & $\mathbf{1 4 , 7 2 9}$ & 1,142 & 547 & 1,719 & 2,961 & 6,335 & 3,154 \\
\hline $\mathbf{3}$ & 1,970 & 1,203 & $\mathbf{3 , 4 8 6}$ & 239 & 1,091 & 673 & 1,589 & 3,103 \\
\hline $\mathbf{4}$ & 1,009 & 874 & 90 & $\mathbf{1 2 , 6 0 6}$ & 4,664 & 1,295 & 490 & 2,677 \\
\hline $\mathbf{5}$ & 5,184 & 2,583 & 1,310 & 4,588 & $\mathbf{4 3 , 1 8 0}$ & 10,445 & 2,304 & 3,180 \\
\hline $\mathbf{6}$ & 3,180 & 3,221 & 726 & 1,205 & 10,410 & $\mathbf{3 2 , 2 7 4}$ & 8,870 & 1,762 \\
\hline $\mathbf{7}$ & 4,136 & 6,499 & 1,186 & 783 & 2,179 & 9,466 & $\mathbf{4 7 , 2 0 9}$ & 1,996 \\
\hline $\mathbf{8}$ & 5,034 & 1,863 & 3,559 & 2,183 & 4,149 & 1,386 & 2,008 & $\mathbf{4 0 , 2 3 2}$ \\
\hline
\end{tabular}

Note: ${ }^{a}$ Destination districts are: 1. Syracuse West, 2. Syracuse East, 3. Syracuse South, 4. SMTC MPA Northwest, 5. SMTC MPA North, 6. SMTC MPA Northeast, 7. SMTC MPA Southeast, 8. SMTC MPA Southwest.

Table 7-4. Total Vehicle-Miles of Travel Flows Between SMTC Districts (in thousand vehicle-miles)

\begin{tabular}{|c|c|c|c|c|c|c|c|c|}
\hline \multirow{2}{*}{$\begin{array}{l}\text { Origin } \\
\text { district }\end{array}$} & \multicolumn{8}{|c|}{ Destination district $^{\mathrm{a}}$} \\
\hline & 1 & 2 & 3 & 4 & 5 & 6 & 7 & 8 \\
\hline 1 & 26,927 & 18,810 & 4,027 & 25,827 & 35,984 & 36,138 & 42,121 & 46,146 \\
\hline 2 & 18,411 & 32,098 & 5,677 & 8,581 & 29,108 & 18,869 & 33,586 & 25,810 \\
\hline 3 & 5,036 & 5,192 & 5,315 & 5,486 & 12,263 & 7,203 & 21,402 & 14,363 \\
\hline 4 & 15,321 & 16,952 & 863 & 52,718 & 45,264 & 21,126 & 13,218 & 19,924 \\
\hline 5 & 36,722 & 33,836 & 14,482 & 39,345 & 158,031 & 90,243 & 36,422 & 44,869 \\
\hline 6 & 35,269 & 21,129 & 8,714 & 19,509 & 88,955 & 129,310 & 66,141 & 30,225 \\
\hline 7 & 44,366 & 30,485 & 10,930 & 20,243 & 38,284 & 76,311 & 180,938 & 31,501 \\
\hline 8 & 37,636 & 14,771 & 29,260 & 16,077 & 54,119 & 20,019 & 28,077 & 135,656 \\
\hline
\end{tabular}

\subsubsection{Average Trip Length}

Average trip lengths for traveling between SMTC OD districts, in terms of PT and VT, are presented in Tables 7-5 and 7-6, respectively. Since POV is the most commonly used mode by the traveling public, average PT and VT distances were expected to be similar. Again, only trips originating and terminating within the 8 districts of SMTC are presented in the tables. Naturally, intra-district trips (shown in bold) were shorter than inter-district trips. Generally speaking, average trip length from district A to district B 
should be fairly close to the average trip length from B to A, because the majority of trips had a corresponding return trip. The shaded cells in Tables 7-5 and 7-6 reflect a significant difference in average trip lengths between Districts 3 and 4 (in two directions). This might be due to small sample size; it also could be a result from potential outliers in the data.

Table 7-5. Average Person-trip Distance Between SMTC Districts

\begin{tabular}{|c|c|c|c|c|c|c|c|c|}
\hline \multirow{2}{*}{$\begin{array}{l}\text { Origin } \\
\text { district }\end{array}$} & \multicolumn{8}{|c|}{ Destination district ${ }^{\mathrm{a}}$} \\
\hline & 1 & 2 & 3 & 4 & 5 & 6 & 7 & 8 \\
\hline 1 & 1.5 & 2.9 & 3.2 & 16.6 & 7.3 & 11.6 & 10.1 & 8.3 \\
\hline 2 & 3.0 & 1.7 & 8.4 & 15.8 & 19.1 & 7.0 & 4.5 & 8.3 \\
\hline 3 & 2.4 & 8.0 & 0.9 & 23.0 & 10.3 & 10.6 & 13.9 & 5.6 \\
\hline 4 & 15.2 & 19.1 & 9.6 & 3.4 & 9.2 & 16.3 & 26.9 & 8.1 \\
\hline 5 & 6.8 & 15.1 & 10.2 & 8.5 & 3.5 & 8.3 & 17.3 & 14.6 \\
\hline 6 & 10.7 & 7.1 & 11.9 & 16.5 & 8.2 & 3.6 & 7.0 & 15.6 \\
\hline 7 & 10.4 & 4.4 & 10.8 & 25.1 & 18.0 & 7.3 & 3.5 & 16.6 \\
\hline 8 & 6.5 & 8.0 & 7.8 & 7.9 & 13.0 & 13.7 & 15.8 & 2.9 \\
\hline
\end{tabular}

Table 7-6. Average Vehicle-trip Distance Between SMTC Districts

\begin{tabular}{|c|c|c|c|c|c|c|c|c|}
\hline \multirow{2}{*}{$\begin{array}{l}\text { Origin } \\
\text { district }\end{array}$} & \multicolumn{8}{|c|}{ 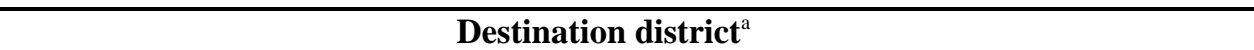 } \\
\hline & 1 & 2 & 3 & 4 & 5 & 6 & 7 & 8 \\
\hline 1 & 2.4 & 3.2 & 3.1 & 16.7 & 7.3 & 10.5 & 11.1 & 9.9 \\
\hline 2 & 3.3 & 2.2 & 5.0 & 15.7 & 16.9 & 6.4 & 5.3 & 8.2 \\
\hline 3 & 2.6 & 4.3 & 1.7 & 23.0 & 11.2 & 10.7 & 13.5 & 4.7 \\
\hline 4 & 15.2 & 19.4 & 9.6 & 4.2 & 9.7 & 16.3 & 27.0 & 7.4 \\
\hline 5 & 7.1 & 13.1 & 11.1 & 8.6 & 3.7 & 8.6 & 15.8 & 14.1 \\
\hline 6 & 11.1 & 6.6 & 12.0 & 16.9 & 8.6 & 4.0 & 7.5 & 17.2 \\
\hline 7 & 10.7 & 5.1 & 9.2 & 25.8 & 17.6 & 8.1 & 3.8 & 15.8 \\
\hline 8 & 7.5 & 7.9 & 8.3 & 7.4 & 13.0 & 14.4 & 14.0 & 3.4 \\
\hline
\end{tabular}

Note: ${ }^{a}$ Destination districts are: 1. Syracuse West, 2. Syracuse East, 3. Syracuse South, 4. SMTC MPA Northwest, 5. SMTC MPA North, 6. SMTC MPA Northeast, 7. SMTC MPA Southeast, 8. SMTC MPA Southwest.

\subsubsection{Trip Purposes}

Due to sample size limitations, only limited statistics by trip purpose can be presented at the OD-level for SMTC districts. Tables 7-7 and 7-8 provide summary statistics on trips made for the purpose of "earning a living" on PT and VT, respectively. Similar tables on trips made for "family/personal business" purposes between the SMTC districts are given in Tables 7-9 and 7-10, for PT and VT respectively. 
Table 7-7. Person Trips Made for the Purpose of "Earning a Living" (1,000 trips)

\begin{tabular}{|c|r|r|r|r|r|r|r|r|}
\hline \multirow{2}{*}{$\begin{array}{c}\text { Origin } \\
\text { district }\end{array}$} & \multicolumn{10}{|c|}{ Destination district $^{\mathrm{a}}$} \\
\cline { 2 - 9 } & $\mathbf{1}$ & $\mathbf{2}$ & $\mathbf{3}$ & $\mathbf{4}$ & $\mathbf{5}$ & \multicolumn{1}{c|}{$\mathbf{5}$} & \multicolumn{1}{c|}{$\mathbf{7}^{\mathbf{1}}$} & $\mathbf{8}$ \\
\hline $\mathbf{1}$ & $\mathbf{6 , 7 0 8}$ & 1,249 & 838 & 915 & 3,351 & 1,332 & 1,188 & 1,337 \\
\hline $\mathbf{2}$ & 1,300 & $\mathbf{3 , 6 9 9}$ & 678 & 317 & 630 & 760 & 1,882 & 865 \\
\hline $\mathbf{3}$ & 243 & 403 & $\mathbf{1 , 0 8 6}$ & 239 & 603 & 173 & 686 & 138 \\
\hline $\mathbf{4}$ & 740 & 739 & 38 & $\mathbf{3 , 8 3 7}$ & 1,487 & 295 & 270 & 755 \\
\hline $\mathbf{5}$ & 3,192 & 918 & 651 & 1,374 & $\mathbf{8 , 8 7 4}$ & 3,853 & 1,362 & 529 \\
\hline $\mathbf{6}$ & 1,421 & 1,219 & 173 & 1,014 & 3,467 & $\mathbf{6 , 7 8 1}$ & 3,973 & 973 \\
\hline $\mathbf{7}$ & 1,147 & 2,300 & 219 & 524 & 1,160 & 4,589 & $\mathbf{8 , 2 7 4}$ & 526 \\
\hline $\mathbf{8}$ & 1,923 & 477 & - & 939 & 389 & 715 & 592 & $\mathbf{5 , 8 7 4}$ \\
\hline
\end{tabular}

Note: ${ }^{a}$ Destination districts are: 1. Syracuse West, 2. Syracuse East, 3. Syracuse South, 4. SMTC MPA Northwest,

5. SMTC MPA North, 6. SMTC MPA Northeast, 7. SMTC MPA Southeast, 8. SMTC MPA Southwest.

The symbol "-" indicates zero sample data.

Table 7-8. Vehicle Trips Made for the Purpose of "Earning a Living" (1,000 trips)

\begin{tabular}{|c|r|r|r|r|r|r|r|r|}
\hline \multirow{2}{*}{$\begin{array}{c}\text { Origin } \\
\text { district }\end{array}$} & \multicolumn{1}{|c|}{$\mathbf{1}^{\mathbf{1}}$} & \multicolumn{1}{|c|}{$\mathbf{2}$} & $\mathbf{3}$ & $\mathbf{4}$ & $\mathbf{5}$ & \multicolumn{1}{|c|}{$\mathbf{6}$} & $\mathbf{7}$ & \multicolumn{1}{|c|}{$\mathbf{8}$} \\
\hline $\mathbf{1}$ & $\mathbf{4 , 0 4 1}$ & 1,249 & 649 & 915 & 3,058 & 1,332 & 1,188 & 1,121 \\
\hline $\mathbf{2}$ & 1,056 & $\mathbf{3 , 1 4 7}$ & 678 & 226 & 630 & 760 & 1,479 & 865 \\
\hline $\mathbf{3}$ & 243 & 403 & $\mathbf{8 8 3}$ & 239 & 365 & 173 & 686 & 138 \\
\hline $\mathbf{4}$ & 740 & 648 & 38 & $\mathbf{3 , 8 3 7}$ & 1,487 & 295 & 270 & 592 \\
\hline $\mathbf{5}$ & 2,876 & 918 & 413 & 1,374 & $\mathbf{7 , 1 1 1}$ & 3,769 & 1,327 & 529 \\
\hline $\mathbf{6}$ & 1,421 & 1,219 & 173 & 1,014 & 3,276 & $\mathbf{6 , 1 0 3}$ & 3,604 & 885 \\
\hline $\mathbf{7}$ & 1,147 & 2,265 & 219 & 477 & 1,160 & 4,473 & $\mathbf{7 , 1 3 9}$ & 407 \\
\hline $\mathbf{8}$ & 1,743 & 477 & - & 706 & 389 & 681 & 545 & $\mathbf{3 , 7 7 2}$ \\
\hline
\end{tabular}

Note: ${ }^{a}$ Destination districts are: 1. Syracuse West, 2. Syracuse East, 3. Syracuse South, 4. SMTC MPA Northwest,

5. SMTC MPA North, 6. SMTC MPA Northeast, 7. SMTC MPA Southeast, 8. SMTC MPA Southwest.

The symbol "-" indicates zero sample data.

Table 7-9. Person Trips Made for the Purpose of "Family/Personal Business" (1,000 trips)

\begin{tabular}{|c|r|r|r|r|r|r|r|r|}
\hline \multirow{2}{*}{$\begin{array}{c}\text { Origin } \\
\text { district }\end{array}$} & \multicolumn{10}{|c|}{ Destination district $^{\mathrm{a}}$} \\
\cline { 2 - 9 } & $\mathbf{1}$ & $\mathbf{2}$ & $\mathbf{3}$ & $\mathbf{4}$ & $\mathbf{5}$ & $\mathbf{6}$ & \multicolumn{1}{c|}{$\mathbf{7}$} & $\mathbf{8}$ \\
\hline $\mathbf{1}$ & $\mathbf{1 4 , 6 3 9}$ & 5,207 & 472 & 579 & 1,951 & 4,029 & 2,901 & 3,350 \\
\hline $\mathbf{2}$ & 4,216 & $\mathbf{1 2 , 2 8 3}$ & 1,783 & 290 & 890 & 2,474 & 5,664 & 1,038 \\
\hline $\mathbf{3}$ & 1,709 & 1,508 & $\mathbf{2 , 1 8 0}$ & - & 194 & 466 & 861 & 2,480 \\
\hline $\mathbf{4}$ & 134 & 13 & 52 & $\mathbf{6 , 2 9 3}$ & 2,153 & 829 & 419 & 1,333 \\
\hline $\mathbf{5}$ & 1,746 & 784 & 366 & 1,570 & $\mathbf{3 2 , 9 7 0}$ & 6,529 & 593 & 1,156 \\
\hline $\mathbf{6}$ & 2,945 & 2,032 & 574 & 64 & 6,468 & $\mathbf{2 3 , 9 5 9}$ & 5,731 & 619 \\
\hline $\mathbf{7}$ & 2,927 & 4,963 & 919 & 130 & 750 & 5,717 & $\mathbf{3 0 , 7 0 7}$ & 1,600 \\
\hline $\mathbf{8}$ & 2,865 & 598 & 2,853 & 850 & 1,265 & 714 & 1,093 & $\mathbf{3 5 , 4 0 9}$ \\
\hline
\end{tabular}

Note: ${ }^{2}$ Destination districts are: 1. Syracuse West, 2. Syracuse East, 3. Syracuse South, 4. SMTC MPA Northwest,

5. SMTC MPA North, 6. SMTC MPA Northeast, 7. SMTC MPA Southeast, 8. SMTC MPA Southwest.

The symbol "-" indicates zero sample data. 
Table 7-10. Vehicle Trips Made for the Purpose of "Family/Personal Business" (1,000 trips)

\begin{tabular}{|c|r|r|r|r|r|r|r|r|}
\hline \multirow{2}{*}{$\begin{array}{c}\text { Origin } \\
\text { district }\end{array}$} & \multicolumn{10}{|c|}{ Destination district $^{\mathrm{a}}$} \\
\cline { 2 - 9 } & $\mathbf{1}$ & $\mathbf{2}$ & $\mathbf{3}$ & $\mathbf{4}$ & $\mathbf{5}$ & \multicolumn{1}{c|}{$\mathbf{5}$} & \multicolumn{1}{c|}{$\mathbf{7}$} & $\mathbf{8}$ \\
\hline $\mathbf{1}$ & $\mathbf{4 , 8 4 8}$ & 3,668 & 92 & 495 & 1,570 & 1,942 & 1,556 & 2,440 \\
\hline $\mathbf{2}$ & 2,753 & $\mathbf{7 , 3 5 1}$ & 378 & 290 & 816 & 1,481 & 3,748 & 831 \\
\hline $\mathbf{3}$ & 1,119 & 138 & $\mathbf{1 , 7 4 9}$ & - & 155 & 446 & 580 & 1,969 \\
\hline $\mathbf{4}$ & 134 & 13 & 52 & $\mathbf{5 , 0 6 5}$ & 1,770 & 829 & 221 & 1,281 \\
\hline $\mathbf{5}$ & 1,716 & 743 & 326 & 1,136 & $\mathbf{2 5 , 5 5 0}$ & 4,343 & 469 & 890 \\
\hline $\mathbf{6}$ & 1,426 & 1,381 & 553 & 64 & 5,108 & $\mathbf{1 8 , 2 7 3}$ & 4,277 & 504 \\
\hline $\mathbf{7}$ & 1,832 & 3,219 & 919 & 93 & 650 & 4,232 & $\mathbf{2 2 , 9 0 4}$ & 939 \\
\hline $\mathbf{8}$ & 2,006 & 456 & 2,626 & 850 & 1,184 & 344 & 741 & $\mathbf{2 4 , 7 0 7}$ \\
\hline
\end{tabular}

Note: ${ }^{2}$ Destination districts are: 1. Syracuse West, 2. Syracuse East, 3. Syracuse South, 4. SMTC MPA Northwest, 5. SMTC MPA North, 6. SMTC MPA Northeast, 7. SMTC MPA Southeast, 8. SMTC MPA Southwest.

The symbol "-" indicates zero sample data.

The OD flows are displayed on a map with line thickness reflecting the volume of travel. Although showing trips with multiple origins or destinations on the same map is possible, the resulting map would be rather busy to visualize any details. Figure 7-1 gives an example of commute flows into District 1 (Syracuse West) from all districts; intra-District 1 flow is shown with a very short line close to the centroid of the district. A similar example map in Figure 7-2 displays trips made for family/personal business into District 2 (Syracuse East).

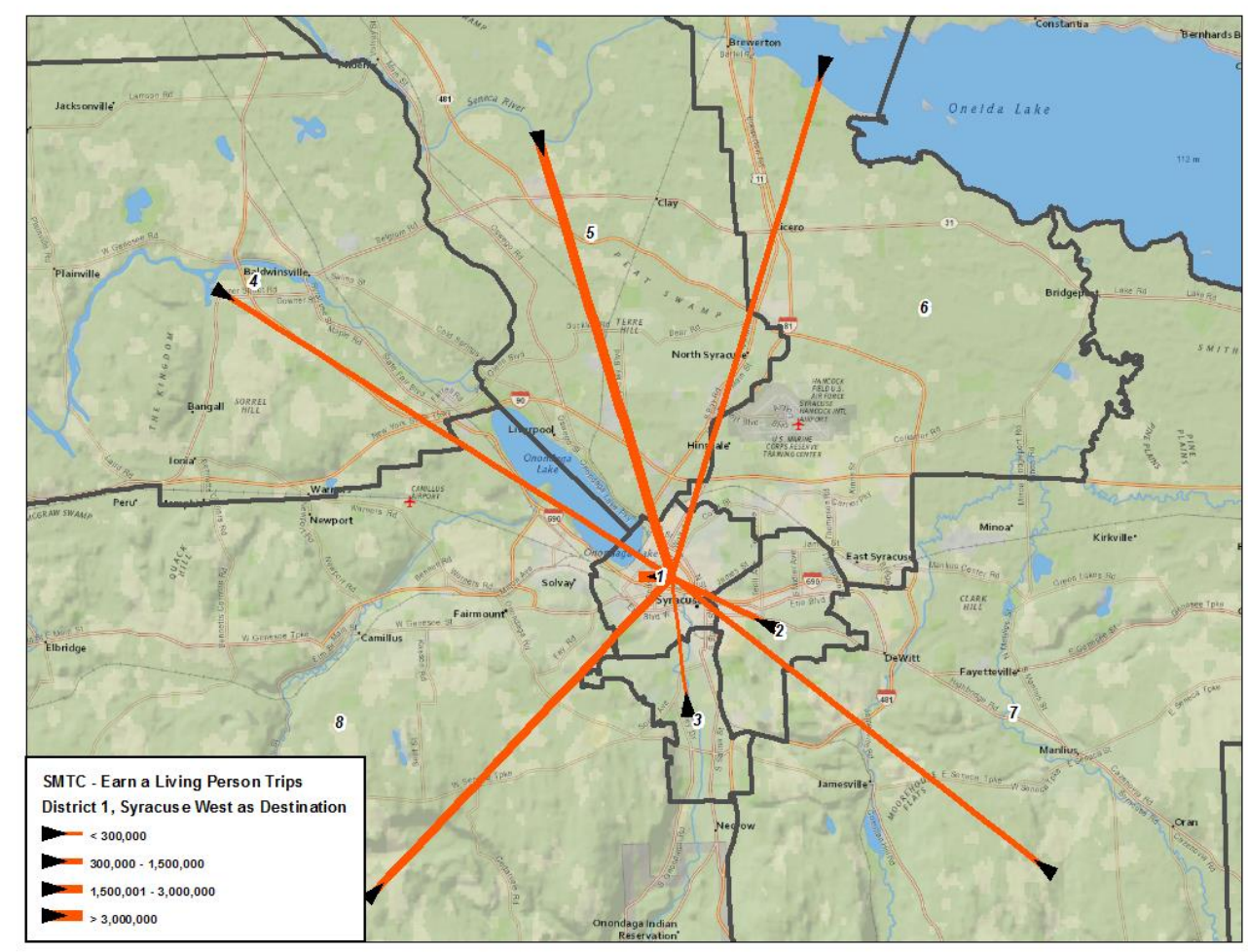

Figure 7-1. Commute flow to District 1 from all SMTC districts in person trips. 


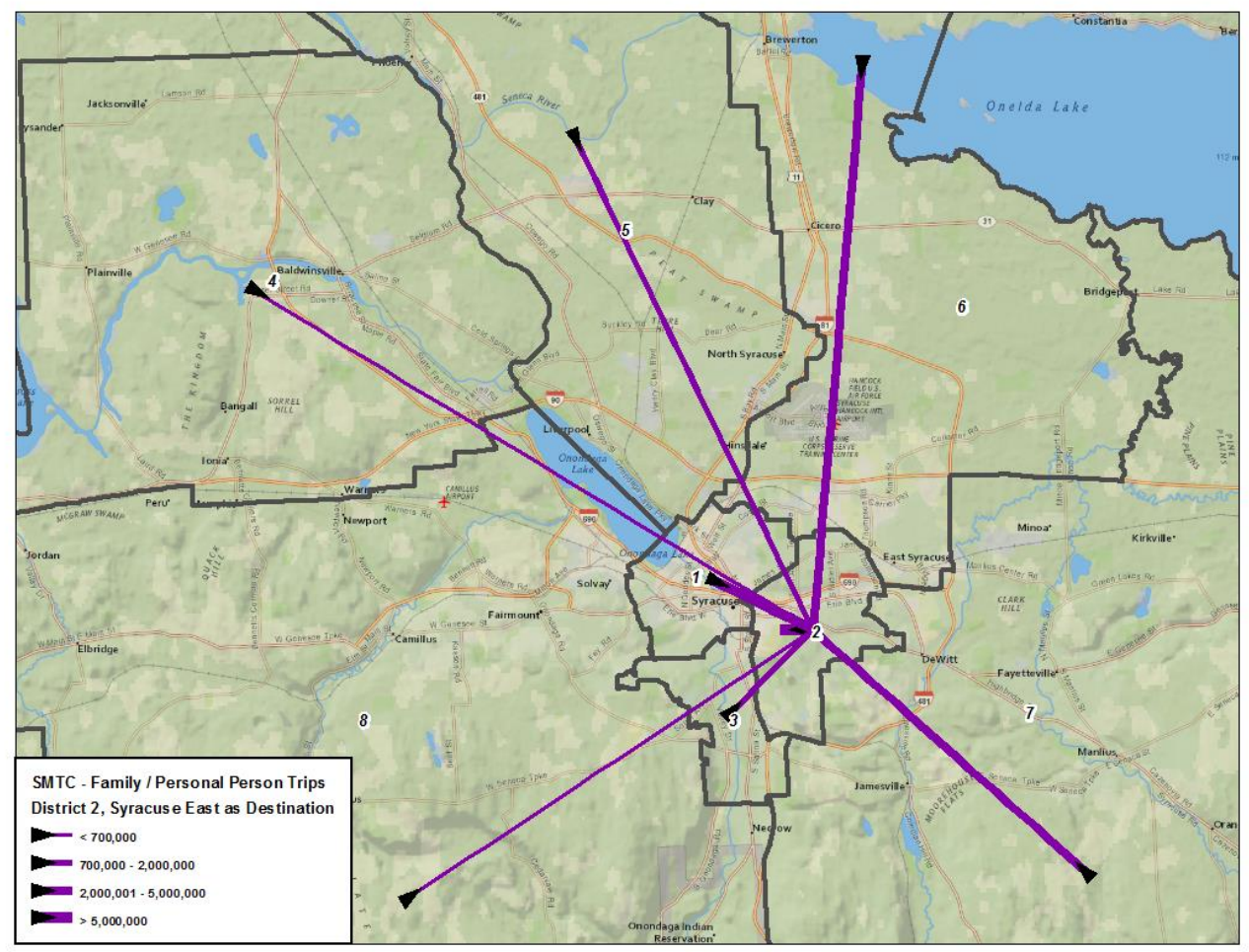

Figure 7-2. Family/personal business trips made from all SMTC districts to District 2 in person trips.

Corresponding PMT and VMT tables for OD flows by the purposes of "earning a living" and "family/personal business" are provided in Tables 7-11 through Table 7-14.

Table 7-11. Person Miles Traveled for the Purpose of "Earning a Living" (1,000 person miles)

\begin{tabular}{|c|r|r|r|r|r|r|r|r|}
\hline \multirow{2}{*}{$\begin{array}{c}\text { Origin } \\
\text { district }\end{array}$} & \multicolumn{1}{|c|}{ Destination district $^{\mathrm{a}}$} \\
\hline $\mathbf{1}$ & $\mathbf{1}$ & $\mathbf{2}$ & $\mathbf{3}$ & $\mathbf{4}$ & $\mathbf{5}$ & $\mathbf{6}$ & \multicolumn{1}{|c|}{} & $\mathbf{8}$ \\
\hline $\mathbf{1 8 , 2 3 3}$ & 3,563 & 1,331 & 17,161 & 25,545 & 17,872 & 11,283 & 10,368 \\
\hline $\mathbf{2}$ & 4,346 & $\mathbf{7 , 7 7 4}$ & 3,136 & 4,064 & 7,766 & 7,121 & 10,158 & 7,423 \\
\hline $\mathbf{3}$ & 1,053 & 2,234 & $\mathbf{3 , 5 3 7}$ & 5,486 & 7,812 & 2,130 & 10,285 & 2,015 \\
\hline $\mathbf{4}$ & 11,553 & 14,553 & 342 & $\mathbf{2 4 , 3 9 5}$ & 17,282 & 5,362 & 7,155 & 9,337 \\
\hline $\mathbf{5}$ & 22,239 & 12,101 & 8,340 & 13,647 & $\mathbf{4 0 , 0 1 7}$ & 34,104 & 21,871 & 6,280 \\
\hline $\mathbf{6}$ & 22,569 & 11,983 & 2,054 & 16,736 & 28,616 & $\mathbf{5 1 , 6 2 3}$ & 33,803 & 15,375 \\
\hline $\mathbf{7}$ & 13,743 & 14,775 & 3,636 & 14,174 & 17,981 & 44,793 & $\mathbf{3 3 , 5 6 3}$ & 9,211 \\
\hline $\mathbf{8}$ & 18,236 & 5,221 & - & 8,634 & 5,849 & 11,701 & 10,593 & $\mathbf{1 9 , 7 6 9}$ \\
\hline
\end{tabular}

Note: ${ }^{a}$ Destination districts are: 1. Syracuse West, 2. Syracuse East, 3. Syracuse South, 4. SMTC MPA Northwest, 5. SMTC MPA North, 6. SMTC MPA Northeast, 7. SMTC MPA Southeast, 8. SMTC MPA Southwest.

The symbol "-" indicates zero sample data. 
Table 7-12. Vehicle Miles Traveled for the Purpose of "Earning a Living" (1,000 vehicle miles)

\begin{tabular}{|c|c|c|c|c|c|c|c|c|}
\hline \multirow{2}{*}{$\begin{array}{l}\text { Origin } \\
\text { district }\end{array}$} & \multicolumn{8}{|c|}{ Destination district $^{\mathrm{a}}$} \\
\hline & 1 & 2 & 3 & 4 & 5 & 6 & 7 & 8 \\
\hline 1 & 15,739 & 3,563 & 1,236 & 17,161 & 22,909 & 17,872 & 11,283 & 9,669 \\
\hline 2 & 3,842 & 7,659 & 3,136 & 2,610 & 7,766 & 7,121 & 9,352 & 7,423 \\
\hline 3 & 1,053 & 2,234 & 3,132 & 5,486 & 6,619 & 2,130 & 10,285 & 2,015 \\
\hline 4 & 11,553 & 13,099 & 342 & 24,395 & 17,282 & 5,362 & 7,155 & 8,095 \\
\hline 5 & 22,133 & 12,101 & 7,147 & 13,647 & 31,020 & 33,433 & 20,577 & 6,280 \\
\hline 6 & 22,569 & 11,983 & 2,054 & 16,736 & 27,782 & 46,162 & 31,816 & 13,194 \\
\hline 7 & 13,743 & 13,970 & 3,636 & 13,938 & 17,981 & 44,329 & $\overline{30,924}$ & 8,380 \\
\hline 8 & 17,337 & 5,221 & 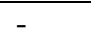 & 7,239 & 5,849 & 10,828 & 9,839 & 13,668 \\
\hline
\end{tabular}

Note: ${ }^{a}$ Destination districts are: 1. Syracuse West, 2. Syracuse East, 3. Syracuse South, 4. SMTC MPA Northwest, 5. SMTC MPA North, 6. SMTC MPA Northeast, 7. SMTC MPA Southeast, 8. SMTC MPA Southwest.

The symbol "-" indicates zero sample data.

Table 7-13. Person-miles-traveled for the Purpose of "Family/person Business" (1,000 person miles)

\begin{tabular}{|c|c|c|c|c|c|c|c|c|}
\hline \multirow{2}{*}{$\begin{array}{c}\text { Origin } \\
\text { district }\end{array}$} & \multicolumn{8}{|c|}{ Destination district ${ }^{\mathrm{a}}$} \\
\hline & 1 & 2 & 3 & 4 & 5 & 6 & 7 & 8 \\
\hline $\mathbf{1}$ & 17,455 & 12,584 & 173 & 7,275 & 12,726 & 47,920 & 26,434 & 30,270 \\
\hline 2 & 9,560 & 24,349 & 7,051 & 5,229 & 16,965 & 10,618 & 21,668 & 9,002 \\
\hline 3 & 1,960 & 5,586 & 1,790 & - & 2,276 & 4,747 & 10,890 & 9,477 \\
\hline 4 & 1,207 & 228 & 521 & 16,443 & 20,286 & 12,954 & 11,379 & 4,068 \\
\hline 5 & 9,494 & 13,554 & 3,967 & 13,781 & 103,647 & 50,510 & 10,886 & 15,814 \\
\hline 6 & 24,533 & 5,981 & 6,825 & 1,126 & 56,049 & 81,573 & 31,658 & 13,584 \\
\hline 7 & 27,329 & 18,154 & 6,712 & 3,965 & 15,518 & 35,399 & 104,786 & 17,356 \\
\hline 8 & 15,627 & 3,986 & 26,708 & 2,276 & 14,362 & 9,941 & 8,892 & 106,032 \\
\hline
\end{tabular}

Note: ${ }^{\mathrm{a} D e s t i n a t i o n}$ districts are: 1. Syracuse West, 2. Syracuse East, 3. Syracuse South, 4. SMTC MPA Northwest, 5. SMTC MPA North, 6. SMTC MPA Northeast, 7. SMTC MPA Southeast, 8. SMTC MPA Southwest.

The symbol "-" indicates zero sample data.

Table 7-14. Vehicle Miles Traveled for the Purpose of "Family/person Business" (1,000 person miles)

\begin{tabular}{|c|r|r|r|r|r|r|r|r|}
\hline \multirow{2}{*}{$\begin{array}{c}\text { Origin } \\
\text { district }\end{array}$} & \multicolumn{1}{|c|}{$\mathbf{1}^{\mathbf{1}}$} & \multicolumn{1}{|c|}{$\mathbf{1}$} & $\mathbf{3}$ & $\mathbf{4}$ & $\mathbf{5}$ & $\mathbf{6}$ & $\mathbf{7}$ & \multicolumn{1}{|c|}{$\mathbf{\mathbf { 6 }}$} \\
\hline $\mathbf{1}$ & $\mathbf{6 , 4 0 8}$ & 10,302 & 57 & 6,105 & 11,202 & 17,062 & 16,528 & 27,816 \\
\hline $\mathbf{2}$ & 7,195 & $\mathbf{1 9 , 4 0 3}$ & 1,942 & 5,229 & 16,252 & 8,195 & 16,144 & 7,341 \\
\hline $\mathbf{3}$ & 1,708 & 688 & $\mathbf{1 , 5 0 9}$ & - & 1,681 & 4,582 & 8,084 & 6,426 \\
\hline $\mathbf{4}$ & 1,207 & 228 & 521 & $\mathbf{1 3 , 3 8 9}$ & 17,116 & 12,954 & 6,062 & 3,602 \\
\hline $\mathbf{5}$ & 9,249 & 13,135 & 3,373 & 9,025 & $\mathbf{8 4 , 5 7 3}$ & 35,605 & 7,933 & 10,495 \\
\hline $\mathbf{6}$ & 9,363 & 4,294 & 6,660 & 1,126 & 45,530 & $\mathbf{5 9 , 7 4 6}$ & 25,218 & 10,964 \\
\hline $\mathbf{7}$ & 16,789 & 13,962 & 6,712 & 2,680 & 12,825 & 27,492 & $\mathbf{8 2 , 3 0 2}$ & 10,060 \\
\hline $\mathbf{8}$ & 11,013 & 2,780 & 25,189 & 2,276 & 14,304 & 5,844 & 6,313 & $\mathbf{7 7 , 4 4 8}$ \\
\hline
\end{tabular}

Note: ${ }^{a}$ Destination districts are: 1 . Syracuse West, 2. Syracuse East, 3. Syracuse South, 4. SMTC MPA Northwest, 5. SMTC MPA North, 6. SMTC MPA Northeast, 7. SMTC MPA Southeast, 8. SMTC MPA Southwest.

The symbol "-” indicates zero sample data.

Other aggregation of trip purposes can also be used to review OD flows. Using District 7 (SMTC MPA Southeast) as an example, PT for "home to work" and "home to other" were summarized and presented in Table 7-15. These results are also illustrated visually in maps provided in Figures 7-3 and 7-4, also showing "home to work" and "home to other" respectively. 
Table 7-15. Origin-destination Flows from District 7 to All SMTC Districts (1,000 person trips)

\begin{tabular}{|c|r|r|r|r|r|r|r|r|}
\hline \multirow{2}{*}{ Trip type } & \multicolumn{8}{|c|}{ Destination district $^{\mathrm{a}}$} \\
\cline { 2 - 10 } & $\mathbf{1}$ & $\mathbf{2}$ & $\mathbf{3}$ & $\mathbf{4}$ & $\mathbf{5}$ & $\mathbf{6}$ & $\mathbf{7}$ & $\mathbf{8}$ \\
\hline Home to work & 945 & 1,432 & 219 & - & 900 & 2,534 & 2,397 & 113 \\
\hline Home to other & 1,856 & 854 & 239 & 91 & 283 & 3,425 & 23,592 & 1,106 \\
\hline
\end{tabular}

Note: ${ }^{a}$ Destination districts are: 1. Syracuse West, 2. Syracuse East, 3. Syracuse South, 4. SMTC MPA Northwest,

5. SMTC MPA North, 6. SMTC MPA Northeast, 7. SMTC MPA Southeast, 8. SMTC MPA Southwest.

The symbol "-" indicates zero sample data.

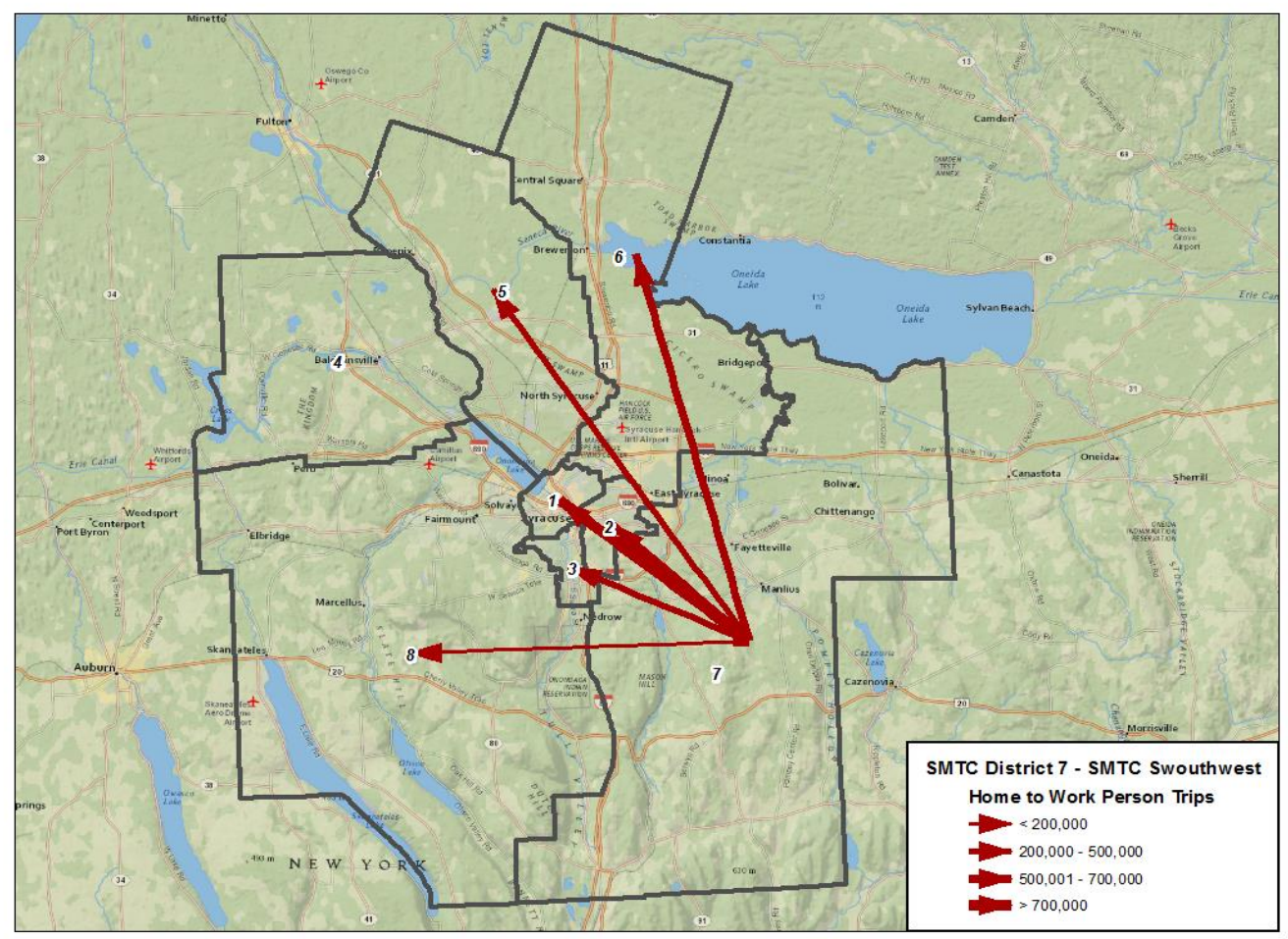

Figure 7-3. Home to work flows of person-trips from District 7 to all SMTC districts. 


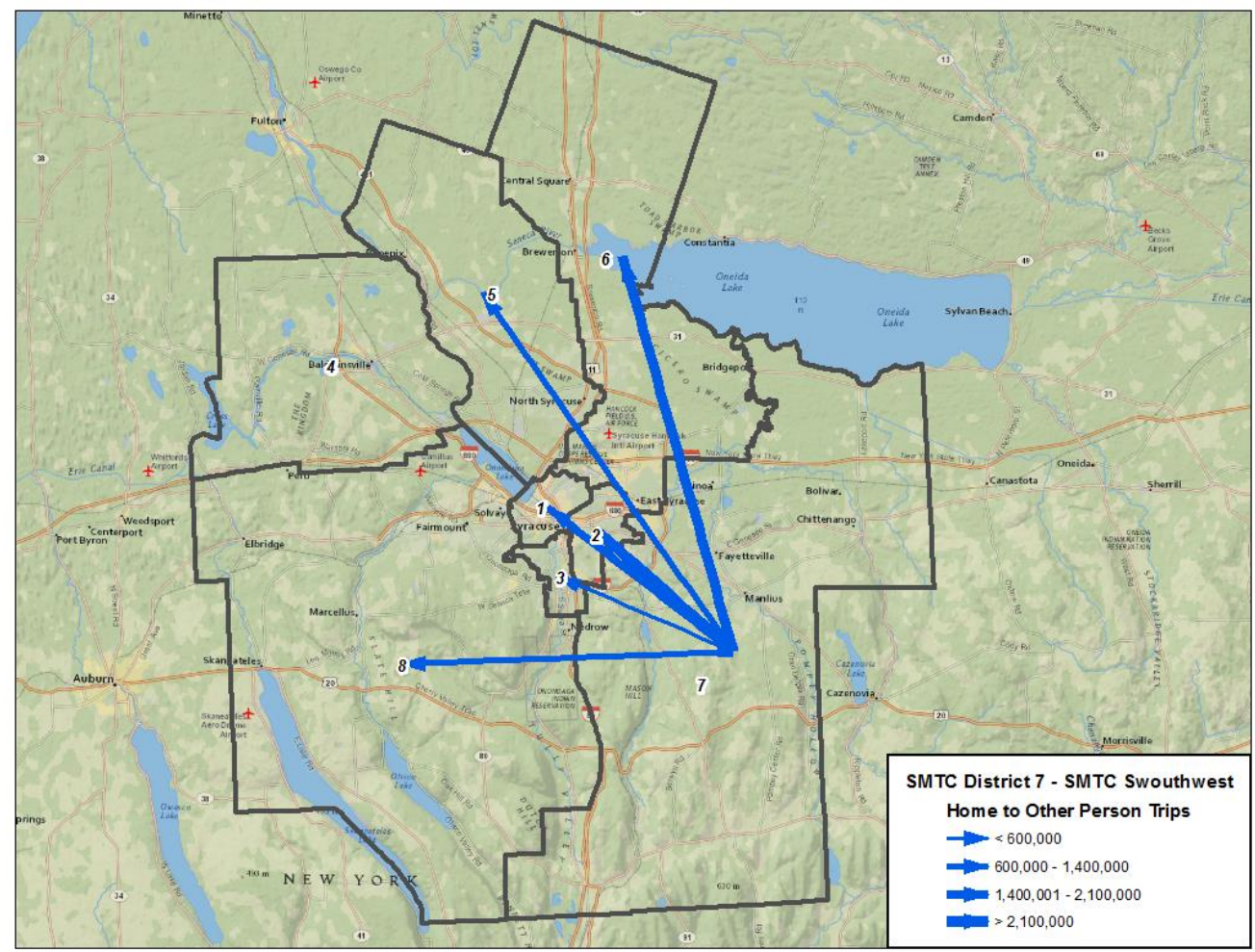

Figure 7-4. Home to Other flows of person-trips from District 7 to all SMTC districts.

\subsubsection{Vehicle Travel}

With the exception of POV (which is the primary mode for most of the SMTC trips), OD flows by mode was not possible due to insufficient samples. The OD flows for PT and PMT by POV are presented in Tables 7-16 and 7-17 below. In fact, these can be used in conjunction with information provided in Tables 7-1 and 7-2 to obtain estimates, at an aggregated level, for OD flows by all other modes. Note that VT and VMT are only applicable for POV thus no additional tables are needed.

Table 7-16. Person Trips by POV Between SMTC Districts (1,000 trips)

\begin{tabular}{|c|r|r|r|r|r|r|r|r|}
\hline \multirow{2}{*}{$\begin{array}{c}\text { Origin } \\
\text { district }\end{array}$} & \multicolumn{10}{|c|}{ Destination district } \\
\cline { 2 - 10 } & $\mathbf{1}$ & $\mathbf{2}$ & $\mathbf{3}$ & $\mathbf{4}$ & $\mathbf{5}$ & \multicolumn{1}{|c|}{} & \multicolumn{1}{c|}{$\mathbf{7}$} & $\mathbf{8}$ \\
\hline $\mathbf{1}$ & $\mathbf{1 4 , 6 3 3}$ & 6,593 & 1,440 & 1,596 & 5,664 & 6,060 & 5,254 & 6,165 \\
\hline $\mathbf{2}$ & 6,417 & $\mathbf{1 9 , 6 4 5}$ & 1,739 & 650 & 2,270 & 4,755 & 8,476 & 3,490 \\
\hline $\mathbf{3}$ & 2,075 & 2,167 & $\mathbf{4 , 6 1 9}$ & 239 & 1,369 & 694 & 2,428 & 3,744 \\
\hline $\mathbf{4}$ & 1,009 & 978 & 90 & $\mathbf{1 6 , 5 8 2}$ & 5,843 & 1,295 & 688 & 3,066 \\
\hline $\mathbf{5}$ & 5,515 & 3,262 & 1,588 & 5,676 & $\mathbf{5 5 , 7 9 4}$ & 13,568 & 2,812 & 3,445 \\
\hline $\mathbf{6}$ & 5,449 & 5,070 & 747 & 1,205 & 13,246 & $\mathbf{4 3 , 5 0 2}$ & 11,927 & 2,047 \\
\hline $\mathbf{7}$ & 5,715 & 8,723 & 2,025 & 981 & 2,502 & 11,796 & $\mathbf{6 4 , 9 8 9}$ & 3,083 \\
\hline $\mathbf{8}$ & 6,925 & 2,075 & 4,165 & 2,746 & 4,415 & 1,873 & 3,206 & $\mathbf{5 6 , 7 1 2}$ \\
\hline
\end{tabular}

Note: ${ }^{2}$ Destination districts are: 1. Syracuse West, 2. Syracuse East, 3. Syracuse South, 4. SMTC MPA Northwest, 5. SMTC MPA North, 6. SMTC MPA Northeast, 7. SMTC MPA Southeast, 8. SMTC MPA Southwest.

The symbol "-" indicates zero sample data. 
Table 7-17. Person Miles Travel Flows by POV Between SMTC Districts (1,000 person-miles)

\begin{tabular}{|c|r|r|r|r|r|r|r|r|}
\hline \multirow{2}{*}{$\begin{array}{c}\text { Origin } \\
\text { district }\end{array}$} & $\mathbf{1}$ & $\mathbf{2}$ & $\mathbf{3}$ & $\mathbf{4}$ & $\mathbf{5}$ & $\mathbf{6}$ & $\mathbf{7}$ & $\mathbf{8}$ \\
\hline $\mathbf{n y y y y y y y y y}$ & $\mathbf{3 5 , 4 5 5}$ & 21,587 & 4,149 & 26,501 & 44,343 & 72,735 & 53,417 & 53,997 \\
\hline $\mathbf{2}$ & 21,698 & $\mathbf{3 8 , 7 7 6}$ & 9,195 & 10,263 & 43,397 & 33,670 & 39,960 & 28,966 \\
\hline $\mathbf{3}$ & 5,203 & 10,917 & $\mathbf{6 , 5 8 6}$ & 5,486 & 14,050 & 7,368 & 31,463 & 18,707 \\
\hline $\mathbf{4}$ & 15,321 & 18,634 & 863 & $\mathbf{6 7 , 3 1 9}$ & 55,229 & 21,126 & 18,534 & 23,760 \\
\hline $\mathbf{5}$ & 40,284 & 49,225 & 16,270 & 49,373 & $\mathbf{2 0 8 , 5 9 4}$ & 111,840 & 48,494 & 50,187 \\
\hline $\mathbf{6}$ & 58,465 & 36,202 & 8,879 & 19,509 & 107,288 & $\mathbf{1 6 7 , 2 6 5}$ & 87,504 & 35,603 \\
\hline $\mathbf{7}$ & 59,964 & 36,206 & 20,149 & 25,559 & 45,134 & 89,454 & $\mathbf{2 4 5 , 9 0 7}$ & 51,250 \\
\hline $\mathbf{8}$ & 48,381 & 16,596 & 32,091 & 21,685 & 57,842 & 25,564 & 51,651 & $\mathbf{1 9 7 , 6 0 7}$ \\
\hline
\end{tabular}

\subsubsection{Auto Occupancy}

Average auto occupancy rates for all purposes between the eight SMTC districts are presented in Table 718. Notice how estimates for three of the OD pairs (shaded cells) were based on very limited NHTS sample sizes (less than five). Thus, caution should be exercised when using these estimates. Although it is desirable to further disaggregate these occupancy rates by trip purpose, sample size limitation of the NHTS data prevented reliable estimates to be produced at this OD level.

Table 7-18. Average Auto Occupancy Rates between SMTC Districts

\begin{tabular}{|c|c|c|c|c|c|c|c|c|}
\hline \multirow{2}{*}{$\begin{array}{c}\text { Origin } \\
\text { district }\end{array}$} & $\mathbf{1}$ & $\mathbf{2}$ & $\mathbf{3}$ & $\mathbf{4}$ & $\mathbf{5}$ & $\mathbf{6}$ & $\mathbf{7}$ & $\mathbf{8}$ \\
\hline $\mathbf{1}$ & $\mathbf{1 . 3}$ & 1.3 & 1.0 & 1.0 & 1.3 & 1.5 & 1.5 & 2.7 \\
\hline $\mathbf{2}$ & 1.2 & $\mathbf{1 . 6}$ & 1.4 & 1.2 & 1.2 & 1.2 & 1.4 & 1.5 \\
\hline $\mathbf{3}$ & 1.0 & 1.7 & $\mathbf{1 . 2}$ & 1.0 & 1.0 & 1.3 & 1.6 & 1.5 \\
\hline $\mathbf{4}$ & 1.0 & 1.1 & 1.4 & $\mathbf{1 . 5}$ & 1.4 & 1.1 & 1.8 & 1.2 \\
\hline $\mathbf{5}$ & 1.1 & 1.2 & 1.0 & 1.3 & $\mathbf{1 . 5}$ & 1.5 & 1.2 & 1.5 \\
\hline $\mathbf{6}$ & 1.5 & 1.3 & 2.0 & 1.0 & 1.4 & $\mathbf{1 . 5}$ & 1.4 & 1.2 \\
\hline $\mathbf{7}$ & 1.5 & 1.2 & 1.2 & 1.1 & 1.4 & 1.5 & $\mathbf{1 . 5}$ & 1.4 \\
\hline $\mathbf{8}$ & 1.4 & 1.8 & 3.3 & 1.3 & 1.4 & 1.7 & 1.4 & $\mathbf{1 . 6}$ \\
\hline
\end{tabular}

As an example to illustrate the degree of small sample size impacts, trips made for all non-work (i.e., not for earning the living) and non-home (not for going home) activities were aggregated into an "other purposes" group. This "other" group contains over $60 \%$ more NHTS trip samples than the "home" group and over 4 times more samples than the "work" group. Even so, as seen in Table 7-19, nearly a quarter of the OD pairs (shaded) did not have sufficient samples to support a reliable estimate, with one pair having no samples at all. Clearly, most of the sample size issues appear to be associated with Districts 3 and 4. A slightly more geographically aggregated region would be necessary in order to obtain more reliable estimates at a higher number of dimensions (e.g., by origin, destination, trip purpose, etc.). 
Table 7-19. Average Auto Occupancy Rates between SMTC Districts for Other ${ }^{\text {a }}$ Trip Purposes

\begin{tabular}{|c|c|c|c|c|c|c|c|c|}
\hline \multirow{2}{*}{$\begin{array}{c}\text { Origin } \\
\text { district }\end{array}$} & \multicolumn{9}{|c|}{ Destination district $^{\mathrm{b}}$} \\
\hline & $\mathbf{1}$ & $\mathbf{2}$ & $\mathbf{3}$ & $\mathbf{4}$ & $\mathbf{5}$ & $\mathbf{6}$ & $\mathbf{7}$ & $\mathbf{8}$ \\
\hline $\mathbf{1}$ & $\mathbf{1 . 5}$ & 1.3 & 1.0 & 1.2 & 1.1 & 1.9 & 2.1 & 3.7 \\
\hline $\mathbf{2}$ & 1.2 & $\mathbf{1 . 7}$ & 1.6 & 1.0 & 1.0 & 1.4 & 1.5 & 1.1 \\
\hline $\mathbf{3}$ & 1.1 & 1.9 & $\mathbf{1 . 6}$ & - & 1.0 & 1.6 & 1.3 & 1.9 \\
\hline $\mathbf{4}$ & 1.0 & 1.2 & 1.4 & $\mathbf{1 . 5}$ & 1.6 & 1.1 & 3.0 & 1.3 \\
\hline $\mathbf{5}$ & 1.3 & 1.1 & 1.0 & 1.7 & $\mathbf{1 . 7}$ & 1.6 & 1.6 & 1.6 \\
\hline $\mathbf{6}$ & 1.9 & 1.3 & 2.3 & 1.0 & 1.6 & $\mathbf{1 . 6}$ & 1.4 & 1.2 \\
\hline $\mathbf{7}$ & 1.6 & 1.1 & 1.4 & 1.3 & 1.9 & 1.8 & $\mathbf{1 . 7}$ & 1.4 \\
\hline $\mathbf{8}$ & 1.9 & 2.0 & 1.3 & 1.1 & 1.3 & 1.9 & 1.5 & $\mathbf{1 . 6}$ \\
\hline
\end{tabular}

Note: ${ }^{a}$ Excluding trips made for home or work purposes.

${ }^{b}$ Destination districts are: 1. Syracuse West, 2. Syracuse East, 3. Syracuse South, 4. SMTC MPA Northwest, 5. SMTC MPA North, 6. SMTC MPA Northeast, 7. SMTC MPA Southeast, 8. SMTC MPA Southwest.

The symbol "-” indicates zero sample data.

\subsection{BMTS REGION}

\subsubsection{Volume of Travel Activities among BMTS Districts}

Similar to those discussed for the SMTC region, Tables 7-20 through Table 7-23 provide PT, PMT, VT, and VMT statistics at the OD level for the BMTS districts. Note that only trips between the five BMTS districts were summarized in these OD flow tables. Again, intra-district trips are highlighted in bold in all tables.

Table 7-20. Total Person Trip Flows between BMTS Districts (in 1,000 person-trips)

\begin{tabular}{|c|r|r|r|r|c|}
\hline \multirow{2}{*}{$\begin{array}{c}\text { Origin } \\
\text { district }\end{array}$} & $\mathbf{1}$ & $\mathbf{2}$ & $\mathbf{3}$ & $\mathbf{4}$ & $\mathbf{5}$ \\
\cline { 2 - 6 } & $\mathbf{1 0 , 1 9 8}$ & 9,202 & 2,027 & 2,545 & 225 \\
\hline $\mathbf{1}$ & 9,316 & $\mathbf{5 2 , 2 5 4}$ & 12,365 & 5,051 & 1,375 \\
\hline $\mathbf{2}$ & 1,914 & 11,575 & $\mathbf{3 0 , 3 0 3}$ & 13,728 & 1,491 \\
\hline $\mathbf{3}$ & 2,798 & 5,499 & 13,141 & $\mathbf{3 7 , 7 8 7}$ & 3,139 \\
\hline $\mathbf{4}$ & 441 & 2,032 & 1,603 & 2,530 & $\mathbf{1 9 , 6 7 1}$ \\
\hline $\mathbf{5}$ & &
\end{tabular}

Note: ${ }^{a}$ Destination districts are: 1. North/East, 2. Binghamton, 3. Vestal/JC, 4. Endicott, 5. Tioga.

Table 7-21. Total Personal-Miles-Traveled Flows between BMTS Districts (in 1,000 person-miles)

\begin{tabular}{|c|c|c|c|c|c|}
\hline \multirow{2}{*}{$\begin{array}{c}\text { Origin } \\
\text { district }\end{array}$} & $\mathbf{1}$ & $\mathbf{5}$ & $\mathbf{3}$ & $\mathbf{4}$ & $\mathbf{5}$ \\
\cline { 2 - 6 } & $\mathbf{1}$ & 68,229 & 22,241 & 27,666 & 7,044 \\
\hline $\mathbf{1}$ & $\mathbf{6 8 , 9 4 5}$ & $\mathbf{1 7 3 , 5 0 5}$ & 80,282 & 59,833 & 27,488 \\
\hline $\mathbf{2}$ & 66,869 & 67,267 & $\mathbf{1 0 4 , 2 6 3}$ & 74,738 & 18,351 \\
\hline $\mathbf{3}$ & 19,781 & 60,763 & 72,710 & $\mathbf{7 5 , 9 1 5}$ & 36,007 \\
\hline $\mathbf{4}$ & 32,424 & 39,133 & 18,599 & 31,390 & $\mathbf{8 2 , 1 8 7}$ \\
\hline $\mathbf{5}$ & 10,872 & &
\end{tabular}

Note: ${ }^{\text {a} D e s t i n a t i o n ~ d i s t r i c t s ~ a r e: ~ 1 . ~ N o r t h / E a s t, ~ 2 . ~ B i n g h a m t o n, ~ 3 . ~ V e s t a l / J C, ~ 4 . ~ E n d i c o t t, ~ 5 . ~ T i o g a . ~}$ 
Table 7-22. Total Vehicle-trip Flows between BMTS Districts (in 1,000 vehicle-trips)

\begin{tabular}{|c|r|r|r|r|r|}
\hline \multirow{2}{*}{$\begin{array}{c}\text { Origin } \\
\text { district }\end{array}$} & \multicolumn{6}{|c|}{ Destination district $^{\mathrm{a}}$} \\
\cline { 2 - 6 } & $\mathbf{1}$ & $\mathbf{2}$ & $\mathbf{3}$ & \multicolumn{1}{|c|}{$\mathbf{4}$} \\
\hline $\mathbf{1}$ & $\mathbf{6 , 5 0 4}$ & 6,301 & 1,234 & 1,819 & 186 \\
\hline $\mathbf{2}$ & 6,339 & $\mathbf{3 4 , 1 1 7}$ & 9,974 & 3,701 & 1,037 \\
\hline $\mathbf{3}$ & 1,470 & 8,635 & $\mathbf{2 0 , 9 5 2}$ & 9,675 & 1,340 \\
\hline $\mathbf{4}$ & 1,990 & 3,848 & 9,206 & $\mathbf{2 2 , 7 1 1}$ & 2,878 \\
\hline $\mathbf{5}$ & 326 & 1,644 & 1,385 & 2,311 & $\mathbf{1 0 , 7 7 0}$ \\
\hline
\end{tabular}

Note: ${ }^{\mathrm{a}}$ Destination districts are: 1. North/East, 2. Binghamton, 3. Vestal/JC, 4. Endicott, 5. Tioga.

Table 7-23. Total Vehicle-Miles-Traveled Flows between BMTS Districts (in 1,000 vehicle-miles)

\begin{tabular}{|c|c|c|c|c|c|}
\hline \multirow{2}{*}{$\begin{array}{l}\text { Origin } \\
\text { district }\end{array}$} & \multicolumn{5}{|c|}{ Destination district $^{\mathrm{a}}$} \\
\hline & 1 & 2 & 3 & 4 & 5 \\
\hline 1 & 38,669 & 50,734 & 13,941 & 20,288 & 6,052 \\
\hline 2 & 51,117 & 127,420 & 68,659 & 38,322 & 20,707 \\
\hline 3 & 15,314 & 51,723 & 86,810 & 53,541 & 16,412 \\
\hline 4 & 22,425 & 39,343 & 51,586 & 53,649 & 33,363 \\
\hline 5 & 8,520 & 31,553 & 16,337 & 29,463 & 56,066 \\
\hline
\end{tabular}

\subsubsection{Average Trip Length}

Average travel distances between BMTS OD districts, in PT and VT, are presented in Tables 7-24 and 725 , respectively. In most cases, PT and VT estimates were very similar because POV is the most commonly utilized mode of transportation for the region. Not surprisingly intra-district trip lengths were shorter than inter-district trips. Since most of the daily trips had a "reversed order" return trip, it was expected that the two traveling directions of a given OD pair (i.e., "A to B" and "B to A") would have a fairly similar average trip length. This was clearly evident for nearly all OD pairs in Tables 7-24 and 725; with the exception of a larger gap between the two OD-pairs involving Districts 1 and 5.

Table 7-24. Average Person-trip Distance between BMTS Districts

\begin{tabular}{|c|c|c|c|c|c|}
\hline \multirow{2}{*}{$\begin{array}{c}\text { Origin } \\
\text { district }\end{array}$} & $\mathbf{1}$ & $\mathbf{2}$ & $\mathbf{3}$ & $\mathbf{4}$ & $\mathbf{5}$ \\
\cline { 2 - 6 } & $\mathbf{6 . 8}$ & 7.8 & 11.0 & 11.0 & 31.3 \\
\hline $\mathbf{1}$ & 7.2 & $\mathbf{3 . 3}$ & 6.5 & 11.9 & 20.0 \\
\hline $\mathbf{3}$ & 10.3 & 5.8 & $\mathbf{3 . 5}$ & 5.5 & 12.3 \\
\hline $\mathbf{4}$ & 11.7 & 11.1 & 5.6 & $\mathbf{2 . 1}$ & 11.5 \\
\hline $\mathbf{5}$ & 24.6 & 19.3 & 11.6 & 12.4 & $\mathbf{4 . 2}$ \\
\hline
\end{tabular}


Table 7-25. Average Vehicle-trip Distance between BMTS Districts

\begin{tabular}{|c|c|c|c|c|c|}
\hline \multirow{2}{*}{$\begin{array}{c}\text { Origin } \\
\text { district }\end{array}$} & $\mathbf{1}$ & $\mathbf{2}$ & $\mathbf{3}$ & $\mathbf{4}$ & $\mathbf{5}$ \\
\cline { 2 - 6 } & $\mathbf{6 . 0}$ & 8.1 & 11.3 & 11.2 & 32.6 \\
\hline $\mathbf{1}$ & 8.2 & $\mathbf{3 . 7}$ & 6.9 & 10.4 & 20.0 \\
\hline $\mathbf{2}$ & 10.4 & 6.0 & $\mathbf{4 . 2}$ & 5.5 & 12.2 \\
\hline $\mathbf{3}$ & 11.3 & 10.2 & 5.6 & $\mathbf{2 . 4}$ & 11.6 \\
\hline $\mathbf{4}$ & 26.2 & 19.2 & 11.8 & 12.8 & $\mathbf{5 . 2}$ \\
\hline $\mathbf{5}$ & &
\end{tabular}

Note: ${ }^{a}$ Destination districts are: 1. North/East, 2. Binghamton, 3. Vestal/JC, 4. Endicott, 5. Tioga.

\subsubsection{Trip Purposes}

Under the same sample size constraint, only limited by-purpose groups had sufficient numbers of samples to allow generation of OD-level statistics for BMTS districts. Tables 7-26 and 7-27 show summary statistics in PT and VT, respectively, on trips made for "earning a living." Similar tables on trips made for "family/personal business" in BMTS districts are given in Tables 7-28 and 7-29 for PT and VT, respectively.

Table 7-26. Person-trips for "Earning a Living" in BMTS Districts (1,000 trips)

\begin{tabular}{|c|c|c|c|c|c|}
\hline \multirow{2}{*}{$\begin{array}{c}\text { Origin } \\
\text { district }\end{array}$} & \multicolumn{5}{|c|}{ Destination district $^{\mathrm{a}}$} \\
\cline { 2 - 6 } & $\mathbf{1}$ & $\mathbf{2}$ & $\mathbf{3}$ & $\mathbf{4}$ & $\mathbf{5}$ \\
\hline $\mathbf{1}$ & $\mathbf{1 , 3 5 0}$ & 2,899 & 203 & 596 & 186 \\
\hline $\mathbf{2}$ & 2,243 & $\mathbf{7 , 5 6 8}$ & 2,904 & 1,107 & 133 \\
\hline $\mathbf{3}$ & 245 & 2,182 & $\mathbf{3 , 6 8 2}$ & 2,839 & 743 \\
\hline $\mathbf{4}$ & 788 & 1,370 & 3,491 & $\mathbf{6 , 7 7 1}$ & 1,298 \\
\hline $\mathbf{5}$ & 189 & 144 & 640 & 787 & $\mathbf{3 , 7 4 0}$ \\
\hline
\end{tabular}

Note: ${ }^{a}$ Destination districts are: 1. North/East, 2. Binghamton, 3. Vestal/JC, 4. Endicott, 5. Tioga.

Table 7-27. Vehicle-trips for "Earning a Living" in BMTS Districts (1,000 trips)

\begin{tabular}{|c|c|c|c|c|c|}
\hline \multirow{2}{*}{$\begin{array}{c}\text { Origin } \\
\text { district }\end{array}$} & $\mathbf{1}$ & $\mathbf{2}$ & $\mathbf{3}$ & $\mathbf{4}$ & \multicolumn{1}{|c|}{ Destination district $^{\mathrm{a}}$} \\
\cline { 2 - 6 } & $\mathbf{1 , 1 3 2}$ & 1,952 & 203 & 596 & 186 \\
\hline $\mathbf{1}$ & 1,296 & $\mathbf{6 , 4 3 5}$ & 2,391 & 858 & 133 \\
\hline $\mathbf{3}$ & 245 & 1,762 & $\mathbf{3 , 5 8 0}$ & 2,300 & 732 \\
\hline $\mathbf{4}$ & 788 & 1,121 & 2,937 & $\mathbf{5 , 5 9 6}$ & 1,298 \\
\hline $\mathbf{5}$ & 124 & 133 & 621 & 729 & $\mathbf{2 , 5 9 0}$ \\
\hline
\end{tabular}

Note: ${ }^{\text {a}}$ Destination districts are: 1. North/East, 2. Binghamton, 3. Vestal/JC, 4. Endicott, 5. Tioga.

Table 7-28. Person-trips for "Family/Personal Business" in BMTS Districts (1,000 trips)

\begin{tabular}{|c|c|c|c|c|c|}
\hline \multirow{2}{*}{$\begin{array}{c}\text { Origin } \\
\text { district }\end{array}$} & $\mathbf{5}$ & $\mathbf{2}$ & $\mathbf{3}$ & $\mathbf{4}$ & $\mathbf{5}$ \\
\cline { 2 - 6 } & $\mathbf{1}$ & 3,038 & 1,208 & 565 & - \\
\hline $\mathbf{2}$ & $\mathbf{4 , 5 8 2}$ & $\mathbf{2 5 , 0 7 7}$ & 5,446 & 1,885 & 216 \\
\hline $\mathbf{3}$ & 3,410 & 5,528 & $\mathbf{1 5 , 5 3 9}$ & 6,122 & 347 \\
\hline $\mathbf{4}$ & 976 & 1,791 & 6,555 & $\mathbf{1 7 , 8 3 9}$ & 935 \\
\hline $\mathbf{5}$ & 379 & 420 & 583 & 1,397 & $\mathbf{9 , 1 8 3}$ \\
\hline
\end{tabular}


Table 7-29. Vehicle-trips for "Family/Personal Business" in BMTS Districts (1,000 trips)

\begin{tabular}{|c|r|r|r|r|r|}
\hline \multirow{2}{*}{$\begin{array}{c}\text { Origin } \\
\text { district }\end{array}$} & \multicolumn{5}{|c|}{ Destination district $^{\mathrm{a}}$} \\
\cline { 2 - 6 } & $\mathbf{1}$ & $\mathbf{2}$ & $\mathbf{3}$ & $\mathbf{4}$ & $\mathbf{5}$ \\
\hline $\mathbf{1}$ & $\mathbf{3 , 2 7 2}$ & 2,226 & 706 & 481 & - \\
\hline $\mathbf{2}$ & 2,907 & $\mathbf{1 8 , 1 9 5}$ & 4,671 & 1,603 & 216 \\
\hline $\mathbf{3}$ & 769 & 4,111 & $\mathbf{1 1 , 5 3 2}$ & 4,760 & 279 \\
\hline $\mathbf{4}$ & 326 & 1,558 & 4,736 & $\mathbf{1 2 , 6 7 6}$ & 845 \\
\hline $\mathbf{5}$ & 65 & 420 & 465 & 1,298 & $\mathbf{5 , 7 5 3}$ \\
\hline
\end{tabular}

Note: ${ }^{a}$ Destination districts are: 1. North/East, 2. Binghamton, 3. Vestal/JC, 4. Endicott, 5. Tioga.

Using line thickness to reflect the volume of trips, OD flows are visually displayed on a map. As an example of commuting trips, Figure 7-5 shows person trips from all BMTS districts to Binghamton (District 2); using geographic centroids of the districts and including intra-district trips that begin and end in District 2. Similarly, Figure 7-6 displays trips made for family/personal business from all BMTS districts into District 2 (Binghamton).

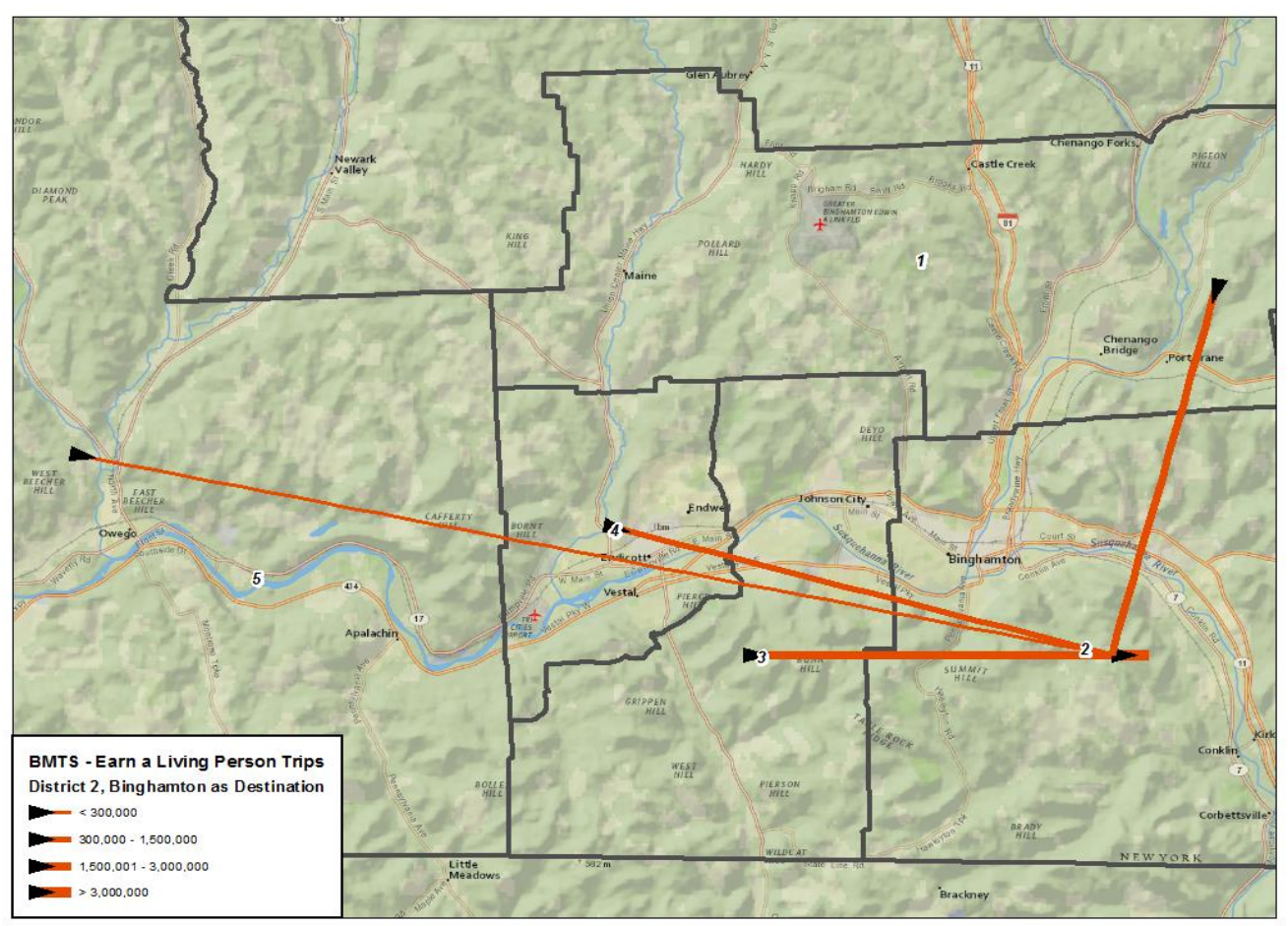

Figure 7-5. Earn a Living (commuting) person-trips from all BMTS districts to District 2. 


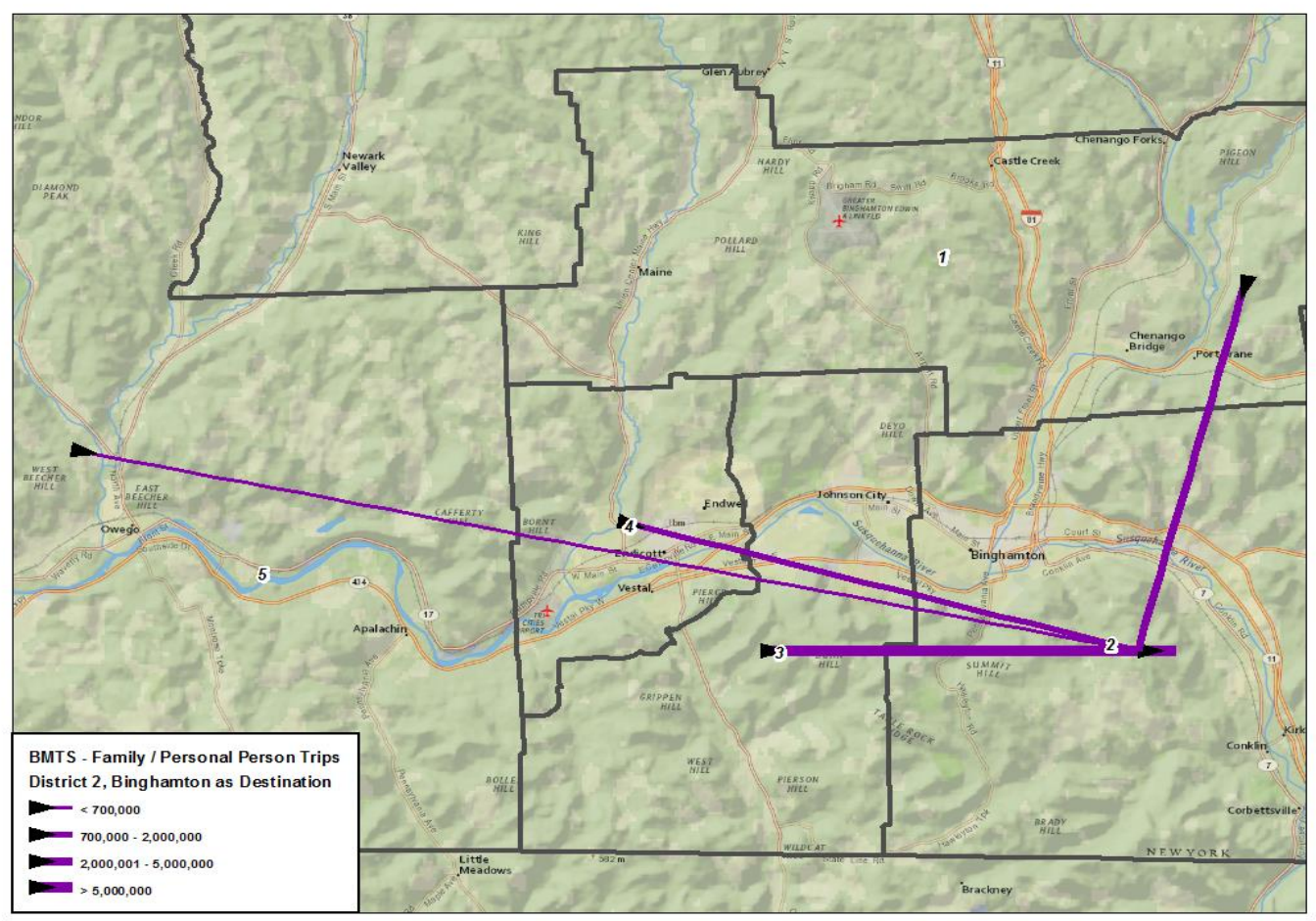

Figure 7-6. Family/Personal Business person-trips from all BMTS districts to District 2.

Corresponding PMT and VMT tables for OD flows of trips made for "earning a living" and "family/personal business" are provided in Tables 7-30 through Table 7-33.

Table 7-30. Person-miles-traveled for "Earning a Living" in BMTS Districts (1,000 person-miles)

\begin{tabular}{|c|c|c|c|c|c|}
\hline \multirow{2}{*}{$\begin{array}{c}\text { Origin } \\
\text { district }\end{array}$} & $\mathbf{1}$ & $\mathbf{2}$ & $\mathbf{3}$ & $\mathbf{4}$ & $\mathbf{5}$ \\
\cline { 2 - 6 } & $\mathbf{1 1 , 7 3 8}$ & 22,120 & 1,959 & 6,861 & 6,052 \\
\hline $\mathbf{1}$ & 15,730 & $\mathbf{2 9 , 5 4 8}$ & 24,460 & 11,558 & 3,140 \\
\hline $\mathbf{2}$ & 2,873 & 14,773 & $\mathbf{2 3 , 5 1 3}$ & 18,356 & 9,686 \\
\hline $\mathbf{3}$ & 8,726 & 14,158 & 22,108 & $\mathbf{1 8 , 8 5 8}$ & 20,388 \\
\hline $\mathbf{4}$ & 5,551 & 3,330 & 7,738 & 9,797 & $\mathbf{2 2 , 2 7 9}$ \\
\hline $\mathbf{5}$ & \multicolumn{2}{|c|}{ Note: ${ }^{\text {a}}$ Destination districts are: 1. North/East, 2. Binghamton, 3. Vestal/JC, 4. Endicott, 5. Tioga. } \\
\hline
\end{tabular}

Table 7-31. Vehicle-miles-traveled for "Earning a Living" in BMTS Districts (1,000 vehicle-miles)

\begin{tabular}{|c|c|c|c|c|c|}
\hline \multirow{2}{*}{$\begin{array}{c}\text { Origin } \\
\text { district }\end{array}$} & $\mathbf{1}$ & $\mathbf{2}$ & $\mathbf{3}$ & $\mathbf{4}$ & Destination district $^{\mathrm{a}}$ \\
\cline { 2 - 6 } & $\mathbf{1 1 , 1 1 4}$ & 21,200 & 1,959 & 6,861 & 6,052 \\
\hline $\mathbf{1}$ & 14,771 & $\mathbf{2 7 , 3 2 5}$ & 22,359 & 8,818 & 3,140 \\
\hline $\mathbf{3}$ & 2,873 & 13,044 & $\mathbf{2 3 , 3 6 0}$ & 15,522 & 9,530 \\
\hline $\mathbf{4}$ & 8,726 & 11,419 & 19,058 & $\mathbf{1 7 , 4 1 8}$ & 20,388 \\
\hline $\mathbf{5}$ & 4,517 & 3,140 & 7,622 & 9,268 & $\mathbf{2 0 , 5 2 9}$ \\
\hline
\end{tabular}

Note: ${ }^{a}$ Destination districts are: 1. North/East, 2. Binghamton, 3. Vestal/JC, 4. Endicott, 5. Tioga. 
Table 7-32. Person-miles-traveled for "Family/Personal Business" in BMTS Districts (1,000 person-miles)

\begin{tabular}{|c|c|c|c|c|c|}
\hline \multirow{2}{*}{$\begin{array}{c}\text { Origin } \\
\text { district }\end{array}$} & $\mathbf{5}$ & $\mathbf{2}$ & $\mathbf{3}$ & $\mathbf{4}$ & $\mathbf{5}$ \\
\cline { 2 - 6 } & $\mathbf{1}$ & 19,506 & 13,259 & 6,376 & - \\
\hline $\mathbf{1}$ & $\mathbf{4 0 , 3 6 5}$ & $\mathbf{7 6 , 9 6 5}$ & 34,757 & 19,825 & 4,069 \\
\hline $\mathbf{2}$ & 26,324 & 32,922 & $\mathbf{3 3 , 3 2 9}$ & 28,429 & 5,433 \\
\hline $\mathbf{3}$ & 9,892 & 18,408 & 34,601 & $\mathbf{3 1 , 8 7 1}$ & 8,949 \\
\hline $\mathbf{4}$ & 4,678 & 8,005 & 8,408 & 18,816 & $\mathbf{3 1 , 5 2 6}$ \\
\hline $\mathbf{5}$ & 455 & &
\end{tabular}

Note: ${ }^{a}$ Destination districts are: 1. North/East, 2. Binghamton, 3. Vestal/JC, 4. Endicott, 5. Tioga.

Table 7-33. Vehicle-miles-traveled for "Family/Personal Business" in BMTS Districts (1,000 vehicle-miles)

\begin{tabular}{|c|c|c|c|c|c|}
\hline \multirow{2}{*}{$\begin{array}{l}\text { Origin } \\
\text { district }\end{array}$} & \multicolumn{5}{|c|}{ Destination district $^{\mathrm{a}}$} \\
\hline & 1 & 2 & 3 & 4 & 5 \\
\hline 1 & 18,202 & 14,798 & 7,594 & 5,607 & - \\
\hline 2 & 23,258 & 60,450 & 29,959 & 16,644 & 4,069 \\
\hline 3 & 7,649 & 24,441 & 27,506 & 21,987 & 3,974 \\
\hline 4 & 4,534 & 15,604 & 25,131 & 25,147 & 7,924 \\
\hline 5 & 455 & 8,005 & 6,697 & 17,697 & 23,290 \\
\hline
\end{tabular}

Note: ${ }^{\mathrm{a}}$ Destination districts are: 1. North/East, 2. Binghamton, 3. Vestal/JC, 4. Endicott, 5. Tioga.

Other aggregated trip purposes were also examined for BMTS districts OD flows. Using District 2 (Binghamton) as the origin district, for example, PT for "home to work" and "home to other" are summarized in Table 7-34. A similar table of trips from all BMTS districts to District 2 (i.e., terminated in Binghamton district) is presented in Table 7-35.

Table 7-34. Origin-destination Flows Originated from District 2 to All BMTS Districts (person trips)

\begin{tabular}{|c|c|c|c|r|r|}
\hline \multirow{2}{*}{ Trip type } & \multicolumn{5}{|c|}{ Destination district $^{\mathrm{a}}$} \\
\cline { 2 - 6 } & $\mathbf{1}$ & $\mathbf{2}$ & $\mathbf{3}$ & $\mathbf{4}$ & $\mathbf{5}$ \\
\hline Home to Work & $1,088,946$ & $1,730,174$ & $1,025,264$ & 51,412 & 93,830 \\
\hline Home to Other & $2,708,633$ & $13,984,969$ & $4,411,606$ & 623,825 & 199,618 \\
\hline
\end{tabular}

Note: ${ }^{a}$ Destination districts are: 1. North/East, 2. Binghamton, 3. Vestal/JC, 4. Endicott, 5. Tioga.

Table 7-35. Origin-destination Flows from All BMTS Districts and Terminated in District 2 (person trips)

\begin{tabular}{|c|c|c|c|r|r|}
\hline \multirow{2}{*}{ Trip type } & \multicolumn{5}{|c|}{ Origin district $^{\text {a }}$} \\
\cline { 2 - 6 } & $\mathbf{1}$ & $\mathbf{2}$ & $\mathbf{3}$ & $\mathbf{4}$ & $\mathbf{5}$ \\
\hline Home to Work & $1,124,365$ & $1,730,174$ & $1,128,555$ & 863,183 & 50,077 \\
\hline Home to Other & $1,931,272$ & $13,984,969$ & $2,353,118$ & $2,046,705$ & $1,376,613$ \\
\hline
\end{tabular}
Note: ${ }^{a}$ Destination districts are: 1. North/East, 2. Binghamton, 3. Vestal/JC, 4. Endicott, 5. Tioga.

\subsubsection{Vehicle Travel}

Due to sample size limitations, an OD-flow by mode was not possible except for the primary mode of POV. The OD flows for POV trips, measured in PT and PMT, are summarized in Table 7-36 and Table 7-37, respectively. Note that by definition, VT and VMT are already based on POV only (see Tables 722 and 7-23), thus no additional tabulations in VT and VMT are needed. 
Table 7-36. Person-trip Flows by POV between BMTS Districts (1,000 trips)

\begin{tabular}{|c|r|r|r|r|r|}
\hline \multirow{2}{*}{$\begin{array}{c}\text { Origin } \\
\text { district }\end{array}$} & \multicolumn{5}{|c|}{ Destination distric ${ }^{\text {t }}$} \\
\cline { 2 - 6 } & $\mathbf{1}$ & $\mathbf{2}$ & $\mathbf{3}$ & $\mathbf{4}$ & \multicolumn{1}{c|}{$\mathbf{5}$} \\
\hline $\mathbf{1}$ & $\mathbf{9 , 3 1 7}$ & 7,434 & 1,986 & 2,487 & 225 \\
\hline $\mathbf{2}$ & 8,239 & $\mathbf{4 7 , 1 1 4}$ & 11,795 & 4,959 & 1,375 \\
\hline $\mathbf{3}$ & 1,914 & 11,009 & $\mathbf{2 5 , 3 1 1}$ & 12,730 & 1,491 \\
\hline $\mathbf{4}$ & 2,679 & 5,407 & 12,393 & $\mathbf{3 0 , 3 7 8}$ & 3,139 \\
\hline $\mathbf{5}$ & 441 & 1,993 & 1,603 & 2,530 & $\mathbf{1 3 , 4 5 7}$ \\
\hline
\end{tabular}

Note: ${ }^{a}$ Destination districts are: 1. North/East, 2. Binghamton, 3. Vestal/JC, 4. Endicott, 5. Tioga.

Table 7-37. Person-miles-traveled Flows by POV between BMTS Districts (1,000 person-miles)

\begin{tabular}{|c|c|c|c|c|c|}
\hline \multirow{2}{*}{$\begin{array}{c}\text { Origin } \\
\text { district }\end{array}$} & \multicolumn{5}{|c|}{ Destination district $^{\mathrm{a}}$} \\
\hline & 1 & 2 & 3 & 4 & 5 \\
\hline 1 & 65,310 & 59,137 & 22,218 & 27,526 & 7,044 \\
\hline 2 & 65,019 & 167,383 & 77,326 & 59,139 & 27,488 \\
\hline 3 & 19,781 & 63,964 & 98,930 & 70,381 & 18,351 \\
\hline 4 & 31,560 & 60,267 & 69,259 & 70,697 & 36,007 \\
\hline 5 & 10,872 & 38,657 & 18,599 & 31,390 & 74,016 \\
\hline
\end{tabular}

\subsubsection{Auto Occupancy Rate}

Average auto occupancy rates for all purposes between BMTS districts are presented in Table 7-38. The shaded cells signify OD pairs that were based on very limited NHTS sample sizes (less than five). As mentioned previously, further disaggregation of occupancy rates by trip purpose increases the number of unreliable estimates (due to reduction in sample sizes). This is evident in Tables 7-39 (other purposes) and 7-40 (purpose of going home). Note that, as a whole in the BMTS region, the "other purposes" group comprised over $62 \%$ more NHTS trip samples than the "home" group has.

Table 7-38. Average Auto Occupancy Rates between BMTS Districts (All Purposes)

\begin{tabular}{|c|c|c|c|c|c|}
\hline \multirow{2}{*}{$\begin{array}{c}\text { Origin } \\
\text { district }\end{array}$} & \multicolumn{5}{|c|}{ Destination district $^{\mathrm{a}}$} \\
\cline { 2 - 6 } & $\mathbf{1}$ & $\mathbf{2}$ & $\mathbf{3}$ & $\mathbf{4}$ & $\mathbf{5}$ \\
\hline $\mathbf{1}$ & $\mathbf{2 . 3}$ & 1.4 & 2.4 & 1.3 & 1.3 \\
\hline $\mathbf{2}$ & 1.6 & $\mathbf{1 . 8}$ & 1.2 & 1.5 & 1.4 \\
\hline $\mathbf{3}$ & 1.6 & 1.5 & $\mathbf{1 . 3}$ & 1.3 & 1.2 \\
\hline $\mathbf{4}$ & 1.3 & 1.5 & 1.4 & $\mathbf{1 . 4}$ & 1.3 \\
\hline $\mathbf{5}$ & 1.4 & 1.3 & 1.4 & 1.3 & $\mathbf{1 . 4}$ \\
\hline
\end{tabular}

Note: ${ }^{a}$ Destination districts are: 1. North/East, 2. Binghamton, 3. Vestal/JC, 4. Endicott, 5. Tioga.

Table 7-39. Average Auto Occupancy Rates between BMTS districts for Purpose of Other

\begin{tabular}{|c|c|c|c|c|c|}
\hline \multirow{2}{*}{$\begin{array}{c}\text { Origin } \\
\text { district }\end{array}$} & $\mathbf{1}$ & $\mathbf{2}$ & $\mathbf{3}$ & $\mathbf{4}$ & $\mathbf{5}$ \\
\cline { 2 - 6 } & $\mathbf{3 . 2}$ & 1.5 & 2.7 & 1.4 &. \\
\hline $\mathbf{1}$ & 1.6 & $\mathbf{2 . 0}$ & 1.4 & 1.5 & 1.0 \\
\hline $\mathbf{2}$ & 1.8 & 1.6 & $\mathbf{1 . 4}$ & 1.3 & 1.5 \\
\hline $\mathbf{3}$ & 1.3 & 1.5 & 1.6 & $\mathbf{1 . 5}$ & 1.2 \\
\hline $\mathbf{4}$ & 2.0 & 1.4 & 1.9 & 1.4 & $\mathbf{1 . 5}$ \\
\hline $\mathbf{5}$ & Note: ${ }^{\text {a }}$ Tripstination district \\
\hline
\end{tabular}


Table 7-40. Average Auto Occupancy Rates between BMTS Districts for Purpose of Home

\begin{tabular}{|c|c|c|c|c|c|}
\hline \multirow{2}{*}{$\begin{array}{c}\text { Origin } \\
\text { district }\end{array}$} & $\mathbf{1}$ & $\mathbf{2}$ & $\mathbf{3}$ & $\mathbf{4}$ & $\mathbf{5}$ \\
\cline { 2 - 6 } & $\mathbf{1}$ & 1.5 & 1.0 & 1.4 & 2.0 \\
\hline $\mathbf{1}$ & $\mathbf{1 . 3}$ & $\mathbf{1 . 6}$ & 1.1 & 1.5 & 1.6 \\
\hline $\mathbf{2}$ & 1.6 & 1.6 & $\mathbf{1 . 2}$ & 1.4 & 1.2 \\
\hline $\mathbf{3}$ & 1.4 & 2.3 & 1.4 & $\mathbf{1 . 4}$ & 1.4 \\
\hline $\mathbf{4}$ & 1.2 & 1.0 & 1.1 & 1.0 & $\mathbf{1 . 4}$ \\
\hline $\mathbf{5}$ & 1.0 & &
\end{tabular}

Note: ${ }^{a}$ Destination districts are: 1. North/East, 2. Binghamton, 3. Vestal/JC, 4. Endicott, 5. Tioga.

\subsection{REMARKS}

Although results from this examination might be of interest to regional transportation planners and analysts, the most challenging issue encountered-as in any survey data-has been one of sample availability. Even though the TAD-based districts in SMTC and BMTS were structured with consideration of the available NHTS data in the beginning, each added "dimension" to the OD flow matrix (e.g., by trip purpose) reduced the number of available data points (i.e., samples) in each cell. This was not necessarily an issue for all districts, but it certainly did have impacts on certain districts, and one should exercise caution when applying the results. 


\section{A SCAN OF CENSUS JOURNEY TO WORK (JTW) DATA}

In an attempt to identify ways for validation of NHTS-based estimates, data from the American Community Survey (ACS) 2006-2010 Census Transportation Planning Package (CTPP, also referred to as JTW data) were processed. The TAD-based data associated with the selected SMTC and BMTS regions were extracted from the ACS website and analyzed. Besides demographic information, CTPP provides commuter-related data that allowed for the study of worker flow patterns.

It is important to note that, several differences in ACS and NHTS data made it indirectly compatible. Although there was a geospatial boundary issue (discussed below), the most fundamental difference between CTPP and NHTS travel data was on each's unit of measure, i.e., workers verses trips. For example, a worker can make multiple trips between various ODs in a day, while the traveler would only be counted once in a residence-workplace flow in the CTPP data.

\subsection{GEOSPATIAL BOUNDARY DIFFERENCES}

As discussed in Section 2 of this report, TAD clusters were used to define districts in SMTC and BMTS for this study. However, both SMTC and BMTS MPO boundaries included partial TADs (i.e., only a portion of a TAD was included under the MPO jurisdiction). The cross-hatched areas shown in Figures 8-1 and 8-2 reflect TAD portions that were NOT considered as a part of the SMTC MPA or BMTS MPO, respectively. These cross-hatched regions are shaded with the same color as the corresponding districts allowing easy identifications of impacted districts.

On the other hand, ACS data associated with the two study regions were completely TAD-based; i.e., no partial TADs. Specifically for example, the number of households in a district was determined by simply combining the total numbers from all TADs within the given district. Note that the most disaggregated data on ACS worker flows was at the TAD level.

No adjustments were made to account for the partial TAD situations for districts in the ACS-based data, since this was beyond the scope of the current study. As a result, this impacts areas in three districts in the SMTC MPA: North (District 5), Northeast (District 6), and the Southeast (District 7); and two districts in the BMTS MPO: North/East (District 1) and Tioga (District 5). Because of the boundary differences, analysis results and statistics associated with these districts might not all be compatible. One should keep this point in mind when reviewing results from the ACS along with estimates produced using the 2009 NHTS data. 


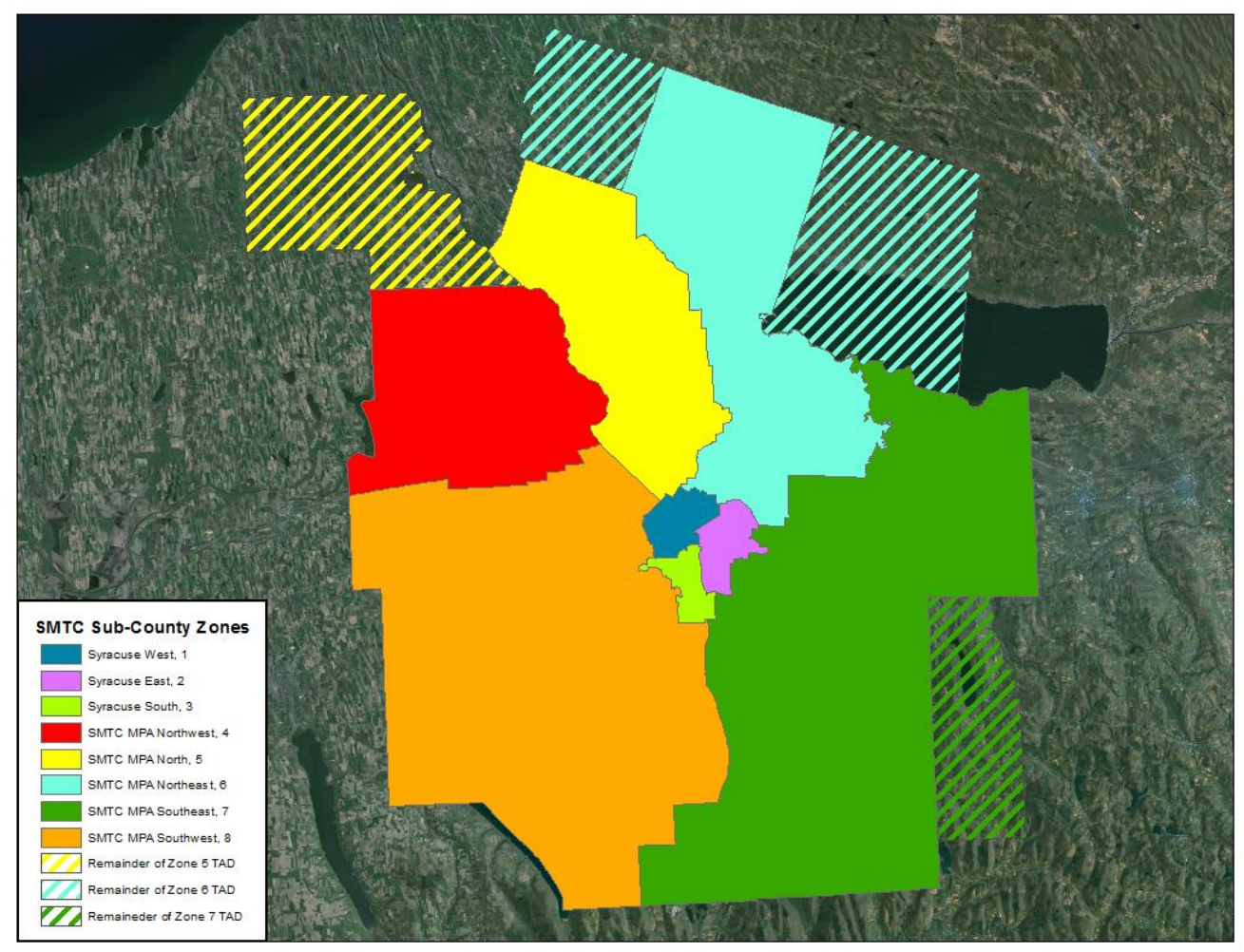

Figure 8-1. Portion of certain TADs not included as a part of the SMTC MPA.

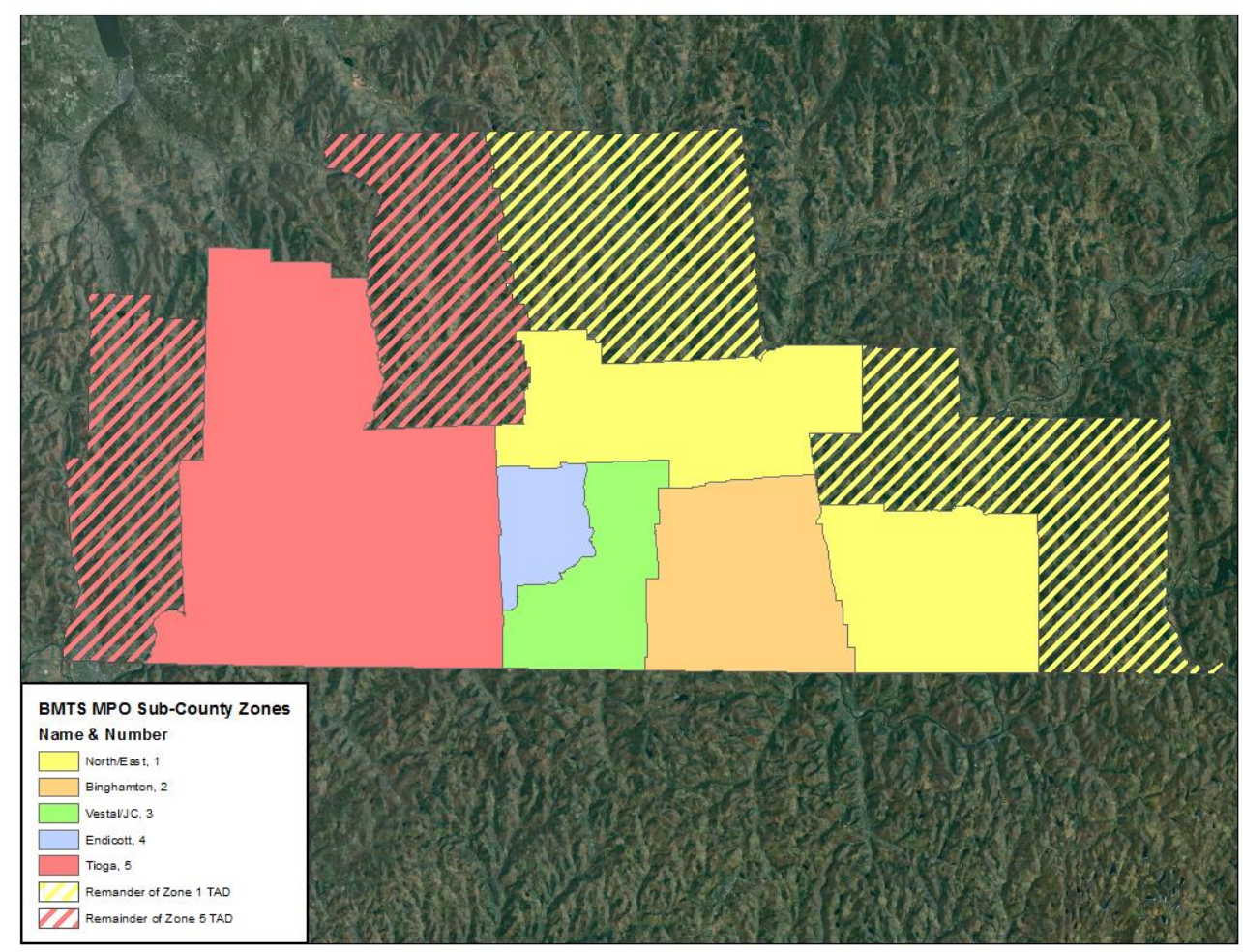

Figure 8-2. Portion of certain TADs not included as a part of the BMTS MPA. 


\subsection{REGIONAL PROFILE FROM ACS DATA}

As a national survey, NHTS samples are weighted with expansion factors so that information collected for each sample can be expanded to its representative population. These expansion factors are generally estimated using data on household and person characteristics provided in the Census data; i.e., the ACS data. Because of this, household-level estimates generated from the NHTS should generally be consistent with the ACS at its survey-targeted level of geography, such as state and major urban areas. Note that 2009 NHTS was calibrated with (i.e., expanded to match) an earlier release of the ACS data; not the 2006-2010 ACS data as used in this study. This study did not explore whether this time difference attributed to any gaps in the results, however.

For this study, 2009 NHTS data was used at a more disaggregated level (i.e., TAD-based clusters) than that considered in calculating the expansion factors. Furthermore, many of the 2009 NHTS data analyses conducted under this study were trip-based; i.e., in view of districts where a trip starts or ends. The household-based expansion factors in 2009 NHTS might not necessarily produce results that are consistent with 2006-2010 ACS based statistics in certain districts. Some examples are provided below.

\subsubsection{Demographic Patterns}

\subsubsection{SMTC}

Figure 8-3 shows the number of households in each SMTC district by its associated household-size distribution based on TAD-level data obtained from the ACS. As mentioned earlier (see Figure 8-1), three of these districts includes TAD areas that were outside the SMTC MPA boundary. For consistency, with respect to maps displayed in this report, extra TAD regions were not shown in Figure 8-3. The ACS-based household numbers shown, however, did include households that resided in those outside TAD regions (impacting color-coded regions of yellow, blue, and green in the map).

As expected, some differences were observed between distributions presented in Figure 8-3 and those based on 2009 NHTS data (Figure 4-2). While both reflect a significant share of single-person households within the downtown area districts (City of Syracuse), NHTS-based data showed much higher shares particularly in the districts of Syracuse West and Syracuse South.

For vehicle ownership, ACS-based distribution presented in Figure 8-4 clearly showed the higher shares of zero-vehicle households within the three City of Syracuse districts seen at the center of map. The ACS-based share of zero-vehicle households for the Syracuse West district was not as high as that estimated using the NHTS data (see figure in Section 4), however. On the other hand, the ACS-based share for Syracuse East was much higher than what NHTS data suggested. Shares by vehicle ownership in other regions were generally consistent between the two datasets. 


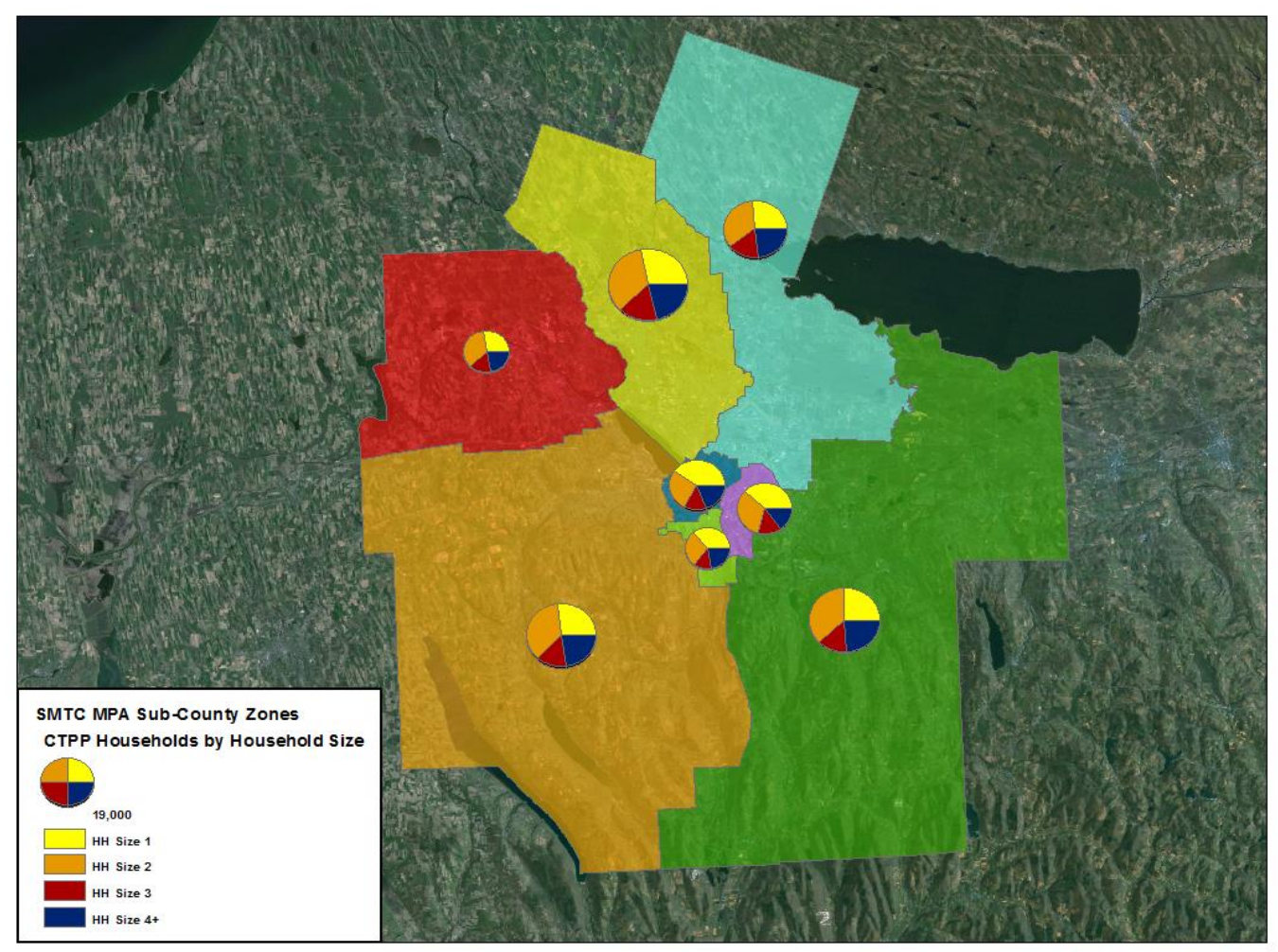

Figure 8-3. Household size distribution in SMTC region based on ACS 2006-2010 data.

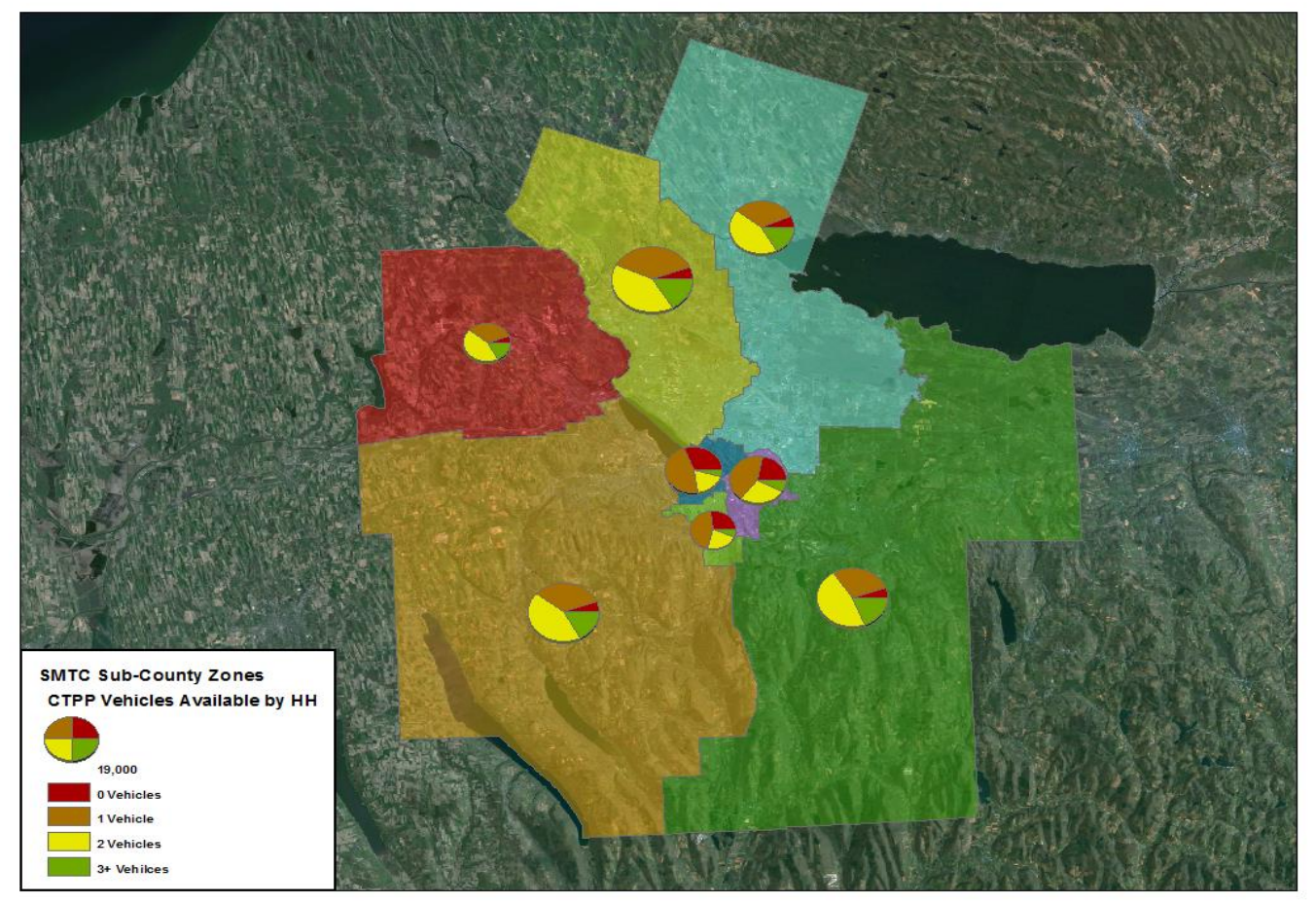

Figure 8-4. Households shares by vehicle ownership in SMTC districts using ACS 2006-2010 data. 


\subsubsection{BMTS}

As in the SMTC case, Figure 8-5 shows the number of households in each BMTS district by its associated household size distribution based on TAD-level data from the 2006-2010 ACS. As mentioned earlier (see Figure 8-2), two of these districts includes TAD areas that are outside the BMTS MPA boundary. For consistency, with respect to maps displayed in this report, extra TAD regions were not shown in Figure 85. The ACS-based household numbers shown, however, do include households that reside in those outside TAD regions. This impacted the regions North/East district (color-coded yellow) and Tioga district (color-coded pink) in the map; both consist of the more rural areas of BMTS region.

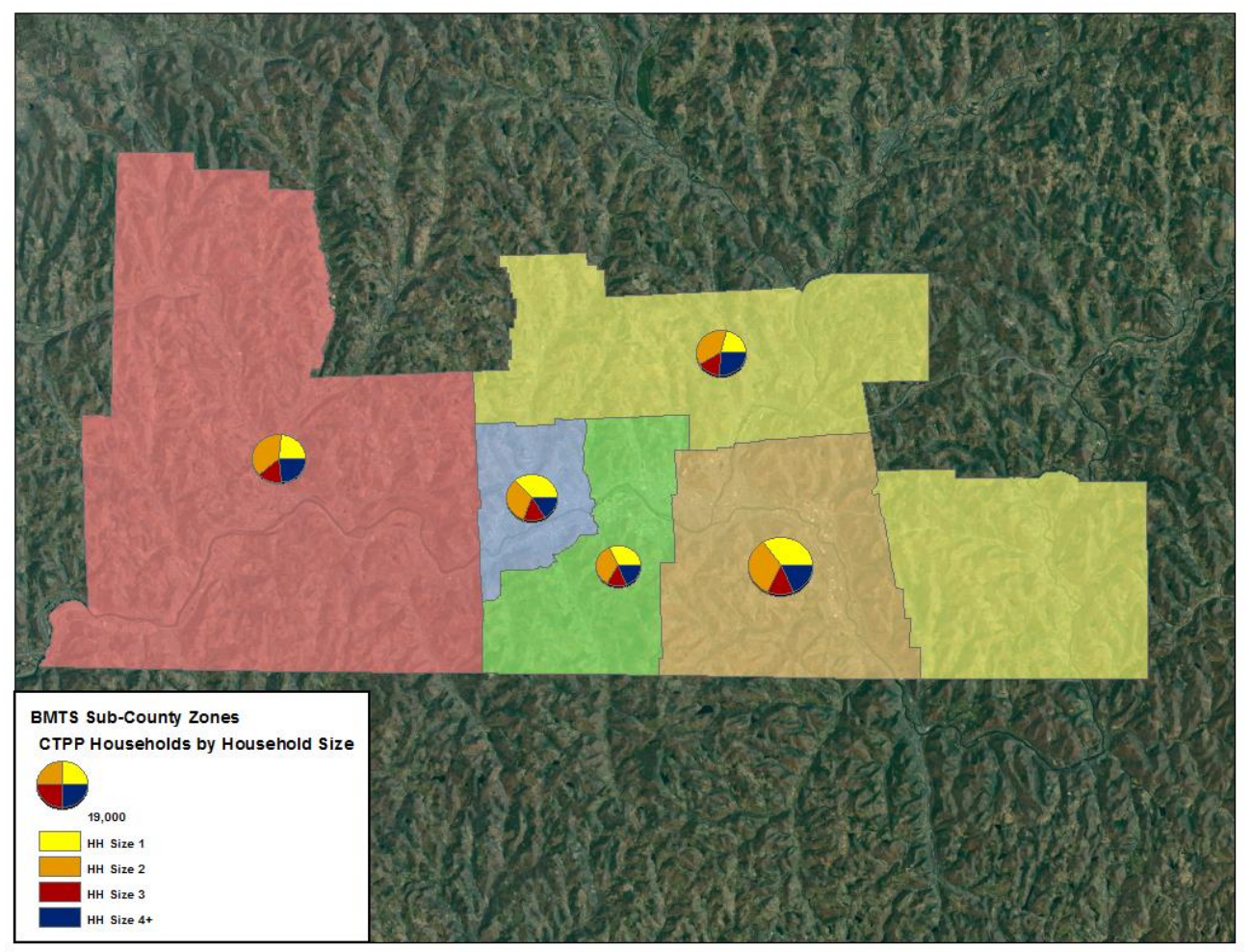

Figure 8-5. Household distributions by size for BMTS districts based on ACS data.

Only small differences were seen between distributions presented in Figure 8-5 and those based on 2009 NHTS data (Figure 5-3). On vehicle ownership, ACS-based distribution presented in Figure 8-6 clearly showed a higher share of zero-vehicle households within the Binghamton district (about 18\%). Under the 2009 NHTS-based results (Section 5.1.3), however, the Vestal/JC district had the highest share of households with zero vehicles (14\%); while the Binghamton district had less than $11 \%$ of households without vehicles . 


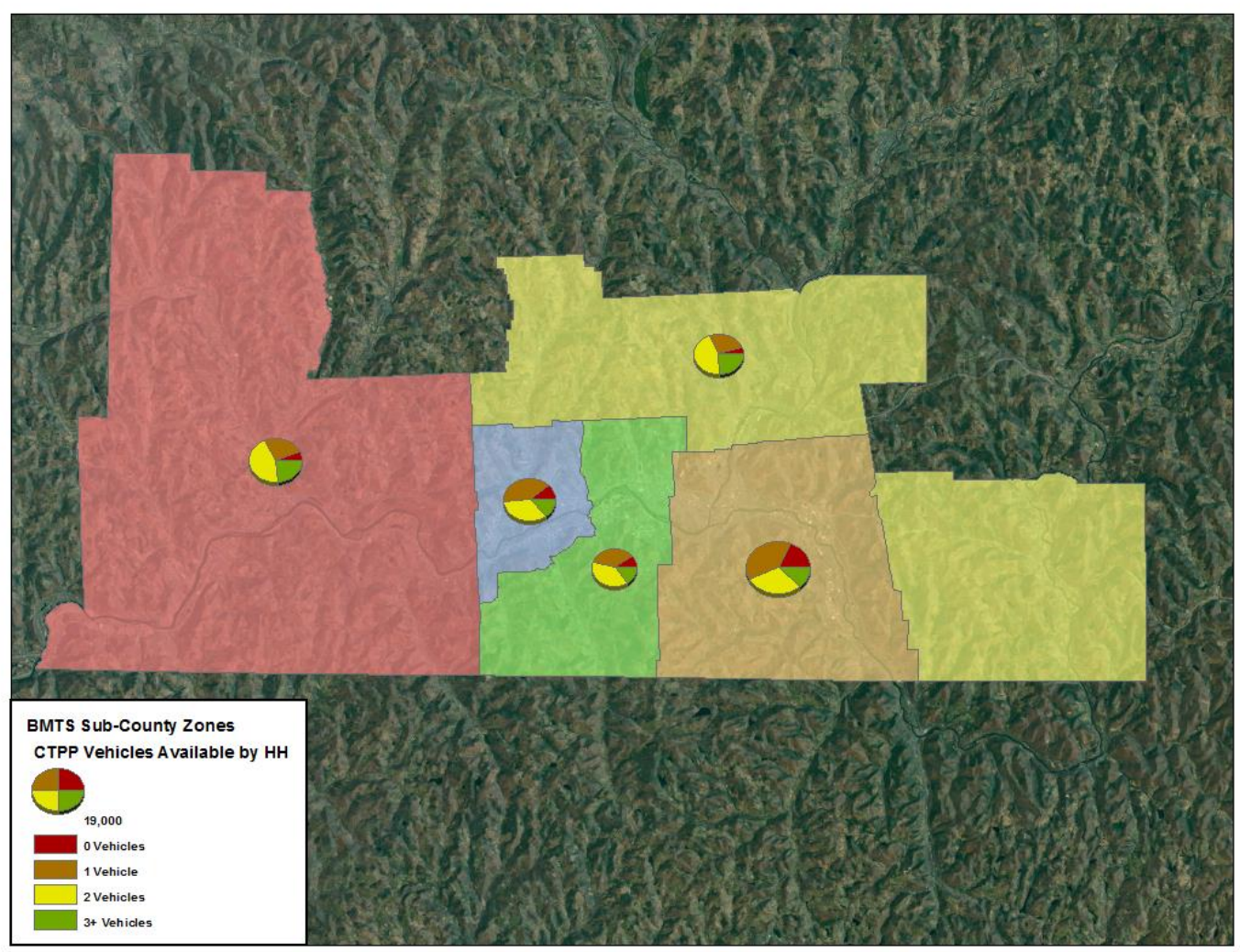

Figure 8-6. Household distribution by vehicle ownership in BMTS using ACS data.

\subsubsection{Commute Worker Flow}

As pointed out previously, 2006-2010 ACS/CTPP data provides information on commuting flows in terms of the number of workers. This is very different from the NHTS-based travel data since most of those statistics are counting trips (PT or VT) with a purpose of "earning a living" (i.e., commute). A worker can take multiple trips in a day between the same OD pair, or travel between various OD pairs during a day, in the NHTS survey data, while it would be counted as one worker flow between the residence and workplace pair.

Based on TAD-level residence-workplace flow data from the CTPP, commuter flows between districts of SMTC are summarized in Table 8-1. Note that the flows include only residents of SMTC districts (including the "extra" portions of TADs in Districts 5, 6, and 7) who work within this specified SMTC region. For simplicity, residents of SMTC region who worked outside the 8-district area (including the "extra" portions of TADs in Districts 5, 6, and 7) were not considered. A similar summary for residents of BMTS (including the extra portions of TADs in Districts 1 and 5) with work locations inside this BMTS region is provided in Table 8-2. Intra-district flows are highlighted in bold in these tables. 
Table 8-1. Census Transportation Planning Package Worker Flows between SMTC Districts

\begin{tabular}{|c|c|r|r|r|r|r|r|r|}
\hline \multirow{2}{*}{$\begin{array}{c}\text { Residence } \\
\text { district }\end{array}$} & \multicolumn{10}{|c|}{ Work place district $^{\mathrm{a}}$} \\
\cline { 2 - 9 } & $\mathbf{1}$ & $\mathbf{2}$ & $\mathbf{3}$ & $\mathbf{4}$ & $\mathbf{5}$ & \multicolumn{1}{|c|}{} & \multicolumn{1}{c|}{} & \multicolumn{1}{|c|}{$\mathbf{\mathbf { 6 }}$} \\
\hline $\mathbf{1}$ & $\mathbf{6 , 9 1 0}$ & 3,875 & 29 & 235 & 2,040 & 2,465 & 1,535 & 1,314 \\
\hline $\mathbf{2}$ & 5,660 & $\mathbf{3 , 5 2 5}$ & 190 & 775 & 8,580 & 9,300 & 2,035 & 1,210 \\
\hline $\mathbf{3}$ & 3,335 & 2,590 & $\mathbf{1 0 0}$ & 235 & 790 & 1,235 & 870 & 1,135 \\
\hline $\mathbf{4}$ & 2,810 & 1,845 & 440 & $\mathbf{3 , 8 8 0}$ & 2,850 & 1,935 & 705 & 1,665 \\
\hline $\mathbf{5}$ & 7,410 & 4,620 & 270 & 1,560 & $\mathbf{1 4 , 0 9 0}$ & 8,915 & 2,525 & 1,875 \\
\hline $\mathbf{6}$ & 5,795 & 3,340 & 175 & 630 & 5,265 & $\mathbf{1 2 , 0 0 0}$ & 2,370 & 1,350 \\
\hline $\mathbf{7}$ & 6,405 & 6,095 & 250 & 345 & 2,525 & 5,799 & $\mathbf{1 1 , 2 7 5}$ & 1,400 \\
\hline $\mathbf{8}$ & 8,295 & 4,555 & 4,595 & 955 & 2,685 & 3,910 & 2,685 & $\mathbf{1 3 , 2 6 0}$ \\
\hline
\end{tabular}

Note: ${ }^{\mathrm{a} D e s t i n a t i o n ~ d i s t r i c t s ~ a r e: ~ 1 . ~ S y r a c u s e ~ W e s t, ~ 2 . ~ S y r a c u s e ~ E a s t, ~ 3 . ~ S y r a c u s e ~ S o u t h, ~ 4 . ~ S M T C ~ M P A ~ N o r t h w e s t, ~}$ 5. SMTC MPA North, 6. SMTC MPA Northeast, 7. SMTC MPA Southeast, 8. SMTC MPA Southwest.

Table 8-2. Census Transportation Planning Package Worker Flows between BMTS Districts

\begin{tabular}{|c|c|c|c|c|r|}
\hline \multirow{2}{*}{ Residence district } & \multicolumn{5}{|c|}{ Work place district $^{\mathrm{a}}$} \\
\cline { 2 - 6 } & $\mathbf{1}$ & $\mathbf{2}$ & $\mathbf{3}$ & $\mathbf{4}$ & \multicolumn{1}{|c|}{$\mathbf{5}$} \\
\hline $\mathbf{1}$ & $\mathbf{5 , 1 8 0}$ & 2,810 & 4,075 & 2,175 & 620 \\
\hline $\mathbf{2}$ & 1,190 & $\mathbf{7 , 6 4 0}$ & 6,455 & 2,820 & 465 \\
\hline $\mathbf{3}$ & 610 & 1,800 & $\mathbf{7 , 8 2 0}$ & 2,900 & 800 \\
\hline $\mathbf{4}$ & 540 & 1,680 & 5,705 & $\mathbf{7 , 7 7 0}$ & 1,535 \\
\hline $\mathbf{5}$ & 229 & 675 & 2,570 & 2,305 & $\mathbf{1 0 , 4 3 5}$ \\
\hline
\end{tabular}

Note: ${ }^{\mathrm{a} D e s t i n a t i o n ~ d i s t r i c t s ~ a r e: ~ 1 . ~ N o r t h / E a s t, ~ 2 . ~ B i n g h a m t o n, ~ 3 . ~ V e s t a l / J C, ~ 4 . ~ E n d i c o t t, ~ 5 . ~ T i o g a . ~}$

Clearly, the volumes of intra-district flows were significant (in terms of total flow from each district) in all but District 3 (Syracuse South) of the SMTC region. Recall, based on previous reviews of NHTS and other geospatial data, Syracuse South is a small and mostly residential community. This is evident from column heading " 3 " in Table 8-1 where only small numbers of workers arrived from all districts. The only exception was for residents from District 8 of SMTC; with nearly 4,600 of its workers having work places in District 3. This should not to be a surprise given the geospatial relationships between Districts 3 and 8 (see Figure 8-1). This is an example how that ACS-based findings provide complementary information that support the finding from NHTS data. 


\section{SUMMARY}

\subsection{OVERVIEW}

The 2009 NHTS data provides a rich set of data that covers all trip types, trip purposes, and modes of transportation at the national level. Being a participant of the 2009 NHTS Add-on program, NYSDOT received significantly more samples than the typical national allocation for each state. This allows NYSDOT analysts and planners to address important transportation issues at more geographically disaggregated regional levels; which is at a much finer level than what the national NHTS data was intended to provide.

Although this pilot study was exploratory in nature, a significant amount of in-depth research has been conducted to investigate sub-county regional travel behaviors and their associated flow patterns. This study examined data from the 2009 NHTS Add-on and 2006-2010 ACS/CTPP, as well as utilized geospatial information associated with regional business and land-use mix patterns to identify travel characteristics and patterns in two NYS MPOs, SMTC and BMTS. Such integration of other data sources with the 2009 NHTS data in the sub-county level analysis proved to be beneficial in providing valueadded insights to NYSDOT regional planners.

The geographic boundaries of TAD-based cluster/districts in this study were determined by a joint effort of the NYSDOT manager, SMTC/BMTS planners, and members of this research team. This process allowed for local knowledge to be taken into account for the boundary-definitions, so that resulting TADbased clusters could reflect each corresponding region in the most practical way. Although TAD-based zones are not at the preferred micro-level, it is much better than national, state, or county levels that typical data could support. As discussed in this report, in most cases, it was evident that sufficient samples are available for "district-level" analysis, especially when considering only one or two factors at a time (for cross tabulations).

\subsection{CHALLENGES ENCOUNTERED}

\subsubsection{NHTS Sample limitations}

Statistics based on extremely small sample sizes are generally subject to higher deviations which tend to make the results less precise and less reliable. As mentioned throughout this report, caution must be exercised when disaggregating the NHTS data to a finer geography than what it was designed to do, or breaking down the samples in higher dimensions (i.e., slicing the sample data too thin).

Because the NHTS data is a household-based survey, only residents of U.S. regions are captured under the sample survey. Consequently, NHTS data contains no information concerning travel activities for foreign visitors; which is a particularly significant portion of NYS tourism. Furthermore, there are no equivalent geocoded-trip NHTS data for non-Add-On neighboring states of NYS. For example, no geospatial details on trips made by Connecticut, New Jersey, or Pennsylvania residents who commute or shop in NYS (particularly in the NYC area) were available from the NHTS, since none of those states were an NHTS Add-On participant. Without this information, a full picture of travel statistics and patterns in NYS cannot truly be accomplished. For this pilot study, for instance, trips made by Canadian 
visitors to the Syracuse region were out-of-scope of the NHTS survey thus not included in the NHTS data. As another example, even though travel by Pennsylvania residents to locations in NYS might be captured by the NHTS, no Add-On equivalent detailed geocoding of trip origin/destination was available; thus, there was no way to pinpoint whether these trips resulted in destinations in Binghamton.

\subsubsection{Weighting Issue of NHTS Data}

Another issue that arose in analysis conducted for this study concerned household and person weighting (i.e., expansion factors), specifically in the context of calculating PTs per household. In general, person and household data were weighted independently of one another in the NHTS data, so that they could be summed up to control totals by various demographic groups (e.g., race, household size, and vehicle count at the household level, and also age and gender at the person level).

Explicitly, the expansion factor associated with a person in a given household is mainly calculated based on person-level demographic characteristics, regardless of the household-specific characteristics in which the person resided. Under this circumstance, certain cases could occur where under-sampled persons (e.g., young people) could have weights that were much larger than the proportional household weights. Subsequently, one might encounter unreasonable or "outlier" situations when person-level data are used along with household-level information to generate statistics (e.g., average per-household person-trips)even though each might seem reasonable as an independent measure.

\subsubsection{ACS and NHTS}

This report identified major differences between ACS and NHTS data examined in this pilot study, specifically for travel-related data. The 2006-2010 ACS/CTPP provides OD data for JTW (i.e., commute) between residence and work place using the number of workers as its measure of unit; while NHTS included trips made for all purposes and measures by PT and VT. Geographic boundaries of certain TAD-based districts of the study regions, SMTC and BMTS, were also different due to the complication of geographically separating out partial TADs that were outside the corresponding MPO boundaries from the ACS data. Because of this, ACS data could be used to provide supplemental information to NHTSbased statistics; however, it was limited in terms of providing benchmark comparisons.

\subsection{CLOSING REMARKS}

This pilot study explored the use of the 2009 NHTS data for OD-level analysis and generated sub-county level (TAD-based cluster) statistics on travel patterns and characteristics. Summary statistics such as PT, VT, PMT, VMT, and associated trip rates were provided for 8 districts in SMTC and 5 districts of BMTS. This more detailed information will allow SMTC and BMTS regional planners to better support their demand modeling needs, including validation and/or calibration of their existing travel demand models.

The same process and general analysis approach used in this exploratory research are transferable and adaptable to other regions with sufficient NHTS samples (i.e., Add-On). As mentioned, Add-On participants receive more NHTS samples which allow more disaggregated analyses to be conducted. Additionally, the benefit of receiving geocoded OD data (for Add-On participates) also means regional travel patterns can be examined in greater detail than at the State/County/MPO level. Generally speaking, 
conducting a traditional travel survey is very costly, and typically unaffordable for many local agencies. Joining the NHTS process as an Add-on certainly has the economies of scale benefit for the NYSDOT. 


\section{APPENDIX A. NEW YORK STATE COUNTIES STUDIED}

The initial review of the 2009 NHTS Add-On data identified the following 62 counties in New York State with sufficient sample sizes that detailed OD travel flows at the county level and travel patterns by activity could be examined at a more disaggregated sub-county level.

\begin{tabular}{|l|l|l||l|l|l|}
\hline \multicolumn{1}{|c|}{ County name } & $\begin{array}{c}\text { FIPS } \\
\text { code }\end{array}$ & $\begin{array}{c}\text { County } \\
\text { FIPS }\end{array}$ & County name & $\begin{array}{c}\text { FIPS } \\
\text { code }\end{array}$ & $\begin{array}{c}\text { County } \\
\text { FIPS }\end{array}$ \\
\hline ALBANY & 1 & 36001 & NIAGARA & 63 & 36063 \\
\hline ALLEGANY & 3 & 36003 & ONEIDA & 65 & 36065 \\
\hline BRONX & 5 & 36005 & ONONDAGA & 67 & 36067 \\
\hline BROOME & 7 & 36007 & ONTARIO & 69 & 36069 \\
\hline CATTARAUGUS & 9 & 36009 & ORANGE & 71 & 36071 \\
\hline CAYUGA & 11 & 36011 & ORLEANS & 73 & 36073 \\
\hline CHAUTAUQUA & 13 & 36013 & OSWEGO & 75 & 36075 \\
\hline CHEMUNG & 15 & 36015 & OTSEGO & 77 & 36077 \\
\hline CHENANGO & 17 & 36017 & PUTNAM & 79 & 36079 \\
\hline CLINTON & 19 & 36019 & QUEENS & 81 & 36081 \\
\hline COLUMBIA & 21 & 36021 & RENSSELAER & 83 & 36083 \\
\hline CORTLAND & 23 & 36023 & RICHMOND & 85 & 36085 \\
\hline DELAWARE & 25 & 36025 & ROCKLAND & 87 & 36087 \\
\hline DUTCHESS & 27 & 36027 & SARATOGA & 91 & 36091 \\
\hline ERIE & 29 & 36029 & SCHENECTADY & 93 & 36093 \\
\hline ESSEX & 31 & 36031 & SCHOHARIE & 95 & 36095 \\
\hline FRANKLIN & 33 & 36033 & SCHUYLER & 97 & 36097 \\
\hline FULTON & 35 & 36035 & SENECA & 99 & 36099 \\
\hline GENESEE & 37 & 36037 & ST. LAWRENCE & 89 & 36089 \\
\hline GREENE & 39 & 36039 & STEUBEN & 101 & 36101 \\
\hline HAMILTON & 41 & 36041 & SUFFOLK & 103 & 36103 \\
\hline HERKIMER & 43 & 36043 & SULLIVAN & 105 & 36105 \\
\hline JEFFERSON & 45 & 36045 & TIOGA & 107 & 36107 \\
\hline KINGS & 47 & 36047 & TOMPKINS & 109 & 36109 \\
\hline LEWIS & 49 & 36049 & ULSTER & 111 & 36111 \\
\hline LIVINGSTON & 51 & 36051 & WARREN & 113 & 36113 \\
\hline MADISON & 53 & 36053 & WASHINGTON & 115 & 36115 \\
\hline MONROE & 55 & 36055 & WAYNE & 117 & 36117 \\
\hline MONTGOMERY & 57 & 36057 & WESTCHESTER & 119 & 36119 \\
\hline NASSAU & 59 & 36059 & WYOMING & 121 & 36121 \\
\hline NEW YORK & 36061 & YATES & 123 & 36123 \\
\hline
\end{tabular}




\section{APPENDIX B. GLOSSARY OF NHTS TERMS}

This glossary provides the most commonly used terms in the NHTS and definitions of those terms. These definitions are provided to assist the user in the interpretation of the NHTS data.

Adult

Block Group

Census Region and Division
For NHTS, this is defined as a person 18 years or older.

A subdivision of a Census tract that averages 1000 to 1100 people, and approximately 400-500 housing units. The source used for the 2009 NHTS was TeleAtlas MatchMaker (derived from Census 2000 definition).

The Census Bureau divides the states into four regions and nine divisions. Note that the divisions are wholly contained within a region, i.e., region lines do not split division lines. The regions and their component divisions are:

\section{Northeast Region:}

- New England Division: Connecticut, Maine, Massachusetts, New Hampshire, Rhode Island, Vermont

- Middle Atlantic Division: New Jersey, New York, Pennsylvania North Central Region:

- East North Central Division: Illinois, Indiana, Michigan, Ohio, Wisconsin

- West North Central Division: Iowa, Kansas, Minnesota, Missouri, Nebraska, North Dakota, South Dakota

\section{South Region:}

- South Atlantic Division: Delaware, Florida, Georgia, Maryland, North Carolina, South Carolina, Virginia, West Virginia

- East South Central Division: Alabama, Kentucky, Mississippi, Tennessee

- West South Central Division: Arkansas, Louisiana, Oklahoma, Texas

\section{West Region:}

- Mountain Division: Arizona, Colorado, Idaho, Montana, Nevada, New Mexico, Utah, Wyoming

- Pacific Division: Alaska, California, Hawaii, Oregon, Washington

Puerto Rico.

For the 2009 NHTS the source used for the 2000 Census Region was: http://www.census.gov/geo/www/cob/rg2000.html. The source used for the 2000 Census Division was:

http://www.census.gov/geo/www/cob/dv2000.html. 


\section{Census Tract}

Child

\section{Consolidated \\ Metropolitan \\ Statistical Area \\ (CMSA)}

\section{Destination}

Driver

Employed

Education Level
A small subdivision of a county, containing approximately 4,000 persons. Tracts can range in population from 2,500 to 8,000. The geographic size of the tract may vary considerably, depending on population density. Tracts were designed to be homogeneous in regard to population characteristics, economic status and living conditions when they were first delineated. Since the first tracts were delineated for the 1890 Census, today's tracts may be far from homogeneous. The source used for the 2009 NHTS was TeleAtlas MatchMaker (derived from Census 2000 definition).

A child is normally defined as a person under the age of 18. An exception to this is for life cycle, where a child can be anyone through the age of 21 who is listed as a child to the household respondent.

A large metropolitan complex of 1 million or more population, containing two or more identifiable component parts designated as primary metropolitan statistical areas (PMSAs). For example, the New York-Northern New JerseyLong Island CMSA is composed of the following fourteen areas: Bridgeport, Danbury, Dutchess County, Jersey City, Middlesex-Somerset-Hunterdon, Monmouth-Ocean, Nassau-Suffolk, New Haven-Meriden, New York, Newark, Newburgh, Stamford-Norwalk, Trenton, Waterbury.

For travel day trips, the destination is the point at which there is a break in travel, except if the break is only to change vehicles or means of transport.

A driver is a person who operates a motorized vehicle. If more than one person drives on a single trip, the person who drives the most miles is classified as the principal driver.

A person is considered employed if (s)he worked for pay, either full time or part time, during the week before the interview. This includes persons who work at home or persons who have more than one job.

The number of years of regular schooling completed in graded public, private, or parochial schools, or in colleges, universities, or professional schools, whether day school or night school. Regular schooling advances a person toward an elementary or high school diploma, or a college, university, or professional school degree. 


\section{Household}

Household Income

Household Members

Household Vehicle

Journey-to-Work Trips (Commute trips)

\section{Means of Transportation}

A group of persons whose usual place of residence is a specific housing unit; these persons may or may not be related to each other. The total of all U.S. households represents the total civilian non-institutionalized population. A household does not include group quarters (i.e., 10 or more persons living together, none of whom are related).

Household income is the money earned by all family members in a household, including those temporarily absent. Annual income consisted of the income earned 12 months preceding the interview. Household income includes monies from all sources, such as wages and salary, commissions, tips, cash bonuses, income from a business or farm, pensions, dividends, interest, unemployment or workmen's compensation, social security, veterans' payments, rent received from owned property (minus the operating costs), public assistance payments, regular gifts of money from friends or relatives not living in the household, alimony, child support, and other kinds of periodic money income other than earnings. Household income excludes in-kind income such as room and board, insurance payments, lump-sum inheritances, occasional gifts of money from persons not living in the same household, withdrawal of savings from banks, tax refunds, and the proceeds of the sale of one's house, car, or other personal property.

Household members include all people, whether present or temporarily absent, whose usual place of residence is in the sample unit. Household members also include people staying in the sample unit who have no other usual place of residence elsewhere.

A household vehicle is a motorized vehicle that is owned, leased, rented or company-owned and available to be used regularly by household members during the two-week travel period. Household vehicles include vehicles used solely for business purposes or business-owned vehicles, so long as they are driven home and can be used for the home to work trip, (e.g., taxicabs, police cars, etc.). Household vehicles include all vehicles that were owned or available for use by members of the household during the travel period, even though a vehicle may have been sold before the interview. Vehicles excluded from household vehicles are those which were not working and were not expected to be working within 60 days, and vehicles that were purchased or received after the designated travel day.

Includes travel to and from a place where one reports for work. Does not include any other work-related travel. Does not include any trips for persons who work at home.

A mode of travel used for going from one place (origin) to another (destination). A means of transportation includes private and public transit 
modes, as well as walking.

The following transportation modes, grouped by major mode, are included in the NHTS data.

Private Vehicle - a stipulation for being a private vehicle is that the vehicle is privately owned or operated.

1. Car. Includes cars and station wagons. Leased and rented cars are included if they are privately operated and not used for picking up passengers in return for fare.

2. Van. Includes vans or minivans designed to carry 5 to 13 passengers, or to haul cargo.

3. Sport Utility Vehicle. Includes vehicles that are a hybrid of design elements from a van, a pickup truck and a station wagon. Examples include a Ford Explorer, Jeep Cherokee, or Nissan Pathfinder.

4. Pickup Truck. Includes vehicles with an enclosed cab that usually accommodates 2-3 passengers, and has an open cargo area in the rear. Late model pickups often have a back seat that allows for total seating of 4 -6 passengers. Pickup trucks usually have the same size of wheelbase as a full-size station wagon. This category also includes pickups with campers.

5. Other Truck: This category consists of all trucks other than pickup trucks (i.e., dump trucks, trailer trucks, etc.).

6. RV or Motor Home: An RV or motor home includes a self-powered recreational vehicle that is operated as a unit without being towed by another vehicle (e.g., a Winnebago motor home).

7. Motorcycle: This category includes large, medium, and small motorcycles and mopeds.

8. Golf Cart: This includes all electric or gas operated vehicles designed for use on a golf course, but whose use has recently extended to use within smaller, often gated, communities.

Public Transportation, as used in FHWA publications and analysis of NHTS data, typically includes the following that are indicated in bold below, mass transit bus, commuter bus, commuter train, subway/elevated rail, and streetcar/trolley.

Bus. This category includes:

9. mass transit systems, these are local public transit buses that are available to the general public,

10. commuter buses, these are buses used for short-distance public transport purposes (e.g., city bus or public bus),school buses, and 
12. charter/tour buses, these are private buses operating on a fixed schedule between population centers, and

13. city to city buses, these are buses that run from one urban center to the other (e.g., Greyhound), and

14. shuttle buses, these are buses that shuttle passengers from one fixed place to another (e.g., airport shuttles).

Train: This category includes:

15. Amtrak/Intercity Train that run from one urban center to another,

16. Commuter trains and passenger trains

17. Subway and elevated rail (also known as rail rapid transit) is a high capacity system operated on a fixed rail or guide way system on a private right of way, and

18. Trolley/streetcars are vehicles that run on a fixed rail system powered by electricity obtained from an overhead power distribution system.

\section{Other Modes}

11. School Buses.

19. Taxi. Taxis include the use of a taxicab by a passenger for fare, including limousines. The taxi category does not include rental cars if they are privately operated.

20. Ferry. This includes travel by passenger line ferries.

21. Airplane. . Airplanes include commercial airplanes and smaller planes that are available for use by the general public in exchange for a fare. Private and corporate planes and helicopters are also included.

22. Bicycle: This category includes bicycles of all speeds and sizes that do not have a motor.

23. Walk: This category includes walking and jogging.

24. Special Transit for People with Disabilities. This includes things like "Dial-A-Ride"

97. Other. Includes any type of transportation not previously listed, (e.g. skate boards, roller blades, sailboats, cruise ships, etc).

Metropolitan

Planning Organization (MPO)

Metropolitan Statistical Area (MSA)
A metropolitan planning organization devises solutions to regional transportation problems concerning land use, air quality, energy, economic development and commerce. Such an organization exists for every urban area with at least 50,000 residents. New York State has thirteen MPOs analyzed in this report: Albany; Binghamton; Buffalo; Elmira; Glens Falls; Ithaca; Kingston; the New York Metropolitan Transportation Council (NYMTC) area; Newburgh; Poughkeepsie; Rochester; Syracuse; and Utica-Rome.

Except in the New England States, a Metropolitan Statistical Area is a county or group of contiguous counties which contains at least one city of 50,000 inhabitants or more, or "twin cities" with a combined population of at least 50,000 . In addition, contiguous counties are included in an MSA if, according 
to certain criteria, they are socially and economically integrated with the central city. In the New England States, MSA's consist of towns and cities instead of counties. The source used for the 2009 NHTS was 1999

Metropolitan Areas: Cartographic Boundary Files. File ma99_99.shp from http://www.census.gov/geo/www/cob/ma1999.html.

Motorized Vehicle

New York City

(NYC)

New York

Metropolitan

Transportation

Council (NYMTC)

Occupancy

Occupancy Rate

Origin

Passenger

Person Miles of Travel (PMT)

Person Trip

Privately Owned Vehicle (POV)
Motorized vehicles are all vehicles that are licensed for highway driving. Snow mobiles and minibikes are specifically excluded.

New York City is defined in this report as the five county area: Bronx, Kings, Queens, New York (Manhattan), and Richmond.

The New York Metropolitan Transportation Council (NYMTC) encompasses includes the following three areas: (1) Nassau, Suffolk; (2) New York City, (which includes the following counties: Bronx, Kings, Queens, New York, and Richmond); and (3) Putnam, Rockland, and Westchester.

Occupancy is the number of persons, including driver and passenger(s) in a vehicle.

NHTS occupancy rates are generally defined as the mileage-weighted averages of the number of persons on a vehicle trip.

Origin is the starting point of a trip.

For a specific trip, a passenger is any occupant of a motorized vehicle, other than the driver.

PMT is a primary measure of person travel. When one person travels one mile, one person mile of travel results. Where 2 or more persons travel together in the same vehicle, each person makes the same number of person miles as the vehicle miles. Therefore, four persons traveling 5 miles in the same vehicle results in 20 person miles $(4 \times 5=20)$.

A person trip is a trip by one or more persons in any mode of transportation. Each person is considered as making one person trip. For example, four persons traveling together in one auto are counted as four person trips.

A privately-owned vehicle or privately-operated vehicle. Either way, the intent here is that this is not a vehicle available to the public for a fee, such as a bus, subway, taxi, etc. 
Travel Day

Travel Day Trip

Travel Day Trip Purpose
A travel day is a 24-hour period from 4:00 a.m. to 3:59 a.m. designated as the reference period for studying trips and travel by members of a sampled household.

A travel day trip is defined as any time the respondent went from one address to another by private motor vehicle, public transportation, bicycle, walking, or other means during the NHTS assigned reporting travel day. However, a separate trip is not counted in two instances:

1. When the sole purpose for the trip is to get to another vehicle or mode of transportation in order to continue to the destination.

2. Travel within a shopping center, mall or shopping areas of 4-5 blocks is to be considered as travel to one destination.

A trip purpose is the main reason that motivates a trip. There are 36 travel day trip purposes used in the 2009 NHTS.

Trip purposes were collected using a From-To approach. For each trip, the origin and destination are on the file in specific terms if reported by the respondent (e.g. from work to Bob's Beef Pit). The 36 trip reasons are defined below. The numbers in parentheses represent the value of WHYTO (trip purpose) in the dataset.

1. To Home (01). Represents a trip to the respondents' primary residence.

2. Go to Work (11). This is the first trip to the work location on travel day.

3. Return to Work (12). A trip to work that is not the first trip to the workplace on the travel day (e.g., returning to work after lunch).

4. Attend Business Meeting/Trip (13). Represents a work related trip whose purpose is to attend a business meeting.

5. Other Work Related (14). A work related trip whose purpose is not specified.

6. Go to School as a Student (21). Represents a trip whose purpose is to go to school as a student.

7. Go to Religious Activity (22). Represents a trip whose purpose is to go to a place to attend a religious activity.

8. Go to Library, School Related (23). Represents a trip whose purpose is to go to the library as part of a school related activity. 
Go to Daycare/Before or After School Care (24). Represents a trip

9. whose purpose is to attend day care or a supervised before or after school care program

10. Other School/Religious Activity (20). Represents school and religious activities that are not captured in WHYTO 21-24 above.

Medical/Dental Services (30). Represents a trip made to obtain

11. medical, dental, or mental health treatment, or other related professional services.

Buy Goods: groceries/clothing/hardware store (41). Represents a

12. shopping trip whose purpose is to purchase commodities for use or consumption elsewhere. This purpose also includes all shopping trips even if nothing is purchased.

Buy Services: video rentals/dry cleaning/post office/car service/bank

13. (42). This category includes the purchase of services other than medical/dental or other professional services.

14. Buy Gas (43). Represents a trip made specifically to get gas.

15. Shopping/Errands (40). Represents shopping and errand trips that are not captured in WHYTO 41-43 above.

16. Go to the Gym/Exercise/Play Sports (51). Represents a trip made for exercise, to engage in exercise or to participate in a sport.

Rest or Relaxation/Vacation (52). Represents a trip made for the

17. purpose of relaxing or taking a vacation, but does not include visiting family.

18. Visit Friends/Relatives (53). Represents the social/recreational trip whose purpose is to visit with family and friends.

Go out/Hang out: entertainment/theater/sports event/go to bar (54).

19. Represents trips whose purpose is entertainment related or hanging out with friends. Typically this event takes place in a public venue.

20. Visit Public Place: historical site/museum/park/library (55). Represents a trip purpose that is educational or enlightening.

21. Social/Recreational (50). This category includes social and recreational trips that are not captured in WHYTO 51-55 above.

Use Professional Services: attorney/accountant (61). Represents a trip

22. made for to engage professional services other than for medical/dental purposes. 
23. Attend Funeral/Wedding (62). Represents a trip whose purpose is to attend a funeral or a wedding.

24. Use Personal Services: grooming/haircut/nails (63). Represents a trip for personal services such as to get a massage or get a haircut.

25. Pet Care: walk the dog/vet visits (64).

Attend Meeting: PTA/home owner's association/local government

26. (65). Represents a trip purpose to attend a non-work related meeting, such as a community meeting

27. Family Personal Business/Obligations (60). Represents a trip for 13 personal business but is not captured in WHYTO 61-65 above.

28. Pickup Someone (71). Represents a trip whose purpose was to pick up a passenger.

Take and Wait (72). Represents a trip made to take someone to a

29. destination and then wait with or for them at the destination and then depart together.

30. Drop Someone Off (73). Represents a trip whose purpose was to drop off a passenger (but not wait for them).

Transport Someone (70). Represents trips with a passenger that are

31. related to picking up or dropping off someone but is not captured in WHYTO 71-73 above.

32. Social Event (81). Represents a trip whose purpose is to attend a social event but eating a meal is not a key component of the event.

33. Get/Eat Meal (82). Represents a trip whose primary purpose is to get and eat a meal.

34. Coffee/Ice Cream/Snacks (83). Represents a trip whose purpose is to get/eat a snack or drink, something less than a meal.

35. Meals (80). Represents a trip whose purpose is to eat or get a meal but is not captured in WHYTO 81-83 above.

36. Other (97). Represents a trip purpose not captured by any of the specific WHYTO categories described above. 
Urbanized Area

Vehicle

Vehicle Miles of Travel (VMT)

Vehicle Occupancy

Vehicle Trip

Vehicle Type
An urbanized area consists of the built up area surrounding a central core (or central city), with a population density of at least 1,000 persons per square mile. Urbanized areas do not follow jurisdictional boundaries thus it is common for the urbanized area boundary to divide a county. For the 2009 NHTS, Urban Areas were calculated two ways.

- Variable URBAN uses the 2000 Urbanized Areas: Cartographic Boundary Files. File ua00_d00.shp from http://www.census.gov/geo/www/cob/ua2000.html. Two codes are used: $0=$ Not in Urban Area, $1=$ in Urban Area

- Variable URBAN1 uses the 2000 Urbanized Areas: Cartographic Boundary Files. File ua00_d00.shp from http://www.census.gov/geo/www/cob/ua2000.html. Four codes are used: $0=$ Not in Urban Area, $1=$ in Urban Cluster, $2=$ in Urban Area, $3=$ in area surrounded by urban areas.

In the 2009 NHTS, the term vehicle includes autos, passenger vans, sport utility vehicles, pickups and other light trucks, RV's, motorcycles and mopeds owned or available to the household.

VMT is a unit to measure vehicle travel made by a private vehicle, such as an automobile, van, pickup truck, or motorcycle. Each mile traveled is counted as one vehicle mile regardless of the number of persons in the vehicle.

Vehicle occupancy is the number of persons, including driver and passenger(s) in a vehicle; also includes persons who did not complete a whole trip. NHTS occupancy rates are generally calculated as person miles divided by vehicle miles.

A trip by a single privately-operated vehicle regardless of the number of persons in the vehicle.

For purposes of the 2009 NHTS, one of the following:

1. Automobile (including station wagon)

2. Van

3. Sport Utility Vehicle

4. Pickup Truck (including pickup with camper)

5. Other Truck

6. RV or Motor Home

7. Motorcycle

8. Other 
Weekday

Weekend

Work-Related Travel (WR)

Worker
Weekday is defined as Monday through Friday. In the previous comparison reports, it was defined as the time between 12:01 a.m. Monday and 6:00 p.m. Friday. This was modified to correctly estimate per person statistics.

Weekend is defined as Saturday and Sunday. See "Weekday" for more on the difference between previous reports.

These are trips related to business activities except travel to the place of work: for example, a plumber drives to a wholesale dealer to purchase supplies for his business or a company executive travels from his office to another firm to attend a business meeting. Business, out-of-town trips, and professional conventions are also included.

See "Employed." 